\title{
Entwicklung von Substraten und Inhibitoren pharmakologisch relevanter Proteintargets
}

\author{
Dissertation \\ zur Erlangung des Doktorgrades \\ den Mathematisch-Naturwissenschaftlichen Fakultäten \\ der Georg-August-Universität zu Göttingen
}

vorgelegt von

Daniel Riester

aus Gottmadingen

Göttingen 2004 
D7

Referent PD Dr. Andreas Schwienhorst

Korreferent: $\quad$ Prof. Dr. Ralf Ficner

Tag der mündlichen Prüfung: 25. Januar 2005 
Teile dieser Arbeit wurden veröffentlicht:

Ninkovic, M., Riester, D., Wirsching, F., Dietrich, R. und Schwienhorst, A. (2001). Fluorogenic assay for penicillin G acylase activity. Anal Biochem, 292, 228-233.

Kamphausen, S., Höltge, N., Wirsching, F., Morys-Wortmann, C., Riester, D., Goetz, R., Thürk, M., and Schwienhorst, A. (2002). Genetic algorithm for the design of molecules with desired properties. J Comp Aid Mol Design, 16, 551-567.

Wirsching, F., Keller, M., Hildmann, C., Riester, D. und Schwienhorst, A. (2003). Directed evolution towards protease-resistant hirudin variants. Mol Genet Metab, 80, 451-462.

Wegener, D., Wirsching, F., Riester, D., and Schwienhorst, A. (2003). A fluorogenic histone deacetylase assay well suited for high-throughput activity screening. Chem Biol, 10, 61-68.

Wegener, D., Hildmann, C., Riester, D., and Schwienhorst, A. (2003). Improved fluorogenic histone deacetylase assay for high-throughput-screening applications. Anal Biochem, 321, 202-208.

Hildmann, C., Ninkovic, M., Dietrich, R., Wegener, D., Riester, D., Zimmermann, T., Birch, O. M., Bernegger, C., Loidl, P., and Schwienhorst, A. (2004). A New Amidohydrolase from Bordetella or Alcaligenes Strain FB188 with Similarities to Histone Deacetylases. J Bacteriol, 186, 2328-2339.

Riester, D., Wegener, D., Hildmann, C., and Schwienhorst, A. (2004). Members of the histone deacetylase superfamily differ in substrate specificity towards small synthetic substrates. Biochem Biophys Res Commun, 324, 1116-1123.

Riester, D., Wirsching, F., Salinas, G., Keller, M., Gebinoga, M., Kamphausen, S., Merkwart, C., Goetz, R., Wiesenfeldt, M., Stürzebecher, J., Bode, W., Friedrich, R., Thürk, M. und Schwienhorst, A. (2005). Novel thrombin inhibitors identified by computer-assisted multiparameter design. PNAS, 24, 8597-8602. 


\section{Inhalt}

1.

EINLEITUNG

1.1 .

Die Serinprotease Thrombin - das zentrale Target in der

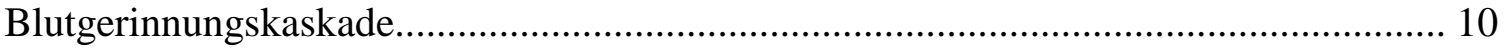

1.1.1.

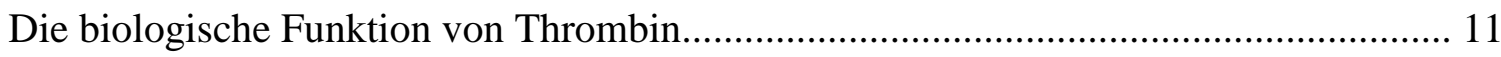

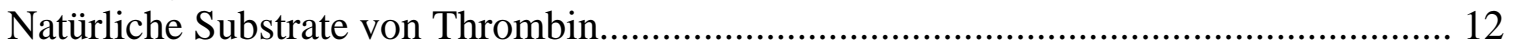

1.1.2.

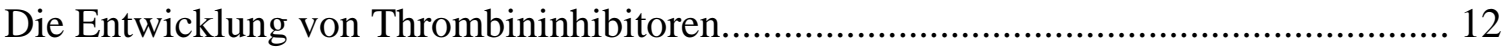

1.1.2.1.

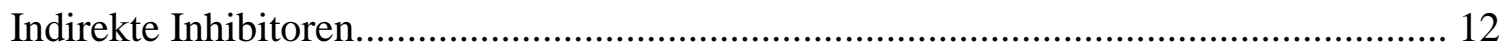

1.1.2.2.

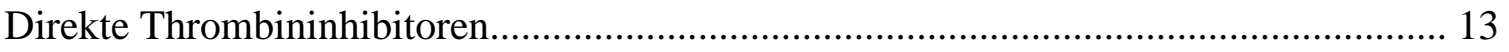

1.1.3.

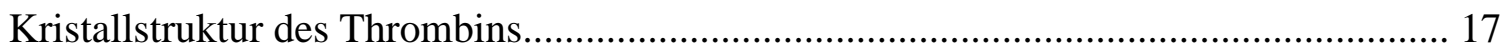

1.1.3.1.

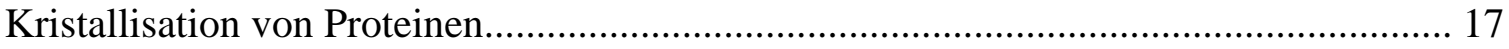

1.1.3.2.

Struktur und Bindungstaschen von Thrombin.......................................................... 18

1.2 .

Histondeacetylasen (HDAC) als Targets in der Tumortherapie..................................... 20

1.2.1.

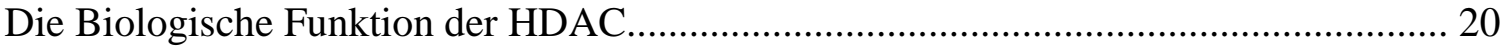

1.2.2.

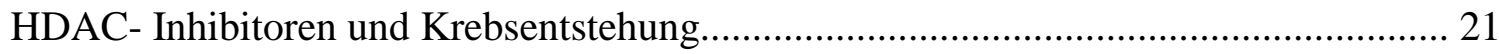

1.2.3.

Strukturen und Wirkung einiger bekannter HDAC-Inhibitoren................................... 24

1.3 .

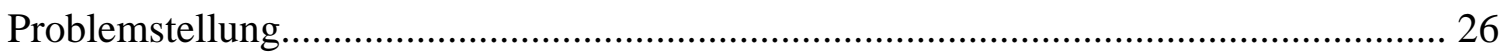

1.3.1.

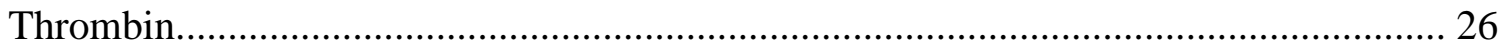

1.3.2.

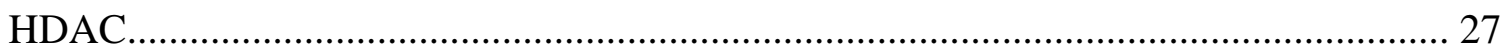


2.

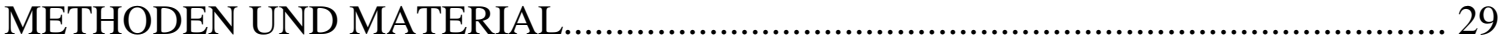

2.1.

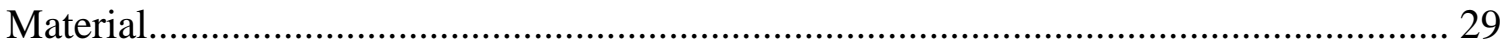

2.1.1.

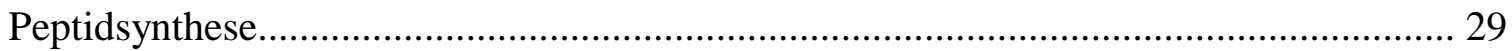

2.1.2.

Analytik und Aufreinigung von Syntheseprodukten per LC-MS................................ 31

2.2.

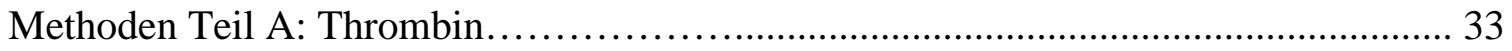

2.2.1.

Proteolytischer Peptidabbau von Hirudinvarianten, Analyse der Fragmente.

2.2.2.

Entwicklung von Inhibitoren mit Computer-unterstütztem Wirkstoffdesign:

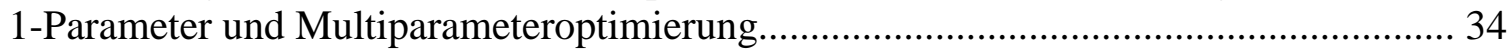

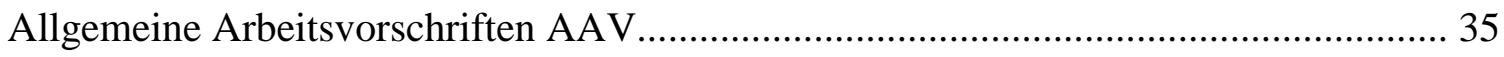

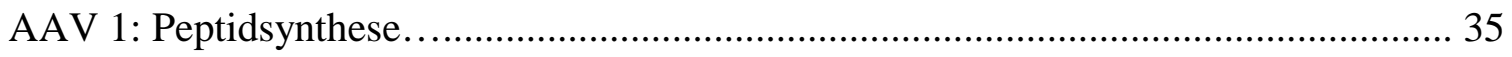

AAV 2: Amidolytischer Thrombinassay mit humanem Thrombin........................... 38

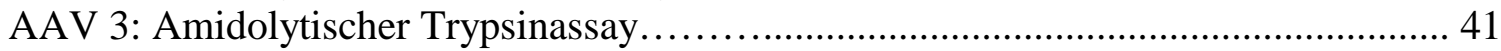

AAV 4: Serum-Protein-Bindungsassay.............................................................. 42

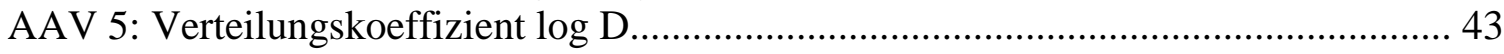

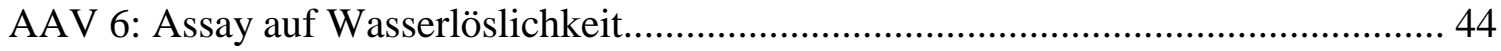

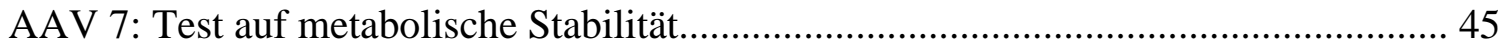

AAV 8: Toxizitätsassay auf der Basis von HeLa-Zellen............................................... 46

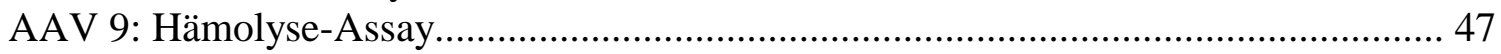

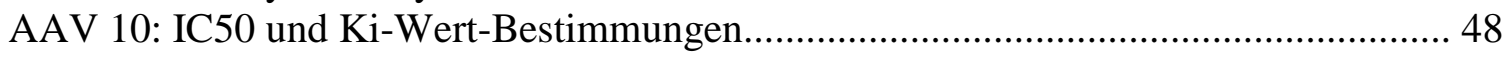

2.2.

Methoden Teil B: Histondeacetylasen................................................................... 53

2.2.3.

Klonierung, Transfektion und Expression von HDAC8 ............................................. 53

2.2.3.1.

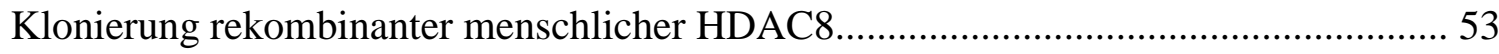

2.2.3.1.a

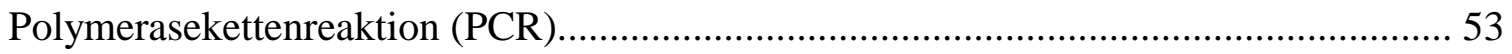

2.2.3.1.b

Ligation - Direkte Klonierung des PCR-Produktes (TA-Cloning)................................ 54

2.2.3.1.c

Sequenzierung nach der Kettenabbruch-Methode................................................ 55

2.2.3.2.

Transformation von Escherichia coli 
2.2.3.2.a

Dialyse.

2.2.3.2.b

2.2.3.2.c

$\mathrm{CaCl} 2$-kompetente Escherichia coli-Zellen. 56

2.2.3.3.

Expression in Escherichia coli

2.2.3.4.

Zellaufschluß durch Disruption.

2.2.3.5.

Analyse der Produkte.

2.2.3.5.a

Denaturierende Polyacrylamidgelelektrophorese (SDS-PAGE)

2.2.3.5.b

Transfer von Proteinen auf PVDF-Membranen (Blotting).

2.2.3.5.c

Immunochemischer Nachweis auf PVDF-Membranen (Western)

2.2.3.6.

Aufreinigung

2.2.3.6.a

Affinitätschromatographie an immobilisierten Metallionen.

2.2.3.6.b

Perfusionschromatographie.

2.2.3.6.c

Affinitätschromatographie mit einem immobilisierten Inhibitor

2.2.3.7.

HDAC Assay

2.2.3.7.a

Zweistufiger Assay.

2.2.3.7.b

Einstufige Assay-Variante. 64

2.2.4.

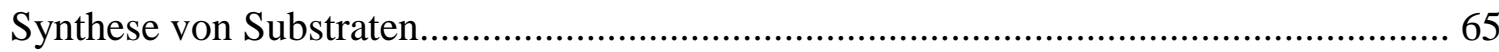

2.2.4.1.

Synthese der Varianten von Boc-Lys-(Ac)-MCA

2.2.4.2.

Tos-Gly-Pro-Lys(Ac)-MCA und Varianten

2.2.5.

Synthese von Inhibitoren.

2.2.5.1.

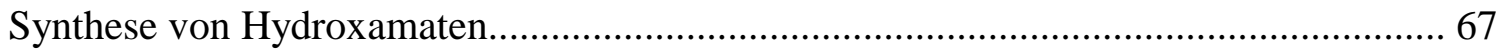

2.2.5.2.

Synthese von Tripeptiden mit verschiedenen Lysyl-Resten.......................................... 69 2.2.5.3.

Synthese einer Benzamid-Bibliothek aus MS275-Derivaten. 
2.2.5.4.

Synthese von Derivaten der Kojisäure.

3.

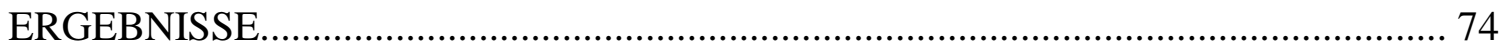

3.1 .

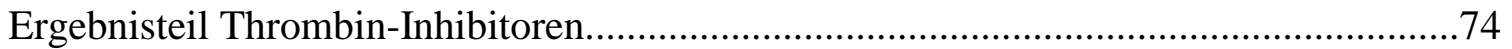

3.1.1.

Resistenz von Hirudin-Varianten gegen proteolytischen Verdau...................................74

3.1.2.

Entwicklung von Thrombin-Inhibitoren bei 1-Parameter-Optimierung.... .78

3.1.3.

Neue niedermolekulare Thrombin-Inhibitoren durch Multiparameter-

Optimierung

3.1.3.1.

Optimierungsverlauf - eine Übersicht. 81

3.1.3.2.

Selektion der besten Substanzen....................................................................... 83

3.1.3.3.

Kinetische Studien von Varianten des Inhibitors 8-5.

3.1.3.4.

Kristallographische Untersuchung von 8-5 im Komplex mit Thrombin. 91

3.1.3.5.

Erste Untersuchungen am Tiermodell

3.2.

Ergebnisteil HDAC. 99

3.2.1.

Enzymherstellung und Reinigung.

3.2.1.1.

Produktion von humaner HDAC8 ....................................................................... 100

3.2.1.2.

Reinigung.

3.2.2.

Optimierung des HDAC-Assay 106

3.2.2.1.

Optimierung synthetischer Substrate. 107

3.2.2.2.

Optimierung des Substrats für dessen Umsetzung durch Trypsin. 108

3.2.3.

Studien zur Substratspezifität von HDAC.

3.2.4.

Synthesen von Inhibitioren der HDAC. 
3.2.4.1.

Tripeptidbibliothek.

118

3.2.4.2.

Synthese einer kleinen Bibliothek aus MS275-Analogen........................................ 123

3.2.4.3.

Inhibition durch Kojisäure-Derivate

4.

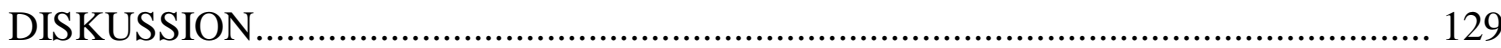

4.1.

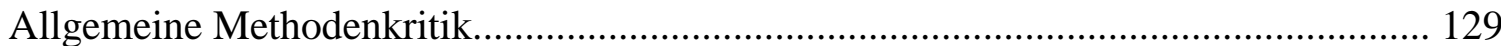

4.1.1.

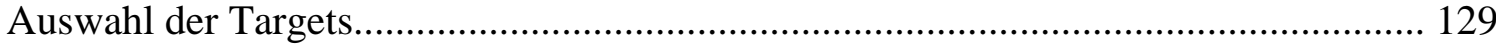

4.1.2.

Methodenwahl der Wirkstoffsuche

129

4.2.

Diskussion der Resultate im Thrombinprojekt.

4.2.1.

Peptidsynthese und Analytik

4.2.2.

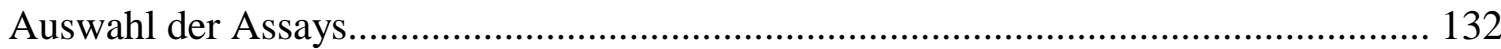

4.2.3.

Computer-unterstützte Multiparameteroptimierung....

4.3 .

Diskussion der Resultate im HDAC-Projekt........................................................ 136

4.3.1.

Heterologe Expression und Reinigung von HDAC 8............................................ 136

4.3.2.

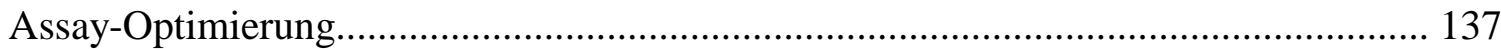

4.3.3.

Substratspezifität und Katalysemechanismus.

5.

ZUSAMMENFASSUNG UND AUSBLICK........................................................... 143

5.1

Zusammenfassung der Resultate im Thrombinprojekt

5.2 .

Zusammenfassung der Resultate im HDAC-Projekt 
6.

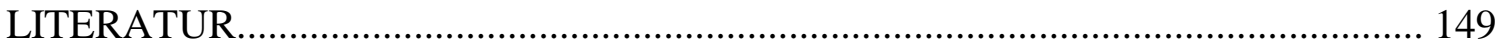

7.

ANHANG: MATERIAL.................................................................................. 162

7.1.

Chemikalien und verwendete Kürzel in der Standard-Peptidsynthese.......................... 162

7.2.

Material und Chemikalien für molekularbiologische Arbeiten...................................... 163

7.3.

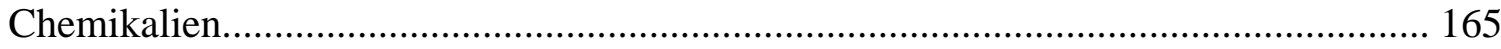

7.4.

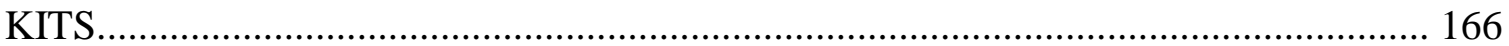

7.5.

Sonstige Materialien und Geräte................................................................................ 166

7.6.

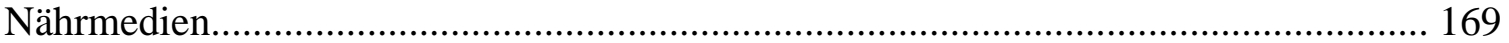

7.7.

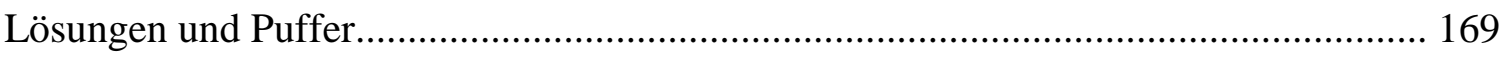

7.8.

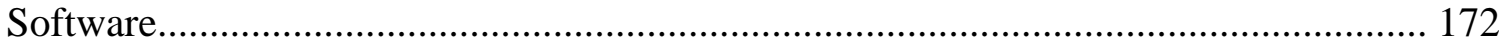

7.9.

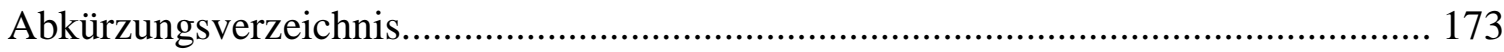

8.

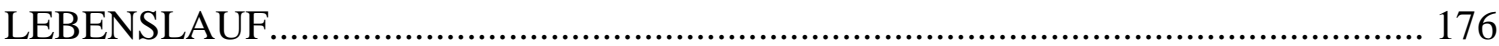




\section{Einleitung}

Moderne Medikamente haben zu zahlreichen Fortschritten in der Medizin, zum Beispiel bei der Behandlung von Magengeschwüren oder der Schizophrenie geführt. Nach Angaben des Verbandes Forschender Arzneimittelhersteller e.V. sind in den Jahren 1988 - 1998 alleine in Deutschland 310 neue Wirkstoffe auf den Markt gekommen. Während noch vor Jahren etwa 60 Neuzulassungen pro Jahr $\mathrm{zu}$ verbuchen waren, sind es gegenwärtig nur noch 20 bis 30 mit weiter fallender Tendenz ! Angesichts der Tatsache, daß nur für ein Drittel aller Krankheiten eine adäquate Behandlung zur Verfügung steht, wird der Ruf nach effizienteren Methoden des Wirkstoffdesign immer lauter. Dabei wird nicht nur eine größere Zahl an Medikamentenzulassungen angestrebt. Das einzelne Medikament soll auch in Bezug auf Wirksamkeit, Verträglichkeit und einfachere Einnahme optimiert werden.

Dieser Herausforderung erfolgreich zu begegnen hängt unter anderem auch davon ab, wie schnell und wieviele neue Wirkstoffe gefunden und entwickelt werden können. In den letzten fünfzehn Jahren hat sich die Wirkstoffsuche durch die rasanten Fortschritte der Molekularbiologie geradezu dramatisch verändert. Ziel ist jetzt v.a., Arzneimittel in möglichst geringen Dosen und hochselektiv auf ein bestimmtes Zielmolekül, das sogenannte „Target“" wirken zu lassen. Meist handelt es sich dabei um Enzyme oder Rezeptoren, die durch einen aktiven Wirkstoff in der Bindung an ihre natürlichen Substraten oder Liganden gehemmt werden sollen.

Ist ein geeigneter Test (oder Assay), der die Wirksamkeit einer Substanz einwandfrei belegt, gefunden, kann häufig mit Hilfe molekularbiologischer Methoden das Target für in-vitro Testsysteme bereitgestellt werden, sei es durch Isolation aus der natürlichen zellulären Umgebung, sei es durch heterologe Expression. Durch Automatisierung und Miniaturisierung solcher Testsysteme ist es heute möglich, tausende Substanzen, d.h. Wirkstoffkandidaten, in kürzester Zeit $\mathrm{zu}$ untersuchen, man spricht vom High Throughput Screening oder abgekürzt HTS.

Die Bereitstellung von Wirkstoffkandidaten mit der nötigen strukturellen Diversität kann durch kombinatorische Chemie mittels Syntheserobotern und durch „Sammeln“ von aufgereinigten Naturstoffen in Form von Substanz-,,Bibliotheken“ erfolgen. Bisher haben sich v.a. zwei Strategien in der Wirkstoffsuche durchgesetzt: (i) Zum einen wird eine sehr große Zahl (>100 000; Spencer, 1998) von Substanzen nach wirksamen Molekülen im HTS durchsucht. Informationen über das Target werden nur insofern benutzt, als ein Testsystem mit dem Target eingesetzt wird. Im Test identifizierte, wirksame Moleküle dienen als Leitsubstanzen um in einer Reihe von weiteren Optimierzyklen immer „geeignetere“ Derivate der primären Wirkstoffkandidaten zu finden. (ii) Wenn z.B. aus röntgenkristallographischen Analysen die Struktur des Targetmoleküls bekannt ist, können durch Anwendung des „Molecular Modelling“ auch „passende“ Ligandenmoleküle für ein bestimmtes Target am Computer in-silico identifiziert werden (Kubinyi, 1998). Anschließend werden nur noch die wirklich vielversprechenden Moleküle synthetisiert und getestet. Doch auch hier müssen noch sehr viele Moleküle getestet werden, bis man eine entwicklungsfähige Leitstruktur erhält, die zu diesem 
Zeitpunkt dann immer noch im Hinblick auf eine Reihe weiterer Eigenschaften außerhalb der reinen Targetbindung optimiert werden muß.

Weder die blinde Suche nach der molekularen „Stecknadel“ , d.h. durch HTS, noch der Ansatz eines „rationalen“, d.h. strukturbasierten Designs haben sich bisher als universell einsetzbares Werkzeug erwiesen, das effizient genug wäre, sich den Anforderungen der modernen Wirkstoffforschung zu stellen.

Der hier vorgestellte Ansatz versucht daher, einen etwas anderen Weg zu beschreiten. Durch Kombination von Methoden des Hochdurchsatzscreenings, der kombinatorischen Synthese und last not least durch Verfahren aus dem Bereich der künstlichen Intelligenz konnte das momentan wohl effizienteste Verfahren in der Wirkstoffoptimierung gefunden werden. Strukturelle Details über Targetmoleküle werden keine benötigt. Innerhalb einer Optimierung muß nur eine relativ begrenzte Zahl von Substanzen getestet werden. Dabei werden etliche, bei der Entwicklung eines Wirkstoffes wichtige Parameter wie Primärwirkung, Spezifität, pharmakologische Eigenschaften und Toxizität mit Hilfe computer-unterstützter Verfahren gleichzeitig und parallel optimiert. Einschränkend soll angemerkt werden, daß die experimentell bestimmten Parameter nicht nur eine möglichst genaue Abbildung der in-vivo Situation darstellen müssen, sondern die zugehörigen Assays bedingt auch HTS-tauglich sein sollten.

Thromboembolische Erkrankungen und Krebserkrankungen gehören weltweit zu den Haupttodesursachen. Es verwundert daher nicht, wenn in der vorliegenden Dissertation die beschriebenen, neuen Forschungsansätze am Beispiel der Targets Thrombin (Thromboembolische Erkrankungen) und Histondeacetylasen (Krebserkrankungen) bearbeitet wurden.

\subsection{Die Serinprotease Thrombin - das zentrale Target in der Blutgerinnungskaskade}

Proteasen spalten Polypeptidketten an deren amidischen Bindungen, zum Beispiel beim enzymatischen Abbau oder bei der Aktivierung eines Proteins oder Peptides aus seiner inaktiven Vorgängerform, dem Zymogen. Um ein Substrat spezifisch erkennen zu können, weisen Enzyme allgemein an ihrer Oberfläche mehrere Bindungstaschen auf, die strukturell komplementär zu den Seitenketten des Substrates sind. Die Nomenklatur zur Beschreibung der Bindungstaschen des Enzyms und der entsprechenden Seitenketten des Substrates wurde von Schechter \& Berger (1967) beschrieben. Die Positionen der Aminosäuren in peptidischen Substraten werden mit P3, P2, P1, P1', P2', P3' usw. bezeichnet, wobei P1 die Aminosäure unmittelbar vor der Spaltstelle und P1' die Aminosäure unmittelbar nach der Spaltstelle ist. Die Bindungstaschen werden analog mit mit dem Buchstaben "S“ bezeichnet. So gehört zum Beispiel die Tasche S1 zur Aminosäureseitenkette P1. 
Eine der am besten untersuchten Klassen von Proteasen sind Serinproteasen. Neben den Verdauungsenzymen Chymotrypsin, Trypsin und Elastase gehören die meisten Proteasen der Blutgerinnungskaskade dieser Enzymklasse an. Während die Verdauungsenzyme verständlicherweise eine große Bandbreite von Peptiden und Proteinen spalten können, wirken andere Serinproteasen wie Thrombin als Enzym in der Gerinnungskaskade hoch spezifisch.

Allen Serinproteasen ist ein gleicher Katalysemechanismus gemeinsam, der sie von anderen Proteaseklassen wie Aspartyl-, Cystein- oder Metalloproteasen unterscheidet. Beim katalytischen Mechanismus der Serinproteasen spielt ein nukleophil aktiviertes Sauerstoffatom der Serinseitenkette eine entscheidene Rolle, daher auch der Name dieser Enzymklasse.

\subsubsection{Die biologische Funktion von Thrombin}

Bei einer Verletzung der Blutgefäße muß der Prozeß der Blutstillung, die Hämostase, durch die hämodynamischen Mechanismen und biochemischen Vorgänge der Blutgerinnung schnell eintreten, um den Blutverlust zu begrenzen. Der Verschluß der verletzten Stelle im Gewebe erfolgt zunächst durch Kontraktion der Gefäßmuskeln sowie durch die Bildung eines Thrombus (Thrombogenese). Die Entstehung von Thromben beruht auf zwei miteinander gekoppelten Prozessen: Zunächst erfolgt sehr schnell eine Aggregation von Blutplättchen (Thrombozyten), dann folgt die Bildung von Fibrin aus Fibrinogen in der plasmatischen Blutgerinnung. Die Thrombozytenaggregation wird durch eine Verletzung der Blutgefäße oder durch Endotheldefekte mit Freisetzung von Kollagen, ADP, PAF (,platelet activating factor"), Serotonin, Katecholaminen und Thromboxan $\mathrm{A}_{2}$ mit der Folge eines Anstiegs der intrazellulären Calciumkonzentration ausgelöst. Zusätzlich wird der sogenannte Plättchenfaktor $3\left(\mathrm{PF}_{3}\right)$ freigesetzt, der die plasmatische Gerinnungskaskade auslöst, ein komplexes System verschiedener Enzyme, die meist als inaktive Vorstufen im Blut vorhanden sind und durch proteolytische Vorgänge stufenweise aktiviert werden (Taube, 1997).

In diesem Prozeß spielt das Enzym Thrombin eine zentrale Rolle; es ist ein Hauptaktivator der Blutplättchenaggregation. Thrombin wird in der Leber als Prothrombin synthetisiert und posttranslational modifiziert. Unter physiologischen Bedingungen bindet das Prothrombin (auch Faktor II genannt) über Calciumionen an negativ geladene Phospholipidmembranen. Aktives Thrombin entsteht durch die von Faktor Xa katalysierte Prozessierung aus Prothrombin und setzt seinerseits wiederum unlösliches Fibrin aus der im Blut gelöst vorliegenden Vorstufe Fibrinogen durch proteolytische Spaltung frei. 


\section{Natürliche Substrate von Thrombin}

Alle natürlichen Substrate von Thrombin haben gemeinsam, daß der eigentlichen Spaltstelle eine basische Aminosäure, vorzugsweise Arginin voransteht, die wiederum in die S1-Tasche innerhalb des aktiven Zentrums von Thrombin bindet. In die kleinere, hydrophobe S2-Tasche können Reste wie Prolin und in die etwas größere, hydrophobe S3-Tasche Reste wie die Seitenkette eines Phenylalanins binden (1.1.3.2). Einige natürliche Substrate von Thrombin mit ihren Spaltstellen sind in Tabelle 1 aufgelistet (Rose \& Di Cera, 2002):

Tab. 1. Sequenzen der Spaltsequenzen von natürlichen Thrombinsubstraten

\begin{tabular}{|c|c|c|c|c|c|c|c|c|}
\hline \multirow[t]{2}{*}{ Thrombin-Substrat } & \multicolumn{7}{|c|}{ Spaltsequenz } & \multirow[t]{2}{*}{ SwissProt Acc. No. } \\
\hline & $\mathrm{P}_{3}$ & $\mathrm{P}_{2}$ & $P_{1}$ & $\mathrm{P}$ & & 2 & $P_{3}$ & \\
\hline Fibrinogen $\alpha$-Kette & $\mathrm{G}$ & $\mathrm{V}$ & $\mathrm{R}$ & $\mathrm{C}$ & & $\mathrm{P}$ & $\mathrm{R}$ & P02671 \\
\hline Fibrinogen $\beta$-Kette & $\mathrm{S}$ & A & $\mathrm{R}$ & $\mathrm{C}$ & & $\mathrm{H}$ & $\mathrm{R}$ & P02675 \\
\hline Thrombinrezeptor PAR1 & $\mathrm{D}$ & $\mathrm{P}$ & $\mathrm{R}$ & $S$ & & $\mathrm{~F}$ & $\mathrm{~L}$ & P56488 \\
\hline Thrombinreceptor-like PAR3 & $\mathrm{P}$ & I & $\mathrm{K}$ & 1 & & $\mathrm{~F}$ & $\mathrm{R}$ & $\mathrm{O} 00254$ \\
\hline Thrombinreceptor-like PAR4 & A & $\mathrm{P}$ & $\mathrm{R}$ & $\mathrm{C}$ & & $\bar{Y}$ & $\mathrm{P}$ & AAC28860 \\
\hline Faktor VIII & $\mathrm{Q}$ & $\mathrm{I}$ & $\mathrm{R}$ & $S$ & & $\mathrm{~V}$ & A & P00451 \\
\hline Faktor VIII & $\mathrm{E}$ & $\mathrm{P}$ & $\mathrm{R}$ & $S$ & & $\mathrm{~F}$ & $S$ & P00451 \\
\hline Faktor XIII & $\mathrm{V}$ & $\mathrm{P}$ & $\mathrm{R}$ & $\mathrm{C}$ & & $\mathrm{V}$ & $\mathrm{N}$ & Q9NQP5 \\
\hline Vitamin K-dependent protein C & $\mathrm{D}$ & $\mathrm{P}$ & $\mathrm{R}$ & I & & I & $\mathrm{D}$ & P04070 \\
\hline
\end{tabular}

\subsubsection{Die Entwicklung von Thrombininhibitoren}

Thromboembolische Krankheiten stellen eine der Haupttodesursachen in der westlichen Welt. Besonders in der letzten Dekade des 20. Jahrhunderts wurden enorme Kraftanstrengungen in akademischer und industrieller Forschung unternommen, um neue Wege der Antithrombosetherapie zu entwickeln. Trotz großer Anstrengungen ist es bis heute noch nicht gelungen, den „idealen“ Thrombininhibitor zu finden, der in sich Eigenschaften wie gute antithrombische Aktivität, hohe Thrombinspezifität, geringe Toxizität, ein vorteilhaftes ADME-Profil mit insbesondere langsamer Elimination und möglichst orale Verfügbarkeit vereint.

\subsubsection{Indirekte Inhibitoren}

Die zur Zeit wichtigsten niedermolekularen Thrombininhibitoren mit klinischer Bedeutung (Heparine, Warfarine) gehören sämtlich in die Klasse der indirekten Inhibitoren, d.h. sie agieren nicht direkt am Thrombin. 
Heparin ist eine körpereigene Substanz und von seiner chemischen Struktur ein sulfatiertes, polyanionisches Glucosaminglykan und vermag daher eine Vielzahl von Komplexen $\mathrm{zu}$ bilden und sich an Oberflächen anzulagern. Der Hauptmechanismus seiner antikoagulatorischen Wirkung ist die Inaktivierung der Gerinnungsfaktoren IXa XIIa, durch einen über Lysinreste entstehenden Heparin-Antithrombin III-Komplex mit der Folge einer gehemmten Thrombinbildung. Erst in höheren Dosen wird auch Thrombin selbst über den Heparinkofaktor II gehemmt.

Warfarine / Cumarine werden auch als Syntheseblocker bezeichnet, weil sie nicht unmittelbar in die Gerinnungskaskade eingreifen, sondern die Synthese der Gerinnungsfaktoren in der Leber hemmen. Dort agieren sie als kompetitive Antagonisten zum strukturanalogen Vitamin $\mathrm{K}_{1}$. Seit vielen Jahren weiß man, daß Vitamin $\mathrm{K}$ zur Synthese von Prothrombin und von einigen anderen Gerinnungsfaktoren unerläßlich ist. Die Vitamin K-abhängige Carboxylierung wandelt die Glutamate in den weitaus stärkeren Calcium-Chelator $\gamma$-Carboxyglutamat um und genau diese Bindung verankert das Prothrombin - durch Calciumionen vermittelt - unter physiologischen Bedingungen an die Phospholipidmembran. Während sowohl das normale als auch das unvollständige Thrombin die gleiche Anzahl an Aminosäure besitzen, liegt der Unterschied in diesen ersten zehn Glutamatresten, die normalerweise vom einem Vitamin K Enzymsystem zu $\gamma$-Carboxyglutamaten carboxyliert werden. Das unvollständige Prothrombin, das sich nach Verabreichung von Vitamin K Antagonisten bildet, ist nicht mehr in der Lage, am aminoterminalen Ende des Enzyms Calciumionen zu binden.

Dem Vorteil einer oralen Verfügbarkeit der Vitamin K Antagonisten steht als Nachteil ein erhebliches Spektrum an potentiellen Gefahren / Nebenwirkungen gegenüber, insbesondere bedingt durch die extrem hohe Serumproteinbindung (bis zu 99,9\%) resultieren ausgesprochen lange Eliminationshalbwertszeiten. Gefürchtet sind v.a. innere Sickerblutungen. Außerdem sind eine Reihe von Interaktionen (Wechselwirkungen mit anderen Medikamenten) bekannt, die zu einer Verstärkung oder Verminderung der Wirkung führen, so daß verstärkt seit etwa 1965 nach weiteren Alternativen in Form selektiverer, direkter Thrombininhibitoren geforscht wurde.

\subsubsection{Direkte Thrombininhibitoren}

Einer der vielversprechensten Ansätze zur Behandlung thromboembolischer Ereignisse in neuerer Zeit ist die Identifizierung von direkten Inhibitoren des Thrombins. Viele blutsaugende Tiere produzieren direkt auf Thrombin wirkende gerinnungshemmende Stoffe, die im Prinzip auch pharmakologisch genutzt werden können. Hirudin aus dem Speichel des Blutegels ist allerdings der einzige Inhibitor, der bisher als Wirkstoff größere Bedeutung erlangt hat. Nicht zuletzt aufgrund seiner polypeptidischen Struktur kommt Hirudin für orale Verfügbarkeiten nicht infrage. Desweiteren zeigt es einen relativ schnellen proteolytischen Abbau, und im Zusammenhang damit auch eine schnelle Elimination aus dem Blutkreislauf (Bichler, J. et al., 1988 und Szewczuk, Z., et al., 1992).

Hier soll nur kurz die Entwicklung nicht-kovalenter Inhibitoren zusammengefasst 
werden, kovalente Inhibitoren wie etwa die Aldehyde oder Boronsäurederivate haben aufgrund ihrer Reaktivität nie den Weg in die Klinik gefunden, und sollen daher nicht näher behandelt werden. Erste, nicht-kovalente, synthetische Inhibitoren leiteten sich von bekannten Thrombinsubstraten (siehe Tab. 1) ab, d.h. sie enthielten positiv geladene Reste wie den des Arginins. Einige Vertreter sind in Abbildung 1 dargestellt. Verbindungen dieses „Guanidin-Typs“ schließen das PPACK 1 (irreversibeler Inhibitor), das Inogatran $\underline{\mathbf{2}}(\mathrm{Ki}=4.2 \mathrm{nM})$ und das Argatroban $\underline{\mathbf{3}}(\mathrm{Ki}=19 \mathrm{nM})$ ein.
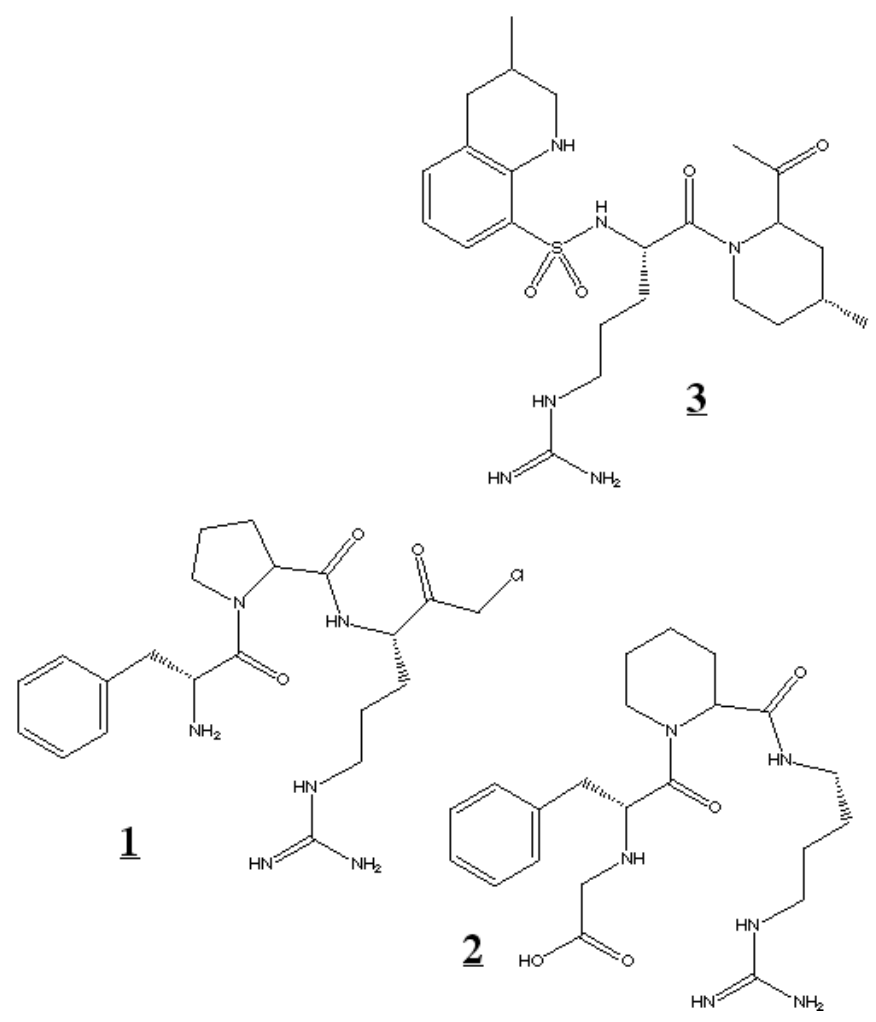

Abbildung 1: Synthetische Thrombininhibitoren. $\underline{1}$, PPACK; $\underline{2}$, Inogatran; $\underline{\mathbf{3}}$, Argatroban.

Im Jahr 1968 wurde mit 4-Amidinophenylbrenztraubensäure $\underline{4}(\mathrm{Ki}=6.5 . \mu \mathrm{M})$ zum ersten $\mathrm{Mal}$ auch ein Inhibitor mit einem Benzamidinrest beschrieben. Weiterentwicklungen dieses Inhibitortyps schließen u.a. das NAPAP $\underline{\mathbf{5}}(\mathrm{Ki}=6 \mathrm{nM})$, das Melagatran $\underline{\mathbf{6}}(\mathrm{Ki}=3.6$ $\mathrm{nM}$ ) und seine Prodrug-Form, das H376/95 $\underline{\mathbf{7}}$ ein (Abb. 2). In letzterer Verbindung wurden die geladenen Teile des Moleküls derart modifziert, daß ein praktisch ungeladenes Molekül entstand, daß in der Tat im Rattenmodell eine Bioverfügbarkeit von ca. $20 \%$ aufwies, im Vergleich zu etwa $5 \%$ für Melagatran. Auf dem Weg zum Wirkort verliert die Prodrug-Form die eingeführten Modifikationen dann wieder, unter Freisetzung von Melagatran. 

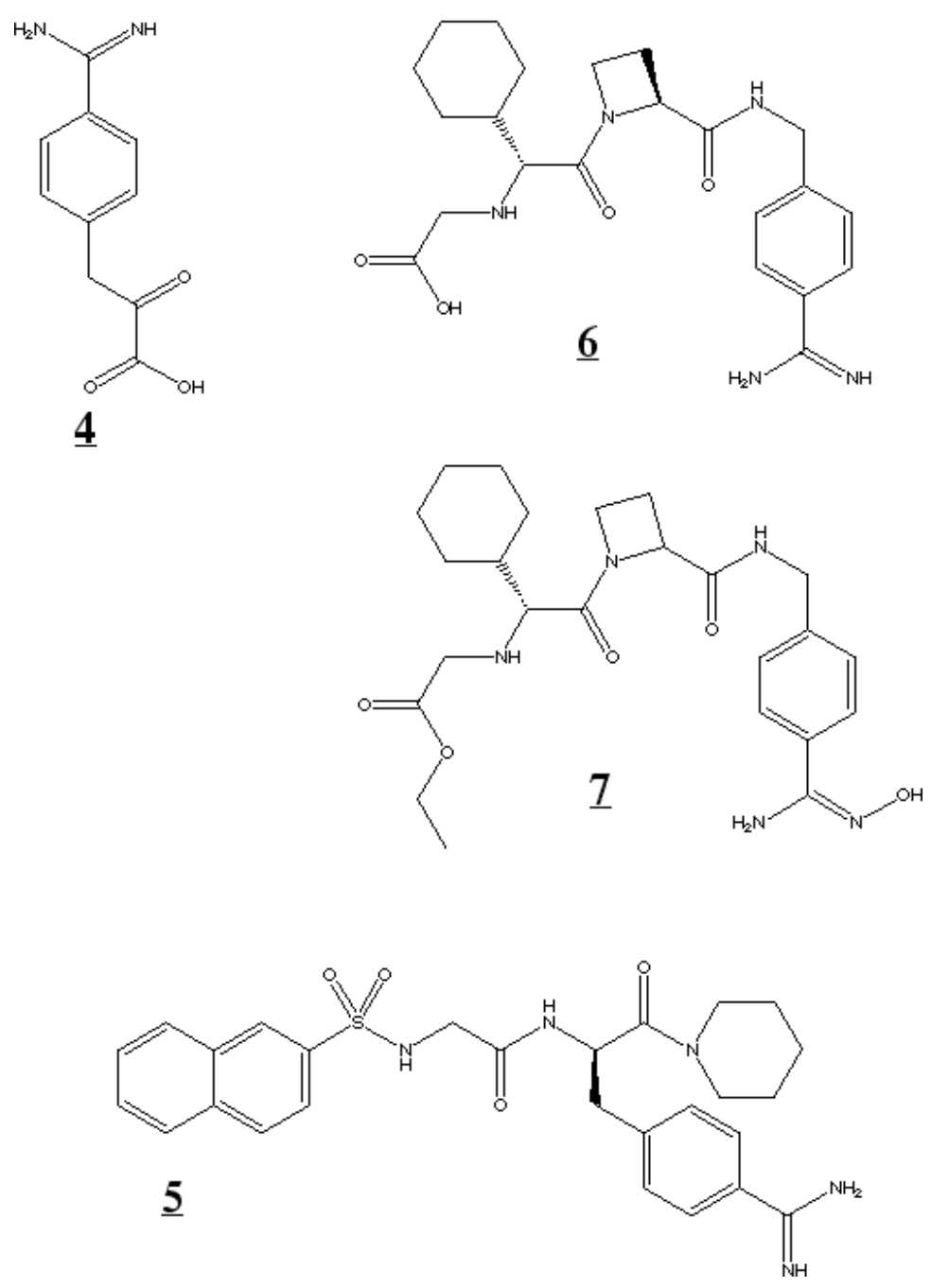

Abbildung 2: Synthetische Thrombininhibitoren. 4, 4-Amidino-phenyl-brenztraubensäure; $\underline{\mathbf{5}}$, NAPAP; , Melagatran; ㄱ, Prodrugform H376/95 des Melagatran.

Auch in einer Anzahl von Drug-Formen ist dieses Prinzip, d.h. die Abschirmung von Ladungen realisiert. Um möglichst die für die Thrombinbindung (saure S1-Tasche im aktiven Zentrum) wichtige basische Funktion aufrecht zu erhalten, wurden Gruppen wie z.B. Amidrazon-Reste $\underline{\mathbf{8}}\left(\mathrm{LB}-30057 ; \mathrm{K}_{\mathrm{i}}=0.38 \mathrm{nM}\right)$ mit reduzierter Basizität eingesetzt (Steinmetzer et al., 2001 und Sanderson et al., 1998). Der Versuch, gänzlich neutrale P1Reste einzusetzen, führt in nicht-kovalenten Inhibitoren allerdings in der Regel zu drastischen Verschlechterungen im $\mathrm{K}_{\mathrm{i}}$-Wert. Wichtige Verbindungen der letztgenannten Gruppe von Thrombininhibitoren, wie $\underline{\mathbf{9}}$ (Lumma et al., 1998) und $\underline{\mathbf{1 0}}\left(\mathrm{K}_{\mathrm{i}}=230 \mathrm{nM}\right.$; Tucker et al., 1998) sind in Abb. 3 dargestellt: 


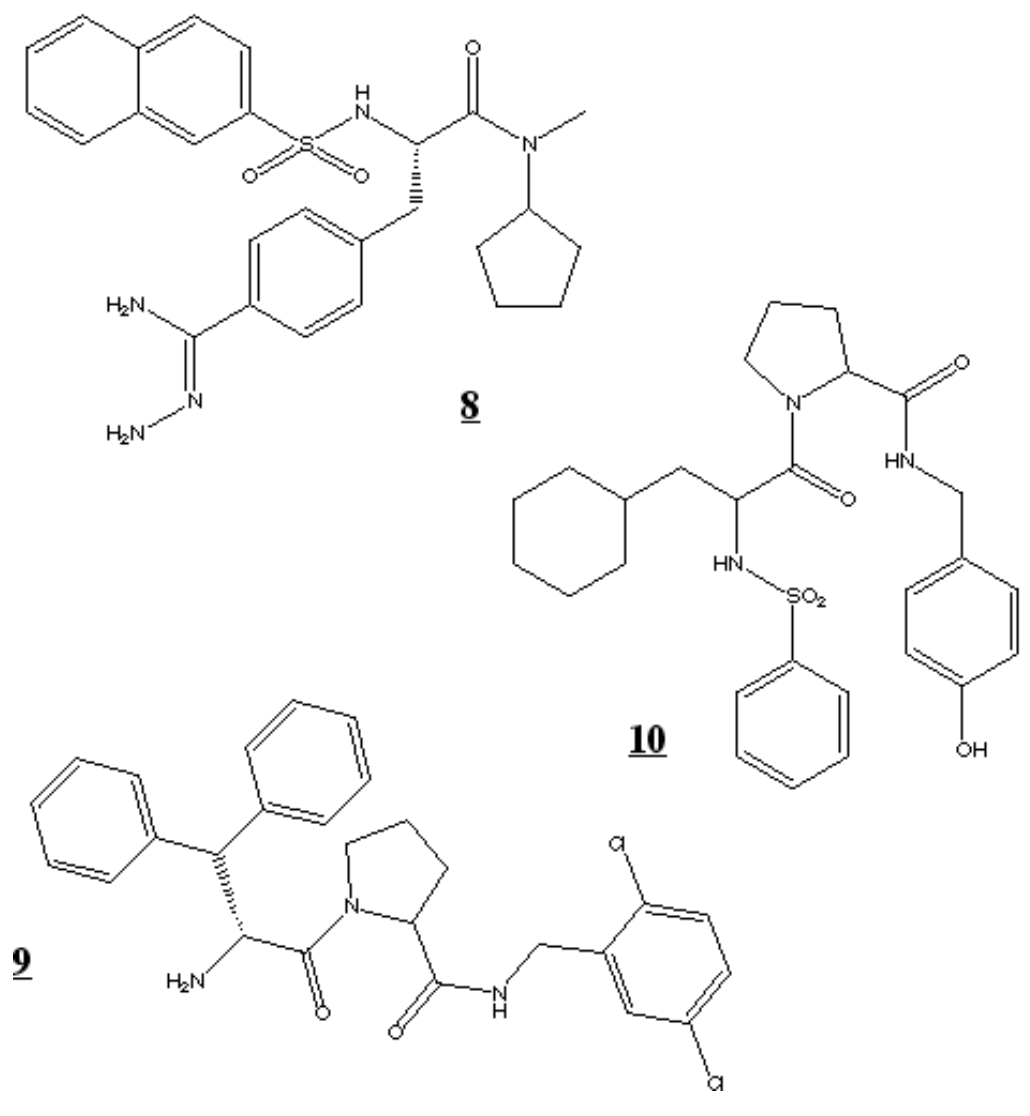

Abbildung 3: Synthetische Thrombininhibitoren. $\underline{\mathbf{8}}$, LB-30057; $\underline{\text {, }}$ D-Dpa-L-Pro-Dcb; 10, Benzylsulfonyl-D-Cha-L-Pro-(4-hydroxybenzylmethane)-amid.

Zusammenfassend kann allerdings festgehalten werden, daß Entwicklungen in diese Richtung bisher noch nicht zu wirklich potenten, oral-verfügbaren Thrombininhibitoren geführt haben. Ximelagatran, die schon erwähnte Prodrug-Form von Melagatran ist die bisher einzige, oral verfügbare Substanz, die zudem seit kurzem in einigen, wenigen Ländern (z.B. Frankreich) auch klinisch zugelassen wurde (Crowther et al., 2004). Nicht unerwähnt bleiben soll an dieser Stelle, daß im September 2004 ein Komitee der amerikanischen Zulassungsbehörde FDA eine Zulassung in den USA und Canada wegen des erhöhten Risikos von Nebenwirkungen (,liver failure“) verweigert hat. Neben der immer noch sehr moderaten Bioverfügbarkeit selbst der Prodrug-Form weist Melagatran eine sehr eingeschränkte Selektivität auf. Es inhibiert z.B. Thrombin und Trypsin etwa gleich gut. Somit ist nach dem heutigen Stand selbst der aktuelle beste Wirkstoff dieser direkten, nicht-kovalenten Thrombininhibitoren noch um einiges vom idealen Thrombininhibitor entfernt. 


\subsubsection{Kristallstruktur des Thrombins}

Für die Strukturbestimmung von kleinen organischen Molekülen bis hin zu Proteinen werden im wesentlichen zwei Verfahren angewandt: die Röntgenstrukturanalyse und die magnetische Kernresonanzspektroskopie (NMR). Die NMR-Spektroskopie basiert auf der Resonanzanregung von Wasserstoffkernen durch Radiowellen (MHz-Bereich) im Magnetfeld (Bloch und Purcell, 1952 Nobelpreis für Physik). Die Fortschritte in der Datenverarbeitung, die Verfügbarkeit von supraleitenden Magneten und andere apparative Verbesserungen führten zur allgemeinen Anwendung höherer Feldstärken und mehrdimensionaler Pulstechniken und damit zur Möglichkeit der Nutzung zur Proteinstrukturaufklärung, allerdings sind derzeit Proteinstrukturen bis maximal $300 \mathrm{kDa}$ auflösbar. Die gute Löslichkeit des Materials und die Ausbildung eindeutiger Strukturen in Lösung sind häufig limitierende Bedingungen.

Röntgenstrahlen, die 1895 von Wilhelm Röntgen (Nobelpreis für Physik 1901) entdeckt wurden, haben Wellenlängen, die mit den Abständen der Atome im Kristall vergleichbar sind (ca. 100 pm) und werden deshalb an Kristallgittern gebeugt. Die entstehenden Beugungsreflexe werden in der Proteinkristallographie mit einem Flächendetektor gleichzeitig registriert. Dabei wird heute üblicherweise eine Bildplatte (,image plate“) eingesetzt. Im Falle der Röntgenkristallographie gibt es keine obere Grenze für die Masse der untersuchten Proteine, es müssen allerdings geeignete Kristalle erhalten werden können.

\subsubsection{Kristallisation von Proteinen}

Organische Moleküle und Proteine findet man in der Natur nur selten kristallin, man muß selbst Bedingungen finden, Proteinkristalle für die Strukturaufklärung wachsen zu lassen. Einige Proteine kristallieren sehr gut, bei anderen wiederum ist es sehr zeitaufwendig, die geeigneten Kristallisationsbedingungen $\mathrm{zu}$ finden, während einige bis zum heutigen Tage nicht kristallisiert werden konnten.

Für die Kristallisation von Proteinen hat sich die sogenannte ,hanging drop “ Methode als geeignet erwiesen, weil oft nur geringe Mengen an aufgereinigtem Protein (wenige Milligramm) zur Verfügung stehen. Ein 5 bis $15 \mu$ großer Tropfen der konzentrierten Proteinlösung wird dabei kopfüber über einem Reservoir plaziert, das etwa $500 \mu \mathrm{l}$ einer konzentrierteren Lösung an Fällungssubstanzen ohne Protein enthält. Wenn sich ein Gleichgewicht zwischen den beiden Lösungen eingestellt hat, kann das Protein kristallisieren.

Will man Kristalle von Proteinen im Komplex mit niedermolekularen Liganden erhalten, gibt es prinzipiell zwei Vorgehensweisen. Bei der Kokristallisation von Protein und Ligand werden die Lösungen mit dem Protein bzw. Liganden vor dem 
Kristallisationsansatz miteinander gemischt und dann kristallisiert. Eine weitere Möglichkeit besteht darin, kleine Moleküle in die Kristalle diffundieren zu lassen, wenn die Bindetasche an einen Wasserkanal stößt. Durch Einlegen des Proteinkristalls in eine Pufferlösung eines Liganden kann dieser in die Bindetasche hineindiffundieren (,soaking“) und sich dort in der Bindetasche anlagern.

\subsubsection{Struktur und Bindungstaschen von Thrombin}

Die Benennung und Numerierung der Aminosäuren des Thrombins und Trypsins lehnt sich in der folgenden Beschreibung der Struktur von Thrombin an die der Protease Chymotrypsinogen an (Bode et al., 1989). Wie die anderen Mitglieder trypsinähnlicher Serinproteasen besteht auch das Thrombin im wesentlichen aus zwei sechssträngigen $\beta$ Faltblättern, die jeweils zu einer faßartigen Struktur angeordnet sind. Die V-förmige AKette verläuft in einer durch die größere B-Kette ausgesparten Kerbe auf der anderen Seite des Thrombins, d.h. auf der der „active-site“ Spalte gegenüberliegenden Seite.

In Abbildung 4 (rechts) ist ein Ausschnitt mit dem Inhibitor NAPAP (Abb.2, $\underline{5}$ ) im aktiven Zentrum zu sehen. Der Benzamidinrest von NAPAP ist tief in der schmalen S1Tasche vergraben und deshalb nur teilweise zu sehen. Ein Teil des Inhibitors ist durch die Seitenkette des Trp60D im 60er Loop verdeckt. Unter der Oberfläche auf der rechten Seite des Ausschnittes befinden sich die Aminosäuren der katalytischen Triade. Die Fibrinogenbindestelle befindet sich i. W. rechts neben der im Ausschnitt vergrößerten Region.

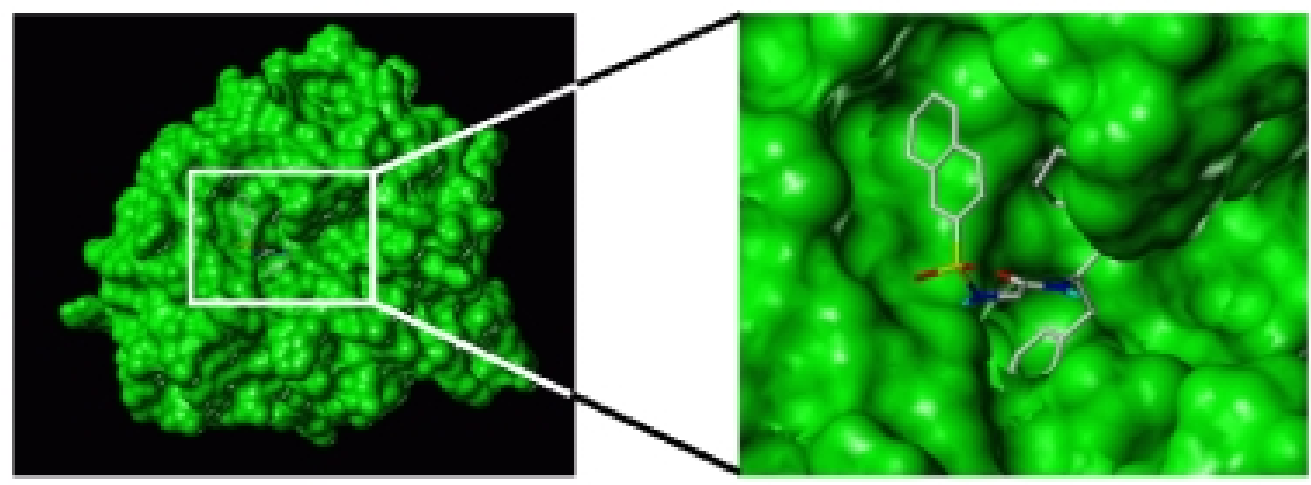

\section{Abbildung 4: Oberflächendarstellung von Thrombin im Komplex mit dem Inhibitor NAPAP (Bode et al., 1990).}

Die drei wichtigsten Bindungstaschen zur Aufnahme des Substrates oder eines Inhibitors lassen sich wie folgt beschreiben:

\section{Aktives Zentrum}

Die $\mathrm{S}_{1}$-Spezifitätstasche des Thrombins ist eine tiefe, schmal eingeschnittene Tasche, an deren Grund die Carboxylatseitenkette des Aspartats 189 sitzt, mit dem die basischen P1- 
Arginin- bzw. Lysinreste eine günstige Salzbrücke ausbilden können. Diese Tasche wird auf der einen Seite durch eine antiparallele Faltblattstruktur, auf der anderen Seite durch eine $\beta$-Schleife begrenzt. Im Unterschied zum Serin 190 des Trypsins besetzt diese Position im Thrombinmolekül ein Alaninrest, so daß die $\mathrm{S}_{1}$-Tasche des Thrombins etwas weniger polar ist und daher eine Wasserstoffbrücke weniger ausbilden kann. Am „oberen“ Ende der S1-Spezifitätstasche schließt sich die sogenannte Oxyanionentasche an, die von drei nach innen gerichteten Aminofunktionen ausgekleidet wird, um so das geladene Sauerstoffatom in einem tetraedrischen Übergangszustand zu stabilisieren.

\section{S2-Bindetasche}

Im Vergleich zu Trypsin besitzt Thrombin viele zusätzliche Ketteninsertionen, die vor allem die ,active-site“ Spalte vertiefen, verengen und so die besondere Substratspezifität bedingen. Zur höheren Substratspezifität von Thrombin gegenüber Trypsin trägt auch die zusätzliche, mittelgroße hydrophobe $\mathrm{S}_{2}$-Bindetasche bei, die durch die in Trypsin nicht vorhandene Schleife aus Tyr60A-Pro60B-Pro60C-Trp60D (den sogenannten 60er Loop) entsteht. Diese Schleife ist trotz ihrer Exposition erstaunlich wenig verformbar und verhindert so den Zutritt der meisten Proteine zur Spaltstelle. In Trypsin ist die Trennung von $\mathrm{S}_{2}$ - und $\mathrm{S}_{3}$-Tasche nicht so deutlich ausgeprägt wie im hochspezifischen Thrombin. Offensichtlich verlangt die Funktion des weitgehend unspezifischen Verdauungsenzyms diese Begrenzung des katalytischen Zentrums nicht. Die $\mathrm{S}_{2}$-Tasche ist sowohl in Thrombin als auch Trypsin durch die hydrophobe Seitenkette von Leucin 99 von der $\mathrm{S}_{3}-$ Tasche getrennt und wird von den Aminosäuren Tyr60A, Trp60D und His57 begrenzt. In der $\mathrm{S}_{2}$-Tasche werden bevorzugt kleine bis mittelgroße hydrophobe Reste gebunden. Im Falle des Thrombinsubstrats Fibrinogen wird diese Tasche durch die Isopropylseitenkette eines Valins besetzt (Bode \& Stubbs, 1995).

\section{Aromatenbindetasche (S3-Tasche)}

Die S3-Tasche des Thrombins ist eine große, hydrophobe Tasche, die bevorzugt aromatische Ringsysteme aufnimmt (Phenylalanin des Fibrinogens, Tyrosin des Hirudins). Deshalb kann diese Tasche als Aromatenbindungsstelle beschrieben werden. Begrenzt wird die Tasche durch die hydrophoben Seitenketten von Leucin 99 und Isoleucin 174. Den Boden der S3-Tasche bildet der Indolring des Tryptophans 215.

Makromolekulare Substrate (Fibrinogen) und auch Inhibitoren nutzen zur Bindung an Thrombin weitere spezifische Bindungsstellen auf der Oberfläche des Thrombins, die lokal weit vom aktiven Zentrum entfernt sind. Die eine ist die positiv geladene, sogenannte Fibrinogenbindungsregion (,,anion binding exosite“), die an der Bindung des Fibrinogens oder auch des Inhibitors Hirudin beteiligt ist. Die zweite stark positiv geladene Oberflächenregion des Thrombin wird als Heparinbindungsstelle bezeichnet (Bode et al., 1992). Die hier zu beobachtende Wechselwirkung beruht auf der elektrostatischen Wechselwirkung zwischen dem durch die Aminosäuren Lysin und Arginin erzeugten positiven Feld des Thrombins und dem negativen Feld des sulfatierten Polysaccharids Heparin. 


\subsection{Histondeacetylasen (HDAC) als Targets in der Tumortherapie}

Der enorme Anstieg der Forschungsaktivitäten im Bereich der HDAC in den letzten Jahren erklärt sich aus dem Bestreben, die Prozesse der Regulation von Transkriptionsvorgängen verstehen zu wollen, die nachweislich einen Einfluß auf die Angiogenese, die Zellzykluskontrolle, Apoptose und Zelldifferenzierung haben. Mehr noch: In der Kombinationstherapie mit existierenden Zytostatika wie Vitamin DAnalogen und PPAR-Liganden (Peroxisome Proliferator Activated Receptor) zeigt sich in Krebs-Modellsystemen beim Einsatz erster HDAC-Inhibitoren eine gesteigerte Effiziens der Behandlung und zum ersten Mal eröffnet sich die Möglichkeit, gezielt in die Transkription spezifischer, „, krankheitserzeugender Gene“ einzugreifen.

Heute sind 11 Vertereter menschlicher HDAC der Klassen I und II beschrieben. Zur Klasse I der HDAC zählt man die Isoformen 1,2,3,8 und 11. Sie stellen ubiquitär im Organismus von Säugern exprimierte Proteine mit einer Aminosäurenlänge von 350-500 Einheiten dar und sind primär im Zellkern lokalisiert, während die Vertreter der HDAC der Klasse II, die Isoformen 4,5,6,7,9 und 10 aus etwa 1000 Aminosäuren aufgebaut sind, im Kern und Zytosol vorkommen und eine gewebe-spezifische Expression aufweisen können. Eine weitere Klasse von Histondeacetylasen ist durch die Sirtuine gegeben, die allerdings keine Sequenzähnlichkeit zu den HDAC Klasse I oder II aufweisen und auch nach einem anderen katalytischen Mechanismus arbeiten.

HDAC beeinflußen die Struktur des Chromatins und verändern damit Protein- / DNAInteraktionen und in der Folge auch Transkriptionsvorgänge. Die Vielfalt der möglichen Eingreifmechanismen der verschiedenen HDAC erhöht sich gewaltig, wenn man bedenkt, daß sie erst im Komplex mit weiteren regulatorischen Proteinen die Transkription modulieren. Angesichts der kombinatorischen Natur dieser Protein- / HDAC-Interaktionen dürfte die Herausforderung darin liegen, spezielle Komplexe dieser Art mit zellulären Funktionen in Zusammenhang zu bringen und Moleküle zu identifizieren, die in dieses Zusammenspiel spezifisch eingreifen können.

\subsubsection{Die Biologische Funktion der HDAC}

Nur wenige Aufgaben und physiologische Rollen der HDAC sind bislang bekannt; für einige HDAC wie z. B. HDAC8 sind nicht einmal Substrate bzw. Interaktionspartner oder ihre Zugehörigkeit zu einem bestimmten Signalweg gesichert. Nachfolgend sind einige wichtige Entdeckungen auf diesem Gebiet beschrieben: 


\section{Organisation der DNA}

Die DNA des Zellkerns ist in bestimmten Hierarchieebenen als Chromatin verpackt. Auf der ersten Ebene sind etwa 146 bp DNA in ca. 1,8 Windungen um einen Histonkern geschlungen, der aus einem Octamer von basischen Proteinen besteht, die eine hohe Affinität zu DNA aufweisen. Dieser Komplex wird als Nukleosom bezeichnet, dessen

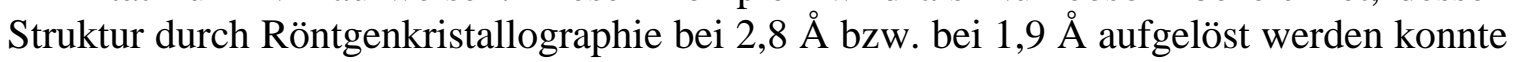
(Luger et al., 1997; Richmond and Davey, 2003). Die Oktamere setzen sich aus je zwei der Kernhistone H2A, H2B, H3 und H4 mit einer Größe von jeweils 100 bis etwas mehr als 200 Aminosäuren zusammen. Die Sequenzen vor allem der Histone 3 und 4 sind bei fast allen Eukaryoten hochkonserviert, was auf eine evolutiv frühe Entstehung des Chromatins hindeutet (Reeve, 2003).

Nach der Isolierung der ersten menschlichen HDAC mittels Affinitätschromatographie (Taunton et al.,1996) weiß man heute, daß Histonacetyltransferasen (HAT) Acetylgruppen von Acetyl-CoA auf bestimmte Lysine übertragen, die von Histondeacetylasen (HDAC) wieder entfernt werden können (Grozinger und Schreiber, 2002, Abb. 5).

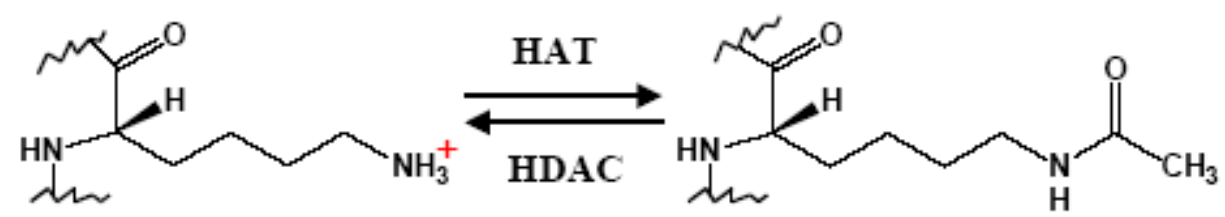

\section{Abbildung 5: HDAC katalysiert die Entstehung von Ladungen am Histon}

Lange Zeit begnügte sich die Wissenschaft mit einer sehr simplen Erklärung für die Wirkung der Histonmodifikationen. So dachte man, durch die Modifikation sinke einfach die positive Ladung der Histone und damit die elektrostatische Anziehung zwischen Protein und DNA. Es konnte gezeigt werden, daß die Maskierung positiver Ladungen der Lysine durch Acetylierungen für die Schwächung der Histon-DNA-Bindung und damit für die Relaxierung eines Chromatinabschnittes verantwortlich gemacht werden kann (Allfrey et al., 1964; Norton et al., 1989; Norton et al., 1990; Puig et al., 1998; Wolffe and Hayes, 1999. Die Verstärkung von internukleosomalen Wechselwirkungen über die Histonschwänze nach deren Deacetylierung wurde demgegenüber als förderlich für die Kondensation des Chromatins in Betracht gezogen (Lee et al., 1993). Desweiteren wurde eine Konformationsänderung der Histonschwänze zu $\alpha$-Helices nach Entfernung der Acetylgruppen beobachtet (Wang et al., 2000). Acetylierte Histone können vereinfacht als aktives, nicht-acetylierte als sich im Ruhezustand befindliches Chromatin beschrieben werden (Abb.6): 


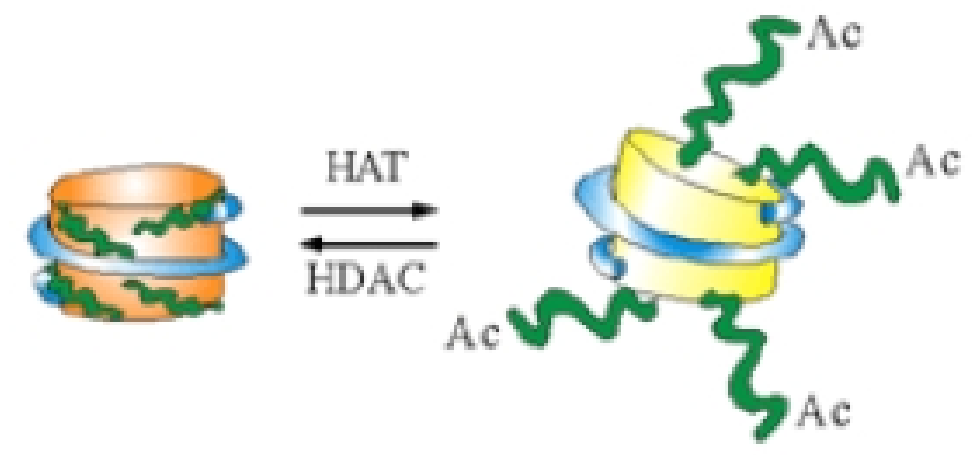

Abbildung 6: HDAC fördert die Kondensation des Chromatins

Inzwischen ist aber klar, dass mehr dahinter steckt als eine allgemeine physikalische Wechselwirkung. Die Effekte sind nämlich sehr spezifisch, je nach dem, welche der vier Histone (H2A, H2B, H3 und $\mathrm{H} 4)$ an welchen Aminosäure-Resten mit welchen chemischen Gruppen modifiziert ist. Wegen der kombinatorischen Komplexität der Modifikationen redet man daher auch vom "Histon-Code".

Die am besten charakterisierten HDAC werden als generelle Transkriptionsregulatoren in einer Reihe von Regulationsnetzwerken der Zelle gesehen (Lagger et al., 2002; Peterson, 2002; Vogelauer et al., 2000). Verschiedene Multiproteinkomplexe mit HDAC1 und HDAC2 sorgen jeweils für die Repression an einem spezifischen Satz von Genen für Wachstumsfaktoren, Zyklinen, Transkriptionsfaktoren und vielen Tumorsuppressoren und greifen damit in Abläufe wie Zellzyklus und Zelldifferenzierung ein (Kim et al., 2003; Lagger et al., 2002; Magnaghi-Jaulin et al., 1998; Marks et al., 2000; Wade, 2001).

\subsubsection{HDAC- Inhibitoren und Krebsentstehung}

Eine wachsende Zahl von experimentellen Beobachtungen belegt einen Einfluß der HDAC in der pathologischen Situation der Krebsentstehung (Chung, 2002). Histondeacetylaseinhibitoren (HDACI) wie Trichostatin A (TSA) und Trapoxin (TPX) zeigten in einer Reihe von Zellinien und im Tiermodell eine Induktion der Zelldifferenzierung, des Zellzyklusarrestes bzw. Apoptose und eine Reversion transformierter Zellmorphologie (Yoshida et al., 1995; Saito et al., 1999; Marks et al., 2000; He et al., 2001; Jung et al., 1999; Rosato et al., 2003; Bouchain et al., 2003). Dabei scheinen transformierte Zellen viel sensitiver auf HDACI $\mathrm{zu}$ reagieren als normale (Butler et al., 2000; Kim et al., 1999; Krämer et al., 2001). Durch Analyse des Acetylierungsmusters der Histone und in Experimenten mit cDNA-Microarrays wurde festgestellt, daß nur ein geringer Anteil $(<10 \%)$ der Gene durch HDACI beeinflußt werden (Butler et al., 2002; Marks et al., 2000; Van Lint et al., 1996). Für das Tumorsuppressorgen Zyklin-Kinase-Inhibitor p21 (WAF) konnte durch Einwirkung von HDACI eine "Derepression", d.h. eine Aktivierung der Genaktiviät gezeigt werden. 
(Butler et al., 2002; Kim et al., 2001; Krämer et al., 2001; Richon et al., 2000; Woo et $a l ., 2002)$. Auf der anderen Seite konnte gezeigt werden, daß HDAC in einer Reihe von Tumoren überexprimiert werden (de Ruijter et al., 2003; Patra et al., 2001) und es dadurch zu einer Repression von Tumorsupressoren oder der Hochregulierung von bestimmten Tumoraktivatoren wie (hypoxia-induced factor) HIF-1 oder Wachstumsfaktoren wie VEGF kommt: Unter besonderen Umständen, bei denen verstärkt Wachstumsfaktoren ausgeschüttet werden, um die Bildung von Blutgefäßen anzuregen, wie etwa bei Hypoxie (Sauerstoffunterversorgung) kommt es zu einer Überexpression von HDAC, was in der Förderung der Angiogenese resultiert (Kim et al., 2001). Die Einwirkung von HDACI konnte hier durch Induktion von p53 und anderen Faktoren und Repression von VEGF und HIF-1 die Angiogenese inhibieren (Kim et al., 2003; Kwon et al., 2002).

Aufgrund dieser Zusammenhänge ist es nicht verwunderlich, daß HDACI ein Potential als vielversprechende Antitumoragenzien zugesprochen wird (Johnstone, 2002; Jung, 2001; Yoshida et al., 2001; Yoshida et al., 2003). Darüber hinaus entdeckte man eine Anti-Malaria-Wirkung bestimmter HDACI (Meinke et al., 2000; Meinke and Liberator, 2001) und die Wirksamkeit von Hydroxamaten auch gegen bakterielle Deacetylasen (Jackman et al., 2000; Kline et al., 2002; Li et al., 2003). Diese Befunde demonstrieren das Potential von HDAC als Schlüsselenzymen in der chemotherapeutischen Intervention bei einer Reihe von Krankheiten. Bei der Therapie von malignen Erkrankungen, besonders im Hinblick auf die Beteiligung von verschiedenen HDAC mit entgegengesetzten Rollen im selben Funktionszusammenhang (Hamamori und Schneider, 2003), wären sicher möglichst selektive HDACI von immensem therapeutischen Wert, um mögliche Nebenwirkungen im Zuge der Beeinflussung kolateraler HDAC zu minimieren (Hu et al., 2003; Jung, 2001; Kim et al., 2003; Kwon et al., 2003).

Aber auch bei der Aufklärung der physiologischen Funktionen einzelner HDAC und deren Einordnung in distinkte Signaltransduktionswege oder deren Zuordnung zu bestimmten Komplexen wären selektive HDACI sehr nützliche Werkzeuge (Kim et al., 2003; Krämer et al., 2001; Spotswood and Turner, 2002). Erste Unternehmungen, solche selektiven HDACI zu entwickeln, wurden zeitgleich mit der vorliegenden Dissertation auch in anderen Laboratorien begonnen (Haggarty et al., 2003b; Hu et al., 2003; Wittich et al., 2002; Wong et al., 2003). 


\subsubsection{Strukturen und Wirkung einiger bekannter HDAC-Inhibitoren}

Aus der bereits gewaltigen und stetig wachsenden Anzahl der als HDAC-Inhibitoren beschriebenen Substanzen folgt an dieser Stelle eine überblicksartige Beschreibung einiger ausgewählter Strukturen:

\section{Kurzkettige Fettsäuren, Bsp. Natiumbutyrat}<smiles>CCCC(=O)O[Na]</smiles>

sodium butyrate

Butyrat war einer der ersten HDAC-Inhibitoren, die regelmässig eingesetzt wurde, nachdem beobachtet werden konnte, daß bei Verwendung niedriger millimolarer Konzentrationen eine Hyperacetylierung von Histonen auftrat (Boffa et al., 1978). Die Fähigkeit von Butyrat, das Wachstum von Darmkrebszellen zu hemmen (Velazques \& Rombeau, 1997), ist heute noch Gegenstand von Untersuchungen. Weitere Mitglieder dieser Gruppe sind Tributyrat und Valproinsäure.

\section{Hydroxamate}

Hydroxamsäurederivate mit den typischen Vertretern Trichostatin A (TSA) und<smiles>CC(/C=C/C(=O)NO)=C\C(C)C(=O)c1ccc(N(C)C)cc1</smiles>

trichostatin A Suberoylanilid-Hydroxamsäure SAHA interagieren mit dem Zink an der Bindungstelle des Enzyms (Finnin, M.S. et al., 1999). TSA wurde 1976 aus einer Streptomyceten-Kultur isoliert und fiel durch seine Aktivität gegen Trichophyton auf (Tsuji et al., 1976). Nach der Synthese stereoselektiver Enantiomere folgte der erste Bericht seiner HDAC-inhibitorischen Aktivität in vivo bei niedrigen nanomolaren Konzentrationen (Yoshida et al., 1990).

SAHA wurde ursprünglich aus einer Reihe von Substanzen entwickelt, die in niedrigen<smiles>O=C(CCCCCCC(=O)Nc1ccccc1)NO</smiles>
mikromolaren Konzentrationen der Induktion der Zelldifferenzierung dienten (Richon et al., 1996). Als HDAC-Inhibitoren wurden sie dann zwei Jahre später beschrieben und befinden sich in der klinischen Phase suberoylanilide hydroxamic acid der Entwicklung als Wirkstoff.

Pharmakologisch betrachtet sind allerdings viele Hydroxamate in vivo instabil und können außerdem durch Hydrolyse Hydroxylamin freisetzen, das potentiell mutagene Eigenschaften hat (Whittaker, $\mathrm{M}$ et al., 1999). Weiterhin sind metabolische und pharmakokinetische Probleme beschrieben, wie Glucuronidierung und Sulfatierung, die zu kurzen Halbwertszeiten in vivo führen (Vassiliou et al., 1999). 


\section{Cyclische Tetrapeptide mit Epoxyketon-Seitenkette}

Trapoxin A (TPX) ist ein irreversibler, in nanomolaren Konzentrationen aktiver HDAC-

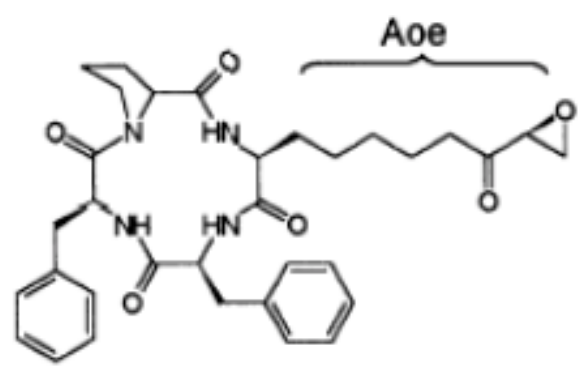

trapoxin

Inhibitor (Kijima et al., 1993). Der Aufbau besteht aus einem zyklischen Tetrapeptid mit einer 2-Amino-8-oxo-9,10-epoxy-dekansäure (Aoe). TPX war, wie bereits erwähnt, als Ligand bei der Isolierung der ersten rekombinanten HDAC mittels Affinitätschromatography verwendet worden. Analoge von TPX sind die sogenannten CHAPs, cyclische Hydroxamsäure-enthaltende Peptide, bei denen das Epoxyketon von Aoe durch Hydroxamsäure ersetzt ist (Furumai et al., 2001). Außerdem gehören phytotoxische Substanzen, die sogenannten HC-Toxine, in diese Gruppe (Kawai et al., 1983).

\section{Weitere cyclische Tetrapeptide}

Das bizyklische Depsipeptid FR901228 (auch FK228 genannt) stammt aus dem Pilz Chromobacterium violaceum (Duran \& Menck,

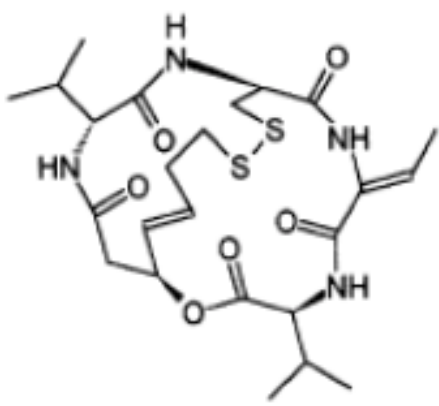

depsipeptide 2001). Ursprünglich als potente, antitumoral wirkende Substanz isoliert (Ueda et al., 1994) wurde es später als mikromolarer HDACInhibitor beschrieben (Nakajima et al., 1998). Die Substanz befindet sich in der klinischen Phase der Entwicklung. Es zeigte eine bemerkenswert selektiv-toxische Wirkung (Byrd et al., 1999) und gilt als Kandidat zur Behandlung bei Leukämien, Schilddrüsen- und Nicht-kleinzelligem Lungenkarzinom. Weitere Substanzen dieser Gruppe ist das Apicidin, einer gegen Plasmodien wirkenden Substanz mit HDAC inhibitorischer Wirkung im niedrigen nanomolaren Bereich (Darkin-Rattray et al., 1996).

\section{Benzamide}

MS275 entstammt der Synthese in einer Serie von Benzamid-Derivaten, die auf ihre

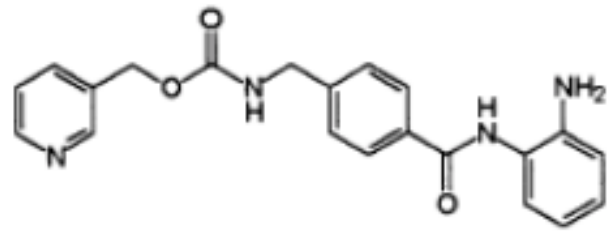

MS-275
Aktivität gegen HDAC getestet werden sollten (Saito et al., 1999). Die 2Aminogruppe oder auch eine 2Hydroxygruppe scheint essentiell für die hemmende Wirkung zu sein (Suzuki et al., 1999). Es ist bei geringen mikromolaren Konzentrationen wirksam und befindet sich bereits in der fortgeschrittenen klinischen Erprobung. Weitere Vertreter dieser Gruppe

sind Dinaline (Acetyldinaline, CI-994), das sich in Phase III der klinischen Entwicklung befindet. 


\subsection{Problemstellung}

\subsubsection{Thrombin}

Bei den hier zu bearbeitenden Aufgaben handelte es sich generell um Arbeiten zur Entwicklung von direkten Thrombininhibitoren. Direkt und hochspezifisch wirkende Inhibitoren sollten nach allgemein geltenden Vorstellungen gegenüber indirekt wirkenden Agenzien einen entscheidenen Vorteil in Bezug auf Nebenwirkungen, Potenz und Eliminationsverhalten aufweisen. Ein möglicher Nachteil eines solchen Stoffes war in der potentiell mangelhaften (oralen) Bioverfügbarkeit zu sehen, den körpereigene / -nahe Substanzen oft mit sich bringen. Aus diesem Grund wurde bei der Bearbeitung der Projekte von vorne herein versucht,

1. Assays möglichst nahe der in vivo-Situation auszulegen, diese wiederzuspiegeln

2. gleichzeitig mehrere Parameter zu optimieren

3. eine robuste, reproduzierbare und effiziente Synthesechemie (>200 Substanzen/Woche) einzusetzen.

\section{Die konkreten Problemstellungen in diesem Projekt lauteten:}

\section{i) Beurteilung von Hirudin und Hirudin-Varianten hinsichtlich ihrer Resistenz gegen Proteolyse}

Innerhalb des Arbeitskreises widmete sich ein Forschungsprojekt der evolutiven Optimierung von Hirudin mit dem Ziel einer Protease-resistenten Variante des Moleküls. Mit Hilfe eines kombinierten Ansatzes aus Phage-Display- und HochdurchsatzScreening-Methoden konnten Varianten isoliert werden, die an verschiedenen Positionen Aminosäuresubstitutionen aufwiesen (Wirsching et al., 1997). Die Aufgabe bestand darin, nachzuweisen, wie sich die Hirudin-Varianten im proteolytischen Verdau verhielten mit der Zielsetzung, einer schnellen enzymatischen Degradation / Elimination entgegenzuwirken unter Beibehaltung der enormen Potenz.

\section{ii) Entwicklung von Inhibitoren durch Computer-unterstütztes Wirkstoffdesign}

Statt etablierte Verfahren wie die der Struktur-basierten Wirkstoffsuche oder der des Hochdurchsatz-Screenings anzuwenden, wurde ein im Arbeitskreis zusammen mit der Firma Novel Science Int. GmbH (Dr. M. Thürk) entwickeltes Verfahren des Computerunterstützten Wirkstoffdesigns eingesetzt. Das Verfahren war bis zu diesem Zeitpunkt nur als ein Optimierverfahren für große Peptide eingesetzt worden, bei denen eine einzige Eigenschaft optimiert worden war, die Inhibition von Thrombin in der sogenannten 


\section{1-Parameteroptimierung}

Hier sollten innerhalb kurzer Zeit Thrombininhibitoren mit sich stetig verbessender inhibitorischer Wirkung entwickelt werden. Als Modellsystem wurden Peptide einer Länge von maximal 12 Aminosäuren gewählt

\section{Multiparameteroptimierung}

In diesem Folgeprojekt sollte es darum gehen, den „proof-of-concept“ für ein neues, verbessertes Verfahren des Wirkstoffdesigns zu erbringen. Im nachfolgend beschriebenen und bearbeiteten Projekt sollte der Versuch unternommen werden, das für die 1Parameteroptimierung entwickelte Verfahren des Computer-unterstützten Wirkstoffdesigns auf die Multiparameter-Optimierung auszudehnen, um unerwünschte Nebenwirkungen von vorn herein auszuschließen und damit die Entwicklung eines Wirkstoffkandidaten wesentlich zu beschleunigen.

Dieses sogenannte CADDIS ${ }^{\top M}$-Verfahren (Computer-assisted Drug Discovery) bietet den Vorteil, schnell und im experimentellen Stadium effizient und kostengünstig zu neuen Wirkstrukturen zu kommen. Im ganzen wurden nicht mehr als ca. 1000 Substanzen getestet, während beim traditionellen HTS- Drug Discovery (High-Troughput Screening) Bibliotheken von >>100.000 Substanzen die Regel sind (Spencer, 1998). Essentiell für den Erfolg dieses Projektes ist, bereits bei der Planung und Auswahl der Assays möglichst ein Abbild der in-vivo Situation zu schaffen.

Die Wahl der Substanzklasse der Peptide bedeutet zwar hohe Diversität, relativ einfache und schnelle Synthesen, beinhaltet auf der anderen Seite jedoch das Risiko mangelnder oraler Bioverfügbarkeit und schneller Elimination. Einen Zellpermeabilitätstest in das Testsystem aufzunehmen lag außerhalb des Rahmens diese Projekts, deshalb wurden stellvertretend die Wasserlöslichkeit und der Verteilungskoeffizient, die Serumproteinbindung und metabolische Stabilität bestimmt und bei der Auswahl der Bausteine nicht-proteinogene Aminosäuren zugefügt.

\subsubsection{HDAC}

Die hier zu bearbeitenden Aufgaben hatten das gleiche Fernziel, die Entwicklung selektiver, spezifischer Inhibitoren. Allerdings waren auf diesem Gebiet bedeutend mehr Grundlagen zu erarbeiten, da die Forschung hier in den letzten Jahren zwar gewaltig angewachsen ist, im Vergleich zum ersten Projekt aber doch deutlich weniger Wissen existiert oder anders formuliert, die Zusammenhänge insgesamt komplexer erschienen in Hinsicht auf die Abbildung der in-vivo-Situation auf brauchbare in-vitro-Instrumente. 


\section{Die Problemstellungen in diesem Projekt lauteten:}

\section{i) Bereitstellung des Targets, Produktion eines rekombinanten Proteins}

Mit der Klonierung, Expression, Reinigung und Charakterisierung einer bisher nicht kommerziell verfügbaren, aber interessierenden Isoform der HDAC, der HDAC8, sollte ein schnell verfügbares, in hinreichender Menge und reproduzierbar herzustellendes Proteintarget bereitgestellt werden, um über das hinsichtlich der Assay- und Inhibitorentwicklung nötige Material zu verfügen.

\section{ii) Assay-Optimierung}

Die Aktivität von HDAC's wird oft durch einen Szintillationsassay bestimmt, bei dem Histone mit radioaktivem $\left[{ }^{3} \mathrm{H}\right]$-Acetat vorab markiert werden müssen, dann mit Enzym inkubiert werden und die Radioaktivität im Überstand nach Abstoppen der Reaktion und einem Fällungsschritt gemessen wird (Lechner et al., 1996).

Die Entwicklung eines fluorogenen Assays mit einfach herzustellenden Substraten in Kombination mit der hohen Empfindlichkeit und der Möglichkeit, das Assayformat auf gängige MTP-Formate auszudehnen, würde in dieser Hinsicht einen Fortschritt bedeuten (Ninkovic et al., 2001, Zimmerman et al., 1977).

\section{iii) Substratentwicklung}

Bei den Synthesen der verschiedenen Substrate wurden zwei Richtungen verfolgt: (i) zum einen sollten effizientere Substrate entstehen mit dem Ziel, den Assay hinsichtlich Umsatz und Menge an benötigtem Substrat zu optimieren, (ii) zum anderen galt es, die Anforderungen der Proteine in Bezug auf strukturelle und stereochemische Beschaffenheiten des Substrats auszuloten, insbesondere hinsichtlich möglicher struktureller Motive für Inhibitoren und um mehr über die Substratspezifität der HDAC's zu erfahren.

\section{iv) Inhibitorentwicklung}

Alle vorangegangenen Aufgaben können als Vorarbeiten einer Entwicklung selektiver, spezifischer Inhibitoren gelten. Dieses im begrenzten Rahmen der Disseration an wenigen Kleinserien von Molekülen zu versuchen, war letztes Ziel der Arbeit. 


\section{Methoden und Material}

\subsection{Material}

Hier sollen kurz die generell verwendeten, zentralen Hilfsmittel zur Lösung der gestellten Aufgaben beschrieben werden, detaillierte Materiallisten über Chemikalien, Pufferzusammensetzungen, Lauf- und Hilsmittel, Kits usw. finden sich im Anhang, spezielles Material ist in den Beschreibungen der Methoden genannt:

\subsubsection{Peptidsynthese}

Für alle Standardpeptidsynthesen wurde ein automatisierter Peptidsynthesizer (MultiPep, INTAVIS AG, Deutschland) benutzt. Das Gerät basiert auf einem Pipettierroboter, der frei in $\mathrm{x}-\mathrm{y}-\mathrm{z}$-Richtungen programmierbar ist und über zwei Dispenser verfügt, die zum einen die Reagenzien über eine Einzelnadel pipettieren, zum anderen über einen 8-fach Verteiler die Harze in der Syntheseplatte waschen. Die Einzelnadel wird bei Bedarf in einer Waschstation von Innen und Außen mit DMF gewaschen. Die Arbeitsfläche ist so ausgelegt, daß sich ein Ständer (Tray 1) mit 4 x 11 Positionen, wo die vorgelösten ASBausteine (13 oder 2-mL Gefäße) plaziert werden, neben einem zweiten Ständer im gleichen Layout befindet, in dem die AS durch Zusammenpipettieren von AS, NMM und Aktivator TBTU in $2 \mathrm{~mL} \mathrm{V-Boden} \mathrm{Einmalgefäßen} \mathrm{aus} \mathrm{Polypropylen} \mathrm{(Intavis} \mathrm{Nr.} \mathrm{30.560)}$ voraktiviert werden. NMM und TBTU werden dazu aus $50 \mathrm{~mL}$ Vorratsgefäßen in einem dritten Ständer entnommen. Die Synthese findet dann in einer speziellen 96-Well Platte statt, die auf einer Station, an die Vakuum angelegt werden kann, plaziert wird. Die Platten sind mit Fritten abgedichtet und laufen nach unten kapillarartig aus, sodaß die viskosen Reaktionslösungen ohne weitere Abdichtungsmassnahmen zurückgehalten werden. Das zur Abspaltung der Fmoc-Schutzgruppen nach jedem Kopplungszyklus verwendete $20 \%$ Piperidin in DMF befindet sich in zwei $150 \mathrm{~mL}$-Flaschen neben der Waschstation.

Das gesamte Gerät (Abb.7) befindet sich oben in einem mittig unterteilten, geschlossenen Plexiglasgehäuse mit ventiliertem Anschluss zur Abluft, im unteren Teil befinden sich die an die beiden Dilutoren angeschlossenen Vorratsflaschen von DMF (1 L zum Nadelwaschen, 2,5 L zum Harzwaschen) und ein Abfallgefäß zum Sammeln der Waschlösungen der Nadel. Das abgesaugte DMF aus dem Syntheseblock wird vor der Vakuumpumpe (KNF Neuberger Laboport) in 5 L Flaschen gesammelt. 


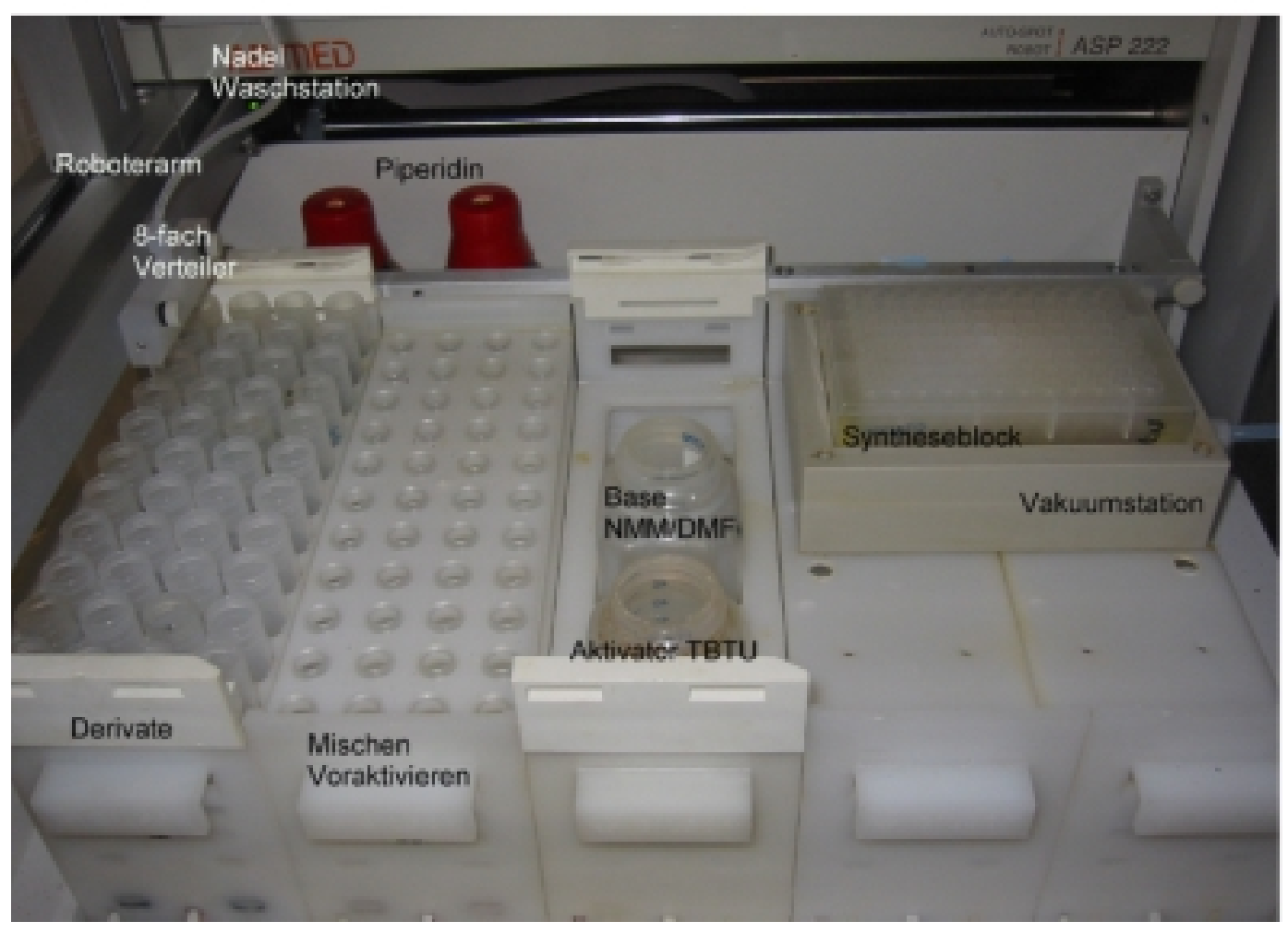

Abbildung 7: Arbeitsfläche des verwendeten Peptidsynthesizers MultiPep (Intavis AG)

Die Steuerung erfolgt über die MultiPep-Software (Intavis AG). Die zu synthetisierenden Sequenzen werden unter Beachtung der Gross- und Kleinschreibweise im Einbuchstabencode der Aminosäuresequenz durch ein Leerzeichen getrennt zeilenweise in eine sogenannte Sequenzdatei (Extension *.seq) eingetragen und in die erste Zeile dieser Liste ein „, .pep “ geschrieben. Nach dem Speichern dieser Datei werden daraus automatisch drei weitere Dateien desselben Namens aber verschiedener Extensionen generiert, die Peptiddatei (*.pep) mit einer Liste der Peptide mit dem erwarteten Molekulargewicht, die Reportdatei (*.rep) mit einer Liste der Mengen an benötigten AS-, Wasch- und Reagenzienlösungen und beim Start der Synthese eine Datei zur Dokumentation der ausgeführten Arbeitsschritte (*.log). Diese Arbeitsschritte werden in einem Pipettier-Unterprogramm festgelegt und beinhalten deren zeitliche Abfolge.

Die Unterprogramme mussten bei Standardsynthesen nicht verändert werden, im Verlauf einer Optimierung mit steigender Wirksamkeit der Produkte wollte man aber gegebenfalls den Syntheseansatz verkleinern und weitere AS-Bausteine verwenden, somit waren dann die Derivatedatei (*.der), eine Liste mit Daten der verwendeten Aminosäuren, deren Reihenfolge den Standort in Tray 1 bestimmt, die Positionsdatei (*.xyz), wo die Koordinaten aller benötigten Positionen festgelegt sind und die Parameterdatei (*.par), die die zu pipettierenden Volumina, Aufnahme- und Abgabegeschwindigkeiten, Extraktions- und Reaktionszeiten für das Pipettier- 
Unterprogramm beinhaltet zu editieren und unter dem Präfix der entsprechenden Sequenzdatei zu speichern, sonst würde der Synthesizer an dieser Stelle automatisch die sogenannten „Standard.der, -.par, -.xyz „- Dateien verwenden.

\subsubsection{Analytik und Aufreinigung von Syntheseprodukten per LC-MS}

Das verwendete Gerät ist eine Waters Alliance HT 2790 HPLC in Verbindung mit einem Micromass ZQ Massenspektrometer und Waters 996 Photodiodenarray Detektor (Abb.8, Waters, Eschborn, Deutschland).

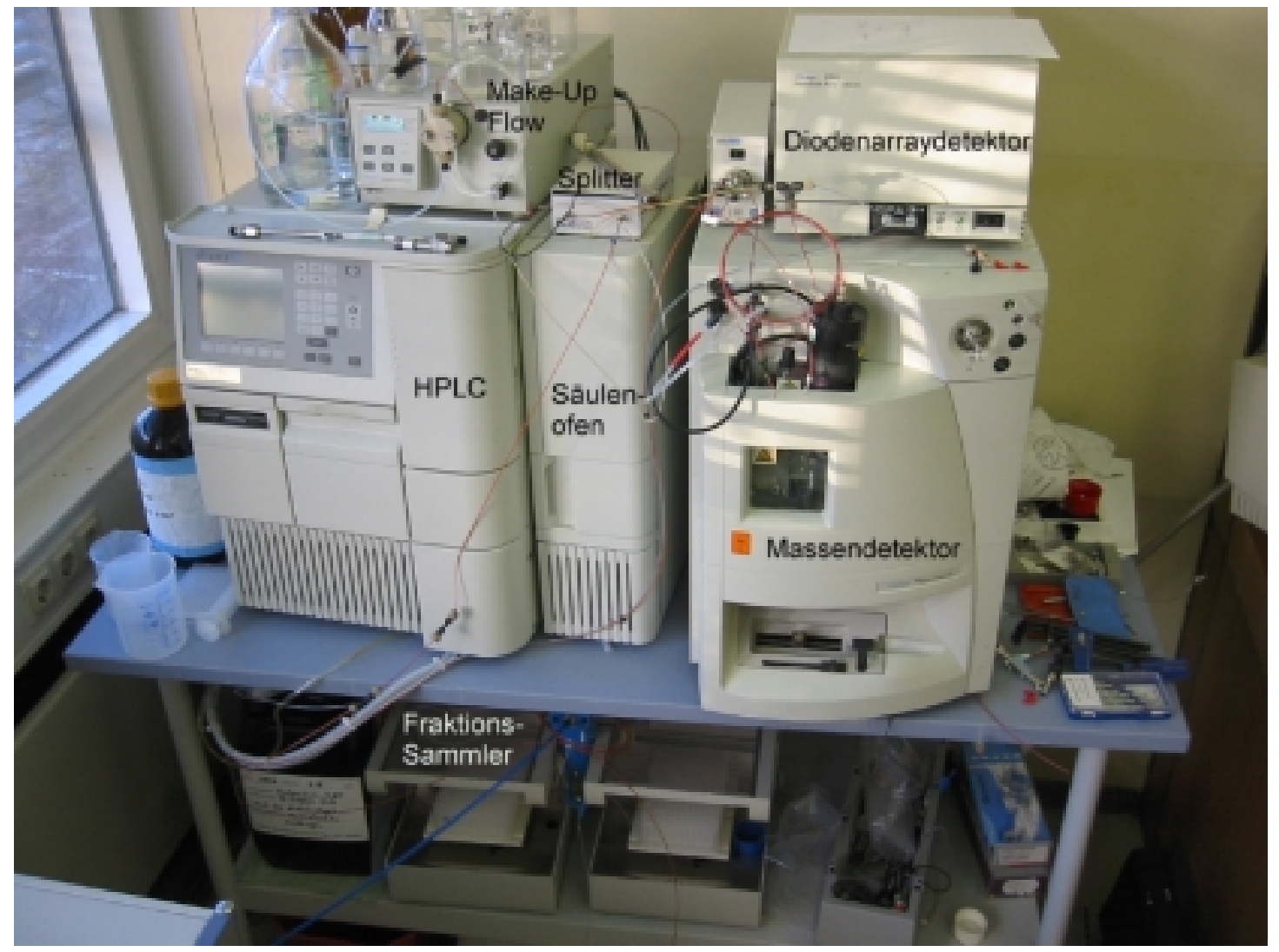

\section{Abbildung 8: LC-MS mit Diodenarraydetektor DAD und Fraktionensammler}

Ein Vorteil dieser Kombination ist das gleichzeitige Aufnehmen von Massen- und UVspektren während der chromatographischen Trennung, wodurch mehr Information gewonnen und eventuell versteckte Verunreinigungen leichter entdeckt werden können. Im Standardbetrieb wurden schnelle Gradienten von Wasser / Acetonitril auf verschiedenen Trennsäulen gefahren, sodaß ein Standard-LC-Lauf 6 min umfasste. Damit konnte das Gerät auch anstelle von Dünnschichtchromatographie für die Kontrolle von 
Reaktionsverläufen im Tagesbetrieb eingesetzt werden, während beim Abarbeiten grosser Probenzahlen, beispielsweise bei Konzentrationbestimmungen verschiedener Analyten oder der Bestimmung von Reinheit und Identität der Produkte von Parallelsynthesen die Datenaufnahme bevorzugt über Nacht erfolgte und durch das Probenkarusell mit Platz für vier MT-Platten erleichert wurde. Das Probenkarusell und der Säulenofen sind temperierbar und soweit nicht anders vermerkt wurde die Proben bei RT belassen und die Säulenofentemperatur auf $30^{\circ} \mathrm{C}$ eingestellt.

Ein weiterer Vorteil dieses Systems ist die Verwendbarkeit als (halb)präparative Anlage, wobei generell eine 10 x 250 mm, $5 \mu$, 300A, C18 Jupiter Säule (Nr. 00G-4053-N0 von Phenomenex, Aschaffenburg, Deutschland) benutzt wurde, deren Fluss dann 1/1000 durch einen Flowsplitter (Acurate, Nr. ACM-01-10 von LC-Packings) getrennt zum FraktionssammLer bzw. den Detektoren unter Zufuhr eines 0,5 mL / min Make-UpFlusses (1:1 ACN / Wasser) aus einem Waters Reagent Manager geführt wurde. Mit Hilfe der FractionLynx-Software konnten dann Fraktionen eines bestimmten $\mathrm{m} / \mathrm{z}$ Wertes gezielt abgetrennt und gereinigt werden.

Während der Massendetektor durch den Z-förmigen Aufbau und Anwendung eines Stickstoff-Gegenstroms im Sammelkonus unter normalen Bedingungen recht unempfindlich gegen Verschmutzungen ist und eine einwöchige Routinereinigung des Sammelkonus ausreichte, mußte er speziell bei den Proben aus den Serumproteinversuchen bereits nach 50 Proben gereinigt werden, da sich sichtbare Ablagerungen bildeten und die Empfindlichkeit nachliess.

\section{Einstellungen des Massendetektors}

Unter Standardbedingungen wurde bei $100^{\circ}$ Source- und $250^{\circ} \mathrm{C}$ Desolvationtemperatur mit $25 \mathrm{~V}$ Konusspannung und 3,5 kV Kapillarspannung im Elektrospray-Positivmodus gemessen und der Gesamtionenstrom TIC (total ion current) durch wiederholtes Abscannen des m/z-Bereiches 120 - 820 über die chromatographische Trennung aufgezeichnet. War die Empfindlichkeit unter diesen Bedingungen nicht ausreichend wegen schlechter Ionisation oder sehr geringen Konzentrationen, wurde auf EinzelionenDetektion SIR umgestellt (single ion record). Damit konnte die Empfindlichkeit um etwa das zehn- bis hundertfache gesteigert werden.

\section{Verwendete Säulen}

Analytisch, Analyt Peptide:

Aqua $5 \mu$ C18, 125A, 150 x 2 mm (Phenomenex Nr. 00F-4299-B0)

Protein \& Peptide C18 250 x 3,9 mm (MZ Analysentechnik, Vydac Nr.218TP54 )

Analytisch, Analyt organische Verbindungen:

Synergi $4 \mu$ Hydro RP, 80A, 150 x 2 mm (Phenomenex Nr. 00F-4375-B0)

Präparativ:

Jupiter 5 $\mathrm{C}$ C18 300A, 250 x 10 mm (Phenomenex Nr. 00G-4053-N0) 


\subsection{Methoden Teil A: Thrombin}

Die hier beschriebenen Methoden orientieren sich in ihrer Abfolge an den Problemstellungen unter 1.3.

\subsubsection{Proteolytischer Peptidabbau von Hirudinvarianten und Analyse der Fragmente}

Nach der erfolgreichen Produktion mit Hilfe eines kombinierten Ansatzes aus PhageDisplay- und Hochdurchsatz-Screening-Methoden evolutiv optimierter HirudinIndividuen mit Aminosäuresubstitutionen an den Positionen 49, 50, 56, 57 sowie 62 bis 64 (Abb. 9), mußte das Ziel, eine Protease-resistente Variante des Moleküls in den Händen zu halten, belegt werden. Die Aufgabe bestand darin, nachzuweisen, wie sich diese Varianten im proteolytischen Verdau verhielten.

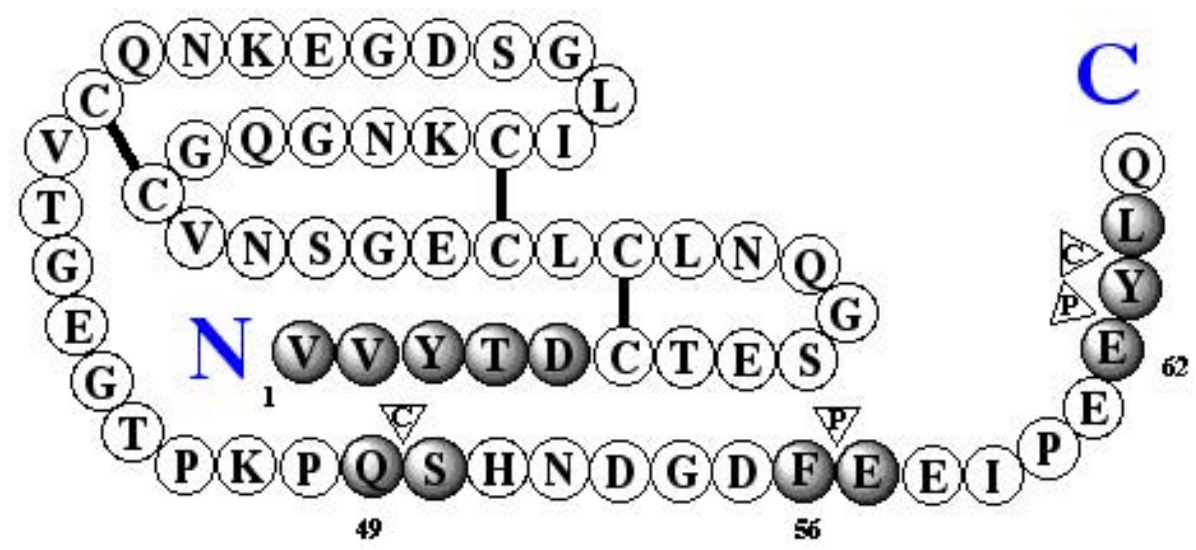

Abbildung 9: Sequenz des rekombinanten Hirudins. Die Positionen 1-5, 49, 50, 56, 57 sowie 6264, die durch Substitionen verändert wurden, sind grau hervorgehoben. Pfeile markieren die Spaltstellen für Pepsin (P) und Chymotrypsin (C).

Dazu wurden zunächst Peptide hergestellt, die aus den Sequenzen der Positionen 46-65 des Wildtyp-Hirudins und der entsprechenden Sequenz der Variante A6.6- $\mathrm{H}^{56}$ bestanden. Nach Festphasensynthese wurden die Peptide mit einer Endkonzentration von $40 \mathrm{mM}$ in DMSO gelöst. Die Lösungen wurden mit destilliertem Wasser auf eine Konzentration von $1 \mathrm{mM}$ verdünnt. $10 \mu \mathrm{l}$ dieser Lösungen wurden mit $90 \mu \mathrm{l}$ einer $50 \mathrm{mM}$ Ammoniumcarbonat-Lösung ( $\mathrm{pH}$ 8.0) vermischt und nach Zugabe von $10 \mu \mathrm{l}$ Enzymlösung ( $1 \mu \mathrm{l} / \mu \mathrm{l}$ Chymotrypsin oder Pepsin) für 24 Stunden bei $30{ }^{\circ} \mathrm{C}$ inkubiert. 
Die Analyse der Spaltprodukte erfolgte mittels Reversed-phase-HPLC-MS (ESI-MS; Waters/MassLynx). Zum Einsatz kam eine 150 x 2 mm-C18 Säule (Aqua, Phenomenex). Es wurde eine Säulentemperatur von $30{ }^{\circ} \mathrm{C}$ eingestellt. Solvent A war $0.1 \%$ Ameisensäure in Wasser. Solvent B bestand aus $0.1 \%$ Ameisensäure in Acetonitril. Ein Gradient von $0 \%$ bis $60 \%$ Solvent B wurde in 30 min durchlaufen.

\subsubsection{Entwicklung von Inhibitoren mit Computer-unterstütztem Wirkstoffdesign: 1-Parameter und Multiparameteroptimierung}

Der computer-unterstützte Optimierprozesses begann mit dem Vorschlag von 170 zufällig ausgewürftelte Peptidsequenzen (Zyklus 0), die synthetisiert und in den nachfolgend beschriebenen Testsystemen charakterisiert wurden. Nach algorithmischer Prozessierung der Daten wurde durch den Computer eine Art Struktur-Funktionsmodell erzeugt, auf dessen Basis 96 neue Substanzen (Zyklus 1) vorgeschlagen wurden (Abb.10). Dieser Prozess wurde über 8 Zyklen durchgeführt.

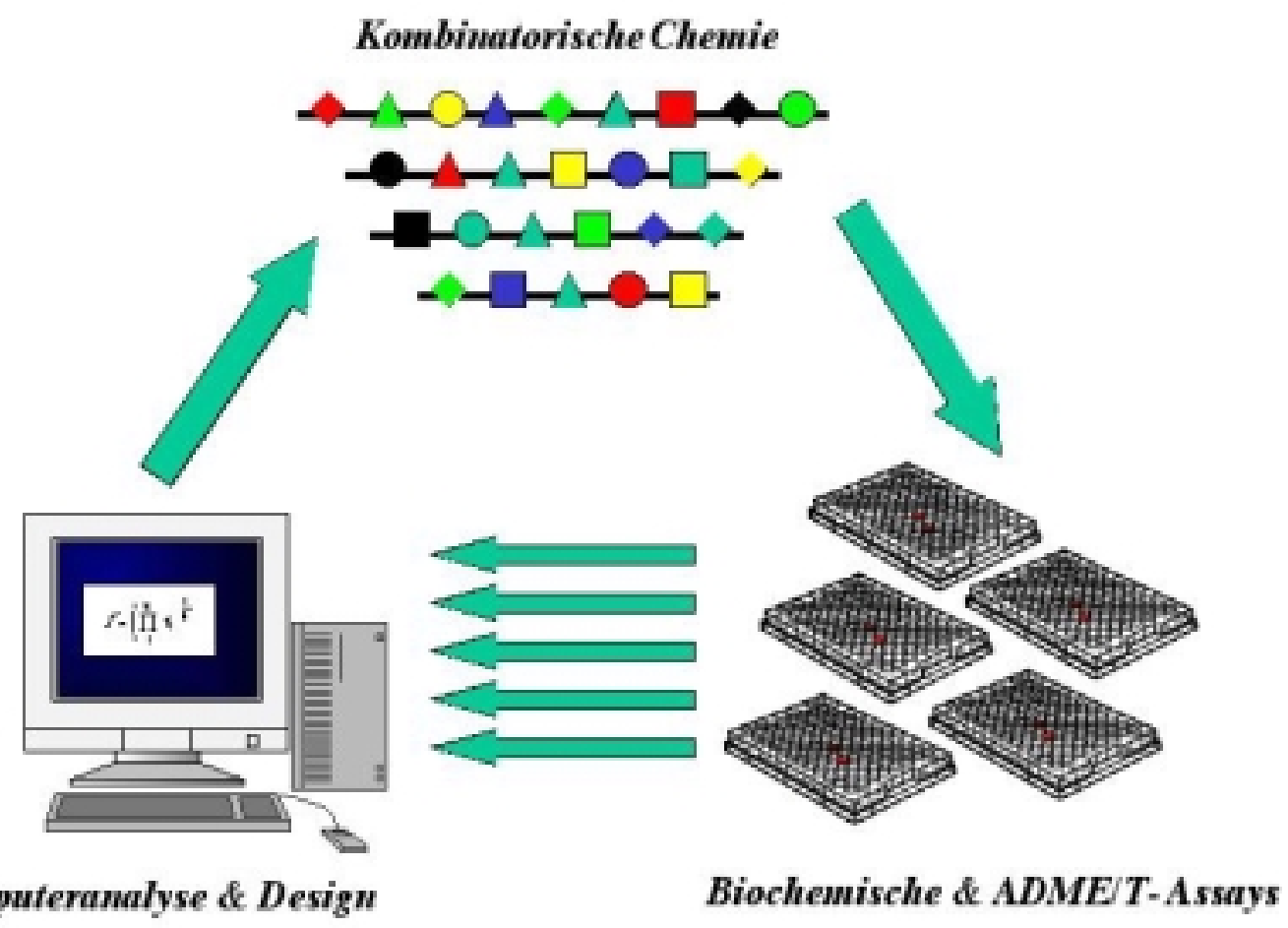

Abbildung 10: Computer-unterstütztes Wirkstoffdesign. Der Optimierprozess ist in Designzyklen organisiert. Jeder Zyklus besteht aus (i) Kombinatorischer Synthese von Kandidatenmolekülen, (ii) einer Bestimmung der "Fitness", d.h. die Quantifizierung einzelner Eigenschaften wie Thrombininhibition einer jeden Substanz, und (iii) eine algorithmische Prozessierung der Daten, die zu einem transienten "Struktur-Funktionsmodell" und einem darauf basierenden Vorschlag neuer, zu synthetisierender Moleküle. 
Durch Standardfestphasensynthese wurden Peptide einer Länge zwischen 3 und 12 Aminosäuren erzeugt. Insgesamt 66 Bausteine (Aminosäuren) wurden verwendet. Alle Peptide wurden folgenden Tests unterzogen:

i) einem amidolytischen Thrombinassay mit humanem Thrombin,

ii) einem amidolytischen Trypsinassay,

iii) einem Serum-Protein-Bindungsassay,

iv) einer Bestimmung des Verteilungskoeffizienten Log D

v) einem Assay auf Wasserlöslichkeit

vi) einem Test auf metabolische Stabilität,

vii) einem Toxizitätsassay auf der Basis von HeLa-Zellen,

viii) einem Hämolyse-Assay und

der abschließenden Bestimmung von $\mathbf{I C}_{\mathbf{5 0}}$ - und $\mathbf{K}_{\mathbf{i}}$-Werten für ausgewählte Substanzen.

Die angewandten Methoden / Assays werden in den folgenden Allgemeinen Arbeitsvorschriften AAV beschrieben:

\section{$\underline{\text { Allgemeine Arbeitsvorschriften AAV }}$}

\section{AAV 1: $\quad$ Peptidsynthese}

Festphasensynthesen bieten gegenüber Synthesen in Lösung zwei entscheidene Vorteile: lösliche Verunreinigungen können durch einfache Wasch- und Filtrationsschritte entfernt werden was in der Folgerung den Einsatz von Reagentienüberschüßen erlaubt, um einen vollständigen Umsatz $\mathrm{zu}$ erzielen und sie sind einfach $\mathrm{zu}$ automatisieren, damit kostengünstig bei der Erstellung großer Substanzbibliotheken. Ursprünglich war diese Technik von Merrifield (Merrifield, R.B., 1963) für die Peptidsynthese entwickelt worden, in neuerer Zeit ist eine große Zahl an Synthesen von nicht-peptidischen Verbindungen möglich. 


\section{Prinzip}

Fmoc-Aminosäuren werden mit Aktivator zu Estern umgesetzt, diese reagieren mit immobilisierten Aminen auf dem Polymer zu Amiden, werden dann durch eine Eliminationsreaktion der Fmoc-Schutzgruppe mit der Base Piperidin selbst zu reaktiven Aminen und im folgenden Schritt mit einer neuen Fmoc-Aminosäure umgesetzt. So entsteht über mehrere Zyklen ein Peptid, dessen funktionelle Seitenkettengruppen (Amine, Guanidine, Säuren, Alkohole) basenstabil geschützt sein müssen, um Nebenreaktionen zu vermeiden. Diese Schutzgruppen werden dann (meist) durch Säuren wie TFA entfernt mit gleichzeitiger Abspaltung vom Trägermaterial. Die flüchtige TFA kann abgedampft und das verbleibende Salz in Ether gefällt werden, wodurch zugleich ein Großteil der abgespaltenen Schutzgruppenreste entfernt wird.

\section{Material}

Chemikalien und verwendete Kürzel in der Standard-Peptidsynthese finden sich im Anhang unter der entsprechenden Rubrik wieder.

Die folgenden Bausteine wurden benutzt:

Fmoc-Ala-OH, Fmoc-Arg(Pbf)-OH, Fmoc-Asn(Trt)-OH, Fmoc-D-Cyclohexylalanin-OH, Fmoc-Cyclohexylglycin-OH, Fmoc-Hydroxyprolin(tBu)-OH, Fmoc-Isoleucin-OH, Fmoc-L-Leucin-OH, Fmoc-Lys(Boc)-OH, Fmoc-Thioprolin-OH, Fmoc-Pro-OH, FmocSer(tBU)-OH, Fmoc-Trp(Boc)-OH, Fmoc-Tyr(tBu)-OH, Fmoc-Val-OH, FmocPhenylglycin-OH, Fmoc-Norleucin-OH, Fmoc-D-Asp(OtBu)-OH, FmocCyclohexylalanin-OH, Fmoc-D-Gln(Trt)-OH, Fmoc-D-Glu(OtBu)-OH, Fmoc-D-His(Trt)$\mathrm{OH}$, Fmoc-Citrullin-OH, Fmoc-D-Leu-OH, Fmoc-D-Lys(Boc)-OH, Fmoc-D-Phe-OH, Fmoc-D-Pro-OH, Fmoc-D-Trp(Boc)-OH, Fmoc-D-Tyr(tBu)-OH, Fmoc-D-Val-OH, Fmoc-Ornithin(Boc)-OH, Fmoc-Lys(ivDde)-OH, Fmoc-D-Norleucin-OH (alle von Novabiochem, Bad Soden, Germany); Fmoc-Cyclopropylalanin-OH, Fmoc-pNitro-Phe$\mathrm{OH}$, Fmoc-L-homoArg(Pmc)-OH, Fmoc-4-methoxy-D-Phe-OH (von Bachem, Heidelberg, Germany); Di-Fmoc-Diaminopropionsre-OH, Fmoc-dichlorPhe-OH, FmocD-Tetrahydroisoquinoline-OH, Fmoc-L-Tetrahydronorhaman-OH, Fmoc-Dtetrahydronorhaman-OH, Fmoc-L-Tetrahydroisoquinolin3-OH, Fmoc-Phenylpiperidin$\mathrm{OH}, \quad$ Fmoc-N-Chyclohexylglycin-OH, Fmoc-2-Azetidine-OH, Fmoc-L,D-3Biphenylpropionsäure-OH, Fmoc-Tranexamsäure, Fmoc-Thienylalanin-OH, Fmoc-LHomocyclohexylalanin, Fmoc-D-Homocyclohexylalanin, Fmoc-4-(2- aminoethyl)1carboxymethylpiperazine-OH, $\quad \alpha$ Fmoc- $\gamma$-Boc-diaminobuttersäure, $\quad$ Fmoc-LNipecotinsäure, Fmoc-L-Pipecolinsäure, Fmoc-D-Pipecolisäure, Fmoc-L-Indolin-OH, Fmoc-Imidazolidine-OH, Fmoc-4-methyl-D-Phe-OH, Fmoc-Naphtyl-D-Ala-OH, Fmoc4-Fluor-D-Phe-OH, Fmoc-3,4-dimethoxy-D-Phe-OH (alle von Neosystems, Strasbourg, France); Fmoc-beta-homo-Arg(Pbf)-OH, Fmoc-L-Aziridin-OH, Fmoc-(2amino)-L-4guanidino(diBoc)buttersäure (von Sigma-Aldrich, Taufkirchen, Germany). 


\section{Methode}

Die Peptide wurden mit Hilfe eines automatisierten Peptidsynthesizer (MultiPep, INTAVIS AG, Deutschland), dem Fmoc-/tBu Peptid-Syntheseprotokoll (Chan und White, 2000) folgend synthetisiert.

Als Festphase diente Rink-Amid-MBHA-Harz von Calbiochem-Novabiochem. Die Fmoc-geschützten Aminosäuren wurden in einer Konzentration von 0.65 M in DMF gelöst, ausgenommem Fmoc-Phenylalanin und Fmoc-Tranexamsäure, die wegen der besseren Löslichkeit in NMP/DMF (1:1 v/v) aufgelöst wurden. Eine $0.5 \mathrm{M}$ Lösung von TBTU in DMF wurde als Kopplungreagenz, eine $4 \mathrm{M}$ Lösung von NMM in DMF als Base verwendet. Rink-Amid-MBHA-Harz wurde in DMF/DCM (1:1) suspendiert und per Multistep-Pipette je $250 \mu \mathrm{L}$ in einen Syntheseblock im 96-well-Format verteilt, sodaß in jedem well $5 \mu \mathrm{mol}$ Fmoc-geschützes Amin auf Harz vorlagen. Die FmocSchutzgruppen wurden durch Zugabe von je zweimal $100 \mu \mathrm{L} 25 \%$ Piperidin in DMF über 10 min und nachfolgendem sechsmaligen Waschen mit je $250 \mu \mathrm{L}$ DMF abgespalten und entfernt. Jeder Kopplungsschritt wurde im fünffachen Überschuß, d.h. $25 \mu \mathrm{mol}$ der Fmoc-geschützten Aminosäure (38,5 $\mu \mathrm{L}$ der $0.65 \mathrm{M}$ Lösung), $25 \mu \mathrm{mol}$ des Aktivators (50 $\mu \mathrm{L}$ der $0.5 \mathrm{M}$ TBTU-Lösung) und $75 \mu \mathrm{mol}$ der Base $(18,8 \mu \mathrm{L}$ der $4 \mathrm{M} \mathrm{N}$ Methylmorpholin/ DMF-Lösung) durchgeführt, wobei nach dem Vermischen der drei Komponenten eine Reaktionszeit von 1 min zur Bildung des Aktivesters eingehalten wurde. Alle C-termini waren demnach Carboxamide. N-termini wurden standardmässig in acetylierter Form durch Zugabe von je $50 \mu \mathrm{L}$ Essigsäureanhydrid und Diisopropylethylamin in DMF (5:5:90) am Ende des Peptidaufbaus und Entfernen der Nterminalen Fmoc-Schutzgruppe synthetisiert. In manchen Fällen wurden die N-termini als freie Amine belassen oder einer Guanidinylierung mit N, N'-bis-Boc-1-guanylpyrazole (Bernatowicz et al., 1993) unterworfen. Die Abspaltung vom Harz wurde durch wiederholte Behandlung mit TFA/DCM/TIPS/H2O (90:5:2,5:2,5), 4 x $50 \mu \mathrm{L}$ pro Well über einen Zeitraum von $2 \mathrm{~h}$ erzielt. Die Peptide wurden durch Verdampfen (Rotationsvakuumverdampfer der Firma Christ, Osterode) weitgehend von TFA befreit, dann mit eiskaltem tBME gefällt und der zentrifugierte Niederschlag von der etherischen Lösung durch abpipettieren befreit. Die Reinheiten betrugen zumeist $90 \%$, die einzigen Verunreinigungen bestanden aus Peptiden, die partiell restliche Schutzgruppen enthielten. Die Ausbeuten erreichten 50 - $65 \%$ in Bezug auf die Menge des eingesetzten Harzes.

Die acht aktivsten Substanzen der vorhergegangenen Zyklen wurden als Kontrollen in den Folgezyklen resynthetisiert.

Bei der Synthese der Substanzen, die D-Phe-4-CN, D-Phe-4-amidin und D-Phe-4hydroxy-amidin enthielten, wurde das säurebeständige Fmoc-Lys(ivDde)-OH (für die Synthese des Homoarginins mittels N, N'-bis-Boc-1-guanylpyrazole) zusammen mit BocD-Phe-4-CN-OH als Bausteine auf einem TFA-stabilen MBHA-Harz (4Methylbenzhydrylamin-Harz, Novabiochem 01-64-0006) verwendet. Im Syntheseverlauf wurde die Boc-Schutzgruppe mit $50 \%$ TFA/DCM und die ivDde-Schutzgruppe mit $2 \%$ Hydrazin/DMF abgespalten. Für das Peptid, das D-Phe-4-CN enthielt, wurde die Abspaltung vom Harz durch Behandlung mit $10 \%$ (v/v) TFMSA in TFA für $1 \mathrm{~h}$ erzielt. Nach Hinzufügung von $10 \mathrm{~mL}$ eiskalten Wassers wurde das Peptid durch 
Festphasenextraktion auf Umkehrphase (C18-Kartuschen, Phenomenex, Aschaffenburg, Deutschland) entsalzt und gereinigt, eluiert durch Methanol und getrocknet in vacuo.

Für das Peptid, das D-Phe-4-hydroxy-amidin enthielt, wurde das Harz-gebundene Peptid mit der D-Phe-4-CN Gruppe über Nacht bei $60^{\circ} \mathrm{C}$ mit 20 Äquivalenten $\mathrm{NH}_{2} \mathrm{OH}^{*} \mathrm{HCl}$ und 10 Äquivalenten Triethylamin in $\mathrm{DMF} / \mathrm{MeOH}$ (5:1) vor Abspaltung und Reinigung behandelt.

Für das Peptid, das D-Phe-4-amidin enthielt, wurde das abgespaltene und zwischengereinigte D-Phe-4-hydroxy-amidin-Derivat in $500 \mu \mathrm{L}$ Essigsäure aufgelöst und $20 \mathrm{mg}$ Palladium auf Aktivkohle hinzugefügt (10\% $\mathrm{Pd} / \mathrm{C}$; Fluka, Taufkirchen, Deutschland). Nach Durchperlen und Behandlung mit $\mathrm{H}_{2}$ für $3 \mathrm{~h}$ (Judkins et al., 1996) wurde das Peptid durch Abdampfen der Essigsäure, gefolgt von einer Fällung in eiskalten tBME gereinigt.

\section{AAV 2: $\quad$ Amidolytischer Thrombinassay mit humanem Thrombin}

Über dieses Assay wird die Hemmwirkung von Testsubstanzen (Peptide bzw. organische Moleküle) auf die Serin-Protease Thrombin, dem zentralen Enzym der Blutgerinngung, bestimmt. Die Hemmwirkung der Testsubstanzen erfolgt anhand von Vergleichsmessungen von inhibiertem zu nicht-inhibiertem Thrombin (Stone et al., 1986). Die Thrombinaktivität wird über die Umsetzung eines fluorogenen Substrates (Tosyl-Gly-Pro-Arg-AMC) in einem Mikrotiterplatten-Fluorimeter (BMG-Polarstar) bestimmt. Die Messungen erfolgen programmgesteuert in einer CyBio-Screeninganlage mit einem darin integrierten Mikrotiterplatten-Fluorimeter (BMG).

\section{Messprinzip}

Das Substrat Tosyl-Gly-Pro-Arg-AMC wird durch die Protease Thrombin an der spezifischen Erkennungssequenz Gly-Pro-Arg $\downarrow$ gespalten, wodurch die fluoreszierende Endgruppe 7-Amino-4-methylcoumarin (AMC) freigesetzt wird. Während das ungespaltene Substrat nach Anregung bei $380 \mathrm{~nm}$ eine sehr geringe FluoreszenzEmission bei $450 \mathrm{~nm}$ zeigt, wird das freigesetzte AMC unter diesen Bedingungen zu einer starken Fluoreszenzemission angeregt. Darüber hinaus ist Absorptionsmaximum des freigesetzten AMC gegenüber dem ungespaltenen Substrat in den längerwelligen UV-Bereich verschoben $(320 \rightarrow 340 \mathrm{~nm})$.

Das zeitabhängig anwachsende Fluoreszenzsignal ist somit direkt mit der proteolytischen Aktivität des Thrombins korreliert. Aus der Steigung der Geraden, die sich aus der Auftragung des Fluoreszenzsignals über der Meßzeit ergibt, läßt sich die proteolytische Aktivität des Thrombins ermitteln. Diese lineare Abhängigkeit besteht für einen Meßzeitraum von mindestens 15 Minuten. 
In Anwesenheit von spezifischen Inhibitoren verläuft die proteolytische Fluoreszenzentwicklung verzögert. Aus dem Quotienten der Steigungen der gehemmten Reaktion und der ungehemmten Reaktion wird der Hemmfaktor ermittelt.

\section{Material}

Der Thrombin-Assay-Puffer wurde aus den Stammlösungen $1 \mathrm{M}$ Tris pH 7,6, $5 \mathrm{M} \mathrm{NaCl}$, BSA (10 mg/mL, sterilfiltriert), PEG 8000 (50\%) angesetzt. Die Stammlösungen sind mit Ausnahme der BSA-Stammlösung autoklaviert worden.

Assay-Puffer (1 L)

$50 \mathrm{~mL} 1 \mathrm{M}$ Tris $\mathrm{pH} 7,6$

$20 \mathrm{~mL} 5 \mathrm{M} \mathrm{NaCl}$

$10 \mathrm{~mL}$ BSA $(10 \mathrm{mg} / \mathrm{mL})$

2 mL PEG $8000(50 \%)$

ad $1 \mathrm{~L}$ mit A. dest. auffüllen

Der Assay-Puffer wurde nach dem Ansetzen sterilfiltriert (0,45 $\mu$ m-ME 25 Mebranfilter, Schleicher \& Schüll) und bis zum Gebrauch bei $4^{\circ} \mathrm{C}$ gelagert.

\section{Tos-GPR-Substrat-Stammlösung $(300 \mu \mathrm{M})$}

10 mg Substrat (N-p-Tosyl-Gly-Pro-Arg-7-Amido-4-Methylcoumarin, Sigma Nr.: T0273) wurden in $10 \mathrm{~mL}$ DMSO im $50 \mathrm{~mL}-$ Messkolben gelöst. Die Lösung wurde auf 50 $\mathrm{mL}$ mit Thrombin-Assay-Puffer aufgefüllt. Nach der Durchmischung wurde diese 300 $\mu \mathrm{M}$ Substrat-Stammlösung in $4 \mathrm{~mL}-$ Fraktionen in braunen $5 \mathrm{~mL}$ Schraubdeckelglasfläschchen abgefüllt und bis zur Verwendung bei $-20^{\circ} \mathrm{C}$ gelagert.

Tos-GPR-Substrat-Lösung ( $30 \mu \mathrm{M})$

$4 \mathrm{~mL}$ der $300 \mu \mathrm{M}$ Substrat-Stammlösung wurden mit $36 \mathrm{~mL}$ Assay-Puffer in 50-mL

Schraubdeckelröhrchen zur Herstellung der $30 \mu \mathrm{M}$ Tos-GPR-Substrat-Lösung verdünnt.

Thrombin-Stammlösung $\left(\mathbf{1 0}^{-2} \mathrm{U} / \mu \mathrm{L}\right)$

10 U lyophilisiertes Thrombin (Sigma Nr.: T-9135) wurden in 1 mL Assay-Puffer gelöst.

Thrombin-Gebrauchslösung $\left(10^{-5} \mathrm{U} / \mu \mathrm{L}\right)$

$40 \mu \mathrm{L}$ der Thrombin-Stammlösung wurden in $40 \mathrm{~mL}$ Assay-Puffer in einem 50-mL

Schraubdeckelröhrchen verdünnt.

Kalibrierung der Thrombin-Aktivität

Einstellung des BMG-Readers:

Assay: Thrombin-Trypsin-96

Layout: $\quad$ Test

Temperatur: $30^{\circ} \mathrm{C}$

In die Wells A1-A3 der schwarzen Mikrotiterplatte (Greiner Fluotrack 200, Art. Nr. 655976) wurden $60 \mu \mathrm{L}$ Assay-Puffer pipettiert, in die Wells A4-A6 je $50 \mu \mathrm{L}$ Assay- 
Puffer. $10 \mu \mathrm{L}$ Thrombin-Gebrauchslösung $\left(10^{-5} \mathrm{U} / \mu \mathrm{L}\right)$ wurden unter mehrfachem Mischen in die Wells A4-A6 einpipettiert. Die Platte wurde $3 \mathrm{~min}$ bei $30^{\circ} \mathrm{C}$ im BMGReader inkubiert. Dann wurden $140 \mu \mathrm{L}$ der $30 \mu \mathrm{M}$ Substrat-Lösung einpipettiert und die Fluoreszenzentwicklung (Ex: 390/Em:450 nm, Gain 73) in 3 min Abständen für 15 min im BMG-Reader gemessen. Die Geradensteigung der Fluoreszenzentwicklung in den Wells A1-A6 wurde über das „BMG-Evaluation“-Programm berechnet und als „Slope/min“ ausgegeben. Die sich ergebenden Werte sollten sein:

Well A1-A3: 0-10 Fluoreszenzeinheiten pro Minute

Well A4-A6: 1800-2200 Fluoreszenzeinheiten pro Minute

\section{Methode}

Durchführung der Messungen in der CyBio-Screening-Anlage

Die peptidischen Testsubstanzen lagen als $40 \mathrm{mM}$ Stammlösungen in DMSO gelöst vor. Aus diesen Stammlösungen wurde zunächst eine $1 \mathrm{mM}$ Arbeitslösung durch Verdünnen mittels Thrombin-Puffer in einer Tochterplatte angesetzt. Aus dieser $1 \mathrm{mM}$ Verdünnung wurden jeweils $30 \mu \mathrm{L}$ Substanzlöung in die etikettierten, schwarzen Mikrotiterplatten an vorher bestimmte Positionen überführt und mit $20 \mu \mathrm{L}$ Assay-Puffer vermischt. Als Referenzmessungen (ohne Inhibitor) dienten 10 diagonal über die Platte verteilte Wells mit je $50 \mu \mathrm{L}$ reinem Assay-Puffer und als Nullwert / Kontrolle zwei Blankmesspunkte mit je $60 \mu \mathrm{L}$ reinem Assay-Puffer. Dann wurden $10 \mu \mathrm{L}$ Thrombin-Gebrauchslösung (10${ }^{5} \mathrm{U} / \mu \mathrm{L}$ ) unter mehrfachem Mischen in die Wells mit Ausnahme der zwei Nullwerte einpipettiert und die Platte 3 min bei $30^{\circ} \mathrm{C}$ im BMG-Reader inkubiert.

Schließlich folgten $140 \mu \mathrm{L}$ der $30 \mu \mathrm{M}$ Substrat-Lösung, somit war die Enkonzentration der Testsubstanzen im Assay bezogen auf das $200 \mu \mathrm{L}$ - Endvolumen $150 \mu \mathrm{M}$.

Dann wurde die Fluoreszenzentwicklung (Ex: 390/Em:450 nm, Gain 73) in 3 min Abständen für 15 min im BMG-Reader gemessen, die Geradensteigung der Fluoreszenzentwicklung in den Wells über das „BMG-Evaluation“-Programm berechnet und als „Slope/min“ ausgegeben.

Für alle Testsubstanzen wurden die Messungen als Dreifachbestimmungen durchgeführt und anschließend Mittelwerte und Standardabweichungen bestimmt. 


\section{AAV 3: Amidolytischer Trypsinassay}

\section{Messprinzip}

Dieses Assay entspricht in Vorbereitung und Durchführung dem Assay der Aktivität des Thrombins, an dessen Stelle jedoch Trypsin eingesetzt wurde.

\section{Material}

Trypsin-Enzym-Lösung

Vorverdünnung 1

$10 \mathrm{mg}$ Trypsin (Sigma )

in $10 \mathrm{~mL}$ Assay-Puffer lösen $(1 \mu \mathrm{g} / \mu \mathrm{L})$

Vorverdünnung 2

$4 \mu \mathrm{L}$ verdünnte Trypsin-Lösung

ad $40 \mathrm{~mL}$ Assay-Puffer $(100 \mathrm{pg} / \mu \mathrm{L})$

Gebrauchslösung

$4 \mathrm{~mL}$ verdünnte Trypsin-Lösung

ad $40 \mathrm{~mL}$ Assay-Puffer $(10 \mathrm{pg} / \mu \mathrm{L})$

Kontrolle / Anhaltswerte:

Eine so angestzteverwendungsfähige Substratlösung hatte in der o.a. Verdünnung vor der Trypsinzugabe einen Fluoreszenzwert von ca 1000-3000 Einheiten, die 100\% Kontrolle (Ansatz ohne Inhibitor) erzeugte einen Fluoreszenzsignal von ca. 2000 Einheiten pro Minute.

\section{Methode}

\section{Durchführung der Messungen in der CyBio-Screening-Anlage}

$30 \mu \mathrm{L}$ der $1 \mathrm{mM}$ Peptidlösungen (Endkonz.: $150 \mu \mathrm{M}$ ) wurden in als 3fach-Bestimmung in schwarze MT-Platten vorlgelegt, dann je $20 \mu \mathrm{L}$ Assay-Puffer zupipettiert.10 $\mu \mathrm{L}$ Trypsin-Gebrauchslösung $(10 \mathrm{pg} / \mu \mathrm{L})$ wurde unter mehrfachem Mischen einpipettiert, und die Platten 3 min bei $30^{\circ} \mathrm{C}$ inkubiert. Dann wurden je $140 \mu \mathrm{L}$ der $30 \mu \mathrm{M}$ SubstratLösung einpipettiert und die Fluoreszenzentwicklung (Ex: 390/Em:450 nm, Gain 73) in 3 min Abständen für 15 min gemessen und schließlich die Geradensteigung im ExcelProgramm berechnet (Slope/min) und durch die Steigung der Geraden der ungehemmten Reaktion (gleicher Ansatz ohne Peptid-Zusatz $+30 \mu \mathrm{L}$ zusätzlichem Assay-Puffer) dividiert. 


\section{AAV 4: Serum-Protein-Bindungsassay}

Die Bindung eines Pharmakon $\mathrm{P}$ an Serumproteine $\mathrm{A}$ ist meist unspezifisch und beruht auf hydrophoben Wechselwirkungen. Es stellt sich das Gleichgewicht $\mathrm{P}+\mathrm{A} \leftrightarrow \mathrm{PA}$ ein, wodurch P wegen der Größe des Komplexes PA im Gefäßraum verbleibt, sich nicht mehr frei, z.B. auch im Gewebe, verteilen kann. Bei hohen Bindungsraten entsteht daher ein (ggf. erwünschter) Depoteffekt. Kritische Situationen können entstehen, wenn die Bindungskapazität von A überschritten wird oder P durch Konkurrenz und Verdrängung freigesetzt wird, insbesondere bei sehr hohen Bindungsraten wie etwa bei cumarinartigen Antikoagulanzien.

\section{Messprinzip}

Die Bestimmung der Bindungrate der Testsubstanzen an menschliches Serumprotein wurde nach einer Ultrafiltrationsmethode durchgeführt (Wright J.D., et al., 1996). Die Menge an ungebundener Substanz wird nach Filtration des Ansatzes bestimmt.

\section{Material}

Interne Standards: Koffein, Quinidin und Warfarin: Sigma

Humanserum: Sigma Nr. S-4246

Dulbecco`s PBS pH 7.4: Gibco BRL Nr. 14200-059

Microcon Filter YM-10 (regenerated cellulose 10,000 MWCO): Amicon Nr 42407

Zentifuge: Sigma 4K15C, Sigma, Osterode

\section{Methode}

Die Substanzen wurden in DMSO in einer Konzentration von $1 \mathrm{mM}$ gelöst und dann 1:100 in Serum verdünnt, sodaß die Endkonzentration im Assay von DMSO 1\% und der Testsubstanzen $10 \mu \mathrm{M}$ betrug. Als Kontrollen wurde als interne Standards Koffein, Quinidin und Warfarin benutzt, deren Bindungsraten an Serumprotein zwischen 8 und $98 \%$ liegen.

Nach einer einstündigen Inkubation der Testsubstanzen und internen Kontrollen in menschlichem Serum bei $37^{\circ} \mathrm{C}$ unter schütteln, folgte eine Ultrafiltration bei $3000 \mathrm{~g}$ für eine weitere Stunde und die Untersuchung des Filtrats mit der Konzentrationsbestimmung der ungebundenen Fraktion mittels analytischer LC-MS.

Für diese Analytik wurden zunächst die m/z-Signale der Molekülionen aus den unbehandeltenden Referenzansätzen gleicher Verdünnung aus den TICChromatogrammen durch Integration quantifiziert und mit den entsprechenden Werten der Testansätze aus den Filtraten (in Doppelbestimmung) verglichen. Aus der Beziehung (1 - (Signalfläche ungebundene Fraktion / Signalfläche Standard )) konnte so direkt die entsprechende Prozentangabe gewonnen werden. 


\section{AAV 5: Verteilungskoeffizient $\log D$}

Der Lipoid-Wasser Verteilungskoeffizient gilt als Maß eines Stoffes, Lipidmembranen zu durchdringen und sich in lipophilen Strukturen anzureichern. Er wird durch die Verteilung zwischen einer wäßrigen und einer lipophilen Phase bestimmt und folgt im Idealfall dem Nernst'schen Verteilungssatz

$\mathrm{D}=\mathrm{C}_{\mathrm{L}} / \mathrm{C}_{\mathrm{W}}$

wobei $\mathrm{C}_{\mathrm{L}}$ und $\mathrm{C}_{\mathrm{W}}$ die Gleichgewichtskonzentrationen in den entsprechenden Phasen bedeuten. Diese Beziehung gilt nur, wenn beide Phasen miteinander völlig unmischbar sind, der gelöste Stoff in keiner der beiden Phasen ionisiert und stark verdünnte Lösungen vorliegen.

Für ADME-Studien werden Verteilungskoeffizienten in Sytemen bestimmt, die den physiologischen Bedingungen nahekommen und von den Bedingungen für die Gültigkeit des Nernst'schen Verteilungssatz abweichen können. Man erhält dabei einen Verteilungskoeffizienten, der nur für das verwendete System gilt (scheinbarer Verteilungskoeffizient) und vom wahren Verteilungskoeffizienten abweichen kann, für dessen Bestimmung man im Falle der Dissoziation des Stoffes in der wäßrigen Phase die Verteilung bei verschiedenen $\mathrm{pH}-$ Werten überprüfen müßte.

\section{Messprinzip}

Die Bestimmung des Verteilungskoeffizienten Log D pH 7,4 basiert auf der klassischen Methode der Flüssig-Flüssig-Extraktion im Schütteltrichter (Sangster, 1997), wie sie in der präparativen organischen Chemie für die Isolierung bestimmter Moleküle verwendet wird. Der PBS-Puffer wurde als wäßrige Phase, 1-Oktanol als organische Phase verwendet. Die Standards oder Referenzen wurden so gewählt, daß der gesamte Bereich der Log D Skala von $-1,5$ bis $+4,5$ abgedeckt wurde.

\section{Material}

Interne Standards: Tamoxifen, Rifampicin, Haloperidol und Furosemid: Sigma Dulbecco`s PBS pH 7.4: Gibco BRL Nr. 14200-059

1-Octanol: Aldrich Nr. 36,056-2

DMSO: Dimethylsulfoxid: Fluka Nr.41648

Schüttler: IKA MTS4

Zentifuge: Sigma 4K15C, Sigma, Osterode 


\section{Methode}

Die Testsubstanzen und Standards wurden $10 \mathrm{mM}$ in DMSO gelöst und 96 Well-MTPlatten mit je $98 \mu \mathrm{L}$ PBS und Oktanol befüllt und 5 min stehen lassen zur Sättigung. Dann wurden $4 \mu \mathrm{L}$ der Referenzen und Testsubstanzen zupipettiert und $1 \mathrm{~h}$ bei RT auf einer Schüttelmaschine bei 700 Umdrehungen / min vermischt. Die Endkonzentration im Gesamtvolumen betrug somit $200 \mu \mathrm{M}$ bei Anwesenheit von 2\% DMSO. Dann wurden die Platten bei $3000 \mathrm{~g}$ bzw. 4095 Umdrehungen / min 1h bei RT zentrifugiert und die Konzentrationen im Überstand von 1-Oktanol durch LC-MS bestimmt. Für diese Analytik wurden zunächst die m/z-Signale der Molekülionen aus entsprechenden 200 $\mu$ molaren Referenzansätzen in DMSO aus den TIC-Chromatogrammen durch Integration quantifiziert und mit den entsprechenden Werten der Testansätze aus der Oktanolphase (in Doppelbestimmung) verglichen. In manchen Fällen war die Konzentration in Oktanol so gering, das die TIC- Chromatogramme keine verwertbaren Signale lieferten. Dann mußten die Messungen unter SIR-Bedingungen (2.1.2) wiederholt und die entsprechenden SIR-Chromatogramme, die etwa um das 100 fache empfindlicher waren, ausgewertet werden.

\section{AAV 6: $\quad$ Assay auf Wasserlöslichkeit}

Die Wasserlöslichkeit eines potentiellen Wirkstoffes ist ein wichtiger Aspekt im Design oder Auswahl von Verbindungen (Lipinski, C. et al., 1997). Moleküle, die in Wasser schwierig zu lösen sind, können die Produktivität in der Entwicklung eines Arzneimittels, das zur oralen Applikation vorgesehen ist, drastisch verringern. Die Wasserlöslichkeit sollte möglichst hoch sein, da mit Ungelöstem zunächst keine Resorption aus dem Darm erfolgen kann und in den folgenden Schritten, noch vor dem Eintritt in die Epithelzellmembran, eine hier aufliegende, unbewegte Wasserschicht (unstirred water layer) durchdrungen werden muss. Die Wasserlöslichkeit wird aber auf der anderen Seite meist schon dadurch limitiert, daß die Substanz genügend lipohil sein muss, um die Lipidbarriere der Zellmembran $\mathrm{zu}$ durchdringen. Im allgemeinen wird eine Wasserlöslichkeit von $3 \mathrm{mg} / \mathrm{mL}$ für eine schnelle und vollständige Resorption angestrebt. Die Testsubstanzen dieses Projektes wurden bei einer Konzentration von $200 \mu \mathrm{M}$ vermessen, was bei deren Molekulargewichtsbereich einer Konzentration von etwa 0,2 $\mathrm{mg} / \mathrm{mL}$ entspricht.

\section{Messprinzip}

Konzentrationsbestimmung im Überstand nach Gleichgewichtseinstellung

\section{Material}

Interne Standards: Warfarin, Rifampicin, Haloperidol and Tamoxifen (Sigma) Dulbecco`s PBS pH 7.4: Gibco BRL Nr. 14200-059 
DMSO: Dimethylsulfoxid: Fluka Nr.41648

Schüttler: IKA MTS4

Zentifuge: Sigma 4K15C, Sigma, Osterode

\section{Methode}

Die Wasserlöslichkeit wurde routinemässig in Dulbecco's PBS bei pH 7,4 bestimmt. Die Testsubstanzen und Standards wurden $10 \mathrm{mM}$ in DMSO gelöst und dann wurden $4 \mu \mathrm{L}$ dieser Stocklösung zu $196 \mu \mathrm{L}$ Puffer pipettiert und $24 \mathrm{~h}$ bei RT auf einer Schüttelmaschine bei 700 Umdrehungen / min vermischt. Die Endkonzentration im Gesamtvolumen betrug $200 \mu \mathrm{M}$ bei Anwesenheit von 2\% DMSO. Dann wurden die Platten bei $3000 \mathrm{~g}$ entsprechend 4095 Umdrehungen / min 1h bei RT zentrifugiert und die Konzentrationen im Überstand durch LC-MS bestimmt und mit der $200 \mu \mathrm{M}$ Konzentration des Stoffes in reinem DMSO verglichen.

\section{AAV 7: $\quad$ Test auf metabolische Stabilität}

Mit diesem Test konnten erste Hinweise darauf gewonnen werden, ob die Testsubstanzen durch Einwirkung der verschiedenen Enzymaktivitäten der Leber einem Metabolismus unterliegen (Kuhnz, W. und Gieschen, H. 1998). Metabolische Vorgänge fallen definitionsgemäß unter den Begriff Elimination, da die Konzentration der betreffenden Wirksubstanz abnimmt. Metabolite können aber auch potenter sein als ihre Muttersubstanz oder überhaupt erst als Metabolit eine Wirkung entfalten (pro-drugKonzept).

\section{Messprinzip}

Konzentrationsbestimmung nach Inkubation mit Leberzellen unter physiologischen Bedingungen und Filtration

\section{Material}

Interne Standards: Diisopyramide, Labetalol and Terfenadine (Sigma)

Assaypuffer $\mathrm{K}_{2} \mathrm{HPO}_{4} ; 100 \mathrm{mM}$; pH 7.4 (Sigma, Nr. P-2222)

DMSO: Dimethylsulfoxid: Fluka Nr.41648

Menschliche Lebermicrosomen und NADPH regenerating system: Gentest Nr H165 und B220

Schüttler: IKA MTS4

Zentifuge: Sigma 4K15C, Sigma, Osterode

Microcon Ultrafiltrationseinheiten YM-10 (regenerated cellulose 10,000 MWCO) Amicon Nr. 42407 


\section{Methode}

Die Mikrosomen mußten bei diesem Assay zunächst mit dem Regeneriersystem aus NADP $1 \mathrm{mM}$, G6P 5mM, G6PDHase $1 \mathrm{U} / \mathrm{mL}$ mit $0.6 \%$ Methanol and $0.6 \%$ Acetonitrile behandelt werden, um ihre Aktivität zu entfalten. DMSO hemmt die Aktivität und wurde deshalb nicht verwendet. Die Testsubstanzen und Standards wurden in einer Konzentration von $1 \mu \mathrm{M}$ mit den Mikrosomen $(0,3 \mathrm{mg} / \mathrm{mL}) 1 \mathrm{~h}$ bei $37^{\circ} \mathrm{C}$ inkubiert, gefolgt von einer Ultrafiltration $(1 \mathrm{~h} / 3000 \mathrm{~g})$ und der Analyse des Filtrats auf die Anwesenheit der Muttersubstanz per LC-MS.

\section{AAV 8: $\quad$ Toxizitätsassay auf der Basis von HeLa-Zellen}

Die toxische Wirkung einer Substanz ist eine konzentrationsabhängige Größe. Sie beruht auf Eingriffen in den Stoffwechsel und/oder die Integrität der betroffenen Zellen, was sich in der Schädigung der den Stoffen direkt ausgesetzten Organe zeigt. Eine Ausnahme dieser Theorie der grundlegenden, basalen Zytotoxizität sind Stoffe, die erst durch Metabolisierung ihre toxische Wirkung entfalten. In diesem Assay wurde eine vergleichsweise hohe Konzentration der Substanzen in Doppelbestimmung eingesetzt, um toxische Wirkungen frühzeitig auszumachen.

\section{Messprinzip}

Über dieses Assay wird die zytotoxische Wirkung von Testsubstanzen auf menschliche HeLa-Zellen im Mikrotiterplaten-Format (96 Well) bestimmt. Die hier verwendete Meßmethode der Zellproliferation nutzt die Mitochondrienvitalität als Indikator für die Zelltoxizität: Lebende Zellen besitzen die Eigenschaft, farblose oder schwach gefärbte Tetrazoliumsalze in intensiv gefärbte Formazanderivate umzuwandeln (Carmichael et al., 1987 / Scudiero et al., 1988). Diese Reduktionsreaktion erfordert intakte Mitochondrien, die im Falle der Einwirkung von toxischen Substanzen und nach dem Absterben der Zellen innerhalb weniger Minuten inaktiv würden. Anhand der begleitenden Messung einer toxischen Referenzsubstanz (1\% Na-Azid in RPMI 1640) und einer nicht toxischen Kontrollsubstzanz (Puffer RPMI1640) wird das toxische Potential der getesten Substanzen ermittelt. Die vorkultivierten Zellkulturplatten und das EZ4U-Färbekit wurden von der Firma Alpha Bioverfahrenstechnik bezogen.

\section{Material}

Vorkultivierte HeLa-Zellen, RPMI-Puffer, EZ4U Tetrazolium-Substrat (alle von Alpha Bioverfahrenstechnik, Kleinmachnow) 


\section{Methode}

In einer sterilen DeepWell-MT-Platte wurden jeweils $110 \mu \mathrm{L}$ der $1 \mathrm{mM}$ in Phosphatpuffer, $\mathrm{pH}$ 7,4 verdünnten Peptidlösung mit $330 \mu \mathrm{L}$ RPMI1640 weiter verdünnt, davon wurden dann je 2 × $200 \mu \mathrm{L}$ (als Doppelbestimmung) entnommen und in die Vertiefungen der vorkultivierten HeLa-Zellkulturplatte eingefüllt (Endkonzentration: 200 $\mu \mathrm{M})$.

Als Konrollen wurden RPMI mit 1\% Azid (100 \% toxisch!) als Positivkontrolle bzw. RPMI 1640 als Negativkontrolle (0\% toxisch) in die vorbestimmten Referenzvertiefungen eingefüllt. Die MT-Platten wurden mit Klebefolie versiegelt und $72 \mathrm{~h}$ bei $37^{\circ} \mathrm{C}$ inkubiert.

Nach Inkubationsende wurde das EZ4U Tetrazolium-Substrat in $2,5 \mathrm{~mL}$ auf $37^{\circ} \mathrm{C}$ vorgewärmter Aktivatorlösung aufgelöst. Man erhielt eine strohgelbe Lösung, die sofort verwendet werden mußte. Pro Well wurden $20 \mu \mathrm{L}$ der Substratlösung eingefüllt und weitere $3 \mathrm{~h}$ bei $37^{\circ} \mathrm{C}$ inkubiert. Anschließend wurde die Absorption bei $450 \mathrm{~nm}$ gegen $620 \mathrm{~nm}$ (Zellhintergrund) gemessen. Die Absorption des Blindwertes (Substrat ohne Zellen) wurde von den Meßwerten abgezogen.

\section{AAV 9: Hämolyse-Assay}

Die Hämolyse von Erythrozyten ist ein Indikator für das Vermögen eines Stoffes, Zellwände irreparabel zu beschädigen (Sitaram und Nagaraj, 1990). Bei pathogenen Bakterien ist dieser Effekt erwünscht und wurde auch bei der Erforschung antibiotisch wirksamer Substanzen, namentlich Peptiden mit einer bestimmte Abfolge von Aminosäuren wie Arg-Trp (Blondelle et al., 1994) beobachtet. Die Lyse von Säugerzellen wie Erythrozyten durch einen Wirkstoff würde jedoch ein „Aus“-Kriterium der Testsubstanz bedeuten. Dieses Assay wurde für das Screening von 96 Testsubstanzen in Dreifachbestimmung ausgelegt.

\section{Messprinzip}

Bestimmung von freigesetztem Blutfarbstoff im Überstand

\section{Material}

Kaninchenblut, frisch abgenommen, heparinisiert (ca. $50 \mathrm{~mL}$ ) Puffer: 0,135 M NaCl, 5 mM Kalium-Phosphatpuffer (pH 7,4) Zentrifuge

\section{Methode}

Das Blut wurde zunächst abzentrifugiert (3 min, $5000 \mathrm{rpm}$ ) und der Überstand (Plasma mit Fibrinogen) abgenommen und verworfen. Dieser Vorgang wurde dreimal wiederholt, 
sodaß der Überstand farblos war. Dann wurde das Sediment (Erythrozyten, RBC red blood cells) im gleichen Volumen 0,135 M NaCl, $5 \mathrm{mM}$ K-Phosphat (pH 7,4) aufgenommen. Falls über Nacht bei $4^{\circ} \mathrm{C}$ gelagerte, gewaschene Erythrozyten verwendet wurden, wurden sie noch dreimal mit $\mathrm{NaCl} / \mathrm{K}-\mathrm{Phosphat-Puffer}$ gewaschen. Dann wurde mit den gewaschenen Erythrozyten in 0,135 M NaCl, $5 \mathrm{mM} \mathrm{K}$-Phosphat (pH 7,4)-Puffer eine Endkonzentration von $2 \%$ RBC eingestellt, indem 1,4 mL der 50\%igen Erythrozytensuspension auf $40 \mathrm{~mL}$ mit Puffer aufgefüllt wurden.

$50 \mu \mathrm{L} 1 \mathrm{mM}$ Peptidlösung (im selben Puffer aus 40 mM DMSO-Stocklösung hergestellt) wurden dann mit weiteren $50 \mu \mathrm{L}$ Puffer und $100 \mu \mathrm{L}$ der $2 \%$ igen Erythrozytensuspension $1 \mathrm{~h}$ bei $37^{\circ} \mathrm{C}$ inkubiert (Endkonzentration der Peptidlösung: 250 $\mu \mathrm{M})$.

Dann wurden die MT-Platten abzentrifugiert (2000 rpm, $30 \mathrm{~min}, \mathrm{RT}$ ) und $100 \mu \mathrm{L}$ des Überstandes in neue Flachboden-MT-Platten überführt und schließlich die Absorption bei $405 \mathrm{~nm}$ im BMG-Reader gemessen.

Kontrollen: (jeweils eine MT-Platte)

1: $100 \mu \mathrm{L} 2 \%$ Triton $\mathrm{x}-100$ (3 fach-Bestimmung)

$+100 \mu \mathrm{L} 2 \%$ ige Erythrozytensuspension

(100\% Hämolyse)

2: $100 \mu \mathrm{L} \mathrm{0,135} \mathrm{M} \mathrm{NaCl,} 5 \mathrm{mM}$ K-Phosphat (pH7,4) (3 fach-Bestimmung)

$+100 \mu \mathrm{L} 2 \%$ ige Erythrozytensuspension

(0 \% Hämolyse)

\section{AAV 10: $I C_{50}$ und $K_{i}$-Wert-Bestimmungen}

Die Bestimmung der $\mathrm{IC}_{50}$ und $\mathrm{K}_{\mathrm{i}}$-Werte (Cheng \& Prusoff, 1973) ist ein wichtiger Punkt in der gesamten Durchführung des Projektes, da erst mit der Bestimmung dieser Werte der Stand der eigenen Entwicklung im Vergleich zu anderen, publizierten Substanzen stattfinden konnte und somit überhaupt erst ein kommerzielles Interesse erzeugt werden kann. Tame (Tame, 1999) gibt an, daß Messungen von $\mathrm{K}_{\mathrm{i}}$-Werten mit Fehlern von bis zu $50 \%$ behaftet sein können. Aus diesem Grund wurde auf die Bestimmung dieser Werte ein besonderes Gewicht gelegt, was sich hinsichtlich des Umfangs und des Layouts, wie im folgenden erkennbar wird, zeigt. Die $\mathrm{K}_{\mathrm{i}}$-Wert-Bestimmung wurde im Verlauf der Optimierung oft durchgeführt, sodaß es sinnvoll erschien, ein bestimmtes Schema von Mehrfachbestimmungen zu etablieren, um möglichst zuverlässige und reproduzierbare Daten zu erhalten. Der $\mathrm{K}_{\mathrm{i}}$-Wert von bekannten Inhibitoren wurde als Kontrolle im hier beschriebenen System ermittelt. 


\section{Messprinzip}

Fluorimetrische Konzentrationsreihenbestimmungen und enzymkinetische Auswertung

\section{Material}

Tos-GPR-Substrat-Lösungen für die Ki-Wert-Bestimmung

Für die $\mathrm{K}_{\mathrm{i}}$-Wert-Bestimmung wurden Tos-GPR-Substrat-Lösungen der Konzentration 2, 4, 6, 8, 10, 20, 30, 40, 50, 70, $100 \mu \mathrm{M}$ benötigt. Da jeweils $140 \mu \mathrm{L}$ Substratlösung in 200 $\mu \mathrm{L}$ Gesamtassayvolumen eingesetzt wurden, war die Substratlösung um diesen Faktor (200/140) höher konzentriert anzusetzen (siehe Tabelle 2). Die Substratlösungen wurden in Thrombin-Puffer angesetzt.

Tabelle 2: Tos-GPR-Substrat: Arbeitslösungen für $\mathbf{K}_{\mathrm{i}}$-Bestimmungen

\begin{tabular}{|c|c|c|c|c|c|}
\hline$[\mathbf{S}], \boldsymbol{\mu} \mathbf{M}^{(1)}$ & {$[\mathbf{S}], \boldsymbol{\mu} \mathbf{M}^{(2)}$} & \multicolumn{4}{|c|}{$\begin{array}{c}\mathrm{X} \mu \mathrm{L} \text { der } 300 \mu \mathrm{M} \text { Substratlösung } \\
\text { ad } \mathrm{mL} \text { Endvolumen }\end{array}$} \\
\hline & & $10 \mathrm{~mL}$ & $20 \mathrm{~mL}$ & $30 \mathrm{~mL}$ & $50 \mathrm{~mL}$ \\
\hline 2 & 2,8 & 93 & 186 & 280 & 466 \\
\hline 4 & 5,6 & 190 & 380 & 570 & 950 \\
\hline 6 & 8,4 & 280 & 560 & 840 & 1400 \\
\hline 8 & 11,4 & 380 & 760 & 1140 & 1900 \\
\hline 10 & 14 & 466 & 932 & 1398 & 2330 \\
\hline 20 & 28 & 933 & 1866 & 2799 & 4666 \\
\hline 30 & 43 & 1433 & 2866 & 4299 & 7165 \\
\hline 40 & 57 & 1900 & 3800 & 5700 & 9500 \\
\hline 50 & 71 & 2366 & 4732 & 7098 & 11830 \\
\hline 70 & 100 & 3333 & 6666 & 9999 & 16666 \\
\hline 100 & 142 & 4733 & 9466 & 14199 & 23665 \\
\hline
\end{tabular}

Angeben ist, wieviel Volumen der $300 \mu \mathrm{M}$ Substratlösung eingesetzt werden muss, um die angegebenen Substratkonzentrationen $\mathrm{zu}$ erreichen. Diese Volumen ist von den vier vorgegebenen Endvolumen abzuziehen

1: Konzentration des Substrats im Assay

${ }^{2}$ : Konzentration der jeweiligen Substratlösung

Dispensieren der Substat-Lösung in die Vorratsplatte (Deep-Well)

Eine Deep-Well -Platte wurde mit jeweils $1 \mathrm{~mL}$ pro Well mit der in Tabelle 2 angegebeben Substratlösung nach folgendem Schema befüllt:

\begin{tabular}{|c|c|c|c|c|c|c|c|c|c|c|}
\hline 1 & 2 & 3 & 4 & 5 & 6 & 7 & 8 & 9 & 10 & 11 \\
\hline $2 \mu M$ & $4 \mu M$ & $6 \mu M$ & $8 \mu \mathrm{M}$ & $10 \mu \mathrm{M}$ & $20 \mu M$ & $30 \mu \mathrm{M}$ & $40 \mu \mathrm{M}$ & $50 \mu \mathrm{M}$ & $70 \mu \mathrm{M}$ & $100 \mu \mathrm{M}$ \\
\hline $2 \mu M$ & $4 \mu \mathrm{M}$ & $6 \mu \mathrm{M}$ & $8 \mu \mathrm{M}$ & $10 \mu \mathrm{M}$ & $20 \mu \mathrm{M}$ & $30 \mu \mathrm{M}$ & $40 \mu \mathrm{M}$ & $50 \mu \mathrm{M}$ & $70 \mu \mathrm{M}$ & $100 \mu \mathrm{M}$ \\
\hline $2 \mu M$ & $4 \mu \mathrm{M}$ & $6 \mu \mathrm{M}$ & $8 \mu \mathrm{M}$ & $10 \mu \mathrm{M}$ & $20 \mu M$ & $30 \mu \mathrm{M}$ & $40 \mu \mathrm{M}$ & $50 \mu \mathrm{M}$ & $70 \mu \mathrm{M}$ & $100 \mu \mathrm{M}$ \\
\hline $2 \mu \mathrm{M}$ & $4 \mu \mathrm{M}$ & $6 \mu \mathrm{M}$ & $8 \mu \mathrm{M}$ & $10 \mu \mathrm{M}$ & $20 \mu \mathrm{M}$ & $30 \mu \mathrm{M}$ & $40 \mu \mathrm{M}$ & $50 \mu \mathrm{M}$ & $70 \mu \mathrm{M}$ & $100 \mu \mathrm{M}$ \\
\hline $2 \mu \mathrm{M}$ & $4 \mu \mathrm{M}$ & $6 \mu \mathrm{M}$ & $8 \mu \mathrm{M}$ & $10 \mu \mathrm{M}$ & $20 \mu \mathrm{M}$ & $30 \mu \mathrm{M}$ & $40 \mu \mathrm{M}$ & $50 \mu \mathrm{M}$ & $70 \mu \mathrm{M}$ & $100 \mu \mathrm{M}$ \\
\hline $2 \mu M$ & $4 \mu \mathrm{M}$ & $6 \mu \mathrm{M}$ & $8 \mu \mathrm{M}$ & $10 \mu \mathrm{M}$ & $20 \mu M$ & $30 \mu \mathrm{M}$ & $40 \mu \mathrm{M}$ & $50 \mu \mathrm{M}$ & $70 \mu \mathrm{M}$ & $100 \mu \mathrm{M}$ \\
\hline $2 \mu M$ & $4 \mu \mathrm{M}$ & $6 \mu \mathrm{M}$ & $8 \mu \mathrm{M}$ & $10 \mu \mathrm{M}$ & $20 \mu M$ & $30 \mu \mathrm{M}$ & $40 \mu \mathrm{M}$ & $50 \mu \mathrm{M}$ & $70 \mu \mathrm{M}$ & $100 \mu \mathrm{M}$ \\
\hline $2 \mu M$ & $4 \mu \mathrm{M}$ & $6 \mu \mathrm{M}$ & $8 \mu \mathrm{M}$ & $10 \mu \mathrm{M}$ & $20 \mu M$ & $30 \mu \mathrm{M}$ & $40 \mu \mathrm{M}$ & $50 \mu \mathrm{M}$ & $70 \mu \mathrm{M}$ & $100 \mu \mathrm{M}$ \\
\hline
\end{tabular}


Thrombin-Stammlösung $\left(\mathbf{1 0}^{-2} \mathrm{U} / \mu \mathrm{L}\right)$

10 U lyophilisiertes Thrombin (Sigma Nr.: T-9135) wurden in 1 mL Assay-Puffer gelöst.

Thrombin-Gebrauchslösung $\left(10^{-5} \mathrm{U} / \mu \mathrm{L}\right)$

$40 \mu \mathrm{L}$ der Thrombin-Stammlösung wurden in $40 \mathrm{~mL}$ Assay-Puffer in einem 50-mL

Schraubdeckelröhrchen verdünnt.

\section{Methode}

Durchführung der Messungen $\left(K_{M}\right.$ bzw $K_{\mathrm{i}}$-Wert)

Vorverdünnung der Testsubstanzen

Die Testsubstanzen (Inhibitoren) lagen i.d.R. als $40 \mathrm{mM}$ Stammlösungen in DMSO gelöst vor. Aus diesen Stammlösungen wurde zunächst eine Arbeitslösung der Konzentration $1 \mathrm{mM}$ in Thrombin-Puffer angesetzt, daraus wurden dann folgende Verdünnungen angesetzt:

$100 \mu \mathrm{M}: 200 \mu \mathrm{L}$ der $1 \mathrm{mM}$-Verdünnung $+1800 \mu \mathrm{L}$ Thrombin-Puffer

$10 \mu \mathrm{M}: 200 \mu \mathrm{L} \operatorname{der} 100 \mu \mathrm{M}-$ Verdünnung $+1800 \mu \mathrm{L}$ Thrombin-Puffer

Dispensieren der Testsubstanzen in die Mikrotiterplatten

Für jede Testsubstanz wurden Vierfachbestimmungen bei sechs verschiedenen Inhibitorund elf verschiedenen Substratkonzentrationen durchgeführt. Pro Testsubstanz wurden 3 Meßplatten nach folgendem Schema angelegt.

Meßplatte 1: Inhibitor $=1,10 \mu \mathrm{M}$

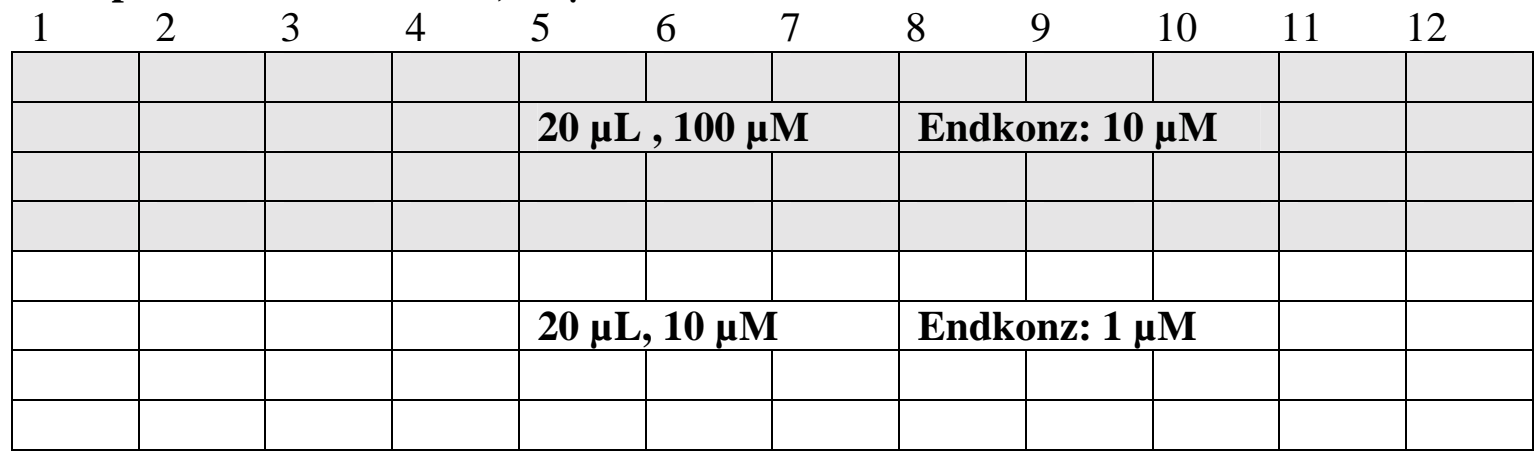

Meßplatte 2: Inhibitor $=2,5 \mu \mathrm{M}$

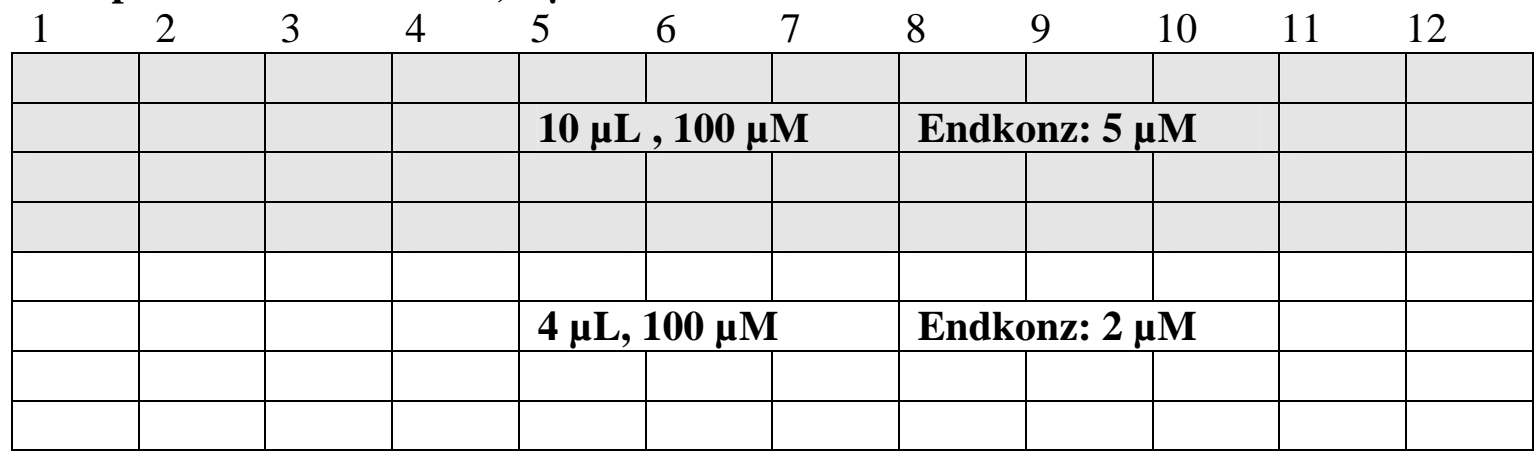


Meßplatte 3: Inhibitor $=200,500 \mathrm{nM}$

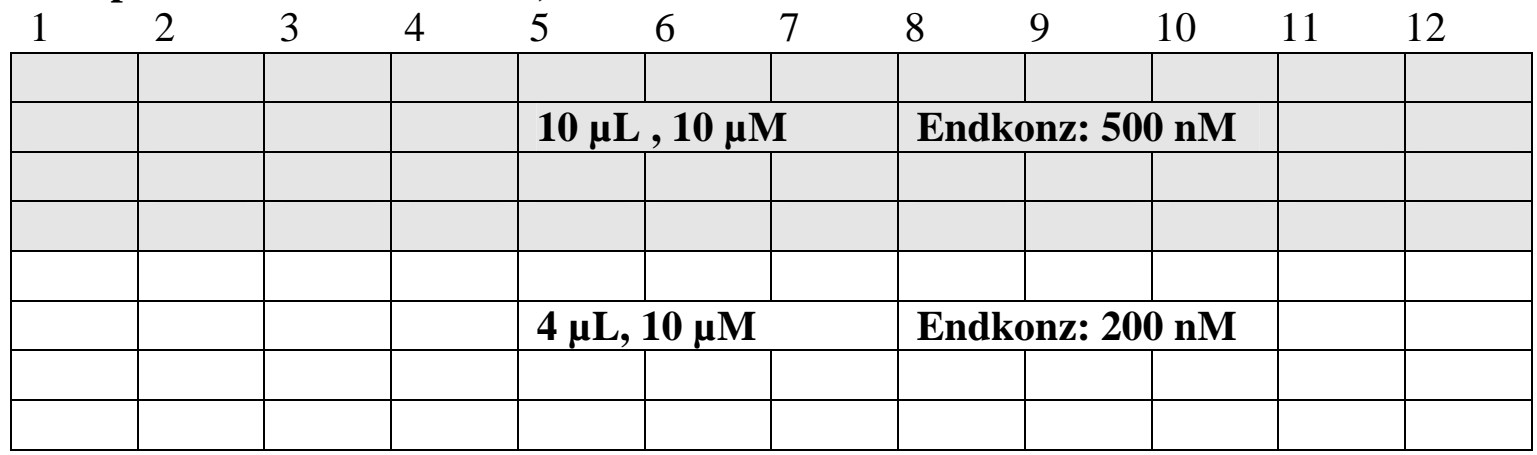

Meßplatte 4: ohne Inhibitor (zur Bestimmung des $\mathbf{K}_{\mathrm{M}^{-}}$-Wertes)

\begin{tabular}{|l|l|l|l|l|l|l|l|l|l|l|l|l|}
1 & 2 & 3 & 4 & 5 & 6 & 7 & 8 & 9 & 10 & 11 & 12 \\
\hline & & & & & & & & & & & \\
\hline & & & & & & & & & & & \\
\hline & & & & & & & & & & & \\
\hline & & & & & & & & & & & \\
\hline & & & & & & & & & & & \\
\hline & & & & & & & & & & & \\
\hline & & & & & & & & & & & \\
\hline & & & & & & & & & & & \\
\hline
\end{tabular}

Dispensieren des Thrombin-Puffers und der Thrombin- und Substratlösung in die Mikrotiterplatten $50-\mathrm{x} \mu \mathrm{L}$ Thrombin-Puffer wurden in die mit der Inhibitorlösung vorbefüllten Fluotrac200-Mikrotiterplatten einpipettiert, wobei x dem Volumen der Inhibitorlösung entspricht. Anschließend wurden $10 \mu \mathrm{L}$ Thrombin-Lösung $\left(10^{-5} \mathrm{U} / \mu \mathrm{L}\right)$ unter mehrmaligem Mischen einpipettiert. Die Mikrotiterpaltte wurde 3 min auf $30^{\circ} \mathrm{C}$ temperiert. Die Reaktion wurde durch Einfüllen von $140 \mu \mathrm{L}$ Substratlösung (mit Mehrkanalpipette aus Deep-WellSubstratvorratsplatte mit $1 \mathrm{~mL}$ Substratlösung pro Well) gestartet.

\section{Messung und Berechnung des $K_{M}$ bzw des $K_{i}$-Wertes}

Die Fluoreszenzentwicklung (Ex: 390/Em:450 nm, Gain 73, 30 ${ }^{\circ} \mathrm{C}$ ) wurde in 3 minAbständen für 15 min gemessen. Die Geradensteigung (Slope/min) der Kinetik wurde über ein Tabellenkalkulations-programm berechnet. Die Geradensteigungen der 4 Parallelbestimmungen wurden gemittelt. Die Meßwerte der 4. Meßplatte werden zur Bestimmung des $\mathrm{K}_{\mathrm{M}^{-}}$Wertes verwendet.

\section{Berechnung des $\mathrm{K}_{\mathrm{M}}$-Wertes}

Der $\mathrm{K}_{\mathrm{M}}$-Wert wurde über einen Hanes-Plot (Auftragung: $\mathrm{S} / \mathrm{V}$ über $\mathrm{S}$ ) bestimmt. Hierzu wurde $\mathrm{V}$ als Mittelwert der Geradensteigungen berechnet und über der zugehörigen 
Substratkonzentration S aufgetragen. Aus dem Hanes-Plot (Abb.11) konnte der $\mathrm{K}_{\mathrm{M}}$-Wert direkt als negativer Abszissenabschnitt abgelesen werden. Der $\mathrm{K}_{\mathrm{M}}$-Literaturwert für Thrombin bezogen auf das Substrat (Tos-GPR-AMC) liegt bei $7 \mu \mathrm{M}$.

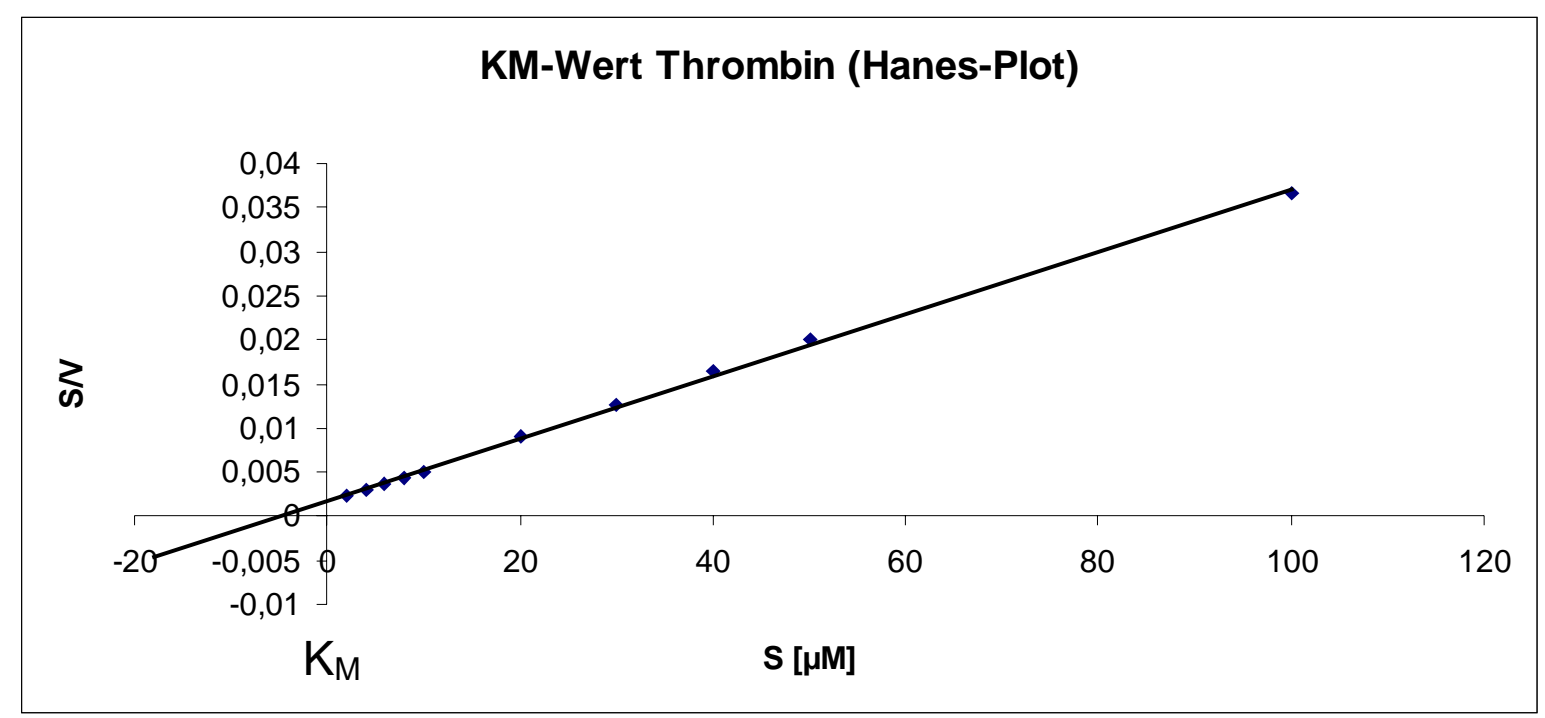

Abbildung 11: Hanes-Plot zur Bestimmung von $K_{M^{-}}$Werten:

Auftrag des Quotienten Substratkonzentration / Reaktionsgeschwindigkeit gegen Substratkonzentration

Zur Bestimmung des $\mathrm{K}_{\mathrm{i}}$-Wertes mußte dann noch der $\mathrm{IC}_{50^{-}}$-Wert (diejenige InhibitorKonzentration, bei der die Thrombin-Hemmung halbmaximal ist) bestimmt werden. Zusätzlich wurde die Substrat-Konzentration angegeben, bei der der $\mathrm{IC}_{50}$-Wert gemessen wurde.

Nach der Bestimmung des $\mathrm{K}_{\mathrm{M}^{-}}$Wertes, des $\mathrm{IC}_{50}$-Wertes und der zugehörigen Substratkonzentration kann der $\mathrm{K}_{\mathrm{i}}$-Wert über folgende Formel (Cheng \& Prusoff, 1973) errechnet werden:

$\mathrm{K}_{\mathrm{i}}=\mathrm{IC}_{50} /\left(1+\left(\mathrm{S} / \mathrm{K}_{\mathrm{M}}\right)\right)$ 


\subsection{Methoden Teil B: Histondeacetylasen}

\subsubsection{Klonierung, Transfektion und Expression von HDAC8}

\subsubsection{Klonierung rekombinanter menschlicher HDAC8}

Durch Kombination von Reverser Transkription und anschließender PCR (RT-PCR) ist es möglich, selektiv in einer Zelle exprimierte Gene in Form ihrer cDNA so zu vervielfältigen, daß genügend Moleküle für eine Klonierung zur Verfügung stehen. Zuerst wird durch Reverse-Transkriptase cDNA synthetisiert, die dann mittels PCR amplifiziert wird. Die cDNA aus menschlicher Leber wurde freundlicherweise von Dr. F. Soto zur Verfügung gestellt.

\subsubsection{1.a Polymerasekettenreaktion (PCR)}

Die Polymerasekettenreaktion (PCR; (Mullis and Faloona, 1987; Saiki et al., 1988)) dient der enzymatischen in vitro Amplifikation spezifischer DNA-Fragmente auch aus einem hohen und komplexen Hintergrund an unspezifischer DNA. Die Reaktion besteht aus aufeinanderfolgenden Amplifikationszyklen, die jeweils durch drei Phasen unterschiedlicher Temperatur charakterisiert sind. In der ersten Phase, der Denaturierungsphase, wird eine doppelsträngige DNA-Matrize (Template) bei einer Temperatur von $94-95{ }^{\circ} \mathrm{C}$ in eine von Sekundärstrukturen freie Einzelstrang-DNA überführt. In der zweiten (Anlagerungs-) Phase (annealing), wird die Temperatur soweit abgesenkt, daß sich spezifische Oligodesoxynukleotide (Primer), die jeweils in entgegengesetzter Orientierung flankierenden Bereichen der $\mathrm{zu}$ amplifizierenden Zielregion in einer Duplex-DNA homolog sind, an den jeweils komplementären Strang der denaturierten Template-DNA anlagern. In der Extensionsphase bei meist $72{ }^{\circ} \mathrm{C}$ werden dann die Oligodesoxynukleotide durch eine thermostabile DNA-Polymerase in $5 \rightarrow 3^{\prime}$-Richtung komplementär zur Zielregion verlängert. In den aufeinanderfolgenden Amplifikationszyklen kommt es idealerweise zur exponentiellen Anreicherung der durch die beiden Primer flankierten Ziel-Sequenz. Um optimale Anlagerungsbedingungen für beide Primer zu schaffen und damit eine spezifische Amplifikation zu gewährleisten, sollten sich die eingesetzten Oligodesoxynukleotide nur wenig im Schmelzpunkt und GC-Gehalt voneinander unterscheiden. Zusätzlich sollten selbst-komplementäre Sequenzen innerhalb der Oligodesoxynukleotide vermieden werden, um die Ausbildung von Sekundärstrukturen oder Dimeren zu unterdrücken.

Für die Amplifikation wurde Amplitaq-DNA-Polymerase (Perkin Elmer) und der mitgelieferte Puffer verwendet. Die PCR-Reaktionen wurden in 0,5 mLReaktionsgefäßen in 50-100 $\mu \mathrm{L}$-Ansätzen in 1 x PCR-Puffer durchgeführt, die außer der 
Template-DNA dNTPs (je 2,5 mM) und 40-50 pmol von beiden Primern enthielten. Für alle PCR-Reaktionen wurde ein hot start durchgeführt, d.h., die DNA-Polymerase wurde erst bei hoher Temperatur im ersten Zyklus zum Ansatz gegeben. Auf diese Weise konnte die Bildung unspezifischer PCR-Produkte vor dem Beginn der Reaktionszyklen verhindert werden. Diese können durch die Verlängerung falsch angelagerter oder durch Ausbildung von Sekundärstrukturen veränderter Primer entstehen. Für die Reaktionen wurde das PCR-Gerät von Biometra (Trio) verwendet, das mit einem beheizbaren Deckel ausgestattet ist, so daß auf eine Überschichtung mit Mineralöl oder Wachs als Verdunstungsschutz verzichtet werden konnte. Das PCR-Programm wurde den folgenden Primerpaaren und Template-Bedingungen angepaßt:

\section{Primer zur Klonierung von HDAC8}

HDAC8pQEcoRIfor: 5'-GAGAATTCATTAAAGAGGAGAAATTAAGCATGGAGGA GCCGGAG-3'

\section{HDAC8XaHISrev: 5'TTATAAATTAAGCTTATCAATGGTGATGGTGATGGTGGC TGCCGCGGCCTTCAATGACCACATGCTTCAGATTCCCTTTG-3’}

Sollte das PCR Produkt für eine direkte Klonierung mittels des TA-Klonierungs-System eingesetzt werden, wurde der Ansatz nach dem letzten Zyklus für mindestens $10 \mathrm{~min}$ bei $72{ }^{\circ} \mathrm{C}$ inkubiert. Durch die matrizenunabhängige Aktivität der Taq-Polymerase werden hierbei einzelne Desoxyadenosin-Reste am 3'-Ende des Duplex-Moleküls angefügt. Das PCR-Produkt konnte daher direkt für eine Ligationsreaktion mit einem dT-Überhänge tragenden Vektor eingesetzt werden.

\subsubsection{1.b Ligation - Direkte Klonierung des PCR-Produktes (TA-Cloning)}

Die mit Amplitaq-DNA-Polymerase generierten PCR-Produkte konnten direkt in den Vektor pCR4-TOPO aus dem TA Cloning ${ }^{T M}$ Kit (Invitrogen) ligiert werden. Das bereits vom Hersteller linearisierte Plasmid trägt kovalent an die ungepaarten 3'-Desoxythymidin-Überhänge (activated vector) gebundene Topoisomerase I, welche Inserts mit dem Plasmid ligiert und sich dabei ablöst (Shuman, 1994). Durch die kovalente Anknüpfung der Topoisomerase wurde aus der normalen trimolekularen Ligation eine sehr viel effizienter ablaufende bimolekulare. Durch die Insertion eines Fremdgenes in den Vektor wird der ORF des flankierenden $c c d \mathrm{~B}$-Genes unterbrochen und daher das vom unveränderten Ursprungsvektor exprimierte, für $E$. coli letale Genprodukt nicht gebildet. So wird erreicht, daß nur Klone, die mit einem rekombinanten Plasmid transformiert wurden, anwachsen können. Hierbei wurde normalerweise soviel Insert wie möglich eingesetzt. Für optimale Ligationsraten wurden frische PCR-Produkte verwendet, da die Desoxyadenosinreste an den 3'-Enden degradieren können.

Der Ligationsansatz aus $1 \mu \mathrm{L}$ pCR4-TOPO-Vektor, $1 \mu \mathrm{L}$ Salzlösung $(1,2 \mathrm{M} \mathrm{NaCl}$, $60 \mathrm{mM} \mathrm{MgCl} 2$ ) und 1-4 $\mu \mathrm{L}$ der PCR-Reaktion wurde bei Bedarf mit sterilem $\mathrm{H}_{2} \mathrm{O}$ auf 6 $\mu \mathrm{L}$ aufgefüllt und für 5-30 min bei RT inkubiert. Der Reaktionsansatz wurde bis zur weiteren Verwendung auf Eis belassen. Das entstandene genickte, aber zirkuläre 
Ligations-Produkt konnte direkt zur Transformation kompetenter XL1-Blue-Zellen (2.2.3.2) verwendet werden.

Das Subklonieren in pQEB-MCS diente der Herstellung des Expressionsvektors pQEHDAC8 (2.2.3.3), dessen Identität durch Sequenzierung festgestellt werden konnte.

\subsubsection{1.c Sequenzierung nach der Kettenabbruch-Methode}

Die Sequenzierungsarbeiten (Sanger et al., 1977) wurden vom Göttingen Genomics Laboratory (G2L) dieses Institutes durchgeführt. Dabei wurde eine modifizierte Form der Kettenabbruch-Methode nach Sanger et al. (1977) verwendet. Fluoreszenz-markierte ddNTPs wurden dazu der Sequenzierungs-PCR zugesetzt, welche nach Einbau in den neusynthetisierten DNA-Strang zum Abbruch der Elongation führen, weil sie kein 3'-OH zur Verknüpfung mit dem nachfolgenden dNTP zur Verfügung stellen. Die ddNTPs werden in einem so starken Unterschuß im Vergleich zu den dNTPs eingesetzt, daß im statistischen Mittel etwa ein Abbruch pro Molekül erfolgt. Da für die 4 verschiedenen ddNTPs unterschiedliche Flourophore verwendet werden, können sie zusammen in einer PCR-Reaktion eingesetzt werden. Die entstandenen DNA-Fragmente wurden mit dem DNA-Sequenzer ABI-Prism 377 oder dem Megabase-Sequencer (kapillar-)elektrophoretisch aufgetrennt, detektiert und die Sequenz automatisch ausgelesen.

\subsubsection{Transformation von Escherichia coli}

\subsubsection{2.a Dialyse}

Um bei der Elektroporation von E. coli einem Kurzschlußstrom durch die Zellsuspension (arcing) vorzubeugen, wurde die Konzentration an Elektrolyten in den Ligationsansätzen gesenkt, indem der Ligationsansatz auf eine Nitrocellulosemembran $(0,025 \mu \mathrm{m}$, Schleicher und Schüll) pipettiert wurde, welche auf einem 10\%igen Glyzerinbad schwamm. Die Mikrodialyse erfolgte für $20 \mathrm{~min}$ bei RT. 5-10 $\mu \mathrm{L}$ des vom Filter mittels Pipette aufgenommen Ligationsansatz wurde direkt für die Elektrotransformation eingesetzt.

\subsubsection{2.b Elektrokompetente Escherichia coli-Zellen (Dower et al., 1988)}

Zur Transformation von Escherichia coli nach der Elektroporationsmethode wurde das Protokoll nach Dower et al. (1988) verwendet. Zur Präparation elektrokompetenter Zellen wurden $50 \mathrm{~mL}$ dYT/Tet mit Escherichia coli XL1-Blue inokuliert und bis zu einer OD600 von ca. 0,5 herangezogen. Die Zellen wurden durch Zentrifugation (HettichRotanta, $4000 \mathrm{Upm}, 10 \mathrm{~min}, 4{ }^{\circ} \mathrm{C}$ ) geerntet, in $50 \mathrm{~mL}$ eiskaltem, sterilem Wasser 
resuspendiert (Waschen) und erneut pelletiert. Dieser Waschschritt wurde mehrmals wiederholt, wobei das Zellpellet nacheinander in $25 \mathrm{~mL}$ und in $10 \mathrm{~mL}$ eiskaltem, sterilem Wasser resuspendiert wurde. Nach dem letzten Zentrifugationsschritt wurde der Überstand abgegossen und das Zellpellet in $1 \mathrm{~mL} 10 \%$ igem (v/v) Glyzerin resuspendiert. Während des gesamten Vorgangs wurden die Zellen auf Eis gehalten. $80 \mu \mathrm{L}$ Aliquots der Zellsuspension wurden in flüssigem Stickstoff schockgefroren und zur späteren Verwendung bei $-80{ }^{\circ} \mathrm{C}$ eingefroren. Transformationstests mit $1 \mathrm{ng}$ pUC18-Plasmid ergaben normalerweise eine Transformationseffizienz von über $107 \mathrm{cfu} / \mu \mathrm{g}$ DNA. Zur Transformation wurden $80 \mu \mathrm{L}$ Zellsuspension auf Eis aufgetaut (45 min) mit 5-10 $\mu \mathrm{L}$ dialysiertem Ligationsansatz versetzt und in eine vorgekühlte Elektroporationsküvette überführt. Die Elektroporation wurde im E. coli-Pulser (BioRad) bei folgenden Einstellungen durchgeführt: $25 \mu \mathrm{F}, 2,5 \mathrm{kV}, 200 \mathrm{Ohm}$, (meist 4,5 ms Zeitkonstante). Unmittelbar nach dem Potentialpuls wurde $1 \mathrm{~mL}$ steriles SOC-Medium in die Elektroporationsküvette pipettiert, der Inhalt in ein Kulturröhrchen überführt, die Küvette zweimal mit einem weiteren Milliliter SOC-Medium in das Röhrchen ausgespült und die Zellsuspension für eine Stunde bei $37{ }^{\circ} \mathrm{C}$ im Roller zur Ausprägung der Antibiotikaresistenz inkubiert. Anschließend wurden $200 \mu \mathrm{L}$ bzw. der durch Zentrifugation (Heraeus Biofuge pico, 20 s, 13000 Upm, RT) pelletierte und in etwa 200 $\mu \mathrm{L}$ resuspendierte Rest der Kultur auf Selektivplatten plattiert. Die Platten wurden über Nacht bei $37{ }^{\circ} \mathrm{C}$ inkubiert. Als Kontrollen wurde jeweils ein Ligationsansatz ohne Insert (Rezyklisierung) und ein Ansatz ohne Ligase und Insert (Anteil an ungeschnittenem Vektor) mitgeführt.

\subsubsection{2.c $\quad \mathrm{CaCl}_{2}$-kompetente Escherichia coli-Zellen}

Mit je 0,5 mL einer Übernachtkultur von E. coli XL1-Blue (Stratagene) wurden $4 \mathrm{x}$ $50 \mathrm{~mL}$ dYT-Medium (mit Tetracyclin) angeimpft und diese Kulturen bei $37{ }^{\circ} \mathrm{C}$ und $150 \mathrm{Upm}$ im Schüttler inkubiert. Nach Erreichen einer $\mathrm{OD}_{600}$ von etwa 0,5 wurden die Zellen für $1 \mathrm{~h}$ auf Eis inkubiert, nachfolgend pelletiert (Hettich-Rotanta/RPC, $4000 \mathrm{Upm}$, $10 \mathrm{~min}, 4^{\circ} \mathrm{C}$ ) und in $50 \mathrm{~mL}$ eiskaltem, sterilem Trituration-Buffer aufgenommen. Nach Inkubation auf Eis für 45 min und erneutem Pelletieren wurden die Zellen in $5 \mathrm{~mL}$ Trituration-Buffer resuspendiert und gesammelt. Nach Zutropfen von $4 \mathrm{~mL}$ 87\%igem Glyzerin und leichtem Mischen, wurden $200 \mu \mathrm{L}$-Aliquots der Zellsuspension auf Trockeneis in Eppendorf-Reaktionsgefäße abgefüllt und bei $-80{ }^{\circ} \mathrm{C}$ bis zur späteren Verwendung eingefroren. Transformationstests mit $1 \mathrm{ng}$ pUC18-Plasmid ergaben normalerweise eine Transformationseffizienz von über $10^{5} \mathrm{cfu} / \mu \mathrm{g}$ DNA.

Die Transformation erfolgte unter großer Sorgfalt. Auf Eis wurden $200 \mu \mathrm{L} \mathrm{CaCl}_{2}$ kompetente Zellen langsam aufgetaut, vorsichtig mit 5 oder $10 \mu \mathrm{L}$ Ligationsansatz vermischt und dann $30 \mathrm{~min}$ auf Eis inkubiert (Adsorption der DNA an die Zelloberfläche). Danach erhielten die Zellen einen Hitzeschock für $60 \mathrm{~s}$ bei $42{ }^{\circ} \mathrm{C} \mathrm{im}$ Heizblock und wurden im Anschluß daran für 2 min auf Eis inkubiert. Nach Zugabe von $800 \mu \mathrm{L} 37{ }^{\circ} \mathrm{C}$ warmen SOC-Medium wurde der Transformationsansatz zur Ausbildung der Antibiotikaresistenz für $1 \mathrm{~h}$ bei $37^{\circ} \mathrm{C}$ im Heizblock geschüttelt. 
Beim direkten „TA-Cloning“ von PCR-Produkten wurden pro Ansatz jeweils $200 \mu \mathrm{L}$ und $800 \mu \mathrm{L}$ Zellsuspension auf LB-Amp/Kan-Platten ausgestrichen. Die Platten wurden üN bei $37^{\circ} \mathrm{C}$ inkubiert.

Als Kontrollen wurde jeweils ein Ligationsansatz ohne Insert (Rezyklisierung) und ein Ansatz ohne Ligase und Insert (Anteil an ungeschnittenem Vektor) mitgeführt.

\subsubsection{Expression in Escherichia coli}

Im Rahmen dieser Arbeit wurden zur heterologen Expression von Proteinen in E. coli der Vektor pQE70 (Qiagen) verwendet, bei dem das Fremdgen unter der Kontrolle eines T5Promotors mit lac-Operator steht. Die Induktion der Expression wurde durch Zugabe von IPTG ins Medium einer in der logarithmisch Wachstumsphase befindlichen Kultur erreicht.

Zur Expression von HDAC8 wurden $11 \mathrm{LB} / \mathrm{Amp}$ mit $5 \mathrm{~mL}$ einer üN gewachsenen $50 \mathrm{~mL}$-Vorkultur (dYT/Amp) von XL1-Blue-pQEHDAC8 inokuliert und bei einer $\mathrm{OD}_{600}$ von 0,6 durch Zugabe von $1 \mathrm{mM}$ IPTG induziert. Nach etwa $16 \mathrm{~h}$ Wachstum wurde die $\mathrm{OD}_{600}$ bestimmt, die Zellen nach Abkühlung auf etwa $8{ }^{\circ} \mathrm{C}$ pelletiert (Hettich Silenta, $4000 \mathrm{Upm}, 30 \mathrm{~min}, 4^{\circ} \mathrm{C}$ ) und das Zellpellet in $50 \mathrm{~mL}$ kaltem HDAC8-Puffer resuspendiert.

\subsubsection{Zellaufschluß durch Disruption}

Um die cytoplasmatisch exprimierten Enzyme freizusetzen, wurden die $\mathrm{OD}_{600}$ der Zellen der 1 1-Expressionskulturen gegen Medium bestimmt, diese geerntet (Hettich Silenta, 30 min, $4000 \mathrm{Upm}, 10^{\circ} \mathrm{C}$ ) und in $50 \mathrm{~mL}$ des jeweiligen kalten Aufschlußpuffers resuspendiert. Mit Hilfe eines Zelldisruptors (mit wassergekühltem (auf $12{ }^{\circ} \mathrm{C}$ ) Basic ZAufschluß-Kopf, IUL Instruments $\mathrm{GmbH}$ ) wurden die Zellen lysiert, indem sie unter hohem Druck (1,8 kbar) durch eine Düse $(0,18 \mathrm{~mm})$ gepreßt wurden. Zusätzlich zu den Scherkräften prallte der Strahl der Zellsuspension danach gegen ein Metallhindernis. Das aufgefangene Lysat wurde durch Zentrifugation von Zelltrümmern befreit (Sorval, 30 min, $\left.9000 \mathrm{Upm}, 4^{\circ} \mathrm{C}\right)$, der geklärte ÜS filtriert $(0,25 \mu \mathrm{m})$ und bis zur Verwendung auf Eis gelagert.

\subsubsection{Analyse der Produkte}

\subsubsection{5.a Denaturierende Polyacrylamidgelelektrophorese (SDS-PAGE)}

Proteine lassen sich unter denaturierenden Bedingungen mittels Elektrophorese in Polyacrylamidgelen der Größe nach auftrennen (Laemmli, 1970). Die Porengröße der inerten Matrix läßt sich über die Acrylamidkonzentration und den Anteil an Quervernetzer steuern. Das im Proben- und Gelpuffer enthaltene SDS ist ein stark negativ geladenes amphipatisches Molekül, welches sich mit seinem hydrophoben Kohlenwasserstoffschwanz an hydrophobe Bereiche von Proteinen anlagert und dabei die 
hydrophoben, stabilisierenden Wechselwirkungen in den Proteinen selbst aufbricht. So werden Strukturen höherer Ordnung aufgelöst und insbesondere Untereinheiten voneinander getrennt. Die zahlreichen negativen Ladungen des SDS überlagern die proteinspezifische Ladung, so daß im elektrischen Feld die Wanderungsgeschwindigkeit der SDS-Peptid-Micellen nur durch ihr Molekulargewicht bestimmt wird. Bei der häufig angewendeten Variante der diskontinuierlichen Gelelektrophorese durchlaufen die Proben ein dem Trenngel vorgeschaltetes Sammelgel, welches durch langsamen Einlauf der Proben aus den Taschen und den sogenannten Stapeleffekt einer Aggregation der Proteine vorbeugt und diese grob vorsortiert und konzentriert. Die Proteine werden zwischen den schnell wandernden $\mathrm{Cl}^{-}$-Ionen und den kaum bewegten GlycinatZwitterionen im Sammelgel fokussiert, bei dem veränderten $\mathrm{pH}-$ Wert im Trenngel wandern die Glycin-Ionen dann vor der Protein-Front. Bei der Elektrophorese im Trenngel mit SDS erhält man über einen bestimmten Bereich eine lineare Beziehung zwischen dem Logarithmus der Molekulargewichte und den Wanderungsstrecken der Proteine. Über den Abgleich mit einem Proteinstandard lassen sich die Molekulargewichte abschätzen. Es wurden standardmäßig 10\%ige (v/v) bzw. ausnahmsweise 12\%ige (v/v) SDS-Polyacrylamidgele verwendet.

\section{Herstellung $10 \%$ iger Polyacrylamidgele}

Die Gele wurden zwischen eine Aluminiumoxid- und eine Glasplatte gegossen. Das (untere) Trenngel wurde zuerst gegossen. Für zwei Gele wurden $6 \mathrm{~mL}$ 30\%iges Protogel $^{\Theta}, 4,5 \mathrm{~mL} 4 \times$ Trenngelpuffer, 7,5 mL Wasser, $40 \mu \mathrm{L}$ TEMED und zuletzt $80 \mu \mathrm{L}$ APS zusammengebracht und bis zu einer Höhe von ca. 2/3 zwischen die Platten gegossen. Jedes Gel wurde mit $500 \mu \mathrm{L}$ Isopropanol überschichtet, welches für eine wellen- und blasenfreie Gelkante sorgte. Nach vollständiger Polymerisation des Acrylamids zu Polyacrylamid wurde das Isopropanol vollständig von den Gelen entfernt. Nach Ansetzen der Sammelgellösung aus $2 \mathrm{~mL} \quad 30 \%$ Protogel $^{\circledR}, \quad 3 \mathrm{~mL} \quad 4 \quad \mathrm{x}$ Sammelgelpuffer, $7 \mathrm{~mL}$ Wasser, $25 \mu \mathrm{L}$ TEMED und $50 \mu \mathrm{L}$ APS wurde diese bis zur Oberkante der Platten eingefüllt und sofort der jeweilige Taschenkamm gesteckt. Beim Gießen und der Handhabung der Gele wurden Handschuhe getragen, da nichtpolymerisierte PAA-Lösung toxisch ist und Hautschuppen bzw. Fette einen nachfolgenden Immunoblot beeinträchtigen könnten.

\section{Probenvorbereitung}

Proteinhaltige Proben wurden 1:5 mit Proteinprobenpuffer versetzt und für 5-10 min bei $99^{\circ} \mathrm{C}$ im Heizblock inkubiert. Dabei bewirkt das im Puffer enthaltene $\beta$-Mercaptoethanol eine Reduktion von möglichen Disulfidbrïcken, das SDS wirkt denaturierend auf die Proteine. Bei nicht sofortiger Verwendung wurden die Proben bei $-20{ }^{\circ} \mathrm{C}$ eingefroren.

\section{Durchführung der Elektrophorese}

Die bei RT für mindestens 30 min auspolymerisierten Polyacrylamidgele wurden in die Laufkammer (Biometra) eingesetzt und der Taschenkamm entfernt. Die obere und untere Kammer wurden mit LaemmLi-Puffer befüllt und die Proben in die Geltaschen gefüllt. Als Protein-Molekulargewichtsstandard dienten $4 \mu \mathrm{L}$ eines Proteinmarkers (Anhang). Die Elektrophorese wurde bis zum Einlauf der Farbmarkerbande in das Trenngel bei einer Stromstärke von $10 \mathrm{~mA} / \mathrm{Gel}$ durchgeführt, dann wurde die Stromstärke auf 25 
mA/Gel erhöht und in der Regel bis zum Auslaufen der Farbbande am unteren Gelrand beibehalten.

\section{Coomassie-Färbung}

Die aufgetrennten Proteinbanden wurden durch Färben des Polyacrylamidgels in einer Schale mit Coomassie Brilliant Blue R250 Protein-Färbelösung für mindestens 45 min bei Raumtemperatur unter leichtem Schütteln sichtbar gemacht. Zum Entfärben wurde das Gel mehrmals für 2-3 min in der Mikrowelle (Brother Powerwave) in demineralisiertem Wasser aufgekocht, wobei das Wasser jeweils gewechselt wurde.

\subsubsection{5.b Transfer von Proteinen auf PVDF-Membranen (Blotting)}

Zum immunochemischen Nachweis von elektrophoretisch aufgetrennten Proteinen müssen diese aus der Gelmatrix befreit werden, um dem Antikörper zugänglich zu werden. Dies wird standardmäßig durch den Transfer der Proteine auf eine Membran erreicht. In dieser Arbeit wurden die Proteine aus den PAA-Gelen mittels Elektrophorese (semi dry Elektroblotter, Biorad) auf PVDF-Membranen $(0,2 \mu \mathrm{m}$, Biorad) überführt.

Dazu wurden auf der Anode des Gerätes ein mit Anoden-Puffer I getränktes und darauf zwei mit Anoden-Puffer II getränkte Filterpapiere (Whatman-Papier) gestapelt. Darauf wurden nacheinander die Membran, das PAA-Gel und drei mit Kathoden-Puffer getränkte Filterpapiere luftblasenfrei aufgelegt. Das PAA-Gel wurde vorher $10 \mathrm{~min}$ in Kathodenpuffer äquilibriert und die PVDF-Membran durch kurzes Schwenken in $\mathrm{MeOH}$ aktiviert. Nach Schließen des Gerätes mit der Kathoden-Platte wurde der Blot für 60 min bei $170 \mathrm{~mA}$ pro Gel $(9 \mathrm{~cm} \times 7 \mathrm{~cm})$ gefahren. Der vollständig erfolgte Transfer ließ sich anhand des ebenfalls transferierten farbigen Proteinmarkers verifizieren.

\subsubsection{5.c Immunochemischer Nachweis auf PVDF-Membranen (Western)}

Auf einer Membran immobilisierte (und normalerweise vorher elektrophoretisch aufgetrennte) Proteine sind für die Erkennung und die Bindung durch einen für das Zielprotein spezischen Antikörper zugänglich. Durch direkte kovalente oder indirekte Kopplung (z. B. über einen anderen Antikörper) eines Reporterenzyms, welches ein detektierbares Signal generiert, an den primären Antikörper wird das Signal ortsspezifisch am nachzuweisenden Zielprotein konzentriert. In dieser Arbeit wurde ausschließlich die an den jeweiligen sekundären Antikörper gekoppelte Alkalische Phosphatase verwendet, welche aus den dem AP-Entwicklungspuffer frisch zugesetzten farblosen Substraten BCIP $(200 \mu \mathrm{L} / 50 \mathrm{~mL}$ Puffer) und NBT (150 $\mu \mathrm{L} / 50 \mathrm{~mL}$ Puffer) einen unlöslichen, violetten Farbstoff generiert.

Die PVDF-Membran mit den anheftenden Proteinen wurden zur Blockierung unspezifisch proteinbindender Bereiche üN bei $4{ }^{\circ} \mathrm{C}$ in $\mathrm{BB}$ und darauf mit dem spezifischen, primären Antikörper für mindestens $1 \mathrm{~h}$ bei RT in BBT unter leichtem Schütteln inkubiert. Überschüssiger, nicht gebundener Antikörper wurde durch Waschen der Membran für je 5 min bei RT unter leichtem Schwenken nacheinander in PBST und 
viermal in PBS entfernt. Dann wurde dem sekundären Antikörper ermöglicht, den konstanten Teil des primären Antikörpers zu binden, indem dieser mit der Membran für mindestens $60 \mathrm{~min}$ in BBT/PBS bei RT leicht geschwenkt wurde. Anschließend wurde wie oben beschrieben gewaschen und schließlich der Blot in AP-Entwicklungspuffer mit BCIP und NBT bei RT im Dunkeln entwickelt, bis die violetten Banden ausreichend deutlich hervortraten.

Verwendete Kombinationen und Verdünnungen der Antikörper (AK):

Primärer AK: monoklonaler Anti-PentaHis-tag-Antikörper aus Maus (1:5000)

Sekundärer AK: $\quad$ Anti-Maus-IgG-AP-Konjugat (1:5000)

\subsubsection{Aufreinigung}

\subsubsection{6.a Affinitätschromatographie an immobilisierten Metallionen}

Exprimierte rekombinante Proteine mit einem terminalen Hexahistidinschwanz (His-tag) wurden über Affinitätschromatographie an immobilisierten $\mathrm{Ni}^{2+}$-Ionen aufgereinigt. Dies ist möglich, weil der Schwanz an zusätzlichen sechs Histidinen (His-tag) 3 freie Valenzen eines bereits über 3 Valenzen an die über einen 7-Atomspacer gekoppelten Iminodiacetylsäuregruppen der Sepharose-Matrix gebundenen $\mathrm{Ni}^{2+}$-Ions komplexieren kann (Porath et al., 1975). Proteine ohne diesen Polyhistidin-Schwanz haben normalerweise keine Affinität zum Liganden und eluieren größtenteils im Durchlauf einer IMAC-Säule, während jene mit His-tag an die Säule binden und sich mit Imidazol wieder eluieren lassen, weil dieses dabei mit dem Histidin um die Komplexierungsstellen am Nickel konkurriert.

In dieser Arbeit wurden selbst hergestellte IMAC-Säulen verwendet, wobei die gesamte Chromatographie mit der Flußrate durchgeführt, die durch Gravitation vorgegeben wurde. IMAC-Säulen wurden gepackt, indem in eine geleerte MIDI100-Kartusche $1 \mathrm{~mL}$ in demineralisiertem Wasser gewaschene Chelating-Sepharose Fast Flow (Pharmacia Biotech AB) gefüllt wurde und nach dem Setzen der Matrix eine obere Fritte eingesetzt wurde. Nach zweimaligem Waschen der Matrix mit je $10 \mathrm{~mL}$ demineralisiertem Wasser wurde die Säule durch zweimal $5 \mathrm{~mL} 100 \mathrm{mM} \mathrm{NiCl}{ }_{2}$ mit Nickel beladen und nach Fortspülen des überschüssigen Nickels mit zweimal $10 \mathrm{~mL}$ demineralisiertem Wasser durch zweimal $10 \mathrm{~mL}$ IMAC-Puffer I bzw. HDAC8-Puffer I äquilibriert. Variable Volumina an Probe wurden auf die Säule geladen und der Durchfluß (FT) aufgefangen. Ein- bis dreimal wurde mit dem jeweiligen Puffer I gewaschen und die Fraktionen ebenfalls aufgefangen (W1 bis W3), bevor mit einem Stufengradienten steigender Imidazol-Konzentration (je $2 \mathrm{~mL}$ von 20, 40, 80, 100, 200, 300, $500 \mathrm{mM}$ Elutions-Puffer, hergestellt durch Mischung von Puffer I mit Puffer II) das Zielprotein in $2 \mathrm{~mL}$ Reaktionsgefäße eluiert wurde. Je $50 \mu \mathrm{L}$ des Durchflusses und der Fraktionen wurde als zur Analyse über SDS-PAGE vorbereitet. Die Fraktionen wurden bis zur weiteren Verwendung auf Eis gelagert. Die Fraktionen wurden normalerweise anschließend in 
Dialyseschläuche (Ausschlußgrenze $\mathrm{Mr} \sim 12000$ ) gefüllt und ü. $\mathrm{N}$. bei $4{ }^{\circ} \mathrm{C}$ unter leichtem Rühren gegen 21 des entsprechenden Puffers ohne Imidazol dialysiert. Die Dialyse wurde dann gegen 11 frischen Puffer für mindestens weitere $2 \mathrm{~h}$ fortgesetzt.

\subsubsection{6.b Perfusionschromatographie}

Die Perfusionschromatographie erlaubt eine sehr hohe Flußrate ohne nennenswerte Beeinträchtigung der Auflösung oder der Kapazität der Säule aufgrund des speziellen Säulenmaterials (Poros 20, Pharmazia) und beschleunigt dadurch die Proteinaufreinigung erheblich. Daher konnte die Reinigung von HDAC8 auch bei RT statt bei $4{ }^{\circ} \mathrm{C}$ erfolgen, wobei das Lysat und die relevanten Fraktionen die meiste Zeit auf Eis gelagert wurden.

Die Chromatographie wurde mit einer an die Vision Workstation (Perseptive Biosystems) angeschlossene Anionenaustauschersäule (Poros $20 \mathrm{HQ}, 7,5 \mathrm{~mL} \mathrm{SV}$ ) und sterilfiltriertem Wasser und Puffern nach einem spezifischen Programm bei einer Flußrate von $10 \mathrm{~mL} / \mathrm{min}$ durchgeführt. Dabei wurde ein biphasischer, linearer Salz-Gradient durch Mischen von HDAC8-Puffer A und B erzeugt. Vorab wurde sowohl die Säule als auch alle relevanten Schläuche und Bauteile (wie z. B. Pumpen) mit ca. $5 \mathrm{SV} 3 \mathrm{M} \mathrm{NaCl}$ bei $10 \mathrm{~mL} / \mathrm{min}$ gespült, um etwaige Proteinreste zu entfernen. Danach wurde mit ca. $5 \mathrm{SV}$ Wasser das Salz aus dem System gewaschen. Das verwendete Programm beinhaltete folgende Schritte:

- Äquilibrierung mit 5 SV HDAC8-Puffer A

- Laden von 5-15 mL sterilfiltriertem Lysatüberstand und Sammeln von $8 \mathrm{~mL}$ Fraktionen

- Waschen mit 4 SV HDAC8-Puffer A und Sammeln von 8 mL-Fraktionen

- Elution mit einem Gradienten mit $10 \mathrm{SV}$ von $0-1,8 \mathrm{M} \mathrm{NaCl}$ in HDAC8-Puffer bei Sammeln von $2 \mathrm{~mL}-$ Fraktionen und $3 \mathrm{SV} 1,8-3 \mathrm{M} \mathrm{NaCl}$ in HDAC8-Puffer bei Sammeln von $4 \mathrm{~mL}-$ Fraktionen

- Stufe mit 2 SV HDAC8-Puffer B

- Zurückfahren der Salzkonzentration auf $0 \mathrm{mM}$ in $2 \mathrm{SV}$

- Äquilibrierung mit 4 SV HDAC8-Puffer A

Während der gesamten Chromatographie wurde die $\mathrm{OD}_{260}$ und $\mathrm{OD}_{280}$ verfolgt. ElutionsFraktionen mit $\mathrm{OD}_{280}>\mathrm{OD}_{260}$ wurden auf Eis gelagert und ein $50 \mu \mathrm{L}$-Aliquot davon und einiger anderer Fraktionen zur Analyse per SDS-PAGE vorbereitet (2.2.3.5).

\subsubsection{6.c Affinitätschromatographie mit einem immobilisierten Inhibitor}

Die Affinitätschromatographie mittels immobilisierter Enzymsubstrate/-inhibitoren stellt eine sehr effiziente Methode der Enzymaufreinigung dar, da das zu isolierende Enzym in der Regel spezifisch mit seinem Substrat/Inhibitor interagiert. Die Entdeckung der ersten HDAC (Taunton et al., 1996) beruhte auf dieser Technik. Die Idee war, als Liganden ein 
mit einem primären Amin versehenes Derivat der Suberoylanilid-Hydroxamsäure SAHA auf eine Cyanogenbromid-aktivierte Sepharosematrix zu koppeln (Kohn et al., 1982), dann die Proteinlösung aufzugeben und mit einem steigenden Gradienten an Acetat zu verdrängen. Aus vorangegangenen Versuchen mit Derivaten von SAHA wußten wir, daß Variationen in para-Stellung der sogenannten Kopfgruppe des Moleküls einen geringen Einfluß auf die inhibitorische Aktivität haben, sodaß hier ein reaktiver Linker angebracht werden konnte (Abb. 12):

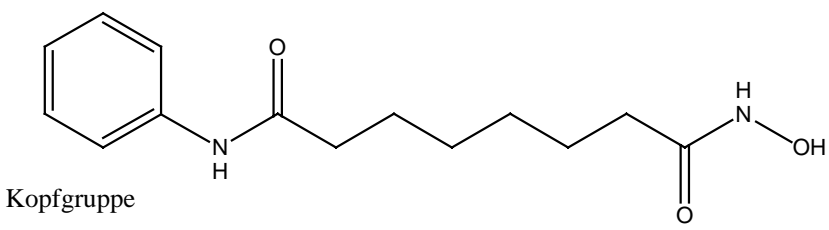

SAHA

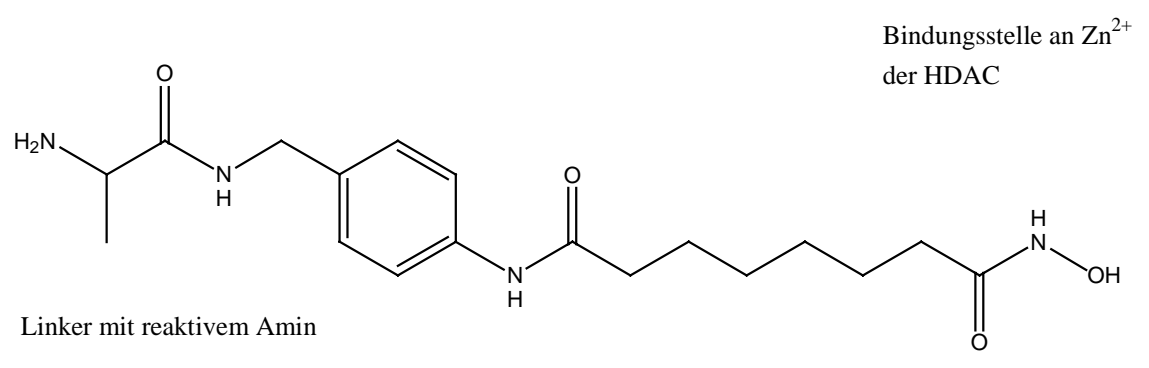

SAHA-Derivat

Abbildung 12: Herstellung einer Affinitätschromatographiesäule. Der natürliche Ligand (oben) und das Derivat (unten), das über den Linker an die Matrix kovalent gebunden wird

Herstellung der Affinitätschromatographiesäule mit cyanogenbromid-aktivierter Sepharose 4B

Zur Synthese wurde N-Boc-Alanin mit N,N-Diisopropylcarbodiimid DIC und NHydroxysuccinimid zum NHS-Ester aktiviert und mit p-Aminobenzylanilin umgesetzt.

Dann wurde das Anilin mit Korksäure und DIC zum Anilid acyliert und die verbleibende freie Säure nach Zwischenreinigung erneut mit DIC und Hydroxybenzotriazol aktiviert auf ein über die Hydroxylgruppe an Tritylharz gebundenes Hydroxylamin gekoppelt und schließlich mit TFA abgespalten und gleichzeitig Boc entfernt.

1,75 mL der cyanogenbromid-aktivierten Sepharose 4B (Amersham Pharmacia No.170430-01) wurden in einer mit Fritte versehenen $5 \mathrm{~mL}$ Einmalspritze nach Herstellerprotokoll mit kalter1 $\mathrm{M} \mathrm{HCl}$ und $0.1 \mathrm{M} \mathrm{NaHCO}_{3} / 0.5 \mathrm{M} \mathrm{NaCl}$ gewaschen und dann mit 7,3 mg $(20 \mu \mathrm{mol})$ des SAHA-Derivats in $5 \mathrm{~mL} 0.1 \mathrm{M} \mathrm{NaHCO} 3 / 0.5 \mathrm{M} \mathrm{NaCl}$, $\mathrm{pH} 8,3$ gelöst $2 \mathrm{~h}$ bei RT unter Schütteln inkubiert, dann abgesaugt und mit $5 \mathrm{~mL} 200 \mathrm{mM}$ Glyzinpuffer, $\mathrm{pH} 8$ für weitere $3 \mathrm{~h}$ nicht umgesetzte Cyanatestergruppen blockiert. Dann wurde mit $0.1 \mathrm{M}$ NaAcetat, $\mathrm{pH} 4$ und $0.1 \mathrm{M} \mathrm{NaHCO} 3, \mathrm{pH} 8.3 \mathrm{im}$ Wechsel gewaschen und im Acetatpuffer bei $4^{\circ} \mathrm{C}$ gelagert bis zur Anwendung. 
Herstellung der Affinitätschromatographiesäule mit NHS-aktivierter Sepharose 4B

NHS-aktivierte Sepharose 4B wurde wegen der höheren Stabilität (vor allem bei höheren pH-Werten) der Amidbindung zwischen Träger und Ligand bevorzugt im Vergleich etwa zur hydrolyseanfälligeren Isoharnstoffbindung bei Verwendung cyanogenbromidaktivierter Sepharose.

Zur Herstellung wurden 4,5 mL NHS-aktivierte Sepharose 4 FastFlow (Amersham Pharmacia No.17-0906-01) in einer mit Fritte versehenen $10 \mathrm{~mL}$ Einmalspritze nach Herstellerprotokoll mit $75 \mathrm{~mL}$ kalter1 $\mathrm{M} \mathrm{HCl}$ und $10 \mathrm{~mL} 0.15 \mathrm{M} \mathrm{NaHPO}_{4} \mathrm{pH}$ 7,4 gewaschen, inzwischen wurden $35 \mathrm{mg}$ der Alanyl-Benzylamid-para-SuberoylanilidHydroxamsäure in 2,2 mL DMF / NMP / Kopplungspuffer (10 / 10 / 80 v/v, pH 7,4), Endkonzentration $44 \mathrm{mM}$ gelöst und dann zum vorbereiteten Träger gegeben, der $\mathrm{pH}$ kontrolliert und $3 \mathrm{~h}$ bei RT unter leichtem Schütteln inkubiert. Dann wurde mit Blockierungspuffer ( $0,5 \mathrm{M}$ Tris, $\mathrm{pH} 7,5)$ gewaschen und $\mathrm{uN}$ bei $4^{\circ} \mathrm{C}$ stehen gelassen. Schließlich wurde mit mit 0,5 M NaAcetat, $\mathrm{pH} 4$ und 0,1 M NaHCO3, pH $8.3 \mathrm{im}$ Wechsel gewaschen und in $20 \%$ Ethanol bei $4^{\circ} \mathrm{C}$ gelagert bis zur Anwendung.

\subsubsection{HDAC Assay}

\subsubsection{7.a Zweistufiger Assay}

\section{Messprinzip}

Das Messprinzip beruht darauf, die Enzyme mit peptidischen Substraten, die über eine Lysyl-Amidbindung mit dem in dieser gebundenen Form nicht fluoreszenten 7-Amido-4methylcoumarin MCA verknüpft wurden, zu inkubieren, dabei wird durch die Enzymaktivität der HDAC in der ersten Phase die $\varepsilon$-Aminogruppe des Lysylrestes der Substrate deacetyliert und so in ein Substrat von Trypsin umgewandelt, das in einer zweiten Stufe zugesetzt wird (Wegener et al., 2003a, Riester et al., 2003). Trypsin spaltet dann die Amidbindung zwischen dem Lysyl-Rest und dem nachfolgenden Fluorophor 7Amino-4-methylcoumarin AMC, welches in dieser ungebundenen Form eine starke Fluoreszenz bei $460 \mathrm{~nm}$ nach Anregung bei $390 \mathrm{~nm}$ zeigt.

Der beschriebene Endpunkt-Assay wurde vor allem zur Messung der Aktivität von HDAC aus Rattenleber und humaner HDAC8 verwendet.

Aber auch Proben von Expressionskulturen oder Fraktionen aus der Chromatographie wurden im Hinblick auf HDAC-Aktivität untersucht, wobei standardmäßig ein leicht modifiziertes Pipettierschema befolgt wurde. 
Falls nicht anders angegeben setzte sich standardmäßig der Ansatz für einen HDACAssay wie folgt zusammen:

\section{- Für Umsatzkurven oder zur $\mathbf{K}_{\mathbf{M}}$-Bestimmung:}

$60 \mu \mathrm{L}$ Assay-Puffer

$10 \mu \mathrm{L}$ Zielenzym (HDAC)

$50 \mu \mathrm{L}$ Substrat, gelöst in Assay-Puffer

Abstoppen mit $80 \mu \mathrm{L}$ Trypsin/TSA-Stoplösung

- Zur Bestimmung des $\mathbf{I C}_{50}$ oder für das Screening:

$10 \mu \mathrm{L}$ HDACI, gelöst in Assay-Puffer

$50 \mu \mathrm{L}$ Assay-Puffer

$10 \mu \mathrm{L}$ Zielenzym (HDAC)

$50 \mu \mathrm{L}$ Substrat, gelöst in Assay-Puffer

Abstoppen mit $80 \mu \mathrm{L}$ Trypsin/TSA-Stoplösung

Puffer (und ggf. Inhibitor oder andere Agenzien) und Enzym (normalerweise bei HDAC aus Rattenleber 1:6 bzw. bei humaner HDAC8 1:4 in Assay-Puffer vorverdünnt) wurden normalerweise zusammen $10 \mathrm{~min}$ bei RT vorinkubiert, bevor die Reaktion mit der Substratzugabe gestartet wurde. Zur Inkubation für $60 \mathrm{~min}$ bei $30^{\circ} \mathrm{C}$ wurden die Meßplatten mit selbstklebender Folie abgedeckt und so Verdunstungseffekte minimiert. Das Auslesen der Fluoreszenzwerte erfolgte bei $30{ }^{\circ} \mathrm{C}$ in einem MTP-Fluoreszenzreader (Fluostar, BMG Labsystems) in 1minütigen Abständen für 50 min direkt nach dem Abstoppen bzw. für $10 \mathrm{~min}$, falls die Meßplatte nicht sofort vermessen wurde, sondern sich vorher für mind. 20 min bei RT entwickeln konnte. Entwicklung bedeutet in diesem Zusammenhang die völlige Spaltung des deacetylierten Produktes aus dem ersten Schritt des Assays durch Trypsin in der zweiten Stufe, so daß sich das Fluoreszenzniveau nicht weiter änderte.

Zur Durchmusterung von Fraktionen nach HDAC-Aktivität wurde der Standard-HDACAssay leicht modifiziert durchgeführt, indem $50 \mu \mathrm{L}$ Probe aus einer Fraktion mit $50 \mu \mathrm{L}$ Substrat $(300 \mu \mathrm{M}$ Boc-Lys(Ac)-AMC oder Tos-GPK(Ac)-AMC) für 60-120 min bei $30{ }^{\circ} \mathrm{C}$ in einem Kompartiment einer 96 well-MTP inkubiert wurden, bevor die Reaktion durch Zugabe von $100 \mu \mathrm{L}$ Trypsin/TSA-Stoplösung (mit $10 \mathrm{mg} / \mathrm{mL}$ bzw. $10 \mu \mathrm{g} / \mathrm{mL}$ Trypsin) beendet wurde.

Bei Fraktionen der HDAC8-Aufreinigung wurde $300 \mu \mathrm{M}$ Boc-Lys(Ac)-AMC in HDAC8-Puffer und $1 \mathrm{mg} / \mathrm{mL}$ Trypsin in TI-Puffer verwendet.

\subsubsection{7.b Einstufige Assay-Variante}


In bestimmten Fällen ermöglicht eine Resistenz des Zielenzyms gegen die Proteolyse durch das zugesetzte Trypsin die direkte Verfolgung der Enzymkinetik in einer kontinuierlichen, einstufigen Assay-Variante (Wegener et al., 2003b und Hildmann et al., 2004). Dieser Umstand wurde in dieser Arbeit zur Messung der Aktivität der FB188HDAH ausgenutzt.

\subsubsection{Synthese von Substraten}

Bei den Synthesen der verschiedenen Substrate wurden zwei Richtungen verfolgt: zum einen die Anforderungen der Proteine an strukturelle und stereochemische Beschaffenheiten des Substrats auszuloten hinsichtlich möglicher struktureller Motive für Inhibitoren und um mehr über die Substratspezifität der HDAC zu erfahren (Riester, D. et al., 2004), zum anderen sollten effizientere Substrate entstehen mit dem Ziel, den Assay hinsichtlich Umsatz und Menge an benötigtem Substrat zu optimieren.

\subsubsection{Synthese der Varianten von Boc-Lys-(Ac)-MCA}

Um die Anforderungen der Enzyme an die räumliche Beschaffenheit der Acylgruppe zu untersuchen, wurde der Acetylrest des Substrats durch folgende Gruppen ersetzt:

Propionyl-, Butyryl, Isobutyryl-, Pivaloyl-, Trifluoracetyl-, und Methansulfonyl- Rest.

\section{Methode}

Typische Ansatzgrößen waren 20-100 $\mu$ mol

$\operatorname{BocLys}\left(\varepsilon-\mathrm{SO}_{2} \mathrm{CH}_{3}\right)$-MCA

Die Synthese wurde durch Acylierung von BocLys-MCA (Bachem) mit einem Überschuss des entsprechenden Methansulfonsäureanhydrids und NMM als Base durchgeführt:

$70 \mu \mathrm{L}$ einer $1 \mathrm{M}$ Lösung von Methansulfonsäureanhydrid in DCM $(70 \mu \mathrm{mol})$ wurde eisgekühlt und in kleinen Portionen zu $16 \mu$ mol BocLys-MCA in $200 \mu \mathrm{L}$ DCM und $8 \mu \mathrm{L}$ NMM $(72 \mu \mathrm{mol})$ pipettiert, gemischt und $30 \mathrm{~min}$ bei $4^{\circ} \mathrm{C}$ gefolgt von $1 \mathrm{~h}$ bei RT geschüttelt, bevor man $50 \mathrm{mg}$ Aminomethyl-polystyrol Harz $(100 \mu \mathrm{mol})$ zum Abfangen des Überschusses an Anhydrid dazugab und $1 \mathrm{~h}$ weiterschüttelte. Dann wurde filtriert, mit DCM gewaschen und die vereinten Filtrate zu einem öligen Rückstand einrotiert. Die Reinigung erfolgte über LC-MS (RP-HPLC) mit dem $\mathrm{m} / \mathrm{z}$ des Molekülions als Triggersignal (Waters FractionLynx). Die Ausbeute betrug 58\% bei einer Reinheit von $>90 \%$. Das ESI-MS zeigte ein Molkülion $[\mathrm{M}+\mathrm{H}]^{+}$von 482,3 $\mathrm{m} / \mathrm{z}$, berechnet waren 482,5 $\mathrm{m} / \mathrm{z}$. Das Absorptionmaxima $\mathrm{UV}_{\max }$ lag bei $325 \mathrm{~nm}$.

BocLys(e-propionyl / -butyryl / -isobutyryl / -pivaloyl)-MCA 
Die Synthese der Substrate mit Propionyl-, Butyryl, Isobutyryl- und Pivaloyl-Rest wurde durch Anwendung der Carbodiimidmethode mittels des Kopplungreagenz EDC in $\mathrm{H}_{2} \mathrm{O}$ / $\mathrm{NaHCO}_{3} /$ Dioxan mit den entsprechenden freien Säuren durchgeführt.

Je $100 \mu \mathrm{mol}$ der Säure wurden in $300 \mu \mathrm{L}$ Wasser / Dioxan (1:1 v/v) gelöst und 1 eq EDC zugegeben. Dann wurden je $20 \mu \mathrm{mol}$ BocLys-MCA in $200 \mu \mathrm{L}$ Dioxan zupipettiert und der $\mathrm{pH}$ auf 6-7 durch Zugabe von $\mu \mathrm{L}$-Portionen einer $0.5 \mathrm{M} \mathrm{NaHCO} 3$ Lösung eingestellt. Bei Isobutyryl- und Pivaloyl-Resten wurde bis 50\% (v/v) Dioxan und 10\% DMF (v/v) zum vollständigen Lösen zugesetzt. Nach $1 \mathrm{~h}$ bei RT unter starkem schütteln wurden die Ansätze zweimal mit DCM extrahiert, die Extrakte eingeengt, in wenig DMSO aufgenommen und über LC-MS (RP-HPLC) mit dem $\mathrm{m} / \mathrm{z}$ des Molekülions als Triggersignal (Waters FractionLynx) gereinigt. Die Ausbeuten betrugen $60-85 \%$ bei einer Reinheit von $>90 \%$. Die ESI-MS zeigten die erwarteten Signale der entsprechenden Molkülionen $[\mathrm{M}+\mathrm{H}]^{+}$und Absorptionmaxima $\mathrm{UV}_{\max }$ bei $325 \mathrm{~nm}$.

$\operatorname{BocLys}(\varepsilon$-trifluoracetyl)-MCA

Bei der Synthese des Substrats mit Trifluoracetyl-Rest wurde zunächst DIC zur Aktivierung von Trifluoressigsäure TFA verwendet, aufgrund der geringen Ausbeute von maximal 60\% mit einem hohen Anteil eines nicht näher bestimmten Nebenproduktes wurde diese Reaktion später mit 5\% TFA-Methylester und 5\% Triethylamin in Methanol (v/v) durchgeführt, was in quantitativem Umsatz und Ausbeuten $>80 \%$ resultierte.

$50 \mu \mathrm{mol}$ BocLys-MCA (21 mg) wurden in $180 \mu \mathrm{L} \mathrm{MeOH}$ gelöst und dann $10 \mu \mathrm{L}$ TEA (71,4 $\mu \mathrm{mol} /$ 1,4 eq) und $10 \mu \mathrm{L}$ TFA-OMe $(83 \mu \mathrm{mol} /$ 1,6 eq) zugegeben. Nach einigen Minuten begann sich ein weißer Niederschlag zu bilden, es wurde weitere $3 \mathrm{~h}$ bei RT geschüttelt, dann überschüssiges $\mathrm{MeOH}$ abgezogen, der Rückstand in wenig DMSO aufgenommen und über LC-MS (RP-HPLC) mit dem $\mathrm{m} / \mathrm{z}$ des Molekülions als Triggersignal (Waters FractionLynx) gereinigt. Die Ausbeute betrug $80 \%$ bei einer Reinheit von $>90 \%$. Die ESI-MS zeigten die erwarteten Signale des entsprechenden Molkülions $[\mathrm{M}+\mathrm{H}]^{+}$von $500 \mathrm{~m} / \mathrm{z} \mathrm{UV}_{\max }$ bei $326 \mathrm{~nm}$

\section{Boc-D-Lys(Ac)-MCA und Boc-L-Orn(Ac)-MCA}

Je 1mmol Boc-D-Lys-OH und Boc-L-Orn-OH (Bachem) wurden mit je 10 eq $\mathrm{Ac}_{2} \mathrm{O}$ in DMF über wenig $\mathrm{Na}_{2} \mathrm{CO}_{3}$ acetyliert und über SPE zwischengereinigt und getrocknet. Die Umsetzung mit 7-AMC (Sigma) erfolgte durch Aktivierung von 0,1mmol der Säuren mit 2 eq DIC und Verwendung eines doppelten Überschusses an Säurekomponente gegenüber dem aromatischen Amin (0,5 eq AMC) in DMF / NMP 1:1 (v/v) üN bei RT. Dann wurde das doppelte Volumen des Ansatzes an Wasser zugegeben und zweifach mit DCM extrahiert und einrotiert. Der Rückstand wurde in wenig DMSO aufgenommen und über LC-MS (RP-HPLC) mit dem $\mathrm{m} / \mathrm{z}$ des Molekülions als Triggersignal (Waters FractionLynx) gereinigt. Nach dieser Reinigung konnten noch etwa $2 \%$ freies 7-AMC $\left(176,1 \mathrm{~m} / \mathrm{z}\right.$ bei $\left.\mathrm{UV}_{\max } 346 \mathrm{~nm}\right)$ detektiert werden, weshalb die Reinigung wiederholt wurde. Die Ausbeuten betrugen 35 und $40 \%$ bei einer Reinheit von $>90 \%$. Die ESI-MS zeigten die erwarteten Signale des entsprechenden Molkülions $[\mathrm{M}+\mathrm{H}]^{+}, \mathrm{UV}_{\max }$ bei $325 \mathrm{~nm}$. 


\subsubsection{Tos-Gly-Pro-Lys(Ac)-MCA und Varianten}

Neben Tos-Gly-Pro-Lys(Ac)-MCA wurden die Tripeptidyl-Varianten Ac-Arg-GlyLys(Ac)-MCA, Ac-Gly-Gly-Lys(Ac)-MCA, Ac-Leu-Gly-Lys(Ac)-MCA und Ac-GlyAla-Lys(Ac)-MCA hergestellt

\section{Methode}

Die Synthese wurde so durchgeführt, daß von käuflichem Boc-Lys(Ac)-MCA die BocSchutzgruppe mit 50\% TFA / DCM über $1 \mathrm{~h}$ bei RT entfernt und eine Zwischenreinigung per HPLC (Waters 2790HT) oder über Festphasenextraktion (SPE) mit C18-Kartuschen (Phenomenex, Aschaffenburg) durchgeführt wurde, um die nach azeotroper Entfernung mit Hexan verbliebene TFA zu entfernen. Die entsprechenden „N-terminalen“ Dipeptide Ac-Arg-Gly-OH, Ac-Gly-Gly-OH, Ac-Leu-Gly-OH Ac-Gly-Ala-OH wurden auf Glybzw. Ala-2-chlorotritylchloridharz (Novabiochem, Läufelfingen, Schweiz) nach FmocStandardsyntheseprotokoll (AAV 1) synthetisiert, der entschützte Aminoterminus mit 2,5 $\% \mathrm{Ac}_{2} \mathrm{O} / 2,5 \%$ DIPEA in DMF (v/v) acetyliert, abgespalten (10\% TFA / DCM v/v) und ebenfalls über SPE entsalzt und getrocknet. Die resultierenden Säuren wurde mit $\mathrm{H}_{2} \mathrm{~N}$ Lys(Ac)-MCA mit 1,5 eq EDC in Dioxan / Wasser bei neutralem pH $\left(\mathrm{NaHCO}_{3}\right)$ umgesetzt, um Kopplungsreagenzien vor der Endreinigung über HPLC durch FlüssigFlüssig-Extraktion weitgehend zu entfernen. Im Fall von Tos-Gly-Pro-OH (Bachem, Schweiz) war ein schlechter Umsatz zu beobachten, der nach Aktivierung mit TBTU / NMM (1 eq / 3 eq) gesteigert werden konnte. Im Falle von Ac-Arg-Gly-Lys(Ac)-MCA wurde vor der Endreinigung noch die Pbf-Schutzgruppe der Guanidinfunktion mit 95\% TFA, 2,5\% TIPS und DCM über $2 \mathrm{~h}$ abgespalten und TFA abrotiert.

Typische Ansatzgrößen waren 20-100 $\mu$ mol, die Ausbeuten lagen bei $50-80 \%$.

\subsubsection{Synthese von Inhibitoren}

\subsubsection{Synthese von Hydroxamaten}

Synthetisiert wurden

- Aminohydroxamsäuren: alle 20 proteinogenen Aminosäuren als Hydroxamate

- Valproinhydroxamsäure

- SAHA und Analoge

\section{Material}


Verwendung fanden N-Fmoc-hydroxylamin-2-chlorotrityl-Harz (Novabiochem 01-640165), die Abspaltung konnte mit verdünnter TFA erfolgen und Hydroxylamin-WangHarz (Novabiochem 01-64-0454), Abspaltung mit TFA / DCM / Wasser 70:28:2 v/v (Mellor et al., 1997, Floyd et al., 1996).

\title{
Methode
}

Synthese an Festphase

Die Synthese von Hydroxamsäuren aus den entsprechenden Carbonsäurederivaten wurde bevorzugt an Festphase durchgeführt, um arbeits- und zeitaufwendige Aufreinigungen des Endproduktes zu vermeiden.

\begin{abstract}
Aminohydroxamsäuren und Valproinhydroxamsäure
Unter Verwendung von N-Fmoc-hydroxylamin-2-chlorotrityl-Harz wurden die 20 proteinogenen Aminosäuren sowie Valproinsäure in Hydroxamate umgewandelt und auch einige SAHA-Analoge hergestellt. Das Harz wurde $1 \mathrm{~h}$ vor der weiteren Verwendung in DCM gequollen, bevor die Fmoc-Schutzgruppe entfernt wurde (40\% Piperidin / DMF, $2 \times 10$ min, dann $6 \times$ waschen mit DMF) und die 1M in DMF / NMP gelösten (Fmoc-Amino- oder Valproin-) Säuren, die zuvor durch Zugabe von 1 eq DIC / HOAt 5 min bei RT aktiviert wurden, in 5 fachem Überschuss bezgl. der Beladung des Harzes zugegeben wurden. Dieser Schritt wurde einmal wiederholt, Reaktionsdauer je $3 \mathrm{~h}$ bei RT. Die Ansatzgröße betrug je $20 \mu \mathrm{mol}$, Reinheiten in Bezug auf das Verhältnis Säure / Hydoxamsäure (wegen fehlender Retention bei RP-HPLC mit MS bestimmt) zwischen $70-90 \%$.
\end{abstract}

Kombinierte Synthese in Lösung und auf Festphase

In manchen Fällen erwies sich dieser kombinierte Ansatz als schnell durchzuführende Alternative.

\section{SAHA und Analoge}

Bei der Synthese von Suberoylanilid-Hydroxamat SAHA, Suberoyl-[Glycyl]-hydroxamat und Suberoyl-[p-Amido-benzoesäure]-hydoxamat wurden zunächst 1 eq der tertButylester von Glycin und p-Aminobenzoesäure (Fluka) bzw. Anilin mit 1,2 eq Korksäuremonoethylester (Lancaster 4272) und 1,2 eq DIC (je $1 \mathrm{M}$ in DCM) bei $4^{\circ} \mathrm{C}$ umgesetzt, wobei sich Diisopropylharnstoff abschied. Nach Zentrifugation wurde der Überstand entnommen und einrotiert. Die Ethylester wurden dann mit 2,5 eq $\mathrm{NaOH}$ in $\mathrm{EtOH} / \mathrm{H}_{2} \mathrm{O} 5: 1 \mathrm{v} / \mathrm{v}$ üN abgespalten und die Zwischenprodukte per SPE gereinigt und getrocknet. Dann wurden die Säuren wie oben 1M in DMF / NMP gelöst, durch Zugabe von 1 eq DIC / HOAt 5 min bei RT aktiviert und in je 5 fachem Überschuss (bezgl. der Beladung) dem entschützten Harz zugegeben. Dieser Schritt wurde einmal wiederholt, Reaktionsdauer je 3h bei RT. Schließlich wurden die Produkte mit TFA / DCM / Wasser 70:28:2 v/v vom Harz abgespalten und simultan die tert-Butylester gespalten. Die Ausbeuten betrugen 50-65 \% bei einer Reinheit von wenigstens 85\%. 
Synthese in Lösung

SAHA wurde als Referenzsubstanz in größerer Menge benötigt und wie folgt hergestellt: $405 \mathrm{mg}$ ( $2 \mathrm{mmol}$ ) Korksäuremonoethylester (Lancaster 4272) werden in $5 \mathrm{~mL}$ DCM und $0,5 \mathrm{~mL}$ TEA gelöst auf $4^{\circ} \mathrm{C}$ gekühlt. Dann werden tropfenweise $320 \mu \mathrm{L}(1,2 \mathrm{eq}, 2,4$ mmol) kaltes Isobutylchloroformat (Fluka) zugegeben, worauf sich eine Suspension bildet. Den Ansatz ließ man unter starkem schütteln auf RT erwärmen und gab $180 \mathrm{mg}$ (1eq, $2 \mathrm{mmol}$ ) Anilin und weitere $360 \mu \mathrm{L}$ TEA (1,3 eq, 2,6 mmol) in $2 \mathrm{~mL}$ DCM langsam zu. Es wurde 15 min bei offenem Gefäß weiter geschüttelt, wobei die Lösung klar wurde. Nach Zugabe von $10 \mathrm{~mL}$ EtOH wurde bis zum öligen Rückstand einrotiert, in $5 \mathrm{~mL}$ EtOH aufgenommen und $200 \mathrm{mg} \mathrm{NaOH}$ (2,5 eq, $5 \mathrm{mmol}$ ) zugegeben und $2 \mathrm{~h}$ refluxiert. Danach wurde der Ansatz auf RT abgekühlt, mit verdünnter $\mathrm{HCl}$ neutralisiert (pH-Papier) und mit 3 x $50 \mathrm{~mL}$ DCM extrahiert. Nach Trocknen über $\mathrm{MgSO}_{4}$ üN wurde einrotiert, in $10 \mathrm{~mL}$ DCM und 0,6 mL TEA (2,1 eq, 4,2 mmol) aufgenommen, erneut auf $4^{\circ} \mathrm{C}$ gekühlt und $320 \mu \mathrm{L}$ kaltes Isobutylchloroformat (1,2 eq, 2,4 mmol) zugegeben.

$350 \mathrm{mg}(2,5 \mathrm{eq}, 5 \mathrm{mmol})$ Hydroxylamin* $\mathrm{HCl}$ (Fluka) wurden inzwischen unter Erwärmen in $1 \mathrm{~mL}$ DMF und $120 \mu \mathrm{L}$ TEA $(0,85 \mathrm{mmol})$ gelöst und langsam unter Rühren

dem Ansatz zugegeben. Es wurde $3 \mathrm{~h}$ bei RT weitergerührt, dann mit verdünnter $\mathrm{HCl}$ angesäuert und mit DCM extrahiert. Die Extrakte wurden einrotiert und das Produkt in Wasser umkristallisiert.

Ausbeute 278mg (53\%), Reinheit 92\%, m/z 265,2 (berechnet 265,15 für $\mathrm{C}_{14} \mathrm{H}_{20} \mathrm{~N}_{2} \mathrm{O}_{3}$ ).

\subsubsection{Synthese von Tripeptiden mit verschiedenen Lysyl-Resten}

Für das Screening nach Sequenzmotiven von inhibitorisch wirksamen Substanzen wurde eine kleine, 480 Substanzen umfassende Bibliothek von Tripeptiden hergestellt, die alle eines von fünf verschiedenen Lysinderivaten enthielten, das an der $\varepsilon$-Aminfunktion des Lysins verändert war und bei denen das verbliebene Dipeptid variiert wurde, sodaß fünf Teilbibliotheken mit je 96 Substanzen generiert wurden.

\section{Material}

Die verwendeten Lysinabkömmlinge (Ein-Buchstaben-Code mit Klammern) waren:
1. Acrylsäurerest
2. Mercaptobernsteinsäurerest
3. Harnstoffrest
4. Formylrest
5. Nicotinoylrest

(C), (F) und (N) sind als Fmoc-geschützte Derivate kommerziell erhältlich (Bachem), die Derivate (A) und (M) wurden aus Fmoc-Lys(Mtt)-OH (Novabiochem) hergestellt.

Die eingesetzten 20 Aminosäuren für die Generierung der Dipeptidsequenz waren: (EinBuchstaben-Code ohne Klammern) 
1. A 4-Phenylpiperidin4-carbonsäure (Neosystem, Strasbourg, France)

2. R D-Histidin (Novabiochem)

3. N Tetrahydroisoquinolin-3-carbonsäure (Novabiochem)

4. D Asparaginsäure (Novabiochem)

5. C 3-Pyridyl-D-Alanin (Neosystem, Strasbourg, France)

6. Q Glutamin (Novabiochem)

7. E Glutaminsäure (Novabiochem)

8. G Allyl-Glycin (Neosystem, Strasbourg, France)

9. $\mathrm{H}$ Histidin

10. I Isoleucin

11. L Thienylalanin

12. K Lysin

13. M Methionin

14. F D-Phenylalanin

15. P Prolin

16. S Serin

17. $\mathrm{T}$ Threonin

18. W Tryptophan

19. $\mathrm{Y}$ Tyrosin

20. V Valin (alle Novabiochem)

\section{Methode}

Die Sub-Bibliotheken (A) und (M) wurden auf mit Fmoc-Lys(Mtt)-derivatisiertem RinkAmid-Harz, hergestellt, sodaß hier der abgeänderte Lysylrest C-terminal steht, während bei $(\mathrm{C}),(\mathrm{F})$ und $(\mathrm{N})$ zuerst die Dipeptide aufgebaut wurden und dann die entsprechenden Lysinderivate gekoppelt wurden, somit $\mathrm{N}$-terminal stehen.

Für die Synthese der Dipeptidsequenz wurden zuerst spaltenweise die Aminosäuren 1 bis 12 gekoppelt, dann folgten reihenweise die restlichen acht Aminsäuren (13 bis 20), sodaß sich folgendes Raster in einem 8 x 12 MTP-Format ergab:

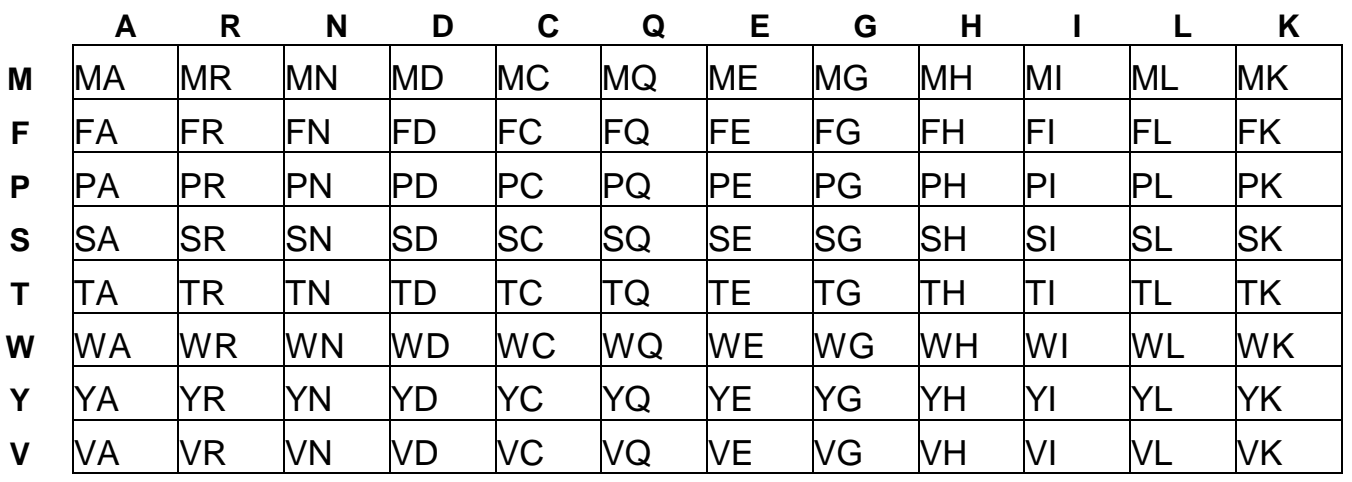


Alle Aminosäurekopplungen (Ansatzgröße von $2 \mu \mathrm{mol}$ ) wurden nach dem FmocStandardsyntheseprotokoll (AAV 1) durchgeführt, d.h. die gesamte Synthese der SubBibliotheken $(\mathrm{C}),(\mathrm{F})$ und $(\mathrm{N})$.

Für die Herstellung von (A) und (M) wurde nach Aufbau des Vorläufer-Tripeptids die 4Methyltrityl-Schutzgruppe vom Lysylrest mit je 3 x $100 \mu \mathrm{L}$ 4\% iger TFA / DCM über 30 min bei RT abgespalten (Park \& Burgess, 2001) und mit 5\% TFA gefolgt von DCM, DMF, 5\% DIPEA in DMF und DMF (je $100 \mu \mathrm{L}$ ) nachgewaschen. Dann wurde mit je 10 eq $(20 \mu \mathrm{mol})$ Acrylsäure bzw. Mercaptobernsteinsäure und 5 eq DIC, beides gelöst in DCM bei $4^{\circ} \mathrm{C}$, über $1 \mathrm{~h}$ bei RT umgesetzt, das Monitoring erfolgte über den Kaiser-Test (Kaiser et al., 1970) von einigen entnommenen Harz-Proben.

\subsubsection{Synthese einer Benzamid-Bibliothek aus MS275-Derivaten}

\section{MS275}

CAS 209783-80-2

$\mathrm{N}$-(2-Aminophenyl)-4-[N-(pyridin-3-yl-methoxycarbonyl)aminomethyl]benzamid

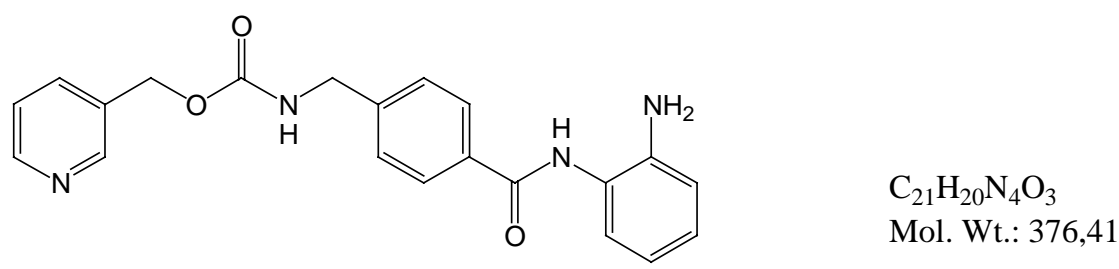

\section{Struktur von MS275}

Diese Molekül ist mit einem $\mathrm{IC}_{50}$-Wert von $2 \mu \mathrm{M}$ (Saito et al., 1999) nicht besonders potent, ist aber der erste HDAC-Inhibitor, der oral appliziert aktiv gegen Krebs im Tiermodell wirkte und keine ernsten Nebenwirkungen beobachtet wurden (Suzuki et al., 1999). Auch aufgrund des fehlenden Hydroxamats ist die Substanz interessant, da damit synthetisch und mechanistisch Wege zu neuen Verbindungen eröffnet werden könnten.

\section{Methode}

In einem parallelen Syntheseansatz einer kleinen, 24 Moleküle umfassenden Bibliothek von Verbindungen sollte die Struktur-Wirkungsbeziehung hinsichtlich des Austausches von Mittel- und Kopfteil unter Beibehaltung der vermuteten Bindungstelle am Phenylendiaminring untersucht werden. Für den Mittelteil wurden fünf und den Kopfteil 3 strukturell dem Originalmolekül ähnliche Substituenten gewählt und die Synthese mit an Festphase immobilisiertem Phenylendiamin durchgeführt.

Phenylendiamin wurde in DMF / DCM 1M gelöst und in 10 Äquivalenten Überschuß zu 2-Chloro-Trityl-chlorid-Harz (Novabiochem 01-64-0114; 1,6mmol/g Beladung) und nach Zugabe von 10 eq TEA üN sanft geschüttelt. Das Harz verfärbte sich von gelblich zu 
gelbbraun. Nach Filtration und Waschen mit DMF wurde das Harz (Beladung 1,4 $\mathrm{mmol} / \mathrm{g}$, bestimmt nach Derivatisierung mit Fmoc-Aminosäure und Quantifizierung des Fmoc-Chromophors) a $10 \mu \mathrm{mol}$ auf 24 Wells eines 96 Well-Syntheseblockes $(500 \mu \mathrm{L}$ Einzelvolumen, mit Fritte versehen) verteilt und mit 5eq der nachfolgenden, Fmocgeschützten Aminosäuren unter Aktivierung mit 5eq TBTU und Zugabe von 15 eq NMM acyliert. Dieser Schritt wurde doppelt mit $2 \mathrm{~h}$ Reaktionszeit bei RT ausgeführt. Nach Abspalten der Fmoc-Schutzgruppe mit 25\% Piperidin in DMF und sechsfachem Waschen mit DMF gefolgt von dreimal DCM wurden 10 eq der Carbonylimidazol-aktivierten Kopfgruppe (0.5 M in Dioxan / DCM 1:1 v/v) zugegeben und üN reagieren lassen. Die Aktivierung der Hydroxlgruppen der Kopfgruppen mit Carbonyldiimidazol war tags zuvor vorbereitet worden, indem die Hydroxylkomponenten mit 1 eq Carbonyldiimidazol $1 \mathrm{M}$ in Dioxan gelöst worden waren und üN sich das aktivierte Hydroxyl bilden konnte (Kontrolle per LC-MS). Eine Zwischenreinigung war nicht nötig. Das Monitoring der Bildung dieses Carbamatsäureesters erfolgte durch die Ninhydrin-Reaktion (Kaiser-Test). Die Harze wurden dann, nach negativem Kaiser-Test mit DMF, gefolgt von tBME gewaschen und getrocknet und die Produkte schließlich mit je dreimal $100 \mu \mathrm{L}$ 5\% TFA in DCM vom Harz in eine $2 \mathrm{~mL}$ Deep-Well-MTP abgespalten, ein Aliquot von $5 \mu \mathrm{L}$ für die Analytik entnommen und mit Hexan die überschüssige TFA als Azeotrop im Rotationsvakuumverdampfer (Christ, Osterode) entfernt. Für die nachfolgenden Assays wurden die Produkte in einer Konzentration von $50 \mathrm{mM}$ in DMSO gelöst.

\subsubsection{Synthese von Derivaten der Kojisäure}

Kojisäure (Abb. 12) oder [5-hydroxy-2-(hydroxymethyl)-4H-pyran-4-on] ist ein bekannter Inhibitor der Tyrosinase (Kahn et al., 1995), eines kupferhaltigen Proteins. In der Struktur dieses Naturstoffes kann man auch ein mögliches Bindungsmotiv für Zinkhaltige HDAC vermuten. Zur Klärung dieser Frage wurden einige chemische Synthesen für die Herstellung von Kojisäure-Derivaten durchgeführt.

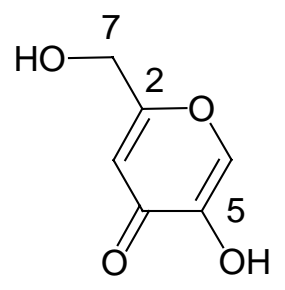

Kojisäure

\section{Struktur von Kojisäure}

\section{Material}

Kojisäure (Lancaster Nr. 3971, Frankfurt) 
Carbonyldiimidazol CDI (Fluka)

Tetrahydrofuran THF (Fluka)

Chemikalien und Reagenzien der Peptidsynthese (AAV 1)

BAM: Bis-(aminomethyl)-benzene-Trityl Harz (Novabiochem 01-64-0140)

BA: 4-(aminomethyl)-benzylalkohol-Trityl Harz (Novabiochem 01-64-0161)

\section{Methode}

Für die Festphasensynthese von 96 Kojisäure-Derivaten wurde zunächst je $2 \mu$ mol BAMund BA- Tritylharzes, suspendiert in DCM / DMF 3:2, in je die Hälfte (2 x 48 wells) einer Syntheseplatte verteilt. Dann wurden die ausgewählten Aminosäuren mit Standardmethoden gekoppelt (AAV 1) und vor der Zugabe der aktivierten Kojisäure entschützt.

Die Aktivierung der Kojisäure erfolgte getrennt davon. $142 \mathrm{mg}$ (1mmol) Kojisäure und $154 \mathrm{mg}$ CDI $(0,95 \mathrm{mmol})$ wurden in $4 \mathrm{~mL}$ THF gelöst und üN bei RT geschüttelt. Der entstandene weiße Rückstand wurde zentrifugiert, THF dekaniert, in frischem THF bei $4^{\circ} \mathrm{C}$ suspendiert, filtriert und getrocknet (Ausbeute 85\%, MS entspricht).

Der Rückstand wurde in $5 \mathrm{~mL}$ NMP unter Erwärmen gelöst und in $100 \mu \mathrm{L}-$ Portionen in jedes well der Syntheseplatte pipettiert (je 8,2 $\mu \mathrm{mol} / 4,1$ eq) und 3h bei RT belassen. Dann wurde abgesaugt, mehrfach mit NMP / DMF / MeOH gewaschen und die Harze unter Vakuum getrocknet.

Die Abspaltung vom Harz und der Aminosäureschutzgruppen erfolgte mit TFA nach der Standardmethode (AAV 1). Nach Entfernen der TFA wurden die Produkte in je 50 $\mu \mathrm{L}$ DMSO aufgenommen zur weiteren Verwendung. 


\subsection{Ergebnisteil Thrombin-Inhibitoren}

Im Folgenden werden die Ergebnisse aus der Entwicklung direkter Thrombin-Inhibitoren vorgestellt. Der erste Teil widmet sich dabei der Beurteilung von Hirudin-Varianten hinsichtlich ihrer Resistenz gegen Proteolyse (3.1.1.), die folgenden Abschnitten zeigen die Ergebnisse aus der Wirkstoffsuche niedermolekularer Inhibitoren, wobei ein im Arbeitskreis zusammen mit der Firma Novel Science Int. GmbH (Dr. M. Thürk) entwickeltes Verfahren des Computer-unterstützten Wirkstoffdesigns eingesetzt wurde, wobei zunächst innerhalb kurzer Zeit Moleküle mit sich stetig verbessernder inhibitorischer Wirkung entwickelt werden sollten (3.1.2.).

Ein verbessertes Entwicklungsverfahren wurde dann bei der gleichzeitigen Optimierung mehrerer Parameter angewandt (3.1.3.), um unerwünschte Eigenschaften der Substanzen von vorne herein zu kontrollieren und auszuschließen. Die aus dieser MultiparameterOptimierung resultierende Leitstruktur (3.1.3.2.) wurde dann umfangreichen kinetischen (3.1.3.3.) und kristallographischen (3.1.3.4.) Untersuchungen unterzogen und auch ersten Tests am Tiermodell (3.1.3.5.) unterzogen, um ihre Eignung als Wirkstoffkandidat zu beurteilen.

\subsubsection{Resistenz von Hirudin-Varianten gegen proteolytischen Verdau}

Innerhalb des Arbeitskreises widmete sich ein Forschungsprojekt der evolutiven Optimierung von Hirudin mit dem Ziel einer Protease-resistenten Variante des Moleküls. Hirudin ist ein aus dem Speichelsekret des Blutegels Hirudo medicinalis isoliertes Polypeptid (Markwardt et al., 1957), das als direkter und spezifischer Thrombininhibitor eine bemerkenswert hohe Bindungsaffinität (Dissoziationskonstante 20-200 fM, Braun et al., 1988) aufweist. Klinische Anwendung findet der Hirudin-Abkömmling Lepirudin bei heparin-induzierter Thrombozytopenie. Nachteilig ist die kurze Halbwertszeit, die eine relativ hohe Dosierung in kurzer Frequenz verlangt (Poschel et al., 2000). Verantwortlich hierfür ist u.a. der Abbau durch Proteasen mit Pepsin- und Chymotrypsinartiger Spezifität (Zinchenko et al., 1976, Kasper et al., 1975) an den Sequenzpositionen Phe ${ }^{56}-\mathrm{Glu}^{57}$ und $\mathrm{Tyr}^{63}$ Leu $^{64}$.

Mit Hilfe eines kombinierten Ansatzes aus Phage-Display- und HochdurchsatzScreening-Methoden konnten im Arbeitskreis Hirudin-Varianten isoliert werden, die an verschiedenen Positionen Aminosäuresubstitutionen aufwiesen (Wirsching et al., 1997 / Abb.9). Die Aufgabe bestand darin, nachzuweisen, wie sich diese Hirudin-Varianten im proteolytischen Verdau verhielten mit der Zielsetzung, einer schnellen enzymatischen Degradation bzw. Elimination entgegenzuwirken unter Beibehaltung der enormen Potenz.

Dazu wurden zunächst Peptide hergestellt, die aus den Sequenzen der Positionen 46-65 des Wildtyp-Hirudins und der entsprechenden Sequenz der isolierten Variante A6.6- $\mathrm{H}^{56}$ mit dem Austausch von Phe ${ }^{56}$ durch $\mathrm{His}^{56}$ sowie Glu ${ }^{62}-\mathrm{Tyr}^{63}$-Leu $^{64}$ durch $\mathrm{Pro}^{62}$-Pro ${ }^{63}$ - 
His $^{64}$ ) bestanden (2.2.1.), da letztgenannte Variante die höchste thrombininhibitorische Aktivität der isolierten Hirudinvarianten aufwies. Die Peptide wurden Pepsin und Chymotrypsin ausgesetzt und die Spaltprodukte mittels Reversed-phase-HPLC-MS (ESIMS; Waters/MassLynx) analysiert (Abb. 13).
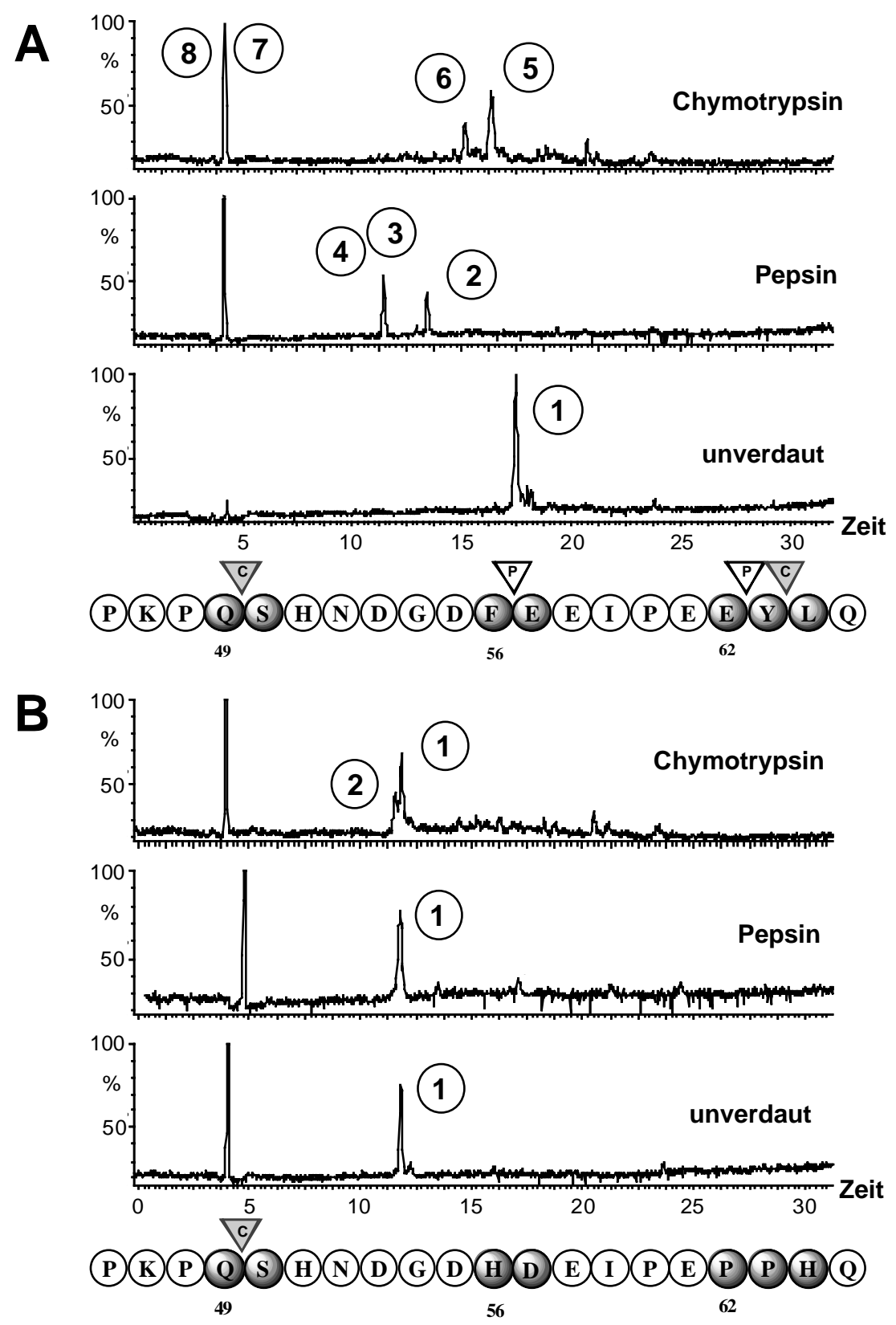

\footnotetext{
Abbildung 13: Protease-Verdau von Peptiden. (A) Wildtyp, (B) Variante A6.6-H ${ }^{56}$ Obere Chromatogramme: 24 h Chymotrypsin-, mittlere Chromatogramme: 24 h Pepsin-Verdau Untere Chromatogramme: Kein Verdau (Inkubation ohne Enzym, Referenz)

Sequenz und Spaltstellen der Peptide sind unter den Chromatogrammen eingefügt.
} 
Während das Wildtyppeptid im Bereich der Positionen 45-65 jeweils 2 Spaltstellen für Pepsin (Pos.56/57 und 62/63) als auch Chymotrypsin (Pos. 49/50 und 63/64) aufweist, zeigt das entsprechende Peptid der Variante A6.6- $\mathrm{H}^{56}$ nur noch eine (Chymotrypsin) Spaltstelle zwischen Pos. 49 und 50. Demnach waren beim Wildtyp (A) bei vollständigem Verdau mit jeder einzelnen Protease drei Fragmente, bei der Variante (B) nur beim Verdau mit Chymotrypsin zwei Fragmente zu erwarten.

Die Auswertung der Spektren aus den Signalen 1 - 8 der Chromatogramme (Abb. 13) ermöglichte eine Zuordnung zu folgenden Peptiden (Tab.3):

Tabelle 3: $\quad$ Signalzuordnungen der LC-MS Analyse zu Peptidfragmenten

\begin{tabular}{|c|l|l|l|}
\hline $\begin{array}{l}\text { Signal-Nr. } \\
\text { Protease }\end{array}$ & $\begin{array}{l}\text { MG exp } \\
{[\mathrm{g} / \mathrm{mol}]}\end{array}$ & $\begin{array}{l}\mathbf{M G}_{\text {berechnet }}[\mathrm{g} / \mathrm{mol}] \\
\mathbf{( A )}\end{array}$ & Sequenz \\
\hline $\begin{array}{c}\mathbf{1} \\
\text { unverdaut }\end{array}$ & 2372,4 & 2371,5 & Wildtyp-Sequenz 46-65 \\
\hline $\begin{array}{c}\mathbf{2} \\
\text { Pepsin }\end{array}$ & 744,7 & 744,8 & H-Pro-Lys-Pro-Gln-Ser-His-Asn-Asp-Gly-Asp-Phe-Glu-Glu- \\
\hline $\begin{array}{c}\mathbf{3} \\
\text { Ile-Pro-Glu-Glu-Tyr-Leu-Gln-NH }\end{array}$
\end{tabular}

Die experimentell bestimmten Molekulargewichte $\mathrm{MG}_{\text {exp }}$ sind aus den erhaltenen $\mathrm{m} / \mathrm{z}$-Signalen der Massenspektren durch Multiplikation mit $\mathrm{z}$ und Subtraktion von $\mathrm{z}(\mathrm{MG}=(\mathrm{m} / \mathrm{z} * \mathrm{z})-\mathrm{z})$ umgerechnet.

Die grün unterlegten Sequenzen entsprechen den erwarteten Spaltprodukten. 
Die erwarteten Spaltprodukt konnten identifiziert werden (Tab.3, grün unterlegt), zusätzlich wurde beim Wildtyp (A) ein Fragment gefunden, das unvollständig von Chymotrypsin an dessen Spaltstelle in Position 49/50 verdaut worden war. Auch bei der Variante A6.6- $\mathrm{H}^{56}$ konnte ein entsprechendes Verhalten gegenüber Chymotrypsin festgestellt werden, die Spaltung an Pos. 49/50 ist nach selbst 24 stündiger Inkubation mit dem Enzym unvollständig, etwa 70\% bleiben unverdaut (Signal 1 in Abb.13, B, oberes Chromatogramm).

Aus diesem Grund wurden weitere A 6.6-Varianten der gemeinsamen Sequenz A.6.6 $\left(\mathrm{Phe}^{56}\right.$-Asp ${ }^{57}$ Pro $^{62}$-Pro ${ }^{63}$-His ${ }^{64}$ ), jedoch mit einem weiteren Austausch an der Position 49/50, hergestellt (Wirsching et al., 2003) und auf ihre Resistenz gegenüber Pepsin und Chymotrypsin untersucht.

Die zusätzliche Einführung von $\mathrm{P}^{50}$ schließlich verhinderte auch die Spaltung an Position 49/50 (Tab. 4).

Tabelle 4: Charakterisierung von Varianten des Hirudinabkömmlings A.6.6 (Phe ${ }^{56}$-Asp ${ }^{57}$ Pro $^{62}$-Pro ${ }^{63}-\mathrm{His}^{64}$ )

\begin{tabular}{|c|c|c|c|c|c|c|c|}
\hline \multirow[t]{2}{*}{ Klon \# } & \multicolumn{2}{|c|}{$\begin{array}{c}\text { Sequenz an der } \\
\text { Hirudin- } \\
\text { Positionen: }\end{array}$} & \multirow{2}{*}{$\begin{array}{l}\text { Thrombin } \\
\text { Inhibition } \\
\text { IC }_{50}[\mathrm{pM}]\end{array}$} & \multicolumn{2}{|c|}{$\begin{array}{l}\text { Resistenz } \\
\text { gegen } \\
\text { Pepsin }^{a}\end{array}$} & \multicolumn{2}{|c|}{$\begin{array}{l}\text { Resistenz gegen } \\
\text { Chymotrypsin }^{a}\end{array}$} \\
\hline & 49 & 50 & & $1 \mathrm{~h}$ & $24 \mathrm{~h}$ & $1 \mathrm{~h}$ & $24 \mathrm{~h}$ \\
\hline HV1-WT & Gln & Ser & 180 & Nein & - & Nein & - \\
\hline A6.6 & Gln & Ser & 720 & Nein & - & Nein & - \\
\hline A6.6- $\mathrm{H}^{56}$ & Gln & Ser & 32000 & $\mathrm{Ja}$ & $\mathrm{Ja}$ & Nein & - \\
\hline A6.6- $H^{56}-P^{49}-R^{50}$ & Pro & Arg & 44000 & $\mathrm{Ja}$ & $\mathrm{Ja}$ & $\mathrm{Ja}$ & $\mathrm{Ja}$ \\
\hline $\mathrm{A} 6.6-\mathrm{H}^{56}-\mathrm{Q}^{49}-\mathrm{P}^{50}$ & Gln & Pro & 20000 & $\mathrm{Ja}$ & $\mathrm{Ja}$ & $\mathrm{Ja}$ & $\mathrm{Ja}$ \\
\hline
\end{tabular}

${ }^{a}>50 \%$ Aktivität nach Inkubation mit $0.1 \mu \mathrm{g} / \mu 1$ des bezeichneten Enzyms (Endkonzentration) für die angegebene Zeit.

Erkauft wird die vollständige Resistenz gegen Pepsin und Chymotrypsin durch einen teilweisen Verlust der inhibitorischen Aktivität gegenüber Thrombin, d.h. eine Steigerung des $\mathrm{IC}_{50}$ um etwa den Faktor 100.

Der Befund, einen proteaseresistenten und mit einem $\mathrm{IC}_{50}$ von $20 \mathrm{nM}$ immer noch recht potenten Thrombininhibitor gefunden zu haben, ermutigt zu weiteren Entwicklungen auf diesem Gebiet. Neue Thrombininhibitoren mit verbesserten Eigenschaften zu entwickeln ist auch Gegenstand der folgenden Absätze. 


\subsubsection{Entwicklung von Thrombin-Inhibitoren bei 1-Parameter- Optimierung}

Ziel war es, den ,proof-of-concept“ für das Verfahren des im Arbeitskreis zusammen mit der Firma Novel Science Int. GmbH (Dr. M. Thürk) entwickelten Computer-unterstützten Wirkstoffdesigns zu erbringen (Kamphausen et al., 2002). Dieses Verfahren wurde zunächst für die Entwicklung von peptidischen Thrombininhibitoren eingesetzt, bei denen als einzige Eigenschaft die inhibitorische Wirkung auf Thrombin verbessert werden sollte (sogenannte 1-Parameter-Optimierung).

Ausgehend von zufällig ausgewürfelten Peptidsequenzen in einem Startset von 192 Verbindungen (Zyklus 0) wurden 4 Designzyklen (2.2.2., Abb.10) mit jeweils etwa 128 Verbindungen gefahren. Ein Zyklus bestand jeweils aus Synthese, Bestimmung der Wirkung (Amidolytischer Thrombinassay, AAV 2) und algorithmischer Prozessierung der Daten, wobei durch den Computer eine Art Struktur-Funktionsmodell erzeugt wird, auf dessen Basis die neuen Substanzen (Zyklus 1) vorgeschlagen wurden. Nach dem 4. Zyklus wurde ein Peptid (NSCI 521) mit einem $\mathrm{K}_{\mathrm{i}}$-Wert von $297 \mathrm{nM}$ identifiziert (Abb. 14).

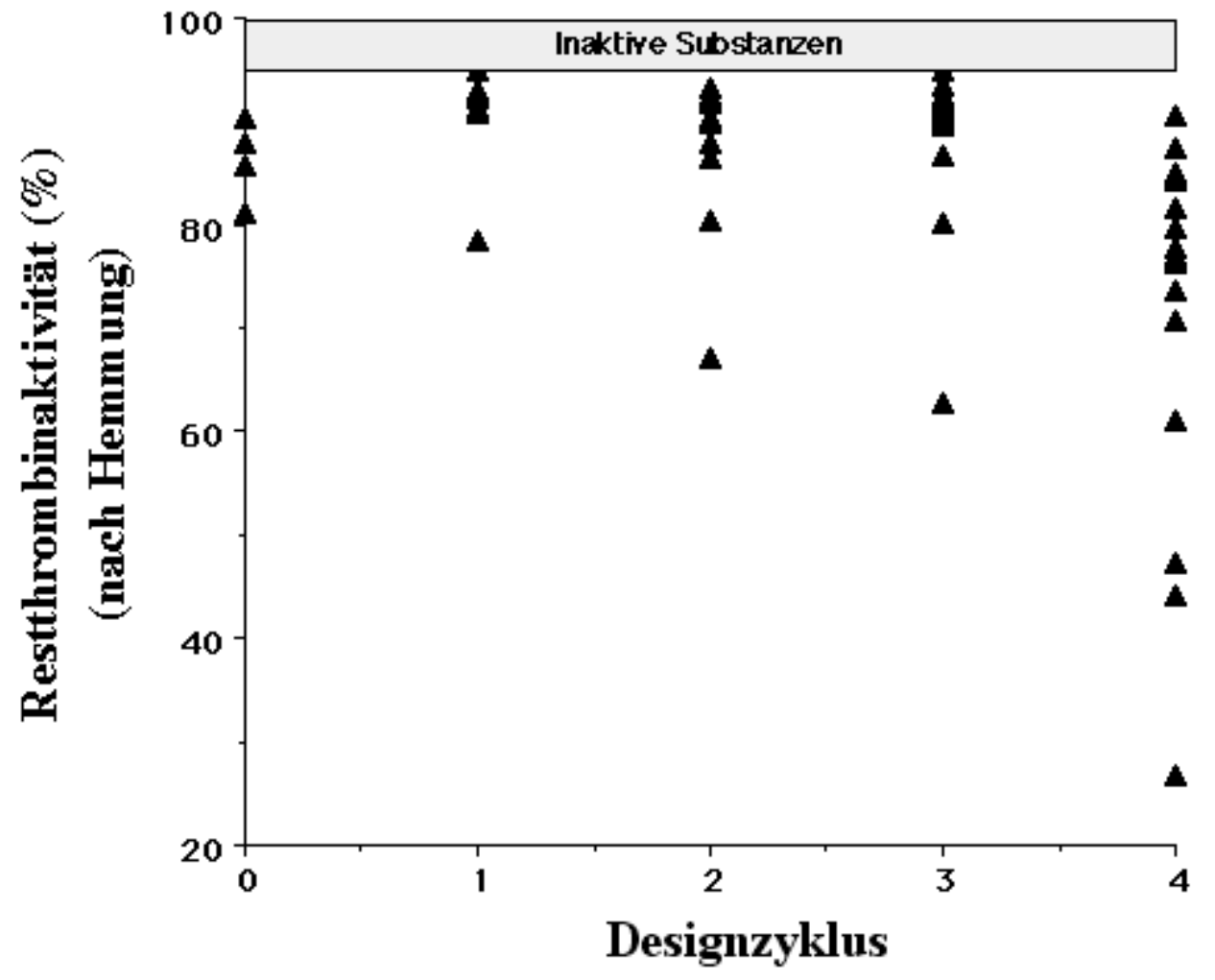

Abbildung 14: Computer-unterstütztes Wirkstoffdesign am Beispiel der Thrombininibitorsuche (1-Parameteroptimierung). Dargestellt sind die Thrombinrestaktivitäten nach Inhibitorbehandlung für alle Substanzen eines jeden Optimierzyklus. Substanzen, die weniger als $5 \%$ Hemmung, d.h. > $95 \%$ Thrombinrestaktivität hervorriefen, wurden als "inaktiv" angenommen. Für die aktivste Sequenz 
(RcccRRRWRK; dargestellt durch das Dreieck rechts unten) wurde ein $\mathrm{K}_{\mathrm{i}}$-Wert von $297 \mathrm{nM}$ bestimmt. Die Nomenklatur der eingesetzten Aminosäure-Bausteine ist der Legende zu Abb. 15 zu entnehmen.

Um zu ermittlen, ob das Peptid NSCI 521 mit der Sequenz RcccRRRWRK das lokale Optimum in der Fitnesslandschaft darstellt, d.h. die algorithmische Prozeßierung erfolgreich war, wurden alle NSCI 521-Varianten mit einem Aminosäureaustausch (1Fehlermutanten) synthetisiert und charakterisiert (Abb. 15A). Dafür wurde jede der zehn Positionen des Peptids (senkrecht) mit einem Set von 30 Aminosäuren ausgetauscht (waagrecht). Die Originalsequenz ist in der Abbildung mit weißen Punkten markiert.

Um zu untersuchen, welche Abschnitte des Moleküls für die Wirkung verantwortlich sind, wurden dann noch verkürzte Varianten von RcccRRRWRK hergestellt (Abb. 15B), indem jeweils N- und C-terminal Aminosäuren weggelassen wurden (weiße Felder), von zwei Nonapeptiden ausgehend bis zur Länge von Tripeptiden.

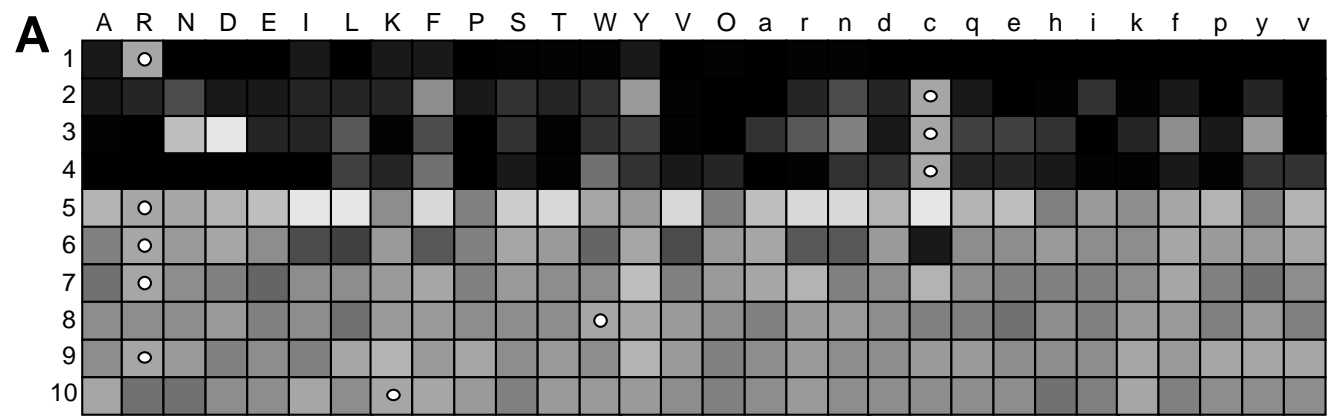

B

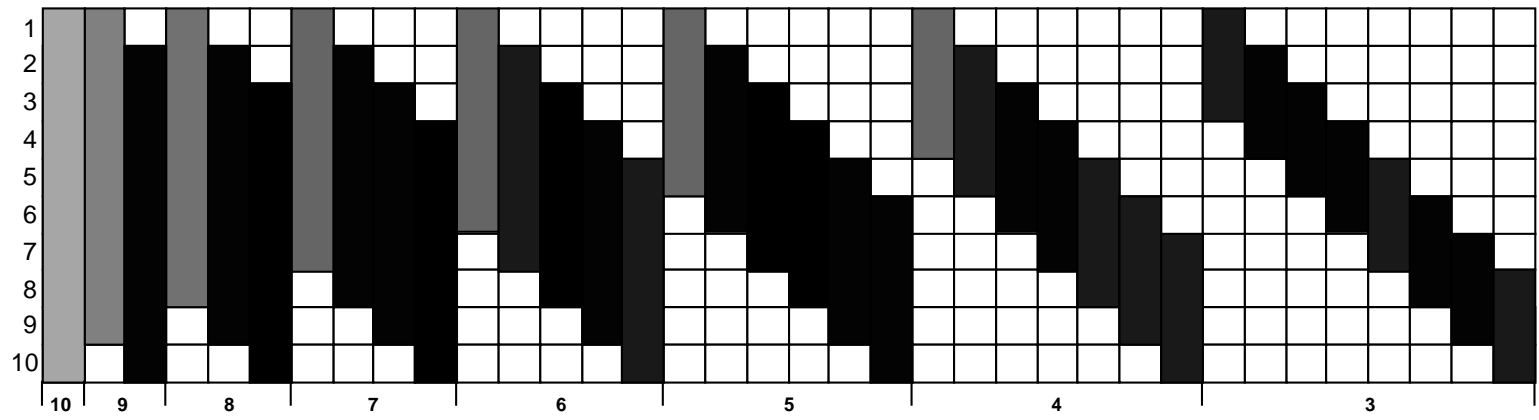

Restthrombinaktivität [\%]

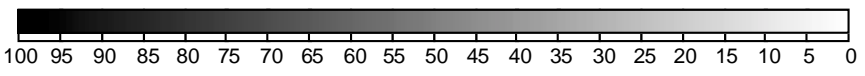

\begin{abstract}
Abbildung 15: Struktur-Aktivitätsstudie an Thrombininhibitor NSCI 521 (RcccRRRWRK).
Die relative Restthrombinaktivität nach Hemmung durch äquimolare Inhibitorderivate ist durch einen Grauwert dargestellt. Analysiert wurden alle 1-Fehlermutanten (A) und alle möglichen verkürzten Varianten (B). Folgende Abkürzungen für Aminosäuren wurden verwendet: A = L-Alanin, R = L-Arginin, $\mathrm{N}=\mathrm{L}$-Asparagin, $\mathrm{D}=\mathrm{L}$-Asparaginsäure, $\mathrm{E}=\mathrm{L}$-Glutaminsäure, $\mathrm{I}=\mathrm{L}$-Isoleuzin, $\mathrm{L}=\mathrm{L}$-Leuzin, $\mathrm{K}=\mathrm{L}$ Lysin, $\mathrm{F}=\mathrm{L}-\mathrm{Phenylalanin}, \mathrm{P}=\mathrm{L}-\mathrm{Prolin}, \mathrm{S}=\mathrm{L}-\mathrm{Serin}, \mathrm{T}=\mathrm{L}$-Threonin, $\mathrm{W}=\mathrm{L}$-Tryptophan, $\mathrm{Y}=\mathrm{L}$-Tyrosin, $\mathrm{V}=\mathrm{L}$-Valin, $\mathrm{O}=\mathrm{L}$-Ornithin, $\mathrm{a}=\mathrm{D}$-Alanin, $\mathrm{r}=\mathrm{L}$-Phenylglycin, $\mathrm{n}=$ L-Norleuzin, $\mathrm{d}=\mathrm{D}$-Asparaginsäure, $\mathrm{c}$
\end{abstract}


$=$ Cyclohexylalanin, $\mathrm{q}=\mathrm{D}$-Glutamin, $\mathrm{e}=\mathrm{D}$-Glutaminsäure, $\mathrm{h}=\mathrm{D}$-Histidin, $\mathrm{i}=$ Citrullin, $\mathrm{k}=\mathrm{D}$-Lysin, $\mathrm{f}=$ D-Phenylalanin, $\mathrm{p}=\mathrm{D}$-Prolin, $\mathrm{y}=\mathrm{D}-\mathrm{Ty}$ rosin, $\mathrm{v}=\mathrm{D}$-Valin.

Es zeigte sich zum einen, daß ein Aminosäureaustausch in den ersten vier Positionen die Wirksamkeit dramatisch senkt (schwarz), während Mutationen in den folgenden Positionen 5-10 die Aktivität kaum beeinflußen. Die Synthese verkürzter Varianten von NSCI 521 ergab, daß tatsächlich die N-terminalen Aminosäuren für die Wirkung verantwortlich sind (grau), alle Deletionen in diesem Bereich führen zum Wirkverlust (schwarz), das N-terminale Tetrapeptid alleine weißt jedoch immer noch eine spürbare Thrombin-inhibitorische Restaktivität von etwa 3\% der Muttersubstanz auf $\left(K_{i}=10,24\right.$ $\mu \mathrm{M}$ bzw. 0,297 $\mu \mathrm{M})$.

Zum anderen konnte mit der Synthese der 1-Fehler-Mutanten (Abb. 15) gezeigt werden, daß das computer-unterstütze Optimierverfahren mit NSCI 521 in der Tat einen unter den besten 5 der 300 Thrombininhibitor-Derivaten hervorgebracht hatte. Nur der Austausch von Cyclohexylalanin an Position 3 mit Asparagin, Aspartat, D-Phenylalanin und DTyrosin (Abb. 16) erzeugt gleichwertige bis leicht bessere Hemmer, ein Befund, den man zumindest bei den ersten beiden Substituenten wegen des großen strukturellen und funktionellen Unterschieds nicht erwartet hätte:

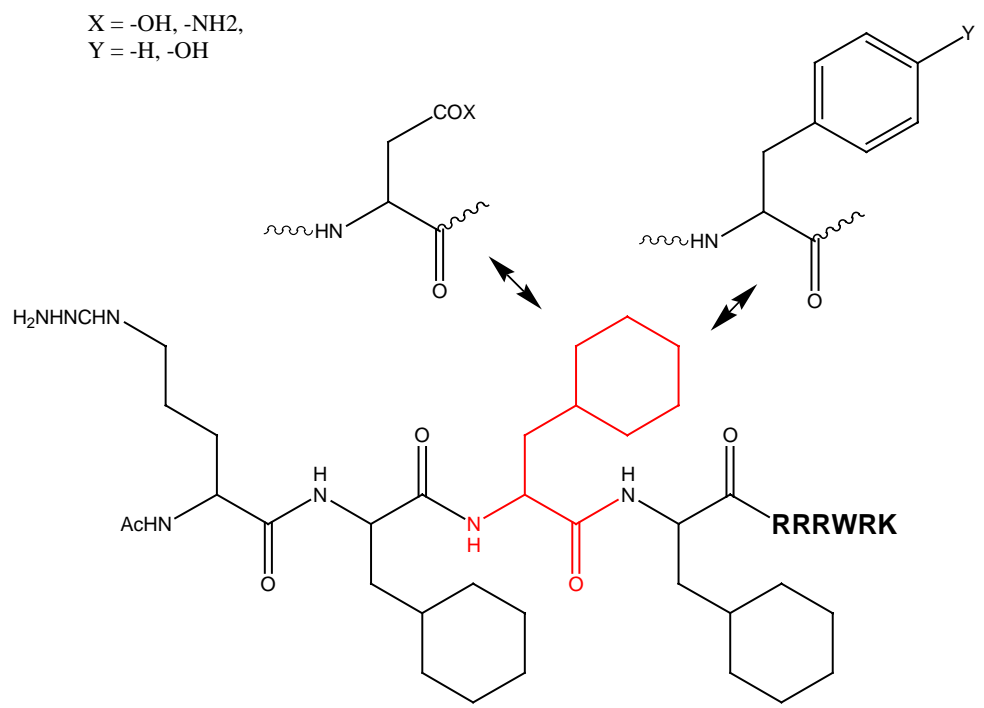

Abbildung 16: Substituenten des Cyclohexylalanylrests Substituenten (oben, schwarz) des Cyclohexylalaninrests (rot), die eine vergleichbare Wirksamkeit des Gesamtmoleküls erzeugen

Eine nähere Charakterisierung von NSCI 521 ergab im Folgenden, daß dieser Inhibitor eine Hemmwirkung nicht selektiv auf Thrombin, sondern auch auf Trypsin ausübte und darüberhinaus auch noch eine relativ hohe Zytotoxizität aufwies, so daß diese Verbindung nicht weiter entwickelt wurde. 


\subsubsection{Neue niedermolekulare Thrombin-Inhibitoren durch Multiparameter-Optimierung}

Bei einem Großteil der in den letzten Jahren entwickelten direkten Thrombin-Inhibitoren ist es nicht bis zur klinischen Anwendung gekommen. Die Gründe für den fehlenden Erfolg sind vielschichtig: Mit mangelnder Selektivität, schlechter oraler Bioverfügbarkeit, geringer metabolischer Stabilität zusammen mit schneller Elimination seien nur einige Probleme genannt. Im Wesentlichen sind es Moleküleigenschaften aus dem Bereich ADMET (Absorption, Distribution, Metabolismus, Elimination und Toxizität), die nach bereits intensiver Entwicklungsarbeit Schwierigkeiten bereiten und zum Misserfolg führen. Idealerweise würde man schon in sehr frühen Stadien der Entwicklung und Optimierung einer Leitstruktur mehrere Parameter, die den o.g. Problemkreis beschreiben können, miteinbeziehen („,early ADME / Tox“). Dabei müssen Kompromisse eingegangen werden, da die unter diesen Aspekten zu entwickelnde, beste Gesamtfunktion einer Substanz nicht mit dem Optimum der Einzelfunktion einhergeht.

Unter diesem Leitgedanken sollte nun der Versuch unternommen werden, ein weiterentwickeltes Verfahren des Computer-unterstützten Wirkstoffdesigns (3.2.) auf die Multiparameter-Optimierung auszudehnen, um unerwünschte Nebenwirkungen von vorn herein auszuschließen. Die Ergebnisse werden hier vorgestellt.

Wieder war der Gesamtprozess in Designzyklen organisiert und als Stoffklasse wurden aufgrund der hohen erreichbaren Diversität und leichten synthetischen Zugänglichkeit Peptide gewählt. Durch Standardfestphasensynthese wurden Peptide einer Länge von maximal 5 Aminosäuren unter Verwendung von insgesamt 66 Bausteinen (Aminosäuren) erzeugt. Alle Peptide wurden folgenden Tests unterzogen: Einem amidolytischen Thrombinassay mit humanem Thrombin und einem amidolytischen Trypsinassay zur Bestimmung der Wirkung und Selektivität, weiterhin einem Serum-ProteinBindungsassay, Test auf metabolische Stabilität, Assay auf Wasserlöslichkeit und Messung des Verteilungskoeffizienten $\log \mathrm{D}$ zur Bestimmung dieser vier wichtigen ADME-Parameter und schließlich einem Toxizitätsassay auf der Basis von HeLa-Zellen und einem Hämolyse-Assay zur Bestimmung toxischer Eigenschaften.

\subsubsection{Optimierungsverlauf - eine Übersicht}

Während des Optimierprozesses waren insgesamt 1042 verschiedene Substanzen in acht Zyklen ( 4 x170, 4 x 84 und 1 x 26 Peptide) synthetisiert und in den beschriebenen Testsystemen charakterisiert worden. In jedem Zyklus wurden 12 ausgewählte (8 positiv und 4 negativ aufgefallene Substanzen) als Kontrollen resynthetisiert und jedes einzelne Peptid einer Analyse über LC-MS unterworfen. Jeder aus den acht verschiedenen Testsystemen gewonnene, komplette Datensatz eines Zyklus durchlief die algorithmische Prozessierung. Im letzten, 8. Zyklus wurden dann nur noch 26 Substanzen synthetisiert 
und charakterisiert. In Abbildung 17 ist die Entwicklung der Eigenschaften am Beispiel der Thrombin- und Trypsininhibition, der HeLa-Toxizität und der hämolytischen Wirkung für alle Substanzen sämtlicher Optimierzyklen dargestellt:
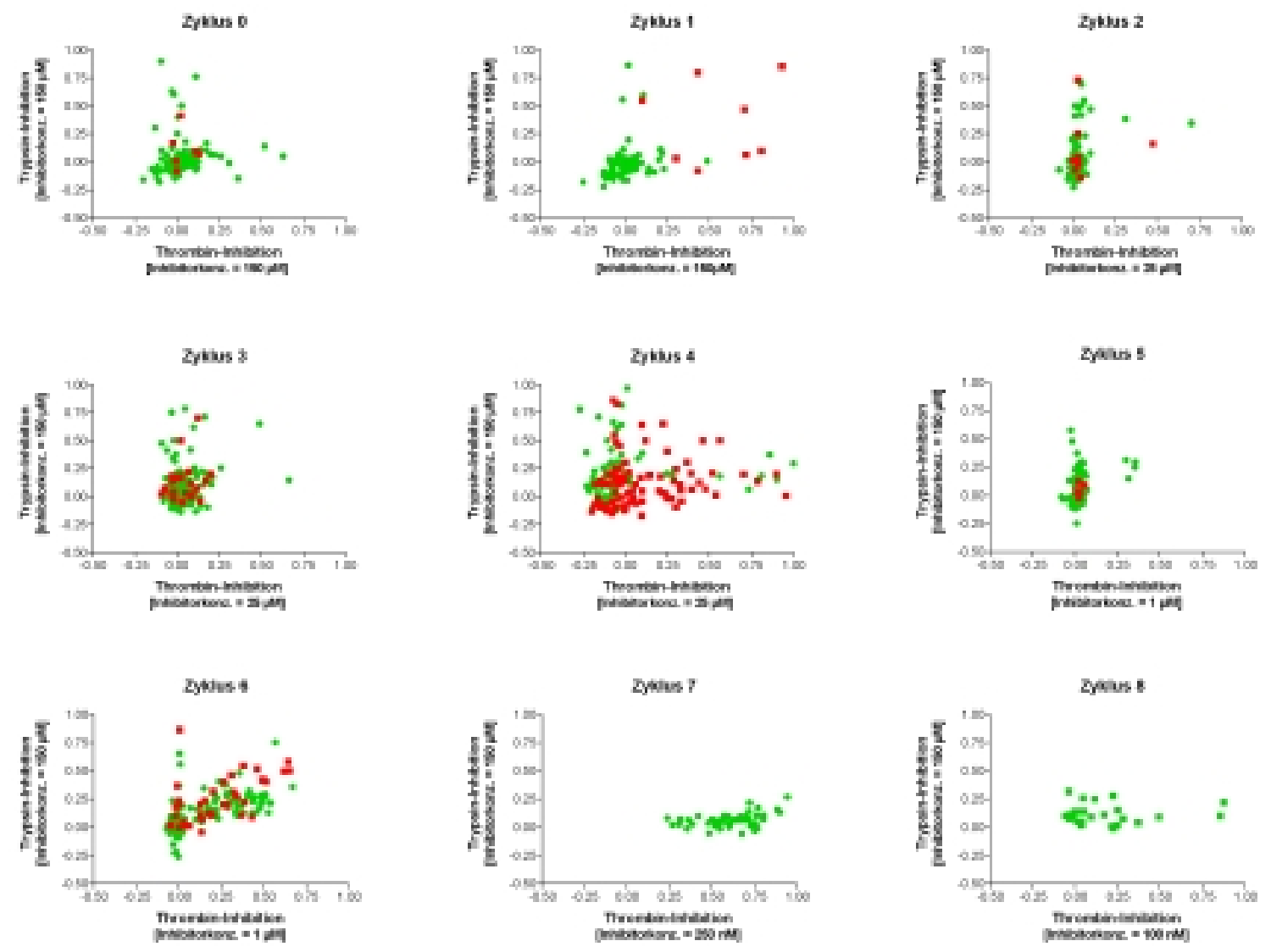

Abbildung 17: Multiparamter-Optimierung von Thrombininhibitoren. Dargestellt ist die Thrombin- und Trypsininhibition bei den jeweils angegebenen Inhibitorkonzentrationen, sowie die HeLaToxizität und die hämolytische Aktivität: Substanzen, die durch grüne Symbole dargestellt werden, zeigten weder HeLa-Toxizität noch hämolytische Aktivität, rote Symbole stellen Substanzen dar, die wenigstens in einem der beiden Assays bei $200 \mu \mathrm{M}$ Endkonzentration Wirkung (>40\%) zeigten.

Selektive, nicht-toxische und hochwirksame Moleküle finden sich in diesen Darstellungen jeweils rechts, unten und als grün markierte Punkte. Zu beachten ist, daß die eingesetzte Inhibitorkonzentration im Trypsinassay konstant für alle Zyklen $150 \mu \mathrm{M}$ betrug, wohingegen die eingesetzte Inhibitorkonzentration im Thrombinassay von anfänglich $150 \mu \mathrm{M}$ stetig auf $100 \mathrm{nM}$ im Assay des Zyklus 8 verkleinert wurde.

\section{Toxizität}

Schon in Zyklus 0 aber auch allen folgenden Zyklen zeigten die meisten Substanzen keine hervorstechenden toxischen oder hämolytischen Wirkungen. Eine gewisse 
Ausnahme stellt Zyklus 4 dar, in dem etwa die Hälfte aller Substanzen toxische und / oder hämolytische Wirkung zeigten. Im Gegensatz dazu zeigte keine der Substanzen aus Zyklus 7 und 8 derartige Wirkungen.

\section{Wirkung und Selektivität}

In Zyklus 0 zeigten die aktivsten Thrombininhibitoren Aktivitäten mit Ki-Werten weit über $1 \mu \mathrm{M}$. In den Zyklen 8 und 9 hingegen zeigten die besten Inhibitoren Ki-Werte im einstelligen nanomolaren Bereich bei gleichzeitig exzellenter Spezifität, d.h. mit vernachlässigbaren Aktivitäten gegenüber Trypsin (Abb. 17; Tab. 5).

\section{Stabilität / Serumproteinbindung / Löslichkeit}

Mit Ausnahme der Substanzen aus den Zyklen 0 und 1 zeigten die meisten Moleküle aller folgenden Zyklen metabolische Stabilitäten größer als $60 \%$, was mit der zunehmenden Verwendung nicht-natürlicher Aminosäuren korrelierte. Die vollständige Löslichkeit in wässriger Phase war praktisch für alle Substanzen bei einer maximalen Konzentration von $200 \mu \mathrm{M}$ gegeben. Dies wird wahrscheinlich wesentlich schon durch die polare chemische Natur des Peptidgerüstes bedingt. Diese Polarität erklärt sicherlich auch, warum extrem starke Serumprotein-Binder ebenfalls nur ausnahmsweise nachzuweisen waren. Bezüglich der Serumproteinbindung waren in den Zyklen 0 und 1 noch Fraktionen zwischen 50 - 70\% vertreten, von Zyklus 2 an zeigte sich dann konstant eine Serumproteinbindung unter $60 \%$.

\subsubsection{Selektion der besten Substanzen}

Die Evolution der Thrombininhibitoren im Laufe des Designprozesses kann auch anhand der Sequenzentwicklung von Zyklus zu Zyklus verfolgt werden. Am Anfang (Zyklus 0 und 1) zeigte die Molekülpopulation alle Merkmale einer Verteilung von zufällig ausgewürfelten Sequenzen. Kein einziges dominantes Sequenzmotiv konnte nachgewiesen werden. In Zyklus 2 wies ein Anteil von $10 \%$ ein N-terminales Ac-L-Arg auf. Dieser Anteil an der Gesamtpopulation stieg in Zyklus 3 auf $38 \%$ an und verblieb auf dieser Höhe bis zum Zyklus 5, bevor er wieder abnahm. In Zyklus 3 waren erstmalig kurze Motive nachzuweisen, z.B. Ac-L-Arg-L-Trp (12\%) und Ac-L-Arg-D-Cha (8\%) am $\mathrm{N}$-Terminus der Peptide. Innerhalb dieser Moleküle wiesen zwei relativ kleine Moleküle die höchsten Aktivitäten auf: Ac-L-Arg-D-Cha-D-Phg-D-Tyr-L-Arg und eine Variante, der das C-terminale L-Arg fehlte. Interessanterweise war auch eine „2-Fehlermutante“ des aktivsten Thrombininhibitors des vorherigen Thrombininhibitor-Projekts (1Parameteroptimierung ) unter den Molekülen des 3. Zyklus. In den Zyklen 4 und 5 stieg der Anteil der Moleküle mit N-terminalem Motiv Ac-L-Arg-D-Cha auf $21 \%$ bzw. $36 \%$. Unter den aktivsten Molekülen waren das Peptid L-Arg-D-Cha-D-Pro-D-Tyr-L-Arg und zwei seiner „2-Fehlermutanten“. Derivate dieses Peptids mit einer „Mutation“, Insertion oder Deletion bildeten mit $28 \%$ die Dominante Fraktion der Population in Zyklus 6. Die gleiche Sequenz wurde in Zyklus 7 weiter variiert. Hier wurde allerdings das zentrale Motiv D-Cha-D-Pro-D-Tyr-X (2 \%) durch die Variante D-Cha-L-Aze-D-Tyr-X (35\%) 
abgelöst. $29 \%$ aller Sequenzen zeigten ein L-Arg an der mit X bezeichneten Position, 52 $\%$ aller Sequenzen wiesen dort ein L-homoArg auf.

Unter den aktivsten Thrombininhibitoren des Zyklus 7 waren drei Pentapeptide: Ac-LAla-D-Cha-L-Aze-D-Tyr-L-homoArg (7-1), Ac-L-Arg-D-Cha-L-Aze-D-Tyr-L-homoArg (7-4, Abb. 18) und $\mathrm{NH}_{2}$-L-Arg-D-Cha-L-Aze-D-Tyr-L-homoArg (7-8), deren strukturelle Ähnlichkeit auffällt, unterscheiden sie sich doch nur noch in der N-terminalen Aminosäure. Hier hatte sich ein offensichtlich ein bestimmtes Motiv durchgesetzt.

Im letzten Zyklus wurde eine stark auf „1-Fehler-Mutanten“ von 7-8 fokussierte Bibliothek von Molekülen realisiert. Die aktivsten Thrombininhibitoren waren hier TrxD-Cha-L-Aze-D-Tyr-L-homoArg (8-1) und sein Derivat mit guanidyliertem N-Terminus (8-5). Die Strukturen der letztgenannten Verbindungen sind in den Abbildungen 18 und 19 dargestellt, die zugehörigen Eigenschaften finden sich in Tabelle 5.

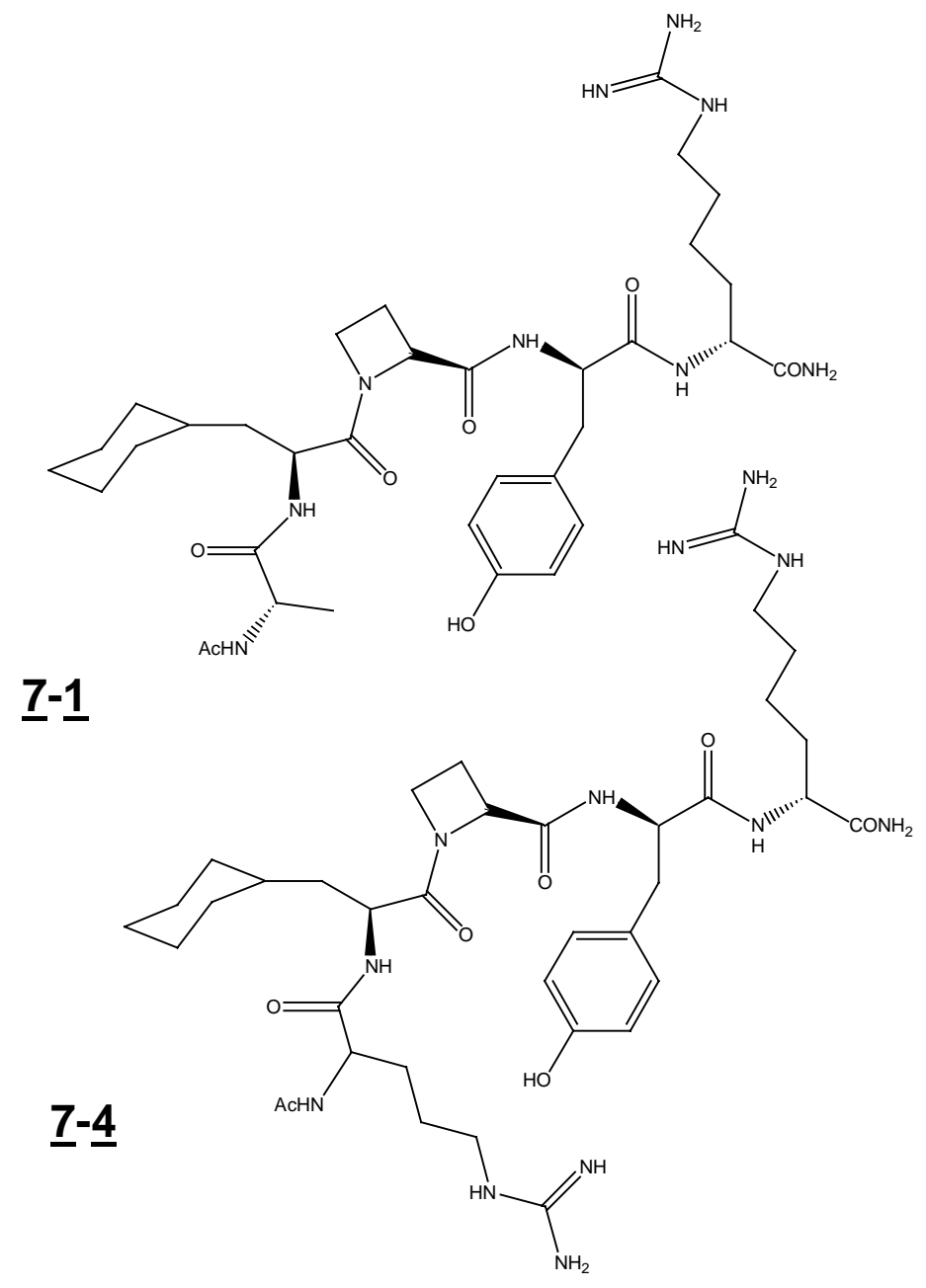

Abbildung 18: Multiparamter-Optimierung von Thrombininhibitoren. Dargestellt sind die Thrombininhitoren 7-1 und 7-4 aus den Zyklen 7 und 8. Strukturell unterscheiden sich diese Moleküle nur am N-Terminus. Die Eigenschaften dieser Moleküle sind in Tab. 5 aufgelistet 
$\underline{7-} \underline{8}$

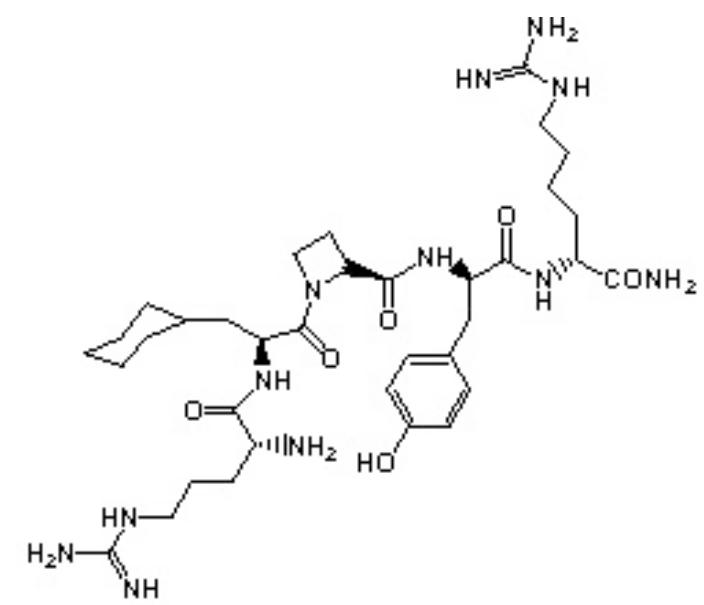

$\underline{8-1}$

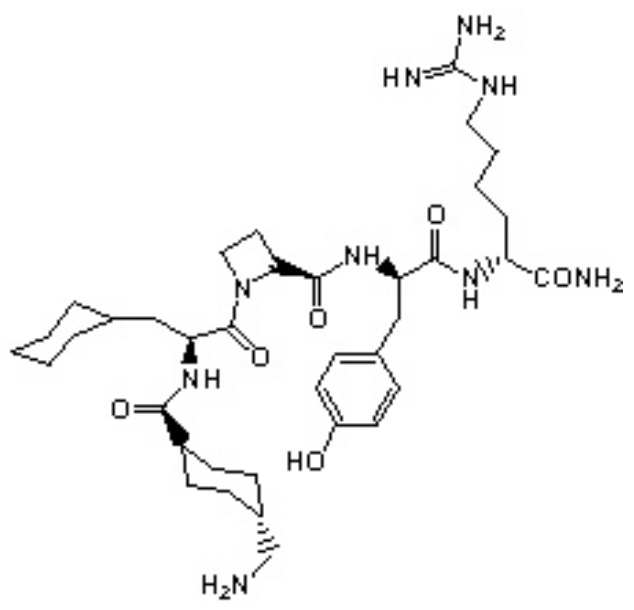

$\underline{8-\underline{5}}$

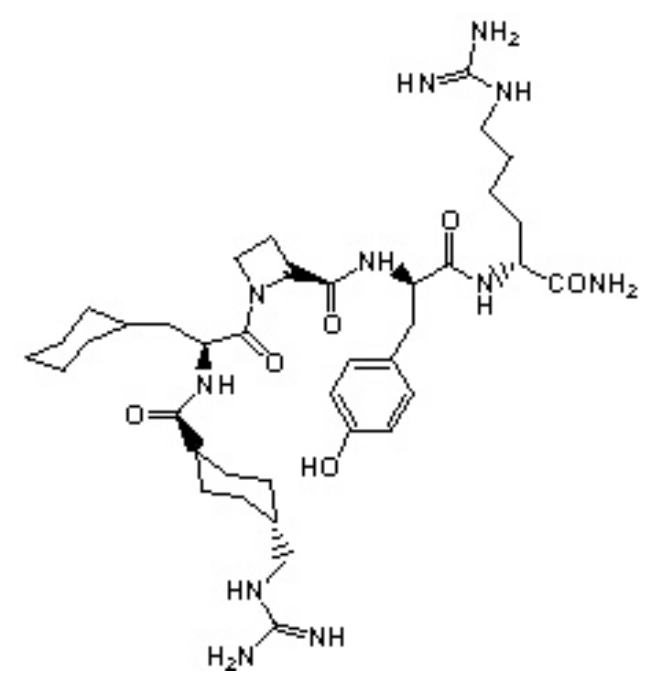

Abbildung 19: Multiparamter-Optimierung von Thrombininhibitoren. Dargestellt sind die Thrombininhitoren 7-8, 8-1 und 8-5 aus den Zyklen 7 und 8. Strukturell unterscheiden sich diese Moleküle ebenfalls nur am N-Terminus. Die Eigenschaften dieser Moleküle sind in Tab. 5 aufgelistet. 
Die Eigenschaften der ausgewählten Substanzen (Abb.18 und 19) sind in Tabelle 5 zusammengefaßt und werden mit Melagatran, Argatraban und NAPAP verglichen:

Tab.5: Eigenschaften ausgewählter Thrombininhibitoren

\begin{tabular}{|c|c|c|c|c|c|c|c|c|}
\hline & \multicolumn{5}{|c|}{ Inhibitoren der Designzyklen 7 und 8} & \multicolumn{3}{|c|}{ Referenz-Inhibitoren } \\
\hline & $7-1$ & $7-4$ & $7-8$ & $8-1$ & $8-5$ & Argatroban & NAPAP & Melagatran \\
\hline \multicolumn{9}{|l|}{$\mathbf{K}_{\mathbf{i}}[\boldsymbol{\mu M}]$} \\
\hline Humanes Thrombin & 0.080 & 0.009 & 0.056 & 0.008 & 0.003 & 0.038 & 0.009 & 0.006 \\
\hline Bovines Thrombin & 0.150 & 0.021 & 0.073 & 0.013 & 0.0072 & 0.019 & 0.006 & 0.0036 \\
\hline Trypsin & $>1000$ & $>1000$ & $>1000$ & $>1000$ & $>1000$ & 4.250 & 690 & 0.004 \\
\hline Factor Xa & $>1000$ & $>1000$ & $>1000$ & $>1000$ & $>1000$ & 210 & 7.9 & 9.4 \\
\hline Factor XIIa & - & $>1000$ & $>1000$ & $>1000$ & $>1000$ & $>1000$ & 450 & 10.4 \\
\hline Urokinase & $>1000$ & $>1000$ & $>1000$ & $>1000$ & $>1000$ & $>1000$ & 230 & 7.9 \\
\hline Plasmin & $>1000$ & $>1000$ & $>1000$ & $>1000$ & $>1000$ & 600 & 30 & 1.4 \\
\hline Plasma-Kallikrein & - & $>1000$ & $>1000$ & $>1000$ & $>1000$ & $>1000$ & 14 & 0.69 \\
\hline \multicolumn{9}{|l|}{$\mathrm{IC}_{200}[\mu \mathrm{M}]$} \\
\hline Thrombin Time & 0.24 & 0.034 & 0.24 & 0.040 & 0.040 & 0.062 & 0.045 & 0.015 \\
\hline aPTT & 6.0 & 1.0 & 2.8 & 0.95 & 0.60 & 0.42 & 0.50 & 0.24 \\
\hline Prothrombin-Time & 14 & 2.0 & - & 2.0 & 1.45 & 0.66 & 1.0 & 0.37 \\
\hline \multicolumn{9}{|l|}{ Toxizität [\%] } \\
\hline HeLa $(30 \mu \mathrm{M})$ & 0 & 0 & 0 & 1.7 & 0 & - & - & - \\
\hline HeLa $(200 \mu \mathrm{M})$ & 17.1 & - & 0 & 5.0 & 2.9 & - & 13 & 12 \\
\hline Hämolyse & 10 & - & $<2$ & $<2$ & $<2$ & - & - & - \\
\hline \multicolumn{9}{|l|}{ ADME } \\
\hline SPB [\%] & 59 & 39 & 2 & 22 & 29 & - & 86 & 7 \\
\hline Metab. Stab. [\%] & 88 & 80 & 92 & 70 & 76 & - & 97 & 93 \\
\hline $\begin{array}{l}\text { Löslichkeit } \\
(200 \mu \mathrm{M})\end{array}$ & 197.9 & - & 200 & 200 & 200 & - & - & - \\
\hline $\begin{array}{l}\text { 7-1, 7-4, 7-8: } \\
\text { 8-1 , 8-5: } \\
\text { hThrombin: } \\
\text { bThrombin: } \\
\text { SPB: }\end{array}$ & $\begin{array}{l}\text { ibitoren } \\
\text { libitoren } \\
\text { manes Th } \\
\text { vines Thr } \\
\text { rumprote }\end{array}$ & $\begin{array}{l}\text { s Zyklus } 7 \\
\text { s Zyklus } 8 \\
\text { mbin } \\
\text { nbin } \\
\text {-Bindung }\end{array}$ & & $\begin{array}{l}\text { P.-Kallikre } \\
\text { IC200: } \\
\text { TT: } \\
\text { aPTT: } \\
\text { Metab. Sta }\end{array}$ & Ve & $\begin{array}{l}\text { ma-Kallikre } \\
\text { bitorkonzen } \\
\text { klumpungsz } \\
\text { rombin Tim } \\
\text { t. Part. Thr } \\
\text { tabolische S }\end{array}$ & $\begin{array}{l}\text { ration bei } \\
\text { it verdop } \\
\text { mboplast } \\
\text { abilität }\end{array}$ & $\begin{array}{l}\text { r die } \\
\text { ist } \\
\text { Time“" }\end{array}$ \\
\hline
\end{tabular}

Generell kann im Hinblick auf die Wirksamkeit festgestellt werden, daß die entwickelten Moleküle sehr gute Thrombin-inhibitorische Eigenschaften aufweisen, mit $\mathrm{K}_{\mathrm{i}}$-Werten der besten Vertreter von $9 \mathrm{nM}, 8 \mathrm{nM}$ und $3 \mathrm{nM}$ für humanes Thrombin. Die Thrombininhibitorische Aktivität ist demnach vergleichbar bzw. sogar leicht besser als die von NAPAP (9 nM) oder Melagatran (6 nM) im gleichen Assay.

Aus diesem Grund wurden weitere kinetische und strukturelle Untersuchungen durchgeführt. 


\subsubsection{Kinetische Studien von Varianten des Inhibitors 8-5}

Zur Klärung der Frage, ob es sich bei der gefundenen Variante 8-5 um ein lokales Optimum in der Fitnesslandschaft (Schuster et al., 1994) handelt oder in der näheren Umgebung im Sequenzraum Thrombininhibitoren mit kleinerem $\mathrm{K}_{\mathrm{i}}$-Wert gefunden werden können sollten durch einen fokussierten Synthesesatz der 8-5-,,Mutanten“ hergestellt und in kinetischen Untersuchungen charakterisiert werden.

Außerdem sollten durch die Synthese entsprechend ausgewählter Substituenten an bestimmten Positionen Rückschlüsse über den Bindemodus der neuen Inhibitoren im Vergleich zu den Bindemodi bekannter Substanzen gezogen werden. Diese Varianten wurden wie 8-5 durch Standardfestphasenchemie hergestellt, mit Ausnahme der Substanzen 8-5I, 8-5J und 8-5K (2.2.1). In der Analytik per LC-MS entsprach die Masse des Hauptproduktes jeweils der aus der Formel errechneten. Die Reinheiten betrugen durchweg $>80 \%$. Alle Varianten wurde jeweils im Hinblick auf Thrombininhibition $\left(\mathrm{K}_{\mathrm{i}^{-}}\right.$ Wert) und Trypsininhibition (\% Inhibition bei $100 \mu \mathrm{M}$ Inhibitorkonzentration) charakterisiert (Tab. 6).

Tab.6: Charakterisierung von Derivaten des Thrombininhibitors 8-5

\begin{tabular}{|c|c|c|c|c|c|c|c|c|c|}
\hline \multirow{2}{*}{$\begin{array}{l}\text { Nr. } \\
\\
8-5\end{array}$} & \multicolumn{5}{|c|}{$\begin{array}{l}\text { Substituenten der Original- } \\
\text { Sequenz 8-5 }\end{array}$} & \multirow{2}{*}{ 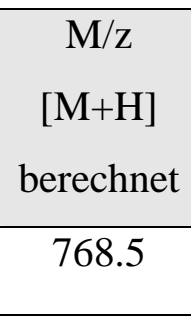 } & \multirow{2}{*}{\begin{tabular}{|c|}
$\begin{array}{c}\mathrm{M} / \mathrm{z} \\
{[\mathrm{M}+\mathrm{H}]} \\
\text { gefunden }\end{array}$ \\
768.6
\end{tabular}} & \multirow{2}{*}{$\begin{array}{c}\% \\
\text { Inhibition } \\
(\text { Trypsin) }\end{array}$} & \multirow{2}{*}{$\begin{array}{c}\mathrm{K}_{\mathrm{i}}[\mathrm{nM}] \\
\text { (Thrombin) }\end{array}$} \\
\hline & $\begin{array}{l}\text { G- } \\
\text { Trx }\end{array}$ & $\begin{array}{l}\text { D- } \\
\text { Cha }\end{array}$ & \begin{tabular}{|l} 
L- \\
Aze \\
\end{tabular} & D-Tyr & \begin{tabular}{|l} 
L- \\
hArg \\
\end{tabular} & & & & \\
\hline $8-5 \mathrm{~A}$ & $\begin{array}{l}\text { D- } \\
\text { Met }\end{array}$ & & & & & 760.4 & 760.4 & 7 & 23 \\
\hline $8-5 B$ & Gly & & & & & 686.4 & 686.6 & 0 & 133 \\
\hline $8-5 \mathrm{C}$ & & $\begin{array}{l}\text { D- } \\
\text { Phe }\end{array}$ & & & & 762.4 & 762.6 & 5 & 57 \\
\hline $8-5 \mathrm{D}$ & & & L-Pro & & & 782.5 & 782.6 & 6 & 80 \\
\hline $8-5 \mathrm{E}$ & & & & D-Phe & & 752.5 & 752.4 & 11 & 7 \\
\hline $8-5 \mathrm{~F}$ & & & & D-Arg & & 761.5 & 761.5 & 14 & 405 \\
\hline $8-5 G$ & & & & L-Tyr & & 768.5 & 768.5 & 18 & 488 \\
\hline $8-5 \mathrm{H}$ & & & & L-Arg & & 761.5 & 761.6 & 4 & $>1000$ \\
\hline $8-5 \mathrm{I}$ & & & & $\begin{array}{l}\text { D- } \\
\text { Phe1 }\end{array}$ & & 777.5 & 777.6 & 18 & 483 \\
\hline
\end{tabular}




\begin{tabular}{|c|c|c|c|l|c|c|c|c|}
\hline Nr. & \multicolumn{3}{|c|}{$\begin{array}{c}\text { Substituenten der Original- } \\
\text { Sequenz 8-5 }\end{array}$} & $\begin{array}{c}\mathrm{M} / \mathrm{z} \\
{[\mathrm{M}+\mathrm{H}]} \\
\text { berechnet }\end{array}$ & $\begin{array}{c}\mathrm{M} / \mathrm{z} \\
{[\mathrm{M}+\mathrm{H}]} \\
\text { gefunden }\end{array}$ & $\begin{array}{c}\% \\
\text { Inhibition } \\
(\text { Trypsin) }\end{array}$ & $\begin{array}{c}\mathrm{K}_{\mathrm{i}} \text { [nM] } \\
\text { (Thrombin) }\end{array}$ \\
\hline 8-5J & & & $\begin{array}{l}\text { D- } \\
\text { Phe2 }\end{array}$ & & 794.5 & 794.6 & 20 & 183 \\
\hline $8-5 \mathrm{~K}$ & & & $\begin{array}{l}\text { D- } \\
\text { Phe3 }\end{array}$ & & 810.5 & 810.5 & 26 & $>1000$ \\
\hline $8-5 \mathrm{~L}$ & & & & Gly & 655.4 & 655.4 & 5 & 42 \\
\hline $8-5 \mathrm{M}$ & & & & L-Met & 729.5 & 729.4 & 0 & 13 \\
\hline $8-5 \mathrm{~N}$ & & & & L-Lys & 726.5 & 726.5 & 8 & 10 \\
\hline $8-5 \mathrm{O}$ & & & & AcLys & 768.5 & 768.6 & 8 & 17 \\
\hline
\end{tabular}

${ }^{\text {a }}$ G-Trx = guanidylierte Tranexamsäure, D-Ph1 = D-Phe-4-CN, D-Phe2 = D-Phe-4-amidin, DPhe3 = D-Phe-4-hydroxy-amidin, AcLys = L-(E-N-acetyl $)$-Lysine

b $\%$ Trypsin-Inhibition bei einer Inhibitorkonzentration von $100 \mu \mathrm{M}$

Die Ergebnisse aus den kinetischen Studien, wie sie Tabelle 6 entnommen werden können, sind:

\section{Synthese}

Die Ergebnisse belegen zunächst eine erfolgreiche Synthese. Neben den hohen Reinheiten (durchweg > 80\%, bezogen auf die Absorption bei 275nm mit Ausnahme der Substanzen 8-5F und 8-5-H, die kein Chromophor besitzen, hier 220nm) wurden in den DAD-Signalen auch die erwarteten Massensignale gefunden. Die in der Tabelle angegebenen Werte aus der LC-MS-Analytik sind aus Gründen der einheitlichen Darstellung als $[\mathrm{M}+\mathrm{H}]^{+}$gewählt worden, in den meisten Fällen dominierte das doppelt geladene $[\mathrm{M}+2 \mathrm{H}]^{2+}$ die Spektren.

\section{Selektivität}

Die Inhibition von Trypsin wurde als Parameter zur Beschreibung der Selektivität gewählt. Man beachte, daß diese Werte bei sehr hohen Konzentration von $100 \mu \mathrm{M}$ bestimmt wurden, in der Regel mehr als das 1000 fache der entsprechenden ThrombinKonzentration. Keine der Substanzen ist ein guter Trypsinhibitor, maximal werden um $20 \%$ Hemmung bei $100 \mu \mathrm{M}$ erreicht. Umgekehrt kann man, mit Ausnahme von 8-5 H und 8-5 K, $\mathrm{K}_{\mathrm{i}}$-Werte im nanomolaren Konzentrationsbereich feststellen. 


\section{Wirkung und Selekivität}

Die in Tabelle 6 aufgelisteten Werte legen nahe, daß es sich bei 8-5 wirklich um ein lokales Optimum handeln könnte: Alle Varianten weisen einen größeren $\mathrm{K}_{\mathrm{i}}$-Wert auf. Auch die experimentellen Befunde für die Substanzen aus den Optimierzyklen, insbesondere aus den Zyklen 7 und 8, in denen bereits eine Fülle von Substanzen mit strukturähnlichem Motiv auffiel, deuten auf ein lokales Optimum hin. Einen letztendlichen Beweis würde nur die Charakterisierung aller 1-Fehler-Mutanten liefern. Darauf wurde im Rahmen dieser Arbeit verzichtet.

\section{Untersuchungen zum Bindungsmodus}

Um die Frage nach einer Substrat-ähnlichen Bindungsweise wie z.B. PPACK (Abb.1, 1) $\mathrm{zu}$ untersuchen, wurden Substitutionen in Richtung der PPACK-Struktur vorgenommen (Tab. 6, Ziffern 8-5 C, -D und -F).

Die Substitution D-Cha $\rightarrow$ D-Phe (Pos.2) führte zu einem um den Faktor 19 größeren $\mathrm{K}_{\mathrm{i}^{-}}$ Wert. Der Austausch L-Aze $\rightarrow$ L-Pro erhöhte den $\mathrm{K}_{\mathrm{i}}$-Wert um den Faktor 27, die Substitution D-Tyr $\rightarrow$ L-Arg führte zu einer Substanz die praktisch keine signifikante Thrombininhibition mehr aufwies $\left(\mathrm{K}_{\mathrm{i}}\right.$-Wert > $\left.1000 \mathrm{nM}\right)$. Eine substratartige Bindung von 8-5 an Thrombin ist daher unwahrscheinlich.

Da wohl über $99 \%$ aller bisher publizierten Thrombininhibitoren mit basischen Resten (wie dem des Arginins oder Benzamidins) in die saure S1-Tasche des Thrombins binden, waren primär also ebensolche, basischen Reste gute P1-Kandidaten, d.h. guanidyl-Trx (Pos.1) und L-homoArg (Pos. 5). Die Struktur des Cyclohexanrestes der Tranexamsäure in Pos. 1 ist offensichtlich von einer gewissen Bedeutung für die Bindung (Tab. 6): Ein Austausch gegen ein guanidyliertes D-Met oder Gly führt zu einem Anstieg um den Faktor 7 bzw. 44 im Ki-Wert (Tab. 6). Ein acetyliertes L-Arg (Variante 7-4, siehe Tab. 6) führt nur zu einer $\mathrm{K}_{\mathrm{i}}$-Verschlechterung um den Faktor 3, ein acetyliertes L-Ala (Variante 7-1, siehe Tab. 6) weist eine Verschlechterung um den Faktor 27 auf.

In keinem dieser Fälle ist die Veränderung im $\mathrm{K}_{\mathrm{i}}$-Wert so dramatisch, wie es für die Mutation eines P1-Rests zu erwarten wäre. Bei Guanidinomethyl-Trx handelt es sich sehr wahrscheinlich also nicht um den P1-Rest. Auch im Falle der Substitutionen des LhomoArg-Restes ergaben sich nur relativ geringe Unterschiede im $\mathrm{K}_{\mathrm{i}}$-Wert (Tab. 6). Ein Austausch durch L-Lys ergab eine Steigerung des $\mathrm{K}_{\mathrm{i}}$-Wertes um den Faktor 3. Ein Austausch durch ein neutrales $\varepsilon$-N-acetyliertes L-Lys ergab eine Steigerung um den Faktor 6. Eine Variante mit L-Met an dieser Position ergab eine $\mathrm{K}_{\mathrm{i}}$-Steigerung um den Faktor 4, eine Variante mit Gly ergab eine $\mathrm{K}_{\mathrm{i}}$-Steigerung um den Faktor 18. Letzteres Ergebnis deutet möglicherweise darauf hin, daß die Länge der Seitenkette für die Bindung eine gewisse Rolle spielen könnte. Zusammengenommen lassen die Ergebnisse wieder nur den Schluß zu, daß L-homoArg mit großer Wahrscheinlichkeit ebenfalls nicht den P1-Rest stellt. 
Da das Motiv D-Cha-L-Aze-D-Tyr (8-5) eine gewisse Ähnlichkeit zum D-Chg-L-AzeBenzamidin-Motiv aus Melagatran aufwies (Abb. 20), könnte man theoretisch mutmaßen, daß der D-Tyr-Rest analog dem Benzamidin in die S1-Tasche bindet.

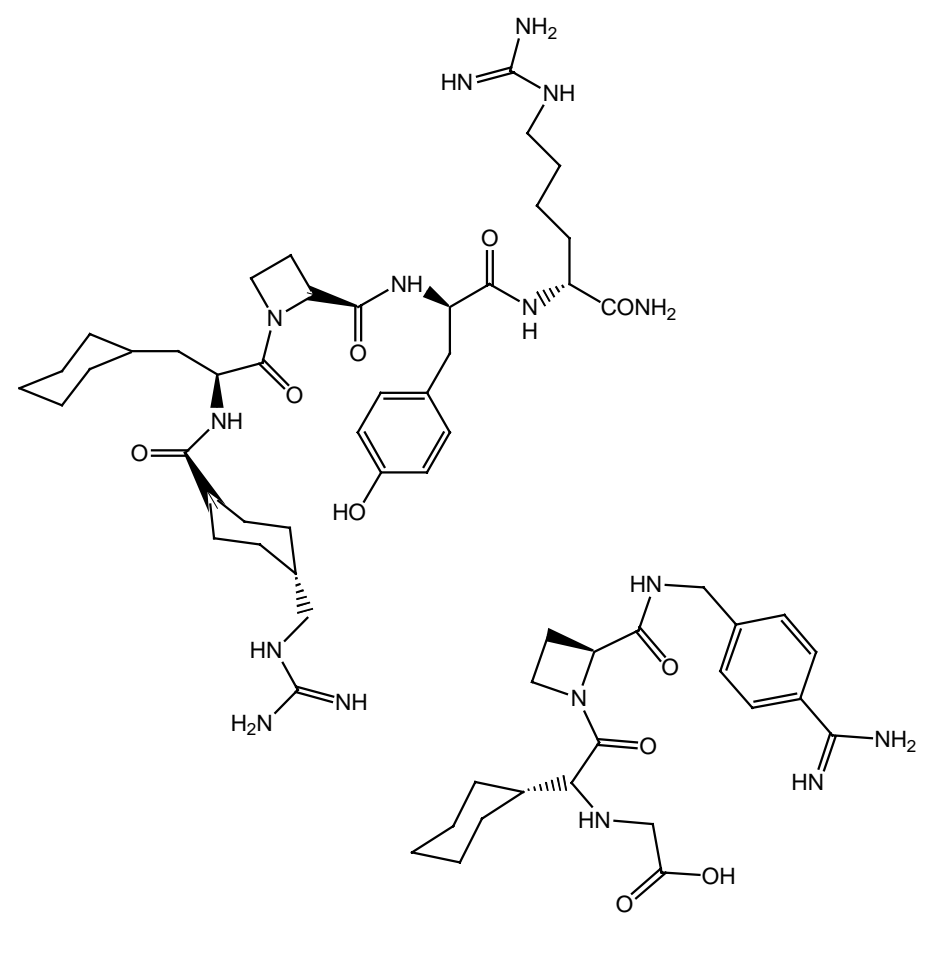

8-5

Melagatran

\section{Abbildung 20: Struktur von 8-5 im Vergleich mit Melagatran}

Daher wurde in 8-5 auch D-Tyr durch eine Vielzahl von Resten substituiert (Tab. 6). Die dem Melagatran ähnlichste Verbindung mit einem D-Phe-4-amidin anstelle des D-Tyr wies eine Steigerung des $\mathrm{K}_{\mathrm{i}}$-Wertes um den Faktor 61 auf. Substitutionen mit anderen basischen Resten wie L- oder D-Arg bzw. anderen 4-substituierten D-Phe-Resten führten ebenfalls zu großen Steigerungen im $\mathrm{K}_{\mathrm{i}}$-Wert (>161fach). L-Tyr führte zu einem um den Faktor 163 größeren $\mathrm{K}_{\mathrm{i}}$-Wert, was auf eine enantioselektive Bindung an dieser Stelle hindeutet. Die Substitution durch D-Phe schließlich ergab einen nur um den Faktor 2 gesteigerten $\mathrm{K}_{\mathrm{i}}$-Wert. Der Beitrag der 4-Hydroxylgruppe an der Gesamtbindungsenergie ist also als eher gering einzustufen.

Zusammenfassend kann also festgestellt werden, daß die Wechselwirkung zwischen Thrombin und Inhibitor 8-5 maßgeblich durch D-Tyr mitbestimmt wird, so wie man es auch von einem P1-Rest erwarten könnte. Sollte D-Tyr tatsächlich in die S1-Tasche binden, so muß diese Bindung allerdings einer ganz anderen Geometrie folgen, als dies für das Benzamidin im Melagatran bekannt ist.

Um weitere Klarheit in diese Vermutungen zu bringen, war hier die kristallographische Untersuchung Mittel der Wahl. 


\subsubsection{Kristallographische Untersuchung von 8-5 im Komplex mit Thrombin}

Um den Bindungsmodus genauer $\mathrm{zu}$ bestimmen wurden kristallographische Untersuchungen von 8-5 am Komplex von 8-5 mit humanem Thrombin (und Hirugen) durchgeführt.

Die Röntgenkristallstruktur von 8-5 im Komplex mit Thrombin wurde in Kooperation mit Dr. R. Friedrich und W. Bode (MPI f. Biochemie, Martinsried-München) mit einer Auflösung, in der Wassermoleküle noch gut erkennbar sind, erhalten. In Abb. 21 ist diese Struktur dargestellt.

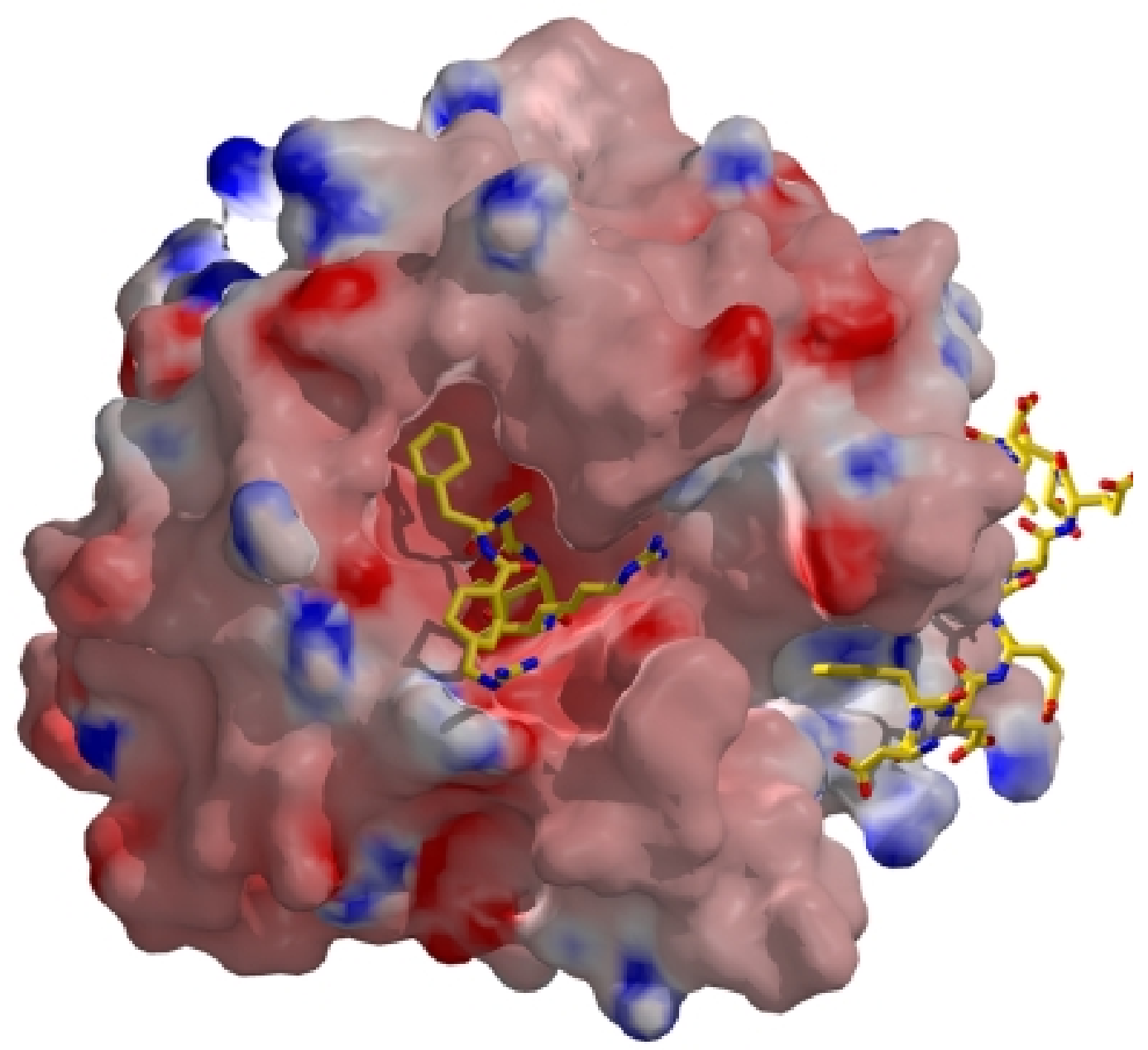

Abbildung 21: Thrombininhibitor 8-5 im Komplex mit Thrombin. Saure Bereiche auf der Oberfläche von Thrombin sind in rot, basische Bereiche in blau dargestellt. Die Struktur enthält ferner noch ein Molekül Hirugen als „Kristallisationshelfer“ (in der Struktur rechts). Gut zu sehen ist Inhibitor 8-5, der im aktiven Zentrum von Thrombin bindet. 
Die Darstellung ist in einer leicht aus der Normalorientierung nach Bode herausgedrehten Form gewählt. Die Struktur enthält zudem ein Hirugen-Molekül, daß als eine Art Kristallisationshelfer eingesetzt wird. Saure Bereiche auf der Oberfläche von Thrombin sind in rot dargestellt, basische Bereiche sind in blau gezeichnet. Eindeutig erkennbar ist, daß 8-5 im aktiven Zentrum des Enzyms bindet, wobei D-Cha in die S3/S4-Tasche, LAze in die S2-Tasche und D-Tyr in die S1-Tasche bindet.

Im Folgenden sollen die wichtigsten Wechselwirkungen der einzelnen 8-5-Reste im Detail besprochen werden:

Pos. 1: Der guanidylierte Trx-Rest weist keine erkennbaren Kontakte zu Thrombin oder Wassermolekülen auf. Nach näherer Inspektion waren auch keine Kontakte innerhalb der Kristallpackung zu erkennen. Überraschenderweise besitzt der Rest dennoch eine definierte Ladungsdichte. Es kann daher vermutet werden, daß entweder bestimmte bevorzugte Konformationen (planare Guanidiniumgruppe, Ringkonformation) oder Abstoßungkräfte von basischen Gruppen (z.B. Arg221A) die Zahl der Freiheitsgrade erheblich reduzieren könnten. Interessant ist, daß der Ring des Trx-Restes zusammen mit der langen, hydrophoben Seitenkette des L-homoArg eine Art Abschirmung vom Medium bewirkt, welche z.B. den Beitrag von Wasserstoffbrücken (z.B. am Nterminalen Amid des Inhibitors) für die Gesamtbindungsenergie verstärken sollte.

Pos. 2: Der Inhibitor 8-5 weist an dieser Stelle D-Cyclohexylalanin und nicht DCyclohexylglycin (wie im Melagatran) auf. Zusammen mit dem nachfolgenden L-AzeRest der für eine starke Krümmung des Inhibitor-Rückrates an dieser Stelle sorgt, führt dies zu einem sehr tiefen Eintauchen in die S3/S4-Tasche. Kein anderer Inhibitor, von dem eine Komplex-Struktur zugänglich ist, taucht in diese Tasche so tief hinein. PPACK etwa penetriert um 1.2 $\AA$ weniger, Melagatran sogar um $2.7 \AA$ weniger tief. Dabei schmiegt sich der D-Cha-Ring sehr schön an die Oberfläche der S3/S4-Tasche an. Eine Substitution durch den starren D-Phe-Ring führt weder zu einer so idealen Passung noch taucht ein solcher Rest derartig tief in die Tasche ein. Die D-Cha-Wechselwirkung dürfte daher eine der wichtigsten Strukturdeterminanten für die Bindung an Thrombin sein. Gleichzeitig trägt der große hydrophobe Rest an dieser Stelle zur Spezifität (z.B. gegenüber Trypsin) bei. Trypsin besitzt eine viel kleinere S3/S4-Tasche. Modellierungsexperimente zeigten ferner, daß im Komplex von 8-5 mit Trypsin der hydrophobe D-Cha-Ring in unvorteilhafte Wechselwirkung mit dem Lys 174 des Trypsins treten würde.

Pos. 3: Der Inhibitor 8-5 enthält an der dritten Position ein L-Aze, das fast deckungsgleich wie der gleiche Rest in Melagatran in der S2-Tasche liegt. Wie schon erwähnt ist L-Aze mit seiner extremen Biegung des Inhibitor-Rückrates zusammen mit DCha (Pos. 2) wesentliche Strukturdeterminante für eine hochaffine Bindung des Inhibitors an Thrombin.

Pos. 4: Der D-Tyr-Ring des Inhibitors 8-5 sitzt sehr tief in der S1-Tasche und besitzt eine einzigartige Ausrichtung die so von keinem bekannten Inhibitor eingenommen wird. 
Obwohl eine neutrale Seitenkette, so macht der D-Tyr-Ring mit seiner 4-Hydroxygruppe eine Wasserstoffbrücke mit der Seitenkette des Asp189 (Thrombin), also eben der Seitenkette, die für die Bindung basischer Reste verantwortlich ist (Abb. 22).

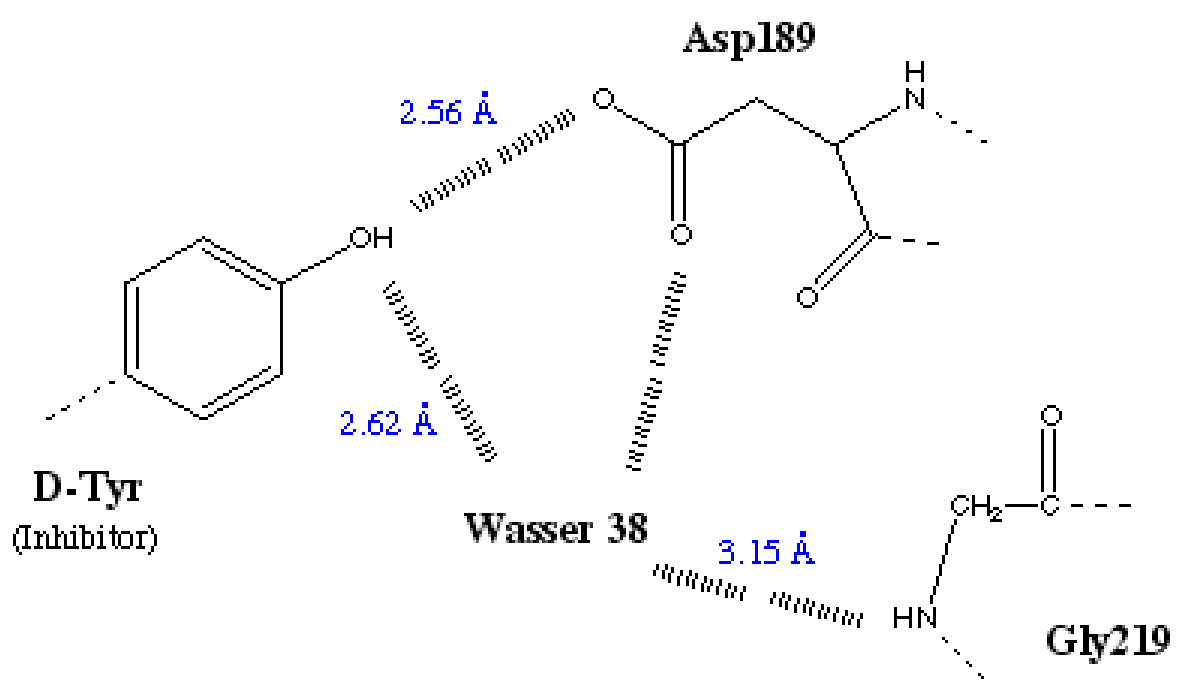

\begin{abstract}
Abbildung 22: Thrombininhibitor 8-5 im Komplex mit Thrombin, Pos. 4, D-Tyrosinrest Wasserstoffbrücken in der S1-Tasche von Thrombin.

D-Tyr des Inhibitors bindet tief in die Tasche und bildet eine Wasserstoffbrücke mit der Seitenkette des Asp189 im Thrombin. D-Tyr als neutrale Seitenkette nutzt damit eine ähnliche Strategie wie praktisch alle basischen Inhibitoren.
\end{abstract}

In diese Wechselwirkung ist auch das Wasser 38 involviert, daß D-Tyr (Inhibitor), Asp189 (Thrombin) und Gly219 (Thrombin) verbrückt. Zudem bildet das CarbonylSauerstoff des D-Tyr-Restes eine Wasserstoffbrücke zur Rückrat-N-H-Gruppe des Glu192 (Thrombin). Die D-Konformation macht dabei erst diese Wechselwirkung und die weiter unten beschriebenen Wechselwirkungen am C-Terminus des Inhibitors möglich. Im Vergleich zur Struktur von Melagatran erscheint der aromatische Ring im Falle des D-Tyr um etwa $60^{\circ}$ gekippt. Das 4-OH (8-5) reicht so tief in die S1-Tasche hinein wie dies für die NH-Gruppe des Melagatran-Benzamidins nachweisbar ist. Daher verwundert es nicht, wenn größere 4-Substituenten am D-Tyr-Ring eine effektive Bindung verhindern: 4-CN- und 4-Benzamidin-Derivate von D-Tyr zeigen 161fache bzw. 61fache Steigerungen im $\mathrm{K}_{\mathrm{i}}-$ Wert. Interessant ist auch ein Vergleich zur Strukturen der einzigen Thrombininhibitoren mit neutralem P1-Rest, für die bisher eine Struktur zugänglich ist, die 2,5-substituierten Benzamide (Lumma et al.; Tucker et al., 1998). Hier sind die aromatischen Ringe im Vergleich zu dem des D-Tyr (8-5) um ca. $30^{\circ}$ gekippt. In diesen Strukturen sind ferner keine Kontakte zwischen Inhibitor und Asp189 ausgebildet. Stattdessen macht die 5-Position des aromatischen Rings im Inhibitor einen direkten, lipophilen Kontakt mit dem aromatischen Ring von Tyr227 (Thrombin), das an der Rückseite der S1-Tasche zu finden ist, die wiederum so nicht in der 8-5-Struktur vorhanden sind. Größere Substituenten an der Position 2 des aromatischen Rings bilden Wasserstoffbrïcken zur N-H-Gruppe des Gly219 (Thrombin) aus. Ein ähnlicher Kontakt wird bei Inhibitor 8-5 durch den C-Terminus realisiert. 
Pos. 5: Die Seitenkette des L-homoArg scheint in van-der-Waals-Kontakt zum Trp60 (Thrombin) in einer Distanz von ca. $4 \AA$ zu stehen. Als basische Seitenkette bildet die Guanidinium-Gruppe des L-homoArg aber auch Wasserstoffbrücken sowohl zum Carbonyl-Sauerstoff im Rückrat von Glu192 als auch zum Wasser 125 (Abb. 23).

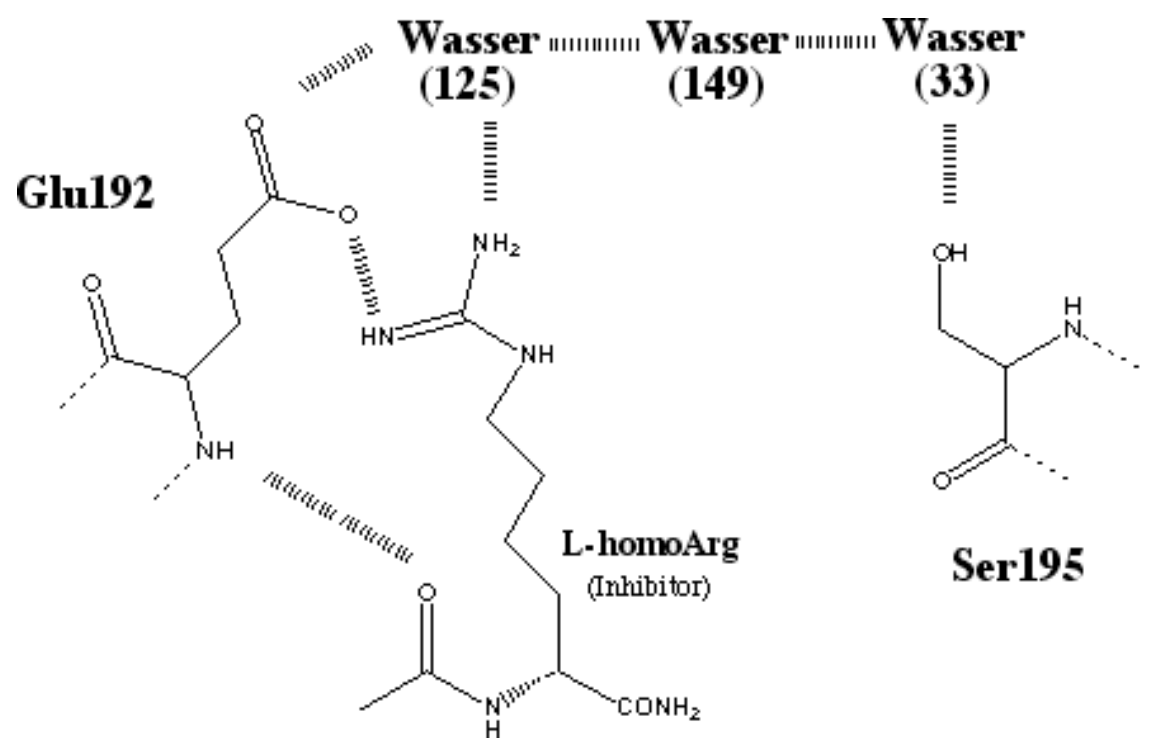

\section{Abbildung 23: Thrombininhibitor 8-5 im Komplex mit Thrombin, Pos. 5}

Wasserstoffbrücken-Netzwerk unter Einbindung von L-homoArg des Inhibitors 8-5 und den Resten Glu192 und Ser195 des Thrombins.

Dabei bilden die erwähnten Wasserstoffbrücken nur einen Teil eines extensiven Wasserstoffbrücken-Netzwerkes, daß Glu192 und L-homoArg (Inhibitor) mit Ser195 des aktiven Zentrums verbindet, wobei letzteres in eine nicht-aktive Konformation „gedrückt“" wird. Die relativ moderate Steigerung im $\mathrm{K}_{\mathrm{i}}$-Wert die bei Substitution des LhomoArg nicht nur durch das ebenfalls basische L-Lys sondern auch durch unpolare Reste wie $\varepsilon$-N-acetyliertes L-Lys oder L-Met zu beobachten sind, scheinen darauf hinzudeuten, daß die Einbindung in das Wasserstofbrücken-Netzwerkes aber wohl eher von untergeordneter Bedeutung für die Bindung ist. Dagegen zeigt die 42fache Steigerung im $\mathrm{K}_{\mathrm{i}}$-Wert bei Substitution von L-homoArg durch Gly an, daß der nur durch lange Seitenketten mögliche van-der-Waals-Kontakt zum Trp60T möglicherweise von größerer Bedeutung ist. Alle erwähnten Substitutionen konservieren allerdings das Cterminale Amid (Abb. 24). 


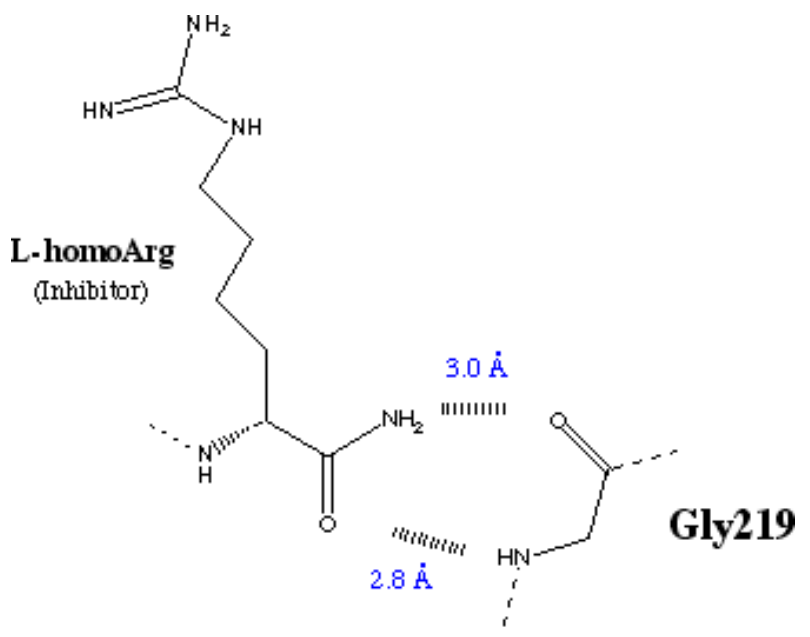

\begin{abstract}
Abbildung 24: Thrombininhibitor 8-5 im Komplex mit Thrombin, Pos. 5, C-Terminus Das C-terminale Amid des Inhibitors bildet zwei Wasserstoffbrücken zum Rückrat des Gly219-Restes im Thrombin.

Dieses bildet zwei neue Wasserstoffbrücken zum Rückrat um das Gly219 (Thrombin) herum, die für die Bindung an Thrombin von großer Wichtigkeit sind.

Für die weitere Derivatisierung, v.a. Zyklisierungen ist nicht nur die schon erwähnte Tatsache der Nähe terminaler Reste von Bedeutung. Auch der N-H-Rest des L-homoArgRückrates kommt bis auf $3.73 \AA$ an den Carbonyl-Sauerstoff des D-Cha-Rückrates heran.
\end{abstract}

Zusammenfassend kann man also sagen, daß im Komplex von $\underline{\mathbf{8}}-\underline{\mathbf{5}}$ mit Thrombin

- der D-Tyrosin-Rest (Pos. 4) in einer neuen und einzigartigen Weise tief in S1 eintaucht

- der Guanidyl-Tranexamsäurerest mit der Homo-Argininseitenkette (Pos. 1 und 5) durch einen Abschirmungseffekt die Gesamtbindungsenergie verstärken kann

- der D-Cyclohexylalanin-Rest durch die vom Azetidin-Rest (Pos. 2 und 3) verursachte Krümmung tiefer als alle bisher untersuchten Inhibitoren in die S3/S4-Tasche eintaucht

In der Stereodarstellung dieses Komplexes (Abb. 25) kann man sich den beschriebenen Bindungszustand nocheinmal bildlich vergegenwärtigen. Zur Betrachtung geht man nahe an die Abbildung heran, sodaß ein Auge die rechte, das andere die linke Bildhälfte erfaßt. Wenn nun der Blick auf Fernsicht adaptiert wird, kann man ein imaginäres dreidimensionales Bild erzeugen. Die Abbildung ist absichtlich zentral positioniert mit abgesetztem Text. 


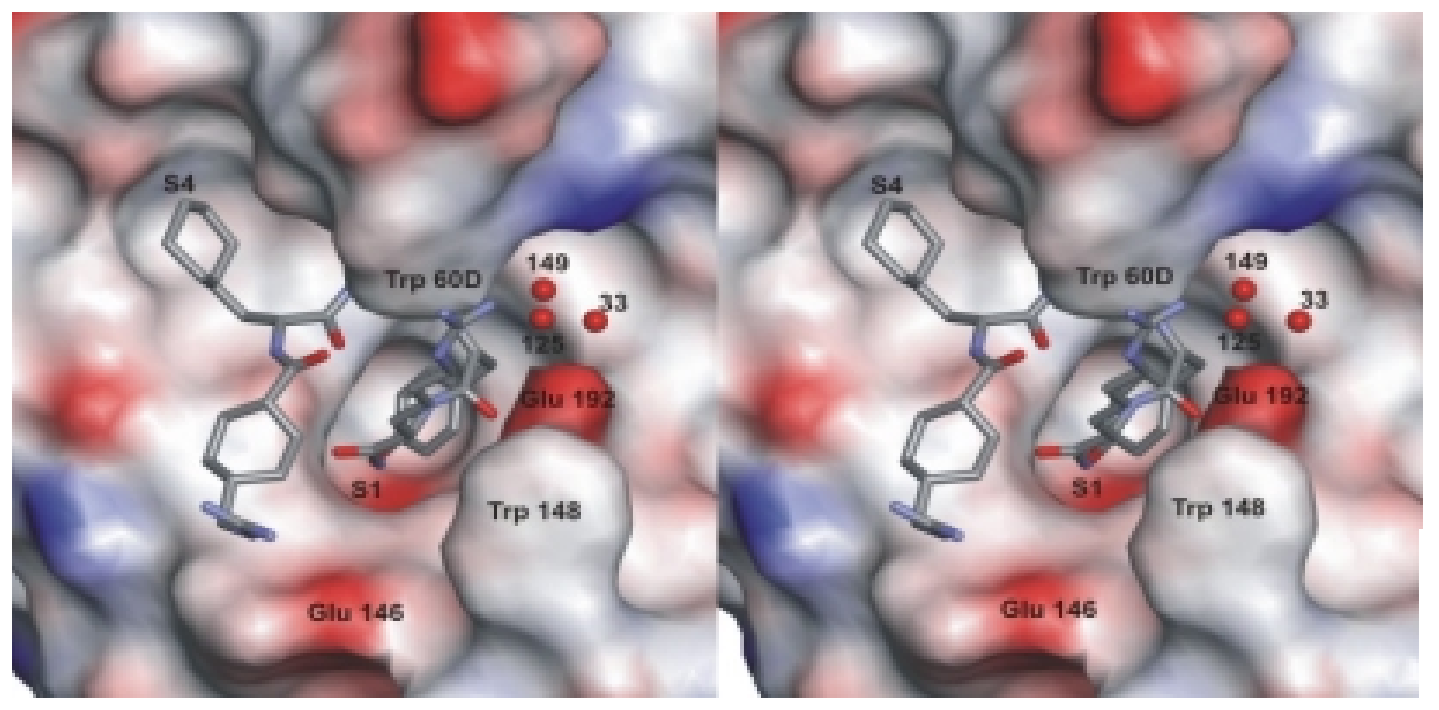

Abbildung 25: Stereodarstellung des Inhibitors 8-5 gebunden im Komplex mit Thrombin Saure Bereiche auf der Oberfläche von Thrombin sind in rot, basische Bereiche in blau dargestellt 


\subsubsection{Erste Untersuchungen am Tiermodell}

Da die neue Klasse von Inhibitoren eine Reihe von herausragenden Eigenschaften wie z.B. auch eine überraschend gute Aktivität in in-vitro-Koagulationsassays zeigte, war es interessant, auch die Elimination der Inhibitoren aus dem Blutkreislauf in-vivo zu untersuchen. Die schnelle Elimination gehört zu den häufigsten Problemen, die in der Vergangenheit eine Weiterentwicklung von Inhibitorkandidaten verhindert haben. Der „Goldstandard“ ist auch hier das Melagatran, das eine sehr langsame Elimination zeigt, ganz im Unterschied zu z.B. NAPAP (Abb. 25).

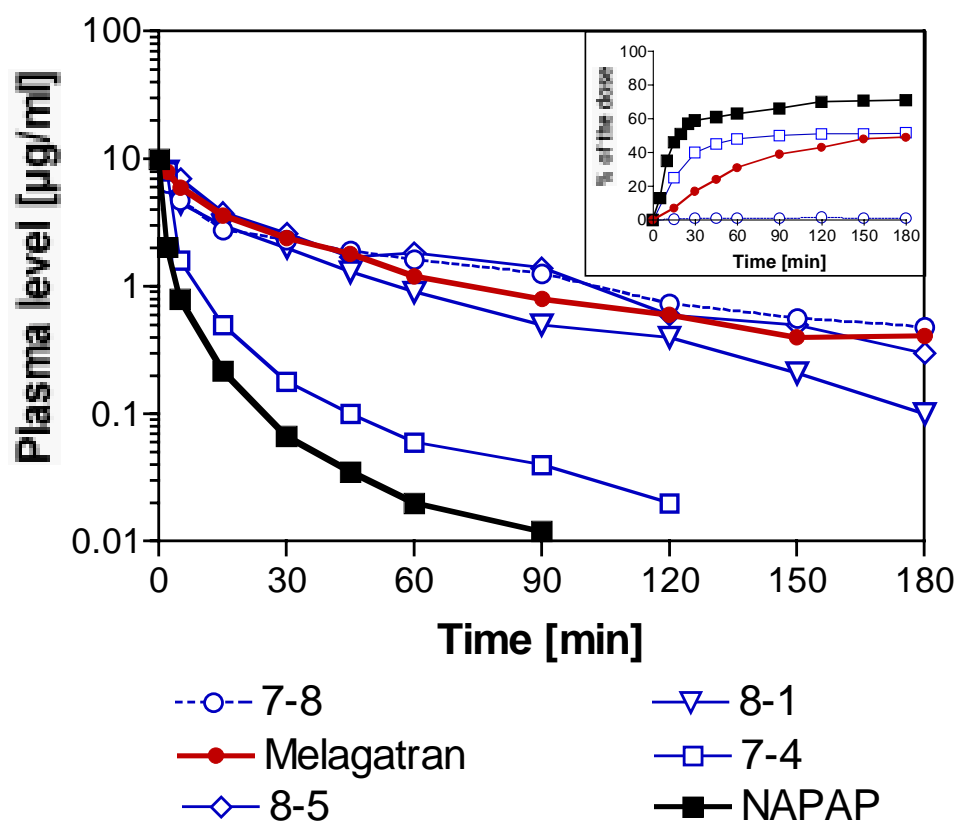

Abbildung 25: Elimination von Thrombininhibitor 8-5 im Rattenmodell. Der Ratte wurde nach Anästhesie mit Ethylurethan intravenös $1 \mathrm{mg}$ Inhibitor pro kg Körpergewicht injiziert und Blutproben nach verschiedenen Zeiten aus der rechten Halsarterie entnommen und auf ihren Gehalt an Inhibitor getestet. (Hauptbild) Elimination aus dem Blutplasma. (Einschub) Elimination auf dem Wege durch die Galle. Zwei Referenzsubstanzen wurden mitgemessen: in rot sind die Daten für Melagatran, und in schwarz die Daten für NAPAP dargestellt.

Alle getesteten Inhibitoren der Zyklen 7 und 8 mit Ausnahme von 7-4 zeigten hier im Rattenmodell eine Melagatran vergleichbare Elimination, die im Falle von 8-5 sogar noch leicht verbessert, d.h. langsamer, im Vergleich zu Melagatran erscheint. Die Elimination der neuen Thrombininhibitor-Serie zeigten - wieder mit Ausnahme von 7-4 - praktisch 
eine vollständige renale „Clearance“ (Abb. 25 Einschub). In der Galle konnte praktisch kein Inhibitor nachgewiesen werden. NAPAP, Melagatran aber auch 7-4 zeigten dagegen eine signifikante Elimination auf dem Leber-Galle-Weg. Nach 6 h konnten $71 \%$ des NAPAP, $49 \%$ des Melagtrans und $51 \%$ der eingesetzten Menge an 7-4 nachgewiesen werden.

Die Strukturen von 7-4 (schnelle Elimination) und 7-8 (langsame Elimination) unterscheiden sich interessanterweise nur in einem Acetyl-Rest, der sich am N-Terminus von 7-4 nicht aber 7-8 befindet. Vorherige Studien mit NAPAP-Analogen hatte ergeben, daß Derivate mit mehr als einer basischen Gruppe (wie z.B. auch 7-8) eine langsamere systemische und biliäre Elimination zeigten als solche mit nur einer basischen Gruppe (wie z.B. 7-4) (Hauptmann et al., 2002, Steinmetzer et al., 2002).

Zusammenfassend kann also festgehalten werden, daß es sich bei 8-5 um das erste Mitglied einer neuen Klasse von Thrombininhibitoren handelt, die sich durch einen bisher unbekannten Bindungsmodus im aktiven Zentrum von Thrombin als auch durch eine bisher nicht erreichte Spezifität von allen anderen, bekannten synthetischen Thrombininhibitoren unterscheidet.

Sehr gut schneidet 8-5 im Vergleich auch in Bezug auf Thrombin-inhibitorische Aktivität im in vitro-Assay und in Koagulationsassays, sowie in Bezug auf verschiedene ADME/Tox-Eigenschaften ab. Eine Weiterentwicklung in Richtung oral verfügbarer Inhibitor-Kandidaten erscheint daher auf jeden Fall sinnvoll. 


\subsection{Ergebnisteil HDAC}

Zwei Enzymgruppen, die Histon-Acetyltransferasen (HAT) und die Histon-Deacetylasen (HDAC) halten den Acetylierungslevel der Kernhistone im dynamischen Gleichgewicht (Grozinger and Schreiber, 2002). Die reversible Acetylierung von bestimmten Lysinen der Kern-Histone $\mathrm{H} 2 \mathrm{~A}, \mathrm{H} 2 \mathrm{~B}, \mathrm{H} 3$ und $\mathrm{H} 4$ ist von entscheidender Bedeutung für die Regulation der Genexpression in eukaryotischen Zellen, sie führt zu einer Relaxierung des Chromatins und in der Folge zu Veränderungen sowohl bei Histon-DNA, als auch bei Histon-Protein-Wechselwirkungen. Allgemein gilt, daß eine Hyperacetylierung mit einer Transkriptionsaktivierung, eine Hypoacetylierung mit Transkriptionsrepression korreliert (Grunstein, 1997; Peterson, 2002).

Eine wachsende Zahl von experimentellen Beobachtungen belegen einen Einfluß der HDAC bei der Kontrolle des Zellzyklus, der Zelldifferenzierung und in der pathologischen Situation der Krebsentstehung (Chung, 2002). Es konnte gezeigt werden, daß HDAC-Inhibitoren (HDACI) wie Trichostatin A (TSA) und Trapoxin (TPX) eine Induktion der Zelldifferenzierung, des Zellzyklusarrestes und eine Reversion von transformierter Zellmorphologie bewirken können (Jung et al., 1999; Marks et al., 2000; Yoshida et al., 1995). Daher ist es nicht verwunderlich, daß HDACI ein Potential als vielversprechende Antitumoragenzien zugesprochen wird (Jung, 2001; Kwon et al., 2003; Saito et al., 1999; Saunders et al., 1999).

Die hier gezeigten Ergebnisse umfassen zunächst die Herstellung des Enzyms und dessen Reinigung (3.2.1.), dann die Optimierung des HDAC-Assays durch neue synthetische Substrate (Wegener et al., 2003a und 2003b / 3.2.2.) und Untersuchungen zur Spezifität verschiedener HDAC mit Hilfe synthetischer Substrate und Inhibitoren (Hildmann et al., 2004 / Riester et al., 2004 / 3.2.3.) und schließlich Ergebnisse aus den Untersuchungen einiger synthetischer Inhibitoren (3.2.4.).

\subsubsection{Enzymherstellung und Reinigung}

Eine wichtige Voraussetzung für die erfolgreiche Durchführung eines HTS-Screenings und der nachfolgenden bzw. begleitenden Sekundär- und ADME/Tox-Assays oder auch für die generelle biochemische Charakterisierung eines (Ziel-)Enzyms stellt die Verfügbarkeit ausreichender Mengen dieses Enzyms in hinreichender Qualität dar. Dabei sind oft Mengen vonnöten, die gar nicht oder nicht unter vertretbarer Aufwendung von Zeit, Mühe und Kosten durch direkte Isolierung aus dem Ursprungsgewebe oder organismus gewonnen werden könnten. Bei humanen Enzymen gelten darüberhinaus besondere Beschränkungen ethischer Natur. In all diesen Fällen besteht der Ausweg in der heterologen Expression des gewünschten Proteins mit einem der vielen, in der Literatur beschriebenen Expressionssysteme (Edwards and Aruffo, 1993; Fischetti et al., 
1993; Geisse et al., 1996; Hollenberg and Gellissen, 1997; Ikonomou et al., 2003; Kost and Condreay, 1999; Oka and Rupp, 1990; Schillberg et al., 2003; Sudbery, 1996; Werner et al., 1998).

Besonders gut untersucht und oft sehr erfolgreich eingesetzt werden diverse, oft speziell modifizierte Stämme von Escherichia coli mit einem oder mehreren der zahlreichen Vektorkonstrukte dafür (Balbas, 2001). Die heterologe Produktion eines Proteins, besonders als Fusion mit einem Aufreinigungs-tag (Nygren et al., 1994), erleichtert nicht nur generell die Aufreinigung, sie vermeidet ebenfalls das Risiko, bei der Isolierung unbemerkt Enzymgemische aus Isoformen oder in der Funktion, d. h. vor allem vom Substratspektrum her ähnliche Enzyme als Kontamination zu erhalten, welche Meßergebnisse verfälschen können. Vor allem bei der Durchmusterung von Molekülbibliotheken nach Inhibitoren kann sich dies fatal auswirken, indem sowohl Wirkstoffe durch andere Enzymaktivitäten maskiert (falsch-negatives Ergebnis) als auch falsch-positive Hits durch deren Hemmung generiert werden.

\subsubsection{Produktion von humaner HDAC8}

Für dieses Enzym ist eine erfolgreiche heterologe Expression in E. coli bereits belegt (Hu et al., 2000). Auch dieses menschliche Enzym ist eine wertvolle Referenz bei Untersuchungen der Selektivität von HDACI und sollte als weiteres Beispielenzym neben der FB188-HDAH die generelle Anwendbarkeit des neuen Assays belegen. Ein weiterer Anreiz, sich näher mit diesem Enzym zu befassen, war durch auffallend wenige biochemische Daten z. B. hinsichtlich der Substratspezifität oder der biologischen Funktion in- vivo gegeben.

Die für HDAC8 codierende cDNA wurde mit den Primern HDAC8pQEEcoRIfor und HDAC8XaHISrev mittels PCR aus einer cDNA-Bibliothek aus humanem Lebergewebe amplifiziert, in pCR4TOPO zwischenkloniert und dann über EcoRI und HindIII in den Expressionsvektor pQE70 umkloniert (Abb. 27). Die rekombinante HDAC8 trägt Cterminal einen (His) ${ }_{6}$-tag, dem eine Faktor Xa-Prozessierungssequenz voransteht. 


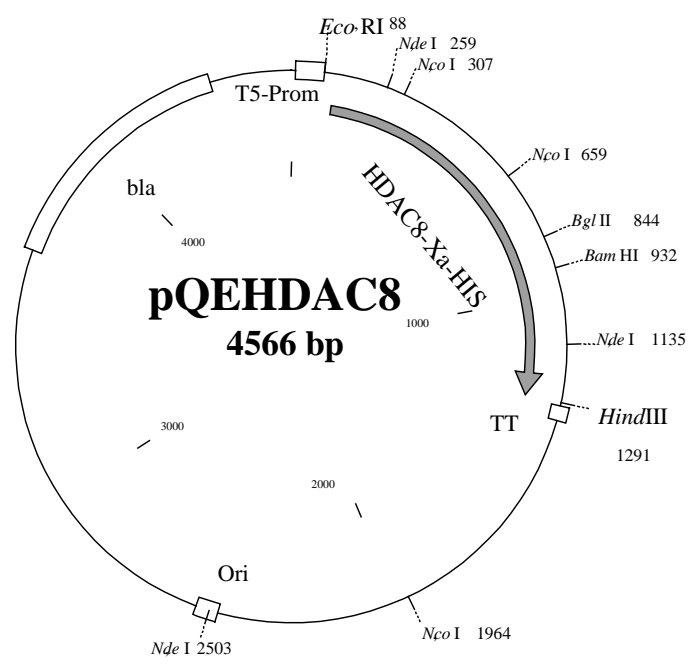

\begin{abstract}
Abbildung 27: Vektorkarte des Expressionsvektors pQEHDAC8.
Dieser diente zur heterologen Produktion von humaner HDAC8 mit einem C-terminalen His $_{6}$-tag und einer Faktor Xa-Spaltstelle. T5-Prom, T5-Promotor mit Lac-Operatorregion; bla, $\beta$-Laktamasegen für die Ampicillinresistenz; ori, Replikationsursprung ColE1.
\end{abstract}

Eine Testexpression wurde mit XL1-Blue-Zellen durchgeführt, die zuvor mit dem korrekten Vektor pQEHDAC8 (Abb. 27) transformiert worden waren. Dazu wurden 50 $\mathrm{ml}$ des Kulturmediums mit $50 \mu \mathrm{l}$ aus einer $4 \mathrm{ml}$ Vorkultur $50 \mathrm{ml}$ dYT/Amp angeimpft und die Bakterienkultur nach $3 \mathrm{~h}$ bei einer OD600 von ca. 0,4 mit $1 \mathrm{mM}$ IPTG induziert. Nach weiteren $3 \mathrm{~h}$ und $20 \mathrm{~h}$ wurden Aliquots abgenommen, die Zellen per Ultraschall aufgeschlossen, die Proteine durch SDS-PAGE (12,5\% PAA) aufgetrennt und mittels Immunoblot mit Anti-PentaHis-AK (1 : 3000) analysiert (Abb. 28), wobei sich in einer Bande bei $\mathrm{Mr} \sim 50000$ die exprimierte HDAC8 (Mr: 45240, (Hu et al., 2000) nachweisen ließ Abb.28):

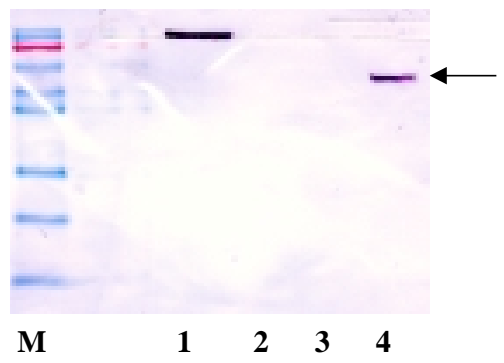

Abbildung 28: Immunodetektion der in XL1-Blue exprimierten, rekombinanten HDAC8 mit Anti-PentaHis-tag-AK.

Eine Pilotexpression von XL1-Blue-pQEHDAC8 wurde in $50 \mathrm{ml} \mathrm{LB} / \mathrm{Amp}$ unternommen. Als Kontrolle wurde ein mit dem Leervektor transformierter Stamm mitgeführt (XL1-Blue-pQE70). Nach Sonifizierung der Zellen wurde die lösliche Lysatfraktion per SDS-PAGE aufgetrennt und geblottet. Der Nachweis des rekombinanten Enzyms (Pfeil, Mr 50000) erfolgte immunologisch über Anti-PentaHis-AK und einen APgekoppelten, sekundären AK durch die NBT/BCIP-Reaktion. M: Prestained Marker (MBI) 10-160 kDa, 1 : Penicillin-Acylase (WPA) mit His-tag als Positivkontrolle (Ninkovic et al., 2001), 2 : FB188-HDAH mit N-terminalem Strep-tag, 3: XL1-Blue-pQE70, 4: XL1-Blue-pQEHDAC8. 
Ein durchgeführter HDAC-Aktivitätstest der löslichen Lysatfraktion mit Boc-Lys(Ac)AMC bzw. Ac-RGK(Ac)-AMC als Substrat bestätigte einen Umsatz der Substrate und damit die Produktion der HDAC8 in aktiver Form.

\subsubsection{Reinigung}

\section{Affinitätschromatographie mittels IMAC-Säule}

Zur Gewinnung der humanen HDAC8 sollte der C-terminale Hexahistidin-tag bei der Aufreinigung an einer mit Nickel beladenen Chelating-Sepharose-Säule ausgenutzt werden. Dazu wurde der lösliche Lysatbestandteil einer 50 ml-Expressionskultur von XL1-Blue-pQEHDAC8 auf eine äquilibrierte IMAC-Säule mit Chelating-SepharoseMatrix (SV etwa $1 \mathrm{ml}$ ) geladen und der Durchlauf aufgefangen. Nach dem Wegwaschen nicht-bindender Proteine mit HDAC8-Puffer wurde HDAC8 mit einem Stufengradienten steigender Imidazol-Konzentration in HDAC8-Puffer eluiert. Alle Fraktionen wurden mittels Immunoblot mit Anti-PentaHis-tag-AK untersucht (Abb. 29).

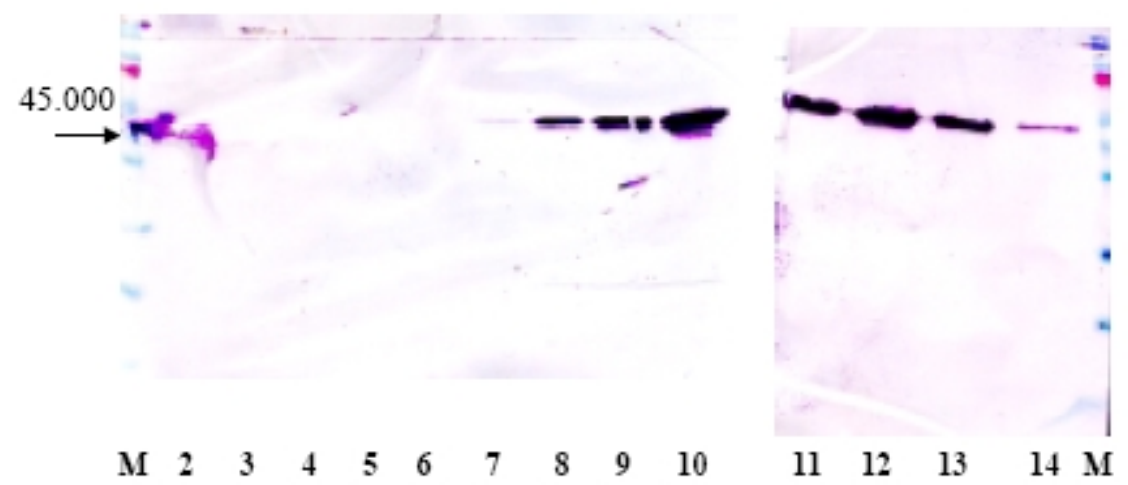

\footnotetext{
Abbildung 29:Immunoblot nach Aufreinigung der HDAC8 mit Histidin-tag über IMAC. HDAC8 mit C-terminalem Hexahistidin-tag wurde in XL1-Blue exprimiert und die Zellen mittels Zelldisruptor aufgeschlossen. Der lösliche Anteil des Lysats wurde auf eine IMAC-Säule geladen und das Enzym mit einem Stufengradienten steigender Imidazol-Konzentration eluiert. Aliquots der Fraktionen wurden mittels SDS-PAGE aufgetrennt und geblottet. Der Nachweis des rekombinanten Enzyms erfolgte immunologisch über Anti-PentaHis-AK und einem AP-gekoppelten, sekundären AK durch die NBT/BCIPReaktion. M: Prestained Marker (MBI) 10-160 kDa, 2 : Lysat, 3 : Durchlauf, 4, 5 : Waschfraktionen, $6: 20$ $\mathrm{mM}$ Imidazol, $7: 40 \mathrm{mM}$ Imidazol, $8: 60 \mathrm{mM}$ Imidazol, $9: 100 \mathrm{mM}$ Imidazol, 10: $200 \mathrm{mM}$ Imidazol, 11: 100 mM Imidazol, 12: 200 mM Imidazol, 13: 300 mM Imidazol, 14: 500 mM Imidazol.
}

HDAC8 ( $\mathrm{Mr} \sim 45000)$ eluierte vor allem bei 100 - $200 \mathrm{mM}$ Imidazol. Diese Fraktionen wurden gepoolt und über Nacht gegen HDAC8-Puffer dialysiert. Mit dem HDAC-Assay 
konnte jedoch nur beim Lysat $(50 \mu \mathrm{l})$ eine Deacetylase-Aktivität mit $150 \mu \mathrm{M}$ BocLys(Ac)-AMC als Substrat festgestellt werden. Ein Western Blot der dialysierten Fraktionen mit Anti-PentaHis-tag-AK bestätigte das Vorhandensein der HDAC8 auch nach der Dialyse.

Das Zielenzym konnte also gereinigt werden, jedoch hatte es seine Aktivität verloren. Deshalb wurden weitere Reinigungsmethoden versucht.

\section{Aufreinigung mittels Anionenaustauschchromatographie}

Da die Aufreinigung der HDAC8 über IMAC zunächst fehlgeschlagen war, erfolgte im weiteren eine Aufreinigung dieses Enzyms mittels Anionenaustausch-Chromatographie an einer Poros $20 \mathrm{HQ}$-Säule (quartäre Polyethylenimingruppen, SV ca. 7,8 ml) mit Hilfe einer Perfusionschromatographieeinheit. Im Vergleich zur IMAC konnte mit dieser Methode zwar nur eine partielle Reinigung realisiert werden, diese war aber ausreichend, um störende Medienbestandteile und einen großen Teil der Wirtsproteine zu entfernen, und hinreichend für die Enzymtests mit dem fluorogenen HDAC-Assay.

Mit einer Vorkultur von XL1-Blue-pQEHDAC8 wurde 11 LB-Medium mit Ampicillin in einem 3 l-Schikanekolben angeimpft und nach Erreichen einer OD600 von 0,6 mit $1 \mathrm{mM}$ IPTG induziert. Nach weiteren $16 \mathrm{~h}$ wurden die Zellen bei einer OD600 von etwa 4 geerntet und nach Resuspendierung in $50 \mathrm{ml}$ HDAC8-Puffer I mit einem Zelldisruptor aufgeschlossen. $5-15 \mathrm{ml}$ der per Zentrifugation geklärten und filtrierten, löslichen Lysatfraktion wurde auf den Anionenaustauscher geladen und die nicht-bindenden Lysatbestandteile weggewaschen. HDAC8 wurde mit einem linearen Salzgradienten von $0-1,8 \mathrm{M} \mathrm{NaCl}$ bei etwa $300 \mathrm{mM}$ eluiert (Abb. 30).

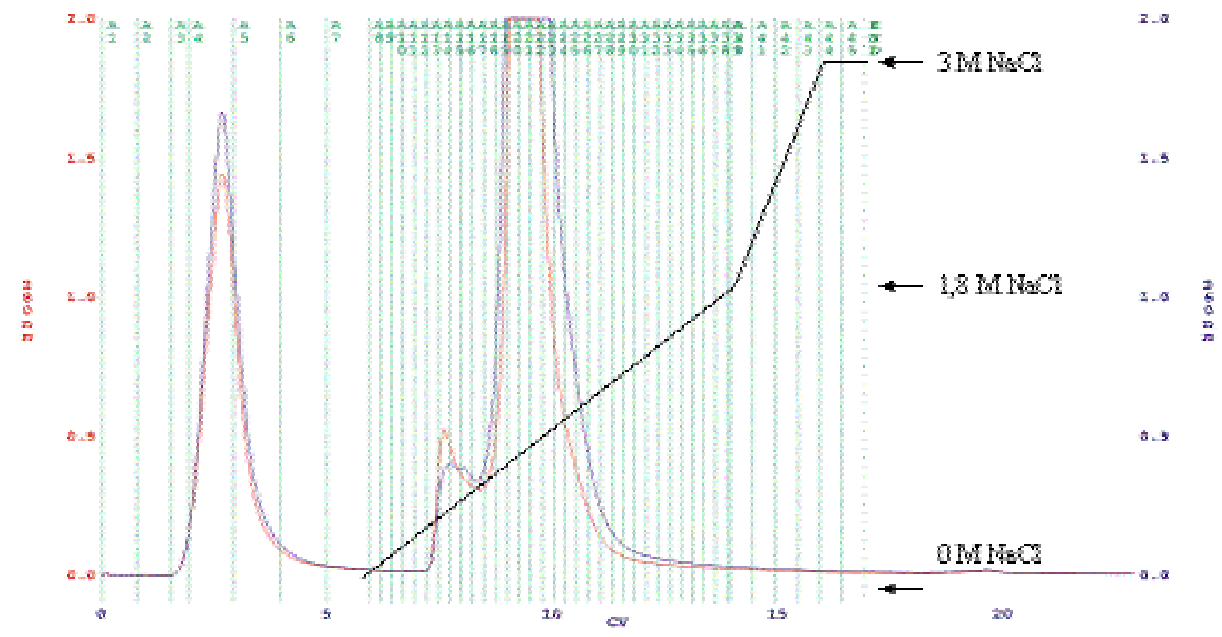

Abbildung 30: Chromatogramm der Aufreinigung von HDAC8 über Anionenaustausch mit der Perseptive BioCad Vision Analage 
Legende zur Abbildung 30:

$15 \mathrm{ml}$ mittels Zelldisruptor aufgeschlossenes und per Zentrifugation geklärtes Lysat einer Expressionskultur von XL1-Blue-pQEHDAC8 wurde auf eine Poros 20 HQ-Anionenaustauschersäule (SV ca. 7,8 ml) geladen. Nach Waschen mit 4 SV HDAC8-Puffer wurde HDAC8 mit einem linearen NaClGradienten (graue Linie) bei ca. $300 \mathrm{mM}$ in Fraktionen von je $2 \mathrm{ml}$ eluiert. Die Extinktion des Eluates wurde bei 260 und $280 \mathrm{~nm}$ (blaue bzw. rote Kurve) photometrisch vermessen.

Diejenigen Eluat-Fraktionen mit einer erhöhten $\mathrm{OD}_{280}$ wurden zur kontrolle auf ihre Aktivität im HDAC-Assay mit $150 \mu \mathrm{M}$ Boc-Lys(Ac)-AMC vermessen (Abb. 31).

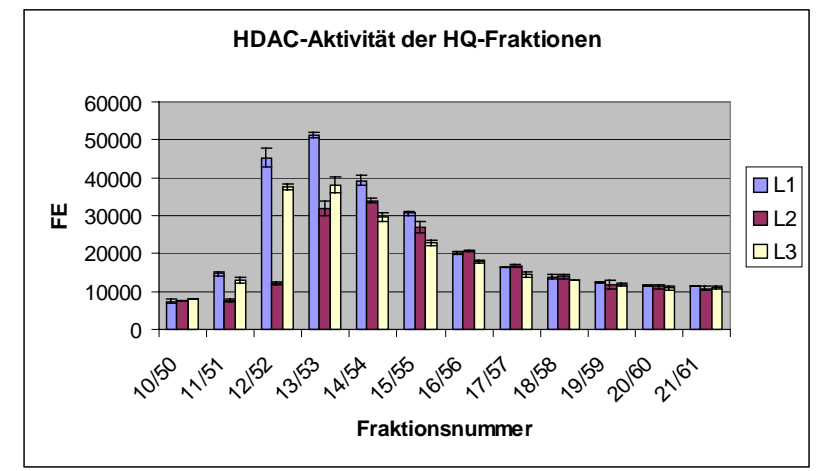

\section{Abbildung 31: HDAC-Aktivitäten einiger Fraktionen des Anionenaustauschers.}

$50 \mu 1$ einiger Fraktionen aufeinander folgender Aufreinigungen (L1, L2, L3: Läufe1-3) wurden parallel mit dem fluorogenen HDAC-Assay mit $150 \mu \mathrm{M}$ Boc-Lys(Ac)-AMC vermessen. Bei den Hintergrundkontrollen wurde dem Ansatz Trypsin vor dem Substrat zugesetzt und die erhaltenen Fluoreszenzeinheiten vom Signal der jeweiligen Fraktion subtrahiert. Die resultiernden Fluoreszenzen für die einzelnen Fraktionen (in relativen Einheiten, FE) sind angegeben.

Die aktivsten Fraktionen (Abb. 30) wurden zusammengeführt und ohne weitere Aufreinigung als HDAC8-Enzymlösung für alle Assays verwendet.

Eine Lagerung dieser Enzym-Lösung von bis zu 3 Tagen in HDAC8-Puffer I mit $10 \%$ Glyzerin bzw. bis zu 7 Tagen in HDAC8-Puffer I ohne Glyzerin war mit weniger als $50 \%$ igem Aktivitätsverlust bei $+8{ }^{\circ} \mathrm{C}$ möglich.

Die HDAC8-Aktivität wie auch die HDAC8-Signale des Immunoblots konnten keinem reinen „HDAC8-Signal“ des Chromatogramms zugeordnet werden. Allerdings war die erzielte Abreicherung an Wirtsproteinen und sonstigen Stoffen hinreichend, um das Enzym ohne nennenswerten Hintergrund in HDAC-Assays einsetzen zu können.

Trotzdem wurde noch der Versuch unternommen, nach dem Anionenaustausch noch eine weitere Aufreinigung nachzuschalten, um die Produktqualität zu verbessern. Hierzu 
wurde eine Liganden-basierte Affinitätschromatographie mit einem immobilisierten Inhibitor (SAHA-Derivat) durchgeführt.

\section{Affinitätschromatographie mit immobiliertem SAHA-Analogen}

Die Affinitätschromatographie stellt eine sehr effiziente Methode der Aufreinigung dar, da das zu isolierende Enzym in der Regel spezifisch mit dem Substrat interagiert. Die Entdeckung der ersten HDAC (Taunton et al., 1996) beruhte auf dieser Technik. Die Idee war, als Liganden ein mit einem primären Amin versehenes Derivat der SuberoylanilidHydroxamsäure SAHA auf eine Cyanogenbromid-aktivierte Sepharosematrix zu koppeln (Kohn et al., 1982), dann die Proteinlösung aufzugeben und mit einem steigenden Gradienten an Acetat zu verdrängen. Aus vorangegangenen Versuchen mit Derivaten von SAHA wußten wir, daß Variationen in para-Stellung der sogenannten Kopfgruppe des Moleküls einen geringen Einfluß auf die inhibitorische Aktivität haben, sodaß hier ein reaktiver Linker angebracht werden konnte (Abb. 12, 2.2.3.6.c). Die kovalente Bindung des aminreaktiven SAHA-Derivats mit der Matrix wurde mit cyanogenbromid-aktivierter Sepharose 4B und später, weger deren höheren $\mathrm{pH}$-Stabilität, mit NHS-aktivierter Sepharose 4 FastFlow geknüpft.

Bei der Durchführung der Chromatographie mit der letztgenannten Matrix wurden $2 \mathrm{~mL}$ proteinhaltiges Eluat aus den Fraktionen 53 und 54 des Laufs 2 der AnionenaustauschChromatographie mit HQ-Säule (Abb.31) auf die mit $20 \mathrm{~mL}$ Lysepuffer A äquilibrierten Säulen mit SAHA-Derivat-Sepharose-Matrix (SV etwa 1,5 ml) geladen und $10 \mathrm{~min}$ bei $4^{\circ} \mathrm{C}$ inkubiert, wobei der Durchlauf aufgefangen wurde. Dann wurden nicht-bindende Proteine mit 4 × 2 mL HDAC8-Puffer weggewaschen und mit 2 x $2 \mathrm{~mL} 200 \mathrm{mM}$ NaAcetat gefolgt von 2 x 2mL $500 \mathrm{mM} \mathrm{Na}$ Acetat eluiert. Der Durchlauf (FlowThrough FT) und alle Fraktionen wurden in $2 \mathrm{~mL}$ Portionen gesammelt und mittels CoomassieFärbung und Immunoblot mit Anti-PentaHis-tag-AK untersucht, als Kontrolle diente der Fraktionspool aus der Anionenaustausch-Chromatographie alleine (Abb. 32).

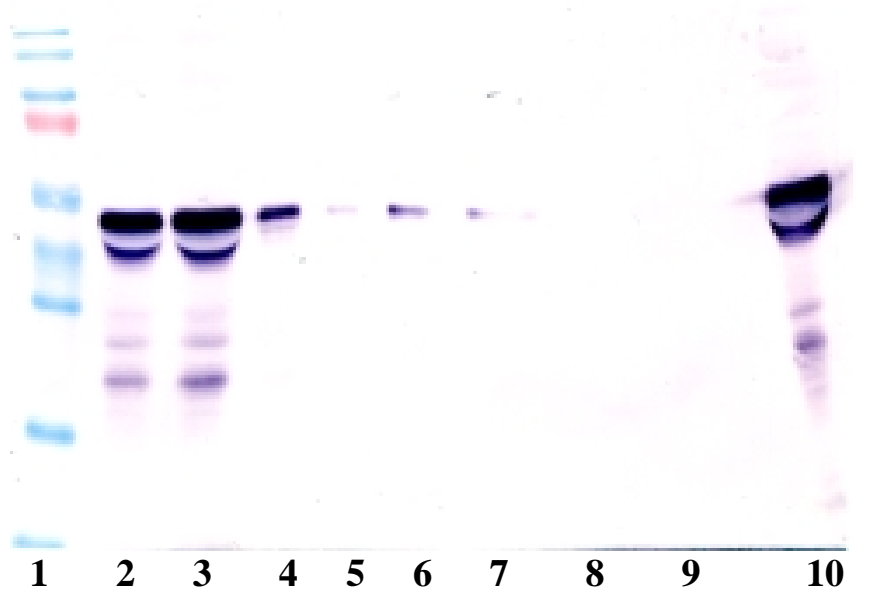

Abbildung 32: Immunoblot nach Aufreinigung der HDAC8 mit AnionenaustauschChromatographie und nachgeschalteter Affinitätschromatographie 
Legende zu Abb. 32:

Je $20 \mu \mathrm{l}$ Aliquots der Fraktionen der SAHA-Affinitätschromatographie-Fraktionen (HQ Lauf2, \#53/54) und vom HDAC8-Pool ohne Affinitätschromatographie wurden mittels SDS-PAGE aufgetrennt und geblottet. Der Nachweis des rekombinanten Enzyms erfolgte immunologisch über Anti-PentaHis-AK und einem APgekoppelten, sekundären AK durch die NBT/BCIP-Reaktion 1: Prestained protein ladder 10-160 kD (MBI), 2: FT, 3: W1, 4: W2, 5: W4, 6: E1, 200 mM NaAc, 7: E2, 200 mM NaAc, 8: E3, 500 mM NaAc, 9: E4, 500 mM NaAc, 10: Pool HDAC8, HQ-Lauf2, Frkt. 53+54 (Kontrolle)

Die Elution der HDAC8 erfolgte offensichtlich schon beim Waschen der Säule mit Puffer. Aliquote der Fraktionen 1 und 2 wurden dann im HDAC-Assay auf Aktivität hin untersucht mit dem Ergebnis, daß keine Deacetylase-Aktivität festgestellt werden konnte. Auch die Dialyse der betreffenden Fraktionen änderte daran nichts und die Versuche wurden eingestellt.

Das Zielenzym konnte zwar gereinigt werden, jedoch hatte es seine Aktivität verloren.

\subsubsection{Optimierung des HDAC-Assay}

Die Entwicklung von Inhibitoren für Histondeacetylasen war bislang insofern erschwert, daß kein für den Einsatz in in vitro-Hochdurchsatzformaten (high throughput screening, HTS) geeigneter Assay zur Verfügung stand. Bestehende Testsysteme beruhten auf radioaktiv markierten Histonen oder Peptidsubstraten und/oder verlangten eine recht aufwendige Abtrennung der Produkte vom Substrat (Gao et al., 2002; Hoffmann et al., 1999; Van den Wyngaert et al., 2000). Während Immunoblots mit gegen acetylierte Lysine gerichteten Antikörpern zwar als nicht-radioaktive Testsysteme die HDACAktivität beispielsweise in Form von hypoacetylierten Histonen wiedergeben (Carmen et al., 1999; Zhang et al., 1998), aber wohl eher ungeeignet für HTS sind, verwendete der erste echte, nicht-radioaktive HDAC-Assay MAL (N-(4-methyl-7-coumarinyl)-N- $\alpha$ (tert.-butyloxy-carbonyl)-N- $\Omega$-acetyllysinamide) als Substrat (Hoffmann et al., 1999). Ungünstigerweise muß hier ebenfalls das Produkt vom Substrat getrennt werden, indem das deacetylierte Produkt mittels Fluoreszenzdetektion nach Ethylacetat-Extraktion und HPLC quantifiziert wird, was den Assay für einen hohen Durchsatz nicht besonders geeignet macht (nicht-homogener Assay!).

Der neu entwickelte HDAC-Enzymtest (Wegener et al., 2003b) besteht aus zwei aufeinanderfolgenden Enzym-katalysierten Reaktionsschritten, wobei erstens die HDAC die $\varepsilon$-Aminogruppe des Lysins in einem peptidischen Kontext deacetyliert und zweitens eine Protease alle so entstandenen acetylfreien Substratmoleküle proteolytisch nach dem Lysin spaltet und somit das dann stark fluoreszierende AMC freisetzt (Abb. 33). 


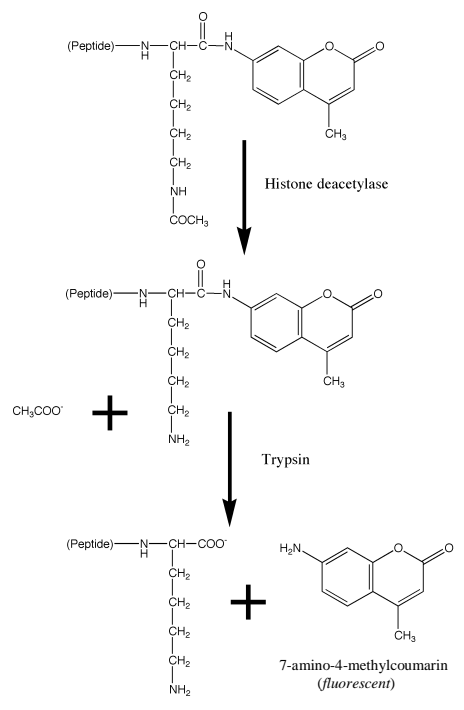

Abbildung 33: Schema des zweistufigen, fluorogenen HDAC-Assays.

Im ersten Schritt deacetyliert die HDAC die $\varepsilon$-Aminoacetylgruppen von Lysinresten in peptidischen Substraten direkt N-terminal vor dem fluorogenen AMC. Das Fluoreszenzsignal wird im zweiten Schritt nach Spaltung des so entstandenen, deacetylierten Substrates durch Trypsin generiert, indem das nun stark fluoreszierende AMC in die Lösung freigesetzt wird.

\subsubsection{Optimierung synthetischer Substrate}

Als mögliche Substrate für Histondeacetylasen wurden zunächst Tripeptide aus dem Kontext des Histons H4 abgeleitet (Kervabon et al., 1979). Mit diesen, von einem natürlichen Substrat abgeleiteten, Peptiden sollte eine mögliche Sequenzspezifität erfaßt werden. Ebenfalls interessierte die Fragestellung, ob diese längeren Peptide einen besseren Umsatz zeigen würden als das bekannte MAL für HDAC aus der Rattenleber (Hoffmann et al., 1999), welches als ein an der $\alpha$-Aminogruppe Boc-geschütztes, $\varepsilon$ acetyliertes Lysin mit C-terminalem AMC-Fluorophor ein verkürztes Minimalsubstrat des oben beschrieben Typs darstellt. MAL wird in dieser Arbeit Boc-Lys(Ac)-AMC genannt.

Die Tripeptidyl-Substrate wurden aus Boc-Lys(Ac)-AMC hergestellt (2.2.4.2.) und bestanden aus einem $\varepsilon$-acetylierten Lysinrest, dem N-terminal verschiedene Dipeptide vorausgingen, und dessen C-Terminus amidisch mit einer AMC-Gruppe verknüpft war.

Im Assay darf weder die Protease bei vorhandener e-Acetylgruppe am Lysin spalten noch das peptidgebundene AMC bei der verwendeten Detektionswellenlänge von $360 \mathrm{~nm}$ nennenswert fluoreszieren. Um dies zu bestätigen wurden Trypsin-Assays in 96 well- 
MTP mit verschiedenen, nicht-acetylierten Peptidyl-AMC-Substraten und einer Konzentration von $200 \mu \mathrm{M}$ bei unterschiedlichen Trypsinkonzentrationen von $5 \mathrm{mg} / \mathrm{ml}$ bis $5 \mathrm{ng} / \mathrm{ml}$ durchgeführt (Wegener et al., 2003c). Auch nach mehrstündiger Inkubation bei $30{ }^{\circ} \mathrm{C}$ konnte keine Spaltung der acetylierten Tripeptid-Substrate bei bis zu $50 \mu \mathrm{g} / \mathrm{ml}$ Trypsin bzw. des Boc-Lys(Ac)-AMC bei der höchsten untersuchten Trypsinkonzentration von $5 \mathrm{mg} / \mathrm{ml}$ im Ansatz beobachtet werden, während die jeweilige Trypsinkonzentration ausreichte, die nicht-acetylierten Substratvarianten mindestens innerhalb von 20 min vollständig umzusetzen.

Die o.g. Dipeptidyl-Lys(Ac)- und Boc-Lys(Ac)-AMC Substrate wurden im HDAC-Assay vermessen (Abb. 34):

\section{Umsatzkurven mit HDAC aus Rattenleber}

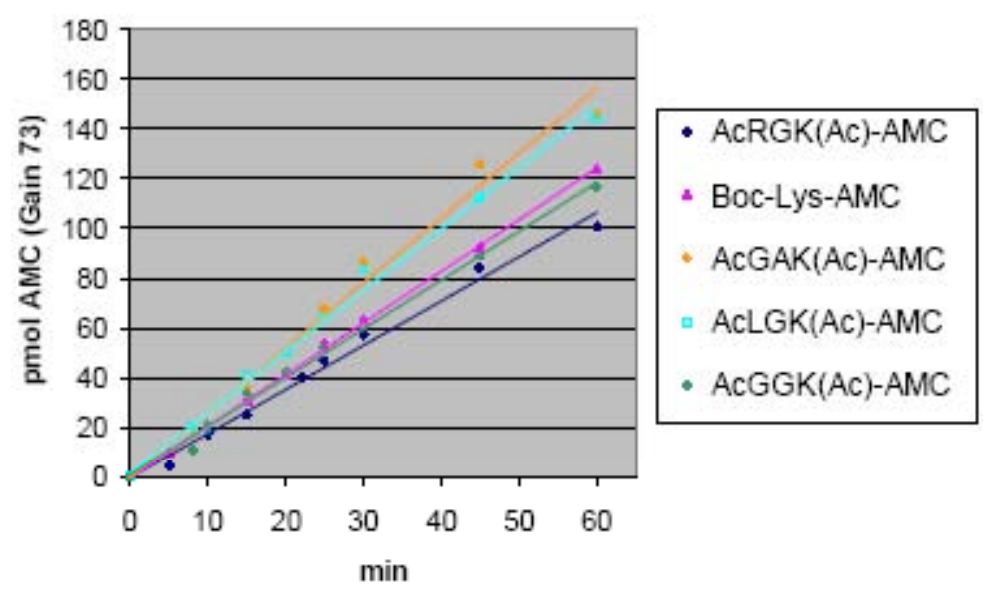

\section{Abbildung 34: Umsatzkurven verschiedener Substrate mit HDAC aus Rattenleber.}

Verschiedene fluorogene Substrate wurden im HDAC-Assay mit HDAC aus Rattenleber inkubiert und die Reaktionsansätze nach den angegebene Zeiten abgestoppt. Die Fluoreszenzsignale durch freigesetztes AMC wurden in einem MTP-Fluoreszenzreader vermessen.

Da aus den Messungen ersichtlich wurde, daß die HDAC aus Rattenleber unter diesen Bedingungen in vitro keine ausgeprägte Sequenzspezifität aufwies, wurde versucht, ein im Hinblick auf einen guten Umsatz durch Trypsin optimiertes Substrat zu generieren. Dazu wurde das bekanntermaßen effektive Trypsinsubstrat Tos-GPR-AMC zum Vorbild genommen und modifiziert, indem der P1-Rest von Arginin in Lysin abgewandelt wurde.

\subsubsection{Optimierung des Substrats für dessen Umsetzung durch Trypsin}

Die Synthese wurde so durchgeführt, daß von käuflichem Boc-Lys(Ac)-MCA die BocSchutzgruppe mit 50\% TFA / DCM über $1 \mathrm{~h}$ bei RT entfernt und eine Zwischenreinigung über Festphasenextraktion (SPE) mit C18-Kartuschen (Phenomenex, Aschaffenburg) 
durchgeführt wurde, um die nach azeotroper Entfernung mit Hexan verbliebene TFA zu entfernen. Das entsprechende „N-terminale“ Dipeptid Tos-Gly-Pro-OH wurde mit $\mathrm{H}_{2} \mathrm{~N}$ Lys(Ac)-MCA und 1,5 eq EDC in Dioxan / Wasser bei neutralem pH $\left(\mathrm{NaHCO}_{3}\right)$ umgesetzt. EDC wurde verwendet, um Kopplungsreagenzien vor der Endreinigung über HPLC durch Flüssig- Flüssig-Extraktion weitgehend zu entfernen. Es war ein schlechter Umsatz zu beobachten, der nach Aktivierung mit TBTU / NMM (1 eq / 3 eq) gesteigert werden konnte. Das korrespondierende nicht-acetylierte HDAC-Substrat Tos-GPK-AMC wurde entsprechend aus Boc-Lys(Z)-MCA hergestellt, die Benzyloxycarbonyl (Z)Schutzgruppe am Ende der Synthese mit $\mathrm{HBr}$ in HOAc abgespalten. Alle synthetischen Substrate wurde per LC-MS gereinigt (2.1.2.).

Die beiden Varianten wurden analog zu den anderen fluorogenen Tripeptiden im Trypsin-Standard-Assay vermessen. Auch in diesem Fall konnte ein Trypsinkonzentrationsbereich gefunden werden, in dem Tos-GPK(Ac)-AMC nicht gespalten wird, während das nicht-acetylierte Substrat schnell zur Gänze umgesetzt wurde.

Umsatzkurven mit diesem neuen Substrat bei einer Konzentration von125 $\mu \mathrm{M}$ und HDAC aus Rattenleber bzw. mit HDAC8 wurden wie bereits für die anderen TripeptidSubstrate beschrieben durchgeführt (Abb. 35).
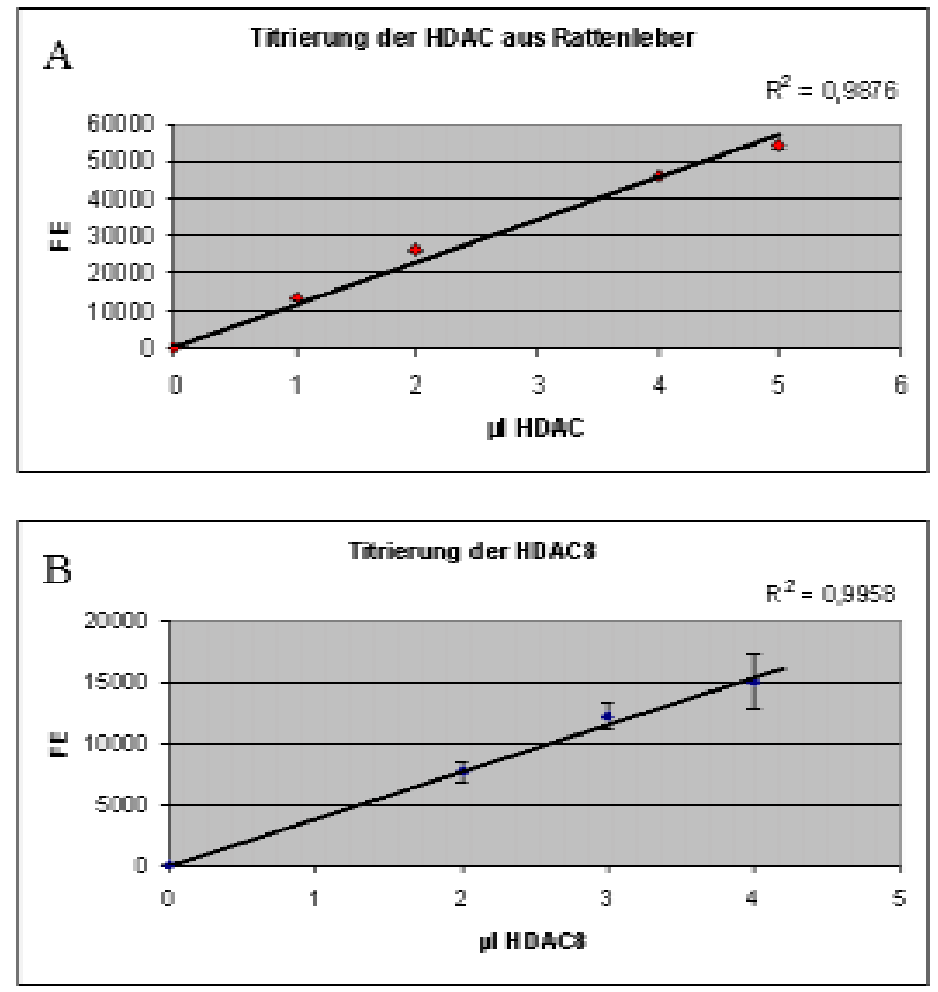

\footnotetext{
Abbildung 35: Titrierung der HDAC-Konzentration im Assay.

Standard-HDAC-Assays wurden mit unterschiedlicher HDAC-Konzentration im Ansatz mit $125 \mu \mathrm{M}$ TosGPK(Ac)-AMC durchgeführt. Die Auftragung der Fluoreszenz (FE) über der Enzymmenge belegt eine lineare Zunahme des Signals mit steigender Enzymkonzentration für A) HDAC aus Rattenleber und B) HDAC8
} 
Damit konnte eine ausreichende Robustheit des Assay im Sinne der Anfälligkeit gegen Schwankungen der eingesetzten Enzymmenge belegt werden, die in der praktischen Anwendung, wie beispielsweise bei der Durchführung eines HTS nicht ungewöhnlich sind und bei einem linearem Zusammenhang Messignal / Enzymmenge einfacher korrigiert werden können.

Zusammenfassend kann man sagen, daß mit dem neuen Substrat eine Verbesserung hinsichtlich Enzymverbrauch und Robustheit des Assay gegeben ist und diesen damit für HTS-Anwendungen nach Inhibitoren besonders geeignet erscheinen läßt.

\subsubsection{Studien zur Substratspezifität von HDAC}

Einige mechanistische Aspekte der von HDAC katalysierten Deacetylierungsreaktion sind noch nicht bis ins Detail geklärt. Die geltende Vorstellung über die Funktion des Zinkions im aktiven Zentrum des Enzyms beinhaltet sowohl Eigenschaften von Metalloproteasen mit der Polarisierung der Carbonylfunktion und einhergehender Steigerung der Elektrophilie des Kohlenstoffs, sowie Bindung des Zinkions an den Sauerstoff und eines dadurch nukleophileren Wassermoleküls, als auch dem von Serinproteasen bekannten Asp-His- Ladungsübertragungs-system (Finnin et al., 1999). Das letztgenannte System ist im HDAC6-ähnlichen Enzym FB188 HDAH nur unvollständig vorhanden (Hildmann et al., 2004). Der Befund, daß gezielt als Übergangszustand-Analoge entwickelte phosphorbasierte Inhibitoren nur schwache Wirkung zeigten (Kapustin et al., 2003) gibt ebenso Anlass den von Finnin et al. postulierten Mechanismus zumindest in Teilen infrage zu stellen bzw. experimentell zu überprüfen.

Ebenso noch nicht vollständig geklärt ist die Frage nach den natürlichen Substraten der verschiedenen HDAC-Subtypen. Neuere Untersuchungen deuten darauf hin, daß einige HDAC bei Acetylierungsvorgängen von Nicht-Histonproteinen und kleineren Molekülen in anderen zellulären Prozeßen eine Rolle spielen können (Kouzarides, 2000), beispielsweise bei der Deacetylierung von Tubulin zur Regelung der Zellmotilität (Zhang et al., 2003). Bei der Charakterisierung von HDACs in Bezug auf ihre natürliche Substratspezifität könnte die Kenntnis ihrer Spezifität bezogen auf kleinere, peptidische Substrate von Nutzen sein. Leider existieren für synthetische Substrate der HDAC bis heute keine umfassenden biochemischen Studien. Mit Derivaten von Lys(Ac) als Sonden sollte die Spezifität verschiedener HDAC untersucht werden, als Basis für die Entwicklung besserer, spezifischer Substrate und Inhibitoren (Riester et al., 2004). Unspezifische Inhibitoren bergen in der Regel ein großes Risiko für Nebenwirkungen in sich, da sie in wichtige nicht-pathogene Zellabläufe eingreifen und daher mehr schaden als nutzen könnten. 


\section{Kleine synthetische Substrate als Sonden der Spezifität}

Zunächst wurde eine Reihe von Substraten synthetisiert (2.2.4.1), mit deren Hilfe der Einfluß von Größe und Elektrophilie des Acylrestes untersucht werden sollte. Alle Produkte basieren auf Boc-Lys( $\varepsilon-X)$-AMC und wurden über LC-MS gereinigt (alle Reinheiten $>90 \%$ ) und charakterisiert (siehe Zusammenfassung in Tab.7):

Alle Substrate wurden in DMSO gelöst und im Assaypuffer verdünnt. Die Pipettierarbeiten und Fluoreszenzdetektion wurden in der CyBio Screening-Anlage wie beschrieben (2.2.3.7.) durchgeführt. Um zeitaufgelöste Signale zu erhalten, wurde von diesen Standardassays abweichend die Reaktion mit Rattenleber-HDAC und HDAC8 bei 0, 20, 40, 60 und 90 min mit Trypsin/TSA abgestoppt, bei den anderen Enzymen ist wegen der Resistenz gegen tryptischen Verdau wie gewohnt (2.2.3.7.) kontinuierlich gemessen worden. $K_{M}$ und $v_{\max }$-Werte wurden wie beschrieben (AAV 10) bei verschiedenen Substratkonzentrationen über den Hanes-Plot bestimmt, alle Messungen wurden in Dreifachbestimmung durchgeführt.

Im gleichen Screeningansatz wurde der inhibitorische Effekt $50 \mathrm{mM}$ hoher Salzkonzentrationen der den Abgangsgruppen der Substrate entsprechenden Säuren (Acetat, Propionat, Trifluoracetat sowie $\mathrm{NaCl}$ als Referenz) bestimmt.

Die untersuchten Enzyme waren
A. HDAC aus Rattenleber (Calbiochem, Bad Soden)
B. HDAC8 (menschlich, rekombinant wie oben beschrieben)
C. FB188 HDAH (HDAC6-ähnlich, Hildmann et al., 2004))
D. HDAH aus Pseudomonas aeruginosa (Hildmann et al., 2004)

Zunächst wurden die Proben eingesetzt, um die sterischen Ansprüche der einzelnen Enzyme und den Effekt der Säurestärke der Abganggruppe zu untersuchen. Da die Substrate exakt auf den bisher verwendeten fluorogenen Substraten basierten, war einfach die Messung an freigesetztem AMC das Mass für eine erfolgte Umsetzung.

\section{Sterische Ansprüche}

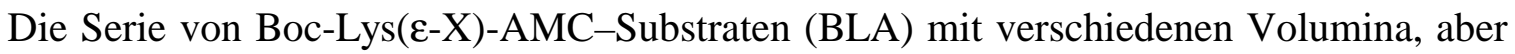
vergleichbaren $\mathrm{pK}_{\mathrm{A}}$-Werten (X = Ac-, Prop-, But-, Isobut-, Pivalin-Rest, vergl. Tab.7) wurde benutzt, um das Volumen der Aktivitätstasche der verschiedenen Mitglieder der HDAC-Superfamilie zu untersuchen (Abb. 37 A-D): 

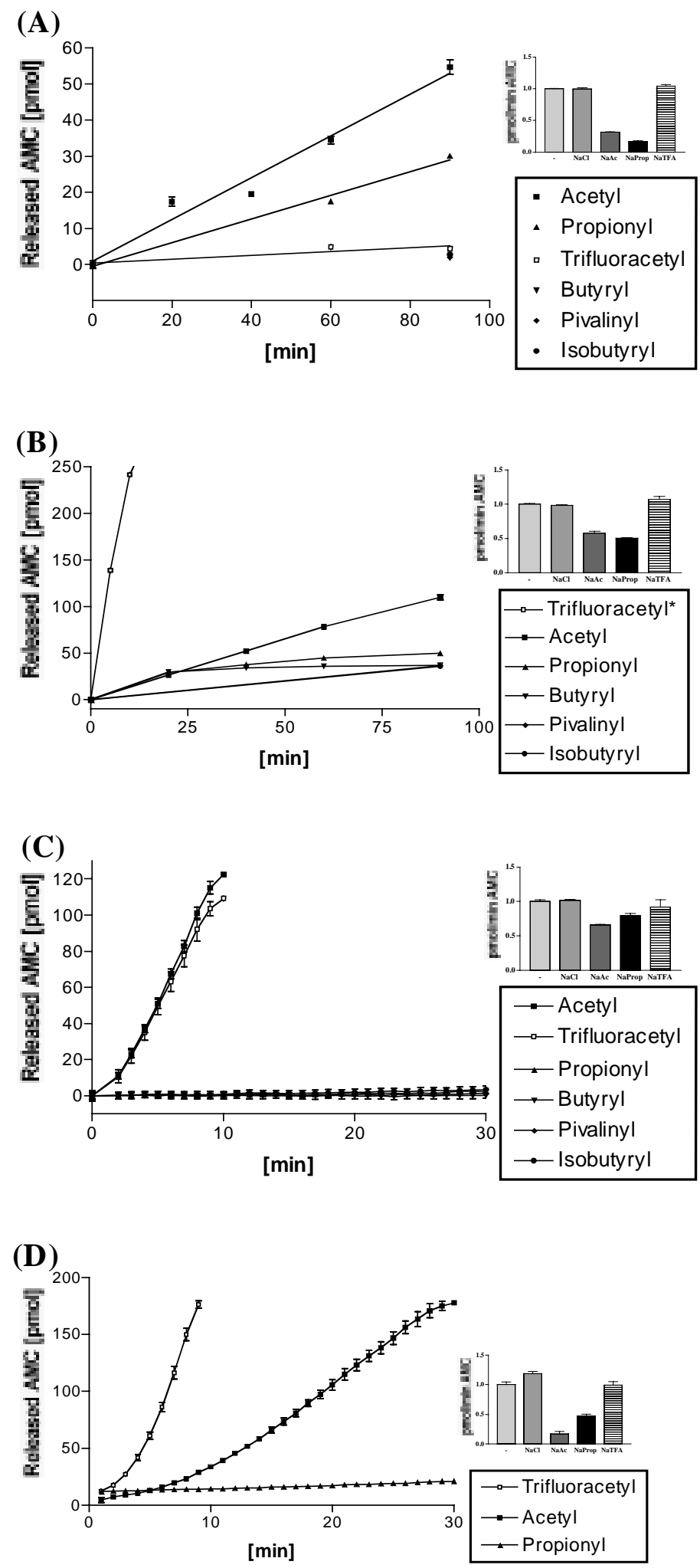

Abbildung 37: Zeitabhängige Aktivität von HDAC und HDAC -ähnlichen Enzymen gegenüber synthetischen Substraten

(A) Rattenleber HDAC, (B) rekombinante humane HDAC 8, (C) HDAC 6-ähnliche FB188 HDAH von Bordetella/Alcaligenes strain FB188 und (D) HDAH von P. aeruginosa 
Legende zu Abb. 37:

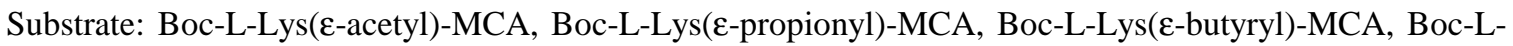
Lys-( $\varepsilon$-isobutyryl)-MCA, Boc-L-Lys( $\varepsilon$-pivalinyl)-MCA und Boc-L-Lys( $\varepsilon$-trifluoracetyl)-MCA (Symbole siehe Legende in Abb.37).

In den Einschüben ist der (inhibitorische) Effekt von $50 \mathrm{mM}$ verschiedener Natriumsalze auf den StandardHDAC-Assay mit Boc-L-Lys( $\varepsilon$-acetyl)-MCA dargestellt (von links nach rechts: ohne Salz - Chlorid Acetat - Propionat - Trifluoracetat)

Die zeitabhängige Aktivitätsentwicklung mit den verschieden Substraten läßt für HDAC aus Rattenleber (A) (HDAC rl) erkennen, daß Acetyl-(BLA) das beste Substrat darstellt $\left(\mathrm{K}_{\mathrm{M}} 3,7 \mu \mathrm{M}\right)$, Propionyl-(BLA) aber noch umgesetzt wird $\left(\mathrm{K}_{\mathrm{M}} 105 \mu \mathrm{M}\right)$. Keines der voluminöseren (BLA)-Substrate wird umgesetzt, was mit den Ergebnissen der Inhibition durch hohe Salzkonzentrationen einhergeht: Acetat und Propionat hemmen als einzige bei einer Konzentration von $50 \mathrm{mM}$, der $\mathrm{IC}_{50}$ von Acetat wurde mit $19 \mathrm{mM}$ bestimmt.

Für (rekombinante) humane HDAC8 sind bis heute keine guten Substrate beschrieben, der $\mathrm{K}_{\mathrm{M}}$ von $>500 \mu \mathrm{M}$ für Acetyl-(BLA) steht in Übereinstimmung mit dessen geringem Umsatz (B) und den vernachlässigbaren Umsätzen der größeren Substrate durch dieses Enzym. Allerdings kann mit hohen Dosen Acetat und Propionat eine Hemmung registriert werden, die im Vergleich zu (A) geringer ausfällt.

Bei der HDAC6-ähnlichen FB188 HDAH (C) kann ein guter Umsatz von einzig Acetyl(BLA) beobachtet werden $\left(\mathrm{K}_{\mathrm{M}} 14 \mu \mathrm{M}\right)$ und weniger prominente Salzeffekte, die verwandte HDAH von P.aeruginosa (D) wird im Gegensatz dazu erheblich vor allem von Acetat gehemmt; setzt aber ebenso nur Acetyl-(BLA) mit einem $\mathrm{K}_{\mathrm{M}}$ von $58 \mu \mathrm{M}$ um.

\section{Effekt der Abgangsgruppe}

Wie oben erwähnt, geht man bei der HDAC-katalysierten Reaktion im Allgemeinen von einem kombinierten Mechanismus Zink-induzierte erhöhte Elektrophilie der Abgangsgruppe / Asp-His-Ladungsübertagungssystem-induzierte erhöhte Nukleophilie eines $\mathrm{H}_{2} \mathrm{O}$ Moleküls aus. Demnach sollten Substrate mit elektrophileren, stärkeren Säureresten als bessere Abgangsgruppen auch besser umgesetzt werden. Aus diesem Grund wurden die Trifluoracetyl TFA-(BLA) und Methansulfonyl Mesyl-(BLA) Substrate zum Einsatz gebracht.

Tatsächlich wurden bei HDAC8 (B) und HDAH von P.aeruginosa (D) deutliche Umsatz-steigerungen mit $\mathrm{K}_{\mathrm{M}}$-Werten von $247 \mu \mathrm{M}$ bzw. 6,3 $\mu \mathrm{M}$ für TFA-(BLA) gegenüber Acetyl-(BLA) gefunden. Für HDAC8 stellt TFA-(BLA) das beste bisher beschriebene Substrat dar.

Für FB188 HDAH (C) sind sowohl TFA-(BLA), als auch Acetyl-(BLA) ähnlich gute Substrate ( $\mathrm{K}_{\mathrm{M}} 39$ bzw. $14 \mu \mathrm{M}$, s. Tab.7). 
Überraschend ist der schlechte oder fehlende Umsatz von TFA-(BLA) durch HDAC rl (A): Produkthemmung kann angesichts fehlender Hemmung durch Na-TFA (Einschub Abb.37 (A), oben rechts außen) ausgeschlossen werden.

Beim Mesyl-(BLA) Substrat, dessen Abgangsgruppe Methansulfonsäure die bei weitem stärkste Säure in der untersuchten Reihe darstellt und deshalb theoretisch die Reaktionsrate hätte beschleunigen müssen, konnte nur mit FB188 HDAH (C) ein Umsatz $\left(K_{M} 82 \mu \mathrm{M}\right)$ festgestellt werden. Eine Erklärung für die fehlende Akzeptanz diese Substrats mag einmal die veränderte Geometrie durch den Austausch von $\mathrm{C}=\mathrm{O}$ durch $\mathrm{O}=\mathrm{S}=\mathrm{O}$ sein, kann aber auch durch eine Produkthemmung erklärt werden, die durch Zugabe von Na-Methansulfonat (mit einem $\mathrm{IC}_{50}$ von $35 \mathrm{mM}$ ) bestätigt wurde. Abzuleitende mechanistische Überlegungen werden noch diskutiert (4.3.3.).Die gewonnenen Daten sind in der folgende Tabelle zusammengefaßt (Tab.7).

Tabelle 7: Eigenschaften synthetischer Substrate und $K_{M^{-}}$Werte für verschiedene HDAC

\begin{tabular}{|c|c|c|c|c|c|c|c|c|c|}
\hline \multirow[t]{3}{*}{ Rest $X=$} & \multirow[t]{3}{*}{ Struktur } & \multirow[t]{3}{*}{$\begin{array}{c}\mathbf{m} / \mathbf{z} \\
\text { kalk. }\end{array}$} & \multirow[t]{3}{*}{$\begin{array}{l}\mathrm{m} / \mathbf{z} \\
\text { exp. }\end{array}$} & \multirow{3}{*}{$\begin{array}{c}\text { Vol. } \\
\text { freie } \\
\text { Säure } \\
{\left[\AA^{3}\right]^{a}}\end{array}$} & \multirow{3}{*}{$\begin{array}{c}\mathbf{p K}_{\mathbf{a}} \\
\text { freie } \\
\text { Säure } \\
\mathbf{b}\end{array}$} & \multicolumn{4}{|c|}{$\begin{array}{c}\mathbf{K}_{\mathrm{M}} \text {-Werte } \\
{[\mu \mathrm{M}]}\end{array}$} \\
\hline & & & & & & $\mathbf{A}$ & $\bar{B}$ & $\mathrm{C}$ & $\bar{D}$ \\
\hline & & & & & & $\begin{array}{c}\text { RL- } \\
\text { HDAC }\end{array}$ & $\begin{array}{c}\text { hum. } \\
\text { HDAC } 8\end{array}$ & $\begin{array}{l}\text { FB188 } \\
\text { HDAH }\end{array}$ & $\begin{array}{l}\text { P.aerog } \\
\text { HDAH }\end{array}$ \\
\hline Acetyl & & 446,4 & 446,4 & 61,2 & 4,76 & 3,7 & $>500$ & 14,4 & 57,7 \\
\hline Propionyl & & 460,4 & 460,5 & 78,2 & 4,88 & 105 & NA & NA & NA \\
\hline Butyryl & & 474,4 & 474,5 & 95,2 & 4,82 & NA & NA & NA & NA \\
\hline Isobutyryl & & 474,4 & 474,5 & - & 4,86 & NA & $\mathrm{NA}$ & $\mathrm{NA}$ & NA \\
\hline Pivalyl & & 488,4 & 488,4 & 112,2 & 5,05 & NA & NA & NA & NA \\
\hline Trifluor- & & 500,3 & 500,5 & & 0,23 & NA & 247 & 38,6 & 6,3 \\
\hline Methyl & & 482,5 & 482,4 & & $-1,98$ & NA & NA & 82,4 & $\mathrm{NA}$ \\
\hline
\end{tabular}

${ }^{a}$ (Xiang, 1998) ${ }^{b}$ www.research.umbc.edu/ dfreyl/acidbase.htm

NA: keine signifikante Aktivität im Standardassay

Tabelle 7 enthält die Daten der Strukturen, berechnete und gefundene Molekülionen $[\mathrm{M}+\mathrm{H}]^{+}$, Molekulares Volumen und $\mathrm{pK}_{\mathrm{A}}$ der freien Säuren (aus der Literatur) und die gemessenen $\mathrm{K}_{\mathrm{M}}$-Werte für die vier untersuchten HDAC- / HDAH-Enzyme. 


\section{Enantioselektivität und Einfluß der Länge der Seitenkette}

Um den Anspruch der vier verschiedenen Enzyme an die stereochemische Beschaffenheit des Substrats und die Länge der Lysin-Seitenkette zu beurteilen, wurden Boc-D-Lys( $(\varepsilon$ Acetyl)-AMC und Boc-L-Orn $(\delta$-Acetyl)-AMC (das Lysinanaloge mit einer um eine Methyleneinheit verkürzten Seitenkette) synthetisiert (2.2.4.1.) und in Analogie zu den Salzen der freien Säuren im vorher beschriebenen Versuch einige acetylierte Polyamine vermessen.

Zunächst wurden die freien Amine dieser Substrate mit Trypsin vermessen, da eine Aussage über die Deacetylierung dieser Substrate durch HDAC im zweistufigen Assay nur dann sinnvoll war, wenn sie in der zweiten Stufe auch von Trypsin umgesetzt würden, was tatsächlich der Fall war.

Dann wurden die Testsubstanzen Boc-D-Lys( $\varepsilon$-Acetyl)-AMC und Boc-L-Orn( $\delta$-Acetyl)AMC mit den vier Enzymen je 60 min inkubiert und die Fluoreszenzentwicklung gemessen. Als Referenz (100\%) diente das bekannte Boc-L-Lys( $\varepsilon$-Acetyl)-AMC.

Die acetylierten Polyamine wurden bei einer Konzentration von $50 \mathrm{mM}$ im Standardassay vermessen. Alle Experimente wurden in Dreifachbestimmung durchgeführt, die Ergebnisse sind in folgenden Diagrammen dargestellt (Abb. 38):
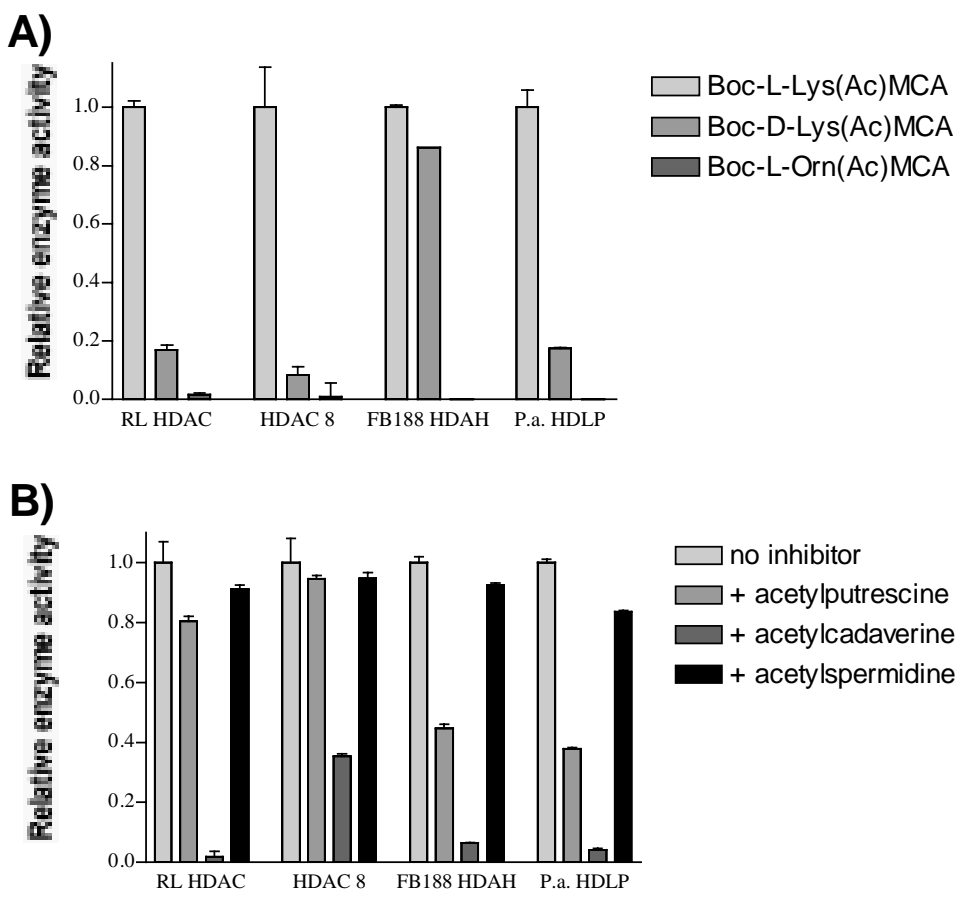

\footnotetext{
Abbildung 38: Ansprüche der HDAC-Enzyme an Stereochemie und Kettenlänge

(A): Umsatz von L-Lysin, D-Lysin und L-Ornithin-Substraten mit HDAC aus Rattenleber, HDAC8, FB188 HDAH (HDAC6-ähnlich) und HDAH aus Pseudomonas aeruginosa

(B): Hemmeffekt ohne Inhibitor und mit $50 \mathrm{mM}$ Acetylputreszin, -cadaverin und -spermidin
}

Die HDAC6-ähnliche FB188 HDAH erweist sich in diesem Experiment als nicht enantioselektiv und setzt beide Enantiomere vergleichbar um, im Gegensatz dazu wird 
bei allen anderen untersuchten Enzymen das D-Substrat kaum akzeptiert (Abb.38 A, jeweils 2.Säule). Noch empfindlicher reagieren alle eingesetzten Enzyme auf eine um eine einzige Methyleneinheit verkürzte Substratvariante, es fand praktisch keine messbare Deacetylierung statt (Abb.38 A, jeweils 3.Säule).

Dieses Ergebnis spiegelt sich auch in den Hemmversuchen mit den Acetylaminen wieder, bei denen die Cadaverin-Variante (Ac-NH- $\left.\left(\mathrm{CH}_{2}\right)_{4}-\mathrm{NH}-\mathrm{Ac}\right)$, die in der Kettenlänge dem Lysin entspricht, den ausgeprägtesten Effekt zeigt (Abb. 38 B, jeweils 3.Säule), während das kürzere acetylierte Putreszin $\left(\mathrm{Ac}-\mathrm{NH}-\left(\mathrm{CH}_{2}\right)_{3}-\mathrm{NH}-\mathrm{Ac}\right)$ und das verlängerte Spermidin (Ac-NH- $\left.\left(\mathrm{CH}_{2}\right)_{4}-\mathrm{NH}-\left(\mathrm{CH}_{2}\right)_{3}-\mathrm{NH}_{2}\right)$ kaum hemmen.

\subsubsection{Synthesen von Inhibitioren der HDAC}

Unter den synthetischen Inhibitoren von HDAC nehmen die Hydroxamate eine besondere Stellung ein. Hydroxamsäurederivate mit den typischen Vertretern Trichostatin A (TSA) und Suberoylanilid-Hydroxamsäure SAHA (Abb. 39) interagieren mit dem Zink an der Bindungstelle des Enzyms (Finnin et al., 1999). TSA, ein Naturstoff aus einer Streptomyceten-Kultur fiel durch seine Aktivität gegen Trichophyton auf (Tsuji et al., 1976), der erste Bericht seiner HDAC-inhibitorischen Aktivität bei niedrigen nanomolaren Konzentrationen in vivo folgte Jahre später (Yoshida et al., 1990). SAHA wurde ursprünglich aus einer Reihe von Substanzen entwickelt, die in niedrigen mikromolaren Konzentrationen zur Induktion der Zelldifferenzierung führten (Richon $e t$ al., 1996). Als HDAC-Inhibitor wurde es dann zwei Jahre später beschrieben und befinden sich in der klinischen Phase der Entwicklung als Wirkstoff.<smiles>O=C(CCCCCCC(=O)Nc1ccccc1)NO</smiles>

SAHA<smiles>CC(/C=C/C(=O)NO)=C\[C@@H](C)C(=O)c1ccc(N(C)C)cc1</smiles> 


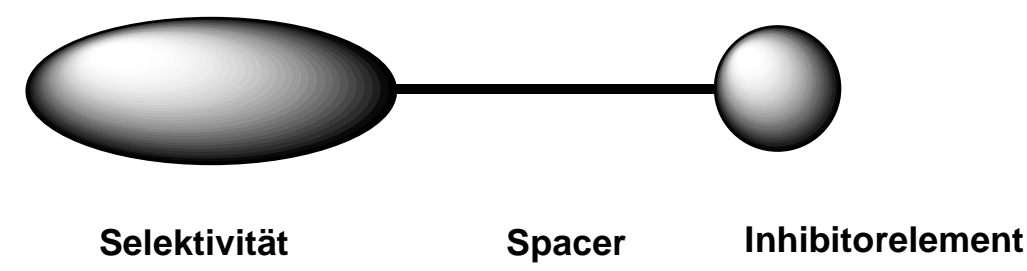

\begin{abstract}
Abbildung 39: Hydroxamat-basierte HDAC-Inhibitoren Suberoylanilid-Hydroxamsäure SAHA und Trichostatin A TSA und ein aus den gemeinsamen Strukturmerkmalen abgeleitetes Inhibitormodell
\end{abstract}

Augenscheinlich ist die strukturelle Ähnlichkeit der Substanzen, so wurde ein allgemeines Modell eines Inhibitors postuliert (Abb. 39, Jung et al., 1997).

Eine ganze Reihe Substanzen mit dem Zink-Chelator Hydroxamat als funktionellem Motiv ist seither entstanden und wird weiterentwickelt, allerdings gelten viele Hydroxamate in vivo als instabil und können durch Hydrolyse Hydroxylamin freisetzen, das potentiell mutagene Eigenschaften besitzt (Whittaker et al., 1999). Auch sind metabolische und pharmakokinetische Probleme beschrieben, die $\mathrm{zu}$ kurzen Halbwertszeiten in vivo führen (Vassiliou et al., 1999). Weiterhin sind unerwünschte Wechselwirkungen mit anderen metall-haltigen Enzymen, wie Metallo-Proteasen, Tyrosinasen oder Phospholipasen zu befürchten. Mit der Weiterentwicklung der Spacerund vor allem der Selektivitäts-bestimmenden Molekülanteile wird versucht, die letztgenannten Probleme zu umgehen.

Doch auch außerhalb der Hydroxamsäuren gibt es interessante HDAC-Inhibitoren, wie das Depsipeptid FR901228 (auch FK228 genannt) aus dem Pilz Chromobacterium violaceum (Duran \& Menck, 2001). Ursprünglich als potente, antitumoral wirkende Substanz isoliert (Ueda et al., 1994) wurde es später als mikromolarer HDAC-Inhibitor beschrieben (Nakajima et al., 1998). Die Substanz befindet sich in der klinischen Phase der Entwicklung. Sie zeigt eine bemerkenswert selektiv-toxische Wirkung (Byrd et al., 1999) und gilt als Kandidat zur Behandlung bei Leukämien, Schilddrüsen- und Nichtkleinzelligem Lungenkarzinom. Eine weitere Substanz dieser Gruppe ist das Apicidin (Abb. 40), einer gegen Plasmodien wirkenden Substanz mit HDAC inhibitorischer Wirkung im niedrigen nanomolaren Bereich (Darkin-Rattray et al., 1996). Weiterhin ist MS275 (Abb. 41) zu nennen, auf das noch näher eingegangen wird (3.2.4.2.). 

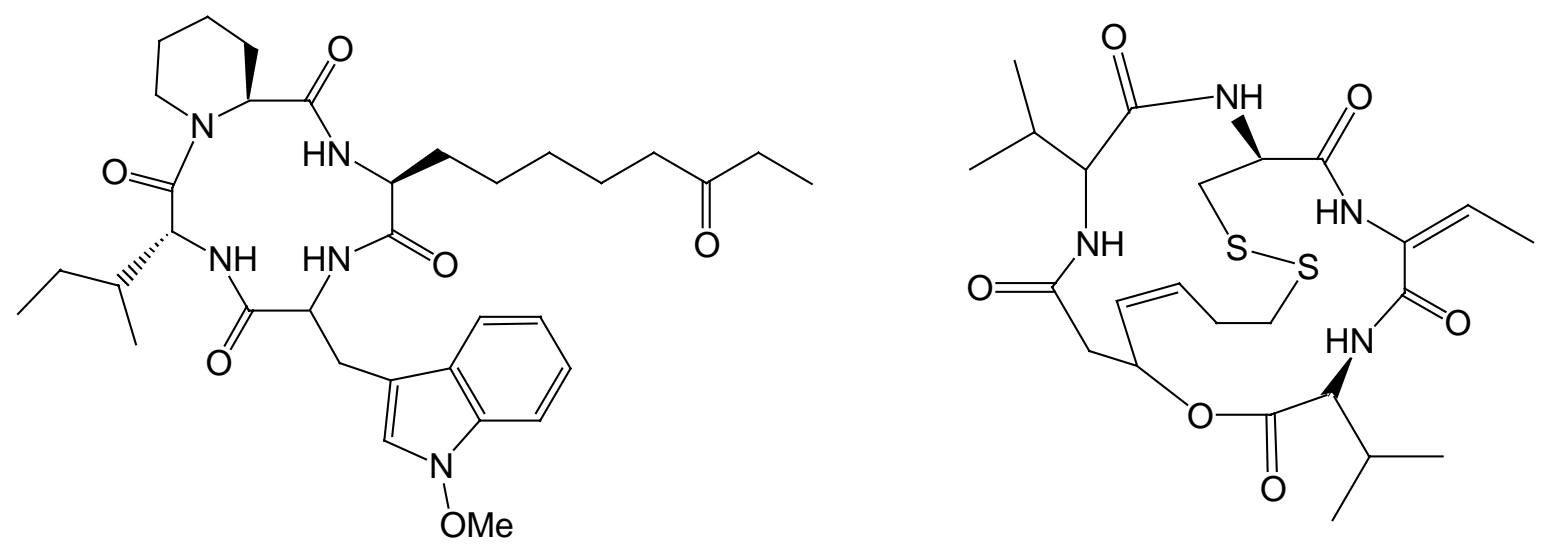

Apicidin

Depsipeptid / FR901228 / FK228

\section{Abbildung 40: Nicht-Hydroxamathaltige HDAC-Inhibitoren}

Die in unserem Arbeitskreis entwickelten Hydroxamsäuren sollen nicht Gegenstand dieser Arbeit sein, wenn auch unter den ersten Synthesen tatsächlich einfache Aminohydroxamsäuren (HA) waren, die mittels festphasengebundenem Hydroxylamin aus den 20 proteinogenen Aminosäuren generiert worden waren. Unter diesen 20 Derivaten zeigten alleine Trp-HA, Tyr-HA und Phe-HA inhibitorische Wirkung im mittleren $\mu$ molaren-Konzentrationsbereich und in der genannten Reihenfolge in abnehmender Stärke.

Ein erster Satz synthetischer Substanzen anderer chemischer Klassen, der auf mögliche HDAC-Inhibitoren hin untersucht wurde, bestand aus einer Tripeptidbibliothek (3.2.4.1.), danach werden einige synthetische Varianten des $\mathrm{zu}$ den Benzamidinen zählenden HDAC-Inhibitors MS275 vorgestellt (3.2.4.2.) und schließlich noch erste Ergebnisse aus der Untersuchung eines bisher nicht als HDAC-inhibitorisch beschriebenen Motivs des Pyranons (3.2.4.3.).

\subsubsection{Tripeptidbibliothek}

Der grundlegende Gedanke bei der Planung der Synthese war, das Motiv der $\varepsilon$-AcetylLysinhaltigen Tripeptidyl -Substrate (3.2.2. ) zu imitieren und dabei

i) die Acetylfunktion des Lysins durch andere, möglicherweise mit dem Zink interagierende oder die Aktivitätstasche blockierende Gruppen zu ersetzen und

ii) durch eine nach Gesichtspunkten hoher Diveristät ausgewählte Bausteingruppe für die Synthese des verbleibenden Dipeptids Informationen über bevorzugte Motive dieses Molekülanteils zu gewinnen 
Die Synthese-Methode der Bibliothek ist unter 2.2.5.2. beschrieben. Die eingesetzten 20 Aminosäuren für die Generierung der Dipeptidsequenz waren: (Ein-Buchstaben-Code ohne Klammern)

1. A 4-Phenylpiperidin4-OH

2. $\mathrm{R}$ D-Histidin

3. N Tetrahydroisoquinolin3-OH

4. D Asparaginsäure

5. C 3-Pyridyl-D-Alanin

6. Q Glutamin

7. E Glutaminsäure

8. G Allyl-Glycin

9. $\mathrm{H}$ Histidin

10. I Isoleucin

11. L Thienylalanin

12. K Lysin

13. M Methionin

14. F D-Phenylalanin

15. P Prolin

16. S Serin

17. $\mathrm{T}$ Threonin

18. W Tryptophan

19. Y Tyrosin

20. V Valin

Bei der Auswahl wurde darauf geachtet, saure und basische, aliphatische und aromatische, natürliche und nicht-natürliche sowie enantiomere Bausteine einzusetzen.

Die verwendeten Lysinabkömmlinge (Ein-Buchstaben-Code mit Klammern) waren:

- Acrylsäurerest

(A)

- Mercaptobernsteinsäurerest (M)

- Harnstoffrest

- Formylrest

- Nicotinoylrest

Zunächst wurde die Bibliothek mit den Dipeptidsequenzen aufgebaut, dann die erhaltenen Zwischenprodukte auf fünf neue Syntheseplatten verteilt und so die fünf Unterbibliotheken fertiggestellt.

Für die Synthese der Dipeptidsequenz wurden zuerst spaltenweise die Aminosäuren 1 bis 12 aus der o.g. Liste auf alle 96 Positionen gekoppelt (X2), dann folgten reihenweise die 
restlichen acht Aminosäuren (13 bis 20), um das Dipeptid zu vervollständigen (X1). Es ergab sich folgendes Raster in einem 8 x 12 MTP-Format:

\begin{tabular}{|c|c|c|c|c|c|c|c|c|c|c|c|c|}
\hline & A & $\mathbf{R}$ & $\mathbf{N}$ & D & C & $\mathbf{Q}$ & $E$ & G & H & I & $\mathbf{L}$ & K \\
\hline M & MA & MR & MN & MD & MC & $\mathrm{MQ}$ & ME & MG & $\mathrm{MH}$ & $\mathrm{MI}$ & $\mathrm{ML}$ & MK \\
\hline $\mathbf{F}$ & $\mathrm{FA}$ & FR & FN & FD & $\mathrm{FC}$ & $\mathrm{FQ}$ & FE & FG & $\mathrm{FH}$ & $\mathrm{FI}$ & $\mathrm{FL}$ & FK \\
\hline $\mathbf{P}$ & PA & PR & PN & PD & PC & $P Q$ & PE & PG & $\mathrm{PH}$ & $\mathrm{PI}$ & PL & PK \\
\hline$S$ & SA & SR & SN & SD & SC & $S Q$ & SE & SG & $\mathrm{SH}$ & SI & $S L$ & SK \\
\hline $\mathbf{T}$ & TA & TR & TN & TD & TC & TQ & TE & $\mathrm{TG}$ & $\mathrm{TH}$ & $\mathrm{TI}$ & TL & TK \\
\hline W & WA & WR & WN & WD & WC & WQ & WE & WG & $\mathrm{WH}$ & WI & WL & WK \\
\hline$Y$ & YA & YR & YN & YD & YC & $Y Q$ & YE & $Y G$ & $\mathrm{YH}$ & $Y I$ & YL & YK \\
\hline V & VA & VR & VN & VD & VC & VQ & VE & VG & $\mathrm{VH}$ & VI & VL & VK \\
\hline
\end{tabular}

Bei den Unterbibliotheken (A) und (M) stand der abgeänderte Lysylrest C-terminal, bei (C), (F) und (N) N-terminal, zusammen mit diesen fünf Lysinderivaten ergab sich also für die fünf Unterbibliotheken das Schema:

1) (C)-X1-X2

2) (F)-X1-X2

3) $(\mathbf{N})-\mathrm{X} 1-\mathrm{X} 2$

4) $\mathrm{X} 1-\mathrm{X} 2-(\mathrm{A})$

5) $\mathrm{X} 1-\mathrm{X} 2-(\mathbf{M})$

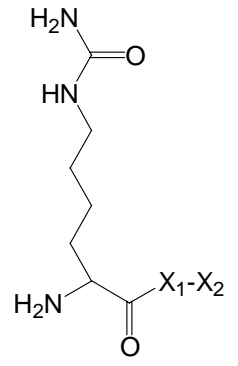

(C)<smiles>[Y2]C(=O)C(N)CCCCNC(=O)O</smiles>

(F)

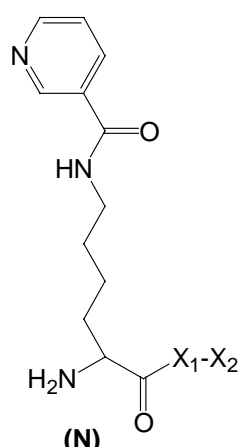

(N)

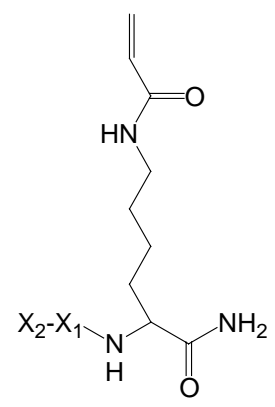

(A)

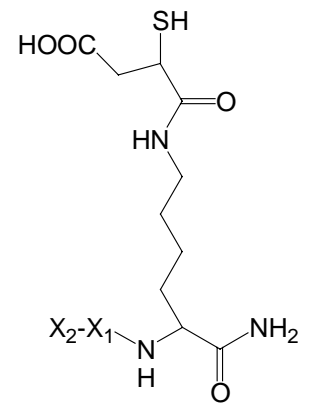

(M) 


\section{Analytik}

Die nach Abspaltung vom Harz, abrotieren der TFA und $40 \mathrm{mM}$ in DMSO aufgenommenen Produkte wurden wie beschrieben der LC-MS-Analytik unterworfen. Bei den Sub-Bibliotheken (A) und (M) wurden Nebenprodukte bis zu $40 \%$ entdeckt, die sich im Wesentlichen auf während der Synthese nicht vollständig entfernte Schutzgruppen zurückführen ließen, wobei in der Folge kein vollständiger Umsatz mit Acryl- bzw. Mercaptobernsteinsäure erfolgt war und Nebenprodukte mit den Massen der freien, nicht-derivatisierten Lysine resultierten. Bei den Sub-Bibliotheken (C), (F) und (N) konnten Reinheiten von Durchschnittlich > 85\% festgestellt werden.

\section{Screening}

Die mit Assay-Puffer aus der $40 \mathrm{mM}$ Stammlösung in DMSO manuell auf 1,8 $\mathrm{mM}$ vorverdünnten Substanzen wurden bei einer Endkonzentration von $150 \mu \mathrm{M}$ und mit 125 $\mu \mathrm{M}$ Tos-GPK(Ac)-AMC mit dem verbesserten HDAC-Assay mit Hilfe der CyBioScreen-Machine gegen HDAC aus Rattenleber auf ihre inhibitorische Wirkung hin untersucht. Beim Verdünnen fielen einige Substanzen als gelb bzw. rötlich gefärbt auf, einige fielen auch als weißer Niederschlag aus. Dieses wurde vermerkt, aber die betroffenen Substanzen trotzdem mitgeführt, da ohnehin ein Abgleich der 'Treffer' (Hits) mit Messungen der Eigenfluoreszenz bzw. Absorptionseigenschaften vorgesehen war.

\section{Ergebnis}

Nur bei den Teilbibliotheken (C), $(F)$ und $(\mathrm{N})$ wurden aktive Substanzen gefunden. Bei den nach Abgleich mit den Absorptionsmessungen als wahrscheinliche Inhibitoren verbliebenen Kandidaten wurde zusätzlich der $\mathrm{pH}$-Wert unter den Meß-Ansätzen analogen Bedingungen überprüft, um auszuschließen, daß verbliebene TFA-Reste die Pufferkapazität überschritten hatten. Dieser lag in allen Fällen wie erwartet bei pH 8.5. Alle Substanzen der Sub-Bibliotheken (C), (F) und (N) wurden einem weiteren Screening bei $30 \mu \mathrm{M}$ unterzogen.

Die hier mehr als 50\%ig hemmend wirkenden Kandidaten wurden mit dem Syntheseraster verglichen, um eine erste, grobe Struktur-Aktivitäts-Analyse durchzuführen. Es fielen auf:

Erstens Substanzen, die unabhängig von der N-terminalen Aminosäure hemmen, solange sie nur das Dipeptid D-Phe-D-His (FR) oder Trp-Lys (WK) aufweisen (Abb. 41).

Zweitens waren Substanzen dabei, deren Dipeptide aus den Kombinationen Ser-Lys (SK), Thr-Lys (TK), Trp-Lys (WK), Val-Lys (VK) oder Tyr-Lys (YK) bestanden und deren N-Terminus nicht vom Typ F war.

Drittens waren auch die Tripeptide (C)IA, (C)PR, (C)IR, (C)ME, (C)WE, (C)MK, (F)FQ, (F)FH, (F)WI, (F)ML, (F)FL, (F)PL, (N)MR und (N)FK aktiv. 
Die meisten Substanzen dieser Teilbibliotheken waren allerdings unwirksam gegen HDAC aus Rattenleber.

Zur Abschätzung des $\mathrm{IC}_{50}$ wurden Standard-HDAC-Assays mit $400-0,4 \mu \mathrm{M}$ der Tripeptide mit den Bausteinen FR und WK der Typen C, F, N und zusätzlich auch der Typen A und M in Einfachansätzen durchgeführt (Tab. 8).

Tabelle 8: $\mathrm{IC}_{50}$-Werte der besten HDAC-Inhibitoren aus der Tripeptidbibliothek

\begin{tabular}{|l|c|c|c|c|c|}
\hline \multicolumn{1}{|c|}{ Dipeptid } & A & C & F & M & N \\
\hline $\begin{array}{l}\text { TA } \\
\text { Thr-Phenylpiperidin }\end{array}$ & - & $95 \mu \mathrm{M}^{*}$ & $374 \mu \mathrm{M}$ & - & $246 \mu \mathrm{M}$ \\
\hline $\begin{array}{l}\text { FR } \\
\text { D-Phe-D-His }\end{array}$ & - & $10 \mu \mathrm{M}^{*}$ & $34 \mu \mathrm{M}$ & - & $7 \mu \mathrm{M}$ \\
\hline $\begin{array}{l}\text { WK } \\
\text { Trp-Lys }\end{array}$ & - & $4 \mu \mathrm{M}^{*}$ & $4-40 \mu \mathrm{M}$ & - & $5 \mu \mathrm{M}$ \\
\hline
\end{tabular}

* Strukturen davon in Abb.41<smiles>CC(O)C(NC(=O)C(N)CCCCNC(N)=O)C(=O)N1CCC(C(N)=O)(c2ccccc2)CC1</smiles>

(C)TA

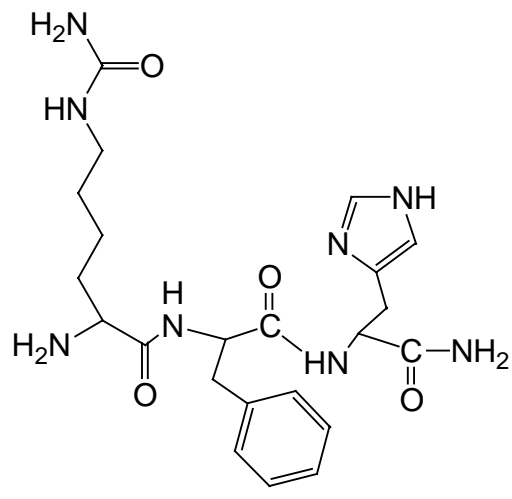

(C)FR<smiles>NCCCCC(Cc1c[nH]c2ccccc12)NC(=O)CNC(=O)C(N)CCCCNC(N)=O</smiles>

(C)WK

\section{Abbildung 41: Strukturen der auffälligen Dipeptidkombination der (C)-Bibliothek}

Aus den Ergebnissen kann man den Schluß ziehen, daß die Kombination aromatische Aminosäure / basische Aminosäure (D-Phe-D-His oder Trp-Lys) den besten Hemmeffekt zeigt, aber auch die Kombination alkoholischer Rest der Aminosäure / basische Aminosäure aktiv ist, wenn der Lysylrest nicht Formyl- ist

Zusätzlich wurden auch alle Tripetide mit -TA vermessen. Die Tripeptide der Teilbibliotheken A und M zeigten auch bei $400 \mu \mathrm{M}$ so gut wie keine Hemmwirkung. 
Die Peptide mit - TA zeigten auch bei den Typen C, F, N selbst nur sehr moderate Hemmung.

\subsubsection{Synthese einer kleinen Bibliothek aus MS275-Analogen}

MS275 entstammt der Synthese einer Serie von Benzamid-Derivaten, die auf ihre Aktivität gegen HDAC getestet werden sollten (Saito et al., 1999). Die 2-Aminogruppe oder auch eine 2-Hydroxygruppe scheint essentiell für die hemmende Wirkung zu sein (Suzuki et al., 1999). Es ist bei geringen mikromolaren Konzentrationen wirksam und befindet sich bereits in der fortgeschrittenen klinischen Erprobung. Weitere Vertreter dieser Gruppe sind Dinaline (Acetyldinaline, CI-994), das sich in Phase III der klinischen Entwicklung befindet. Seit kurzem ist auch ein Hybrid-Molekül kommerziell erhältlich (Biomol, Hamburg), das aus dem Kopf- und Spaceranteil von SAHA und dem als Bindemotiv verwendeten 1,2-Phenylendiamins von MS275 (wobei das SAHA-Derivat als Carbonsäure mit dem Diamin amidisch verknüpft wurde) besteht.

\section{Synthese}

In einem parallelen Syntheseansatz (2.2.5.3.) einer kleinen, 24 Moleküle umfassenden Bibliothek von Verbindungen sollte die Struktur-Wirkungsbeziehung hinsichtlich des Austausches von Mittel- und Kopfteil unter Beibehaltung der vermuteten Bindungstelle am Phenylendiaminring untersucht werden. Für den Mittelteil wurden fünf und den Kopfteil 3 strukturell dem Originalmolekül ähnliche Substituenten gewählt (Abb. 42) und die Synthese mit an Festphase immobilisiertem Phenylendiamin durchgeführt. Die Produkte wurden für den nachfolgenden Assay in einer Konzentration von $50 \mathrm{mM}$ in DMSO gelöst und je ein Aliquot entnommen für die Analyse.

\section{Analytik}

Die Analytik der Produkte mittels LC-MS ergab eine Reinheit von durchweg über 80\%, bestimmt über das Diodenarray-Chromatogramm, Wellenlänge 210-500nm und die Identität der Proben wurde durch Nachweis der entsprechenden Molekülionen (einfach und doppelt geladen, $[\mathrm{M}+\mathrm{H}]^{+}$und $[\mathrm{M}+\mathrm{H}]^{2+}$ ) im Hauptsignal erbracht. Ausgenommen davon sind diejenigen Produkte, die als Mittelteil 2-Aminobenzoesäure (B1, Abb.42) enthielten - das aromatische Amin war nur zu ca. 30\% zum Carbamatsäureester umgesetzt worden, was durch die geringere Reaktivität und möglicherweise auch sterische Effekte erklärt werden kann.

\section{Screening}

Die mit Assay-Puffer aus der $50 \mathrm{mM}$ Stammlösung in DMSO manuell auf $180 \mu \mathrm{M}$ vorverdünnten Substanzen wurden bei einer Endkonzentration von $15 \mu \mathrm{M}$ und mit 125 $\mu \mathrm{M}$ Tos-GPK(Ac)-AMC mit dem verbesserten HDAC-Assay mit Hilfe der CyBioScreen-Machine gegen HDAC aus Rattenleber auf ihre inhibitorische Wirkung hin untersucht, die Messungen wurden in Dreifachbestimmung durchgeführt, der Mittelwert berechnet und angegeben. Bezugssubstanz ist die Originalsequenz von MS275 
(Produktnummer 18 in dieser Synthese). Die so ermittelten Hemmwerte wurden auf MS275 (Hemmwert $=100 \%)$ bezogen.

MS275

CAS 209783-80-2

$\mathrm{N}$-(2-Aminophenyl)-4-[N-(pyridin-3-yl-methoxycarbonyl)aminomethyl]benzamid

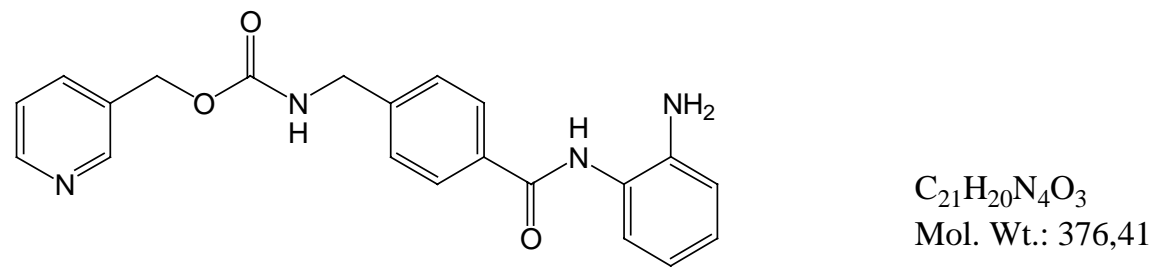

C

Kopfgruppen-Substituenten

1) 2-hydroxymethyl-pyridin

2) 4-hydroxymethyl-pyridin

3) 3-hydroxymethyl-pyridin

4) 3-aminobenzylalkohol

$\mathrm{C} 1$<smiles>[R]OCc1ccccn1</smiles>

$\mathrm{C} 2$<smiles>[R]OCc1ccncc1</smiles>

C3<smiles>[R]OCc1cccnc1</smiles>

C4<smiles>[R]OCc1cccc(N)c1</smiles>

B

Mittelteil-Substituenten

1) 2-aminobenzoesäure

2) Tranexamsäure

3) 3-aminomethylbenzoesäure

4) Piperidin-4-yl-essigsäure

5) 4-aminomethylbenzoesäure

6) 6-Aminohexansäure

B1<smiles>[R]C(=O)c1ccccc1N</smiles>

B5<smiles>[R]C(=O)c1ccc(CN)cc1</smiles>

B2<smiles>[R]C(=O)C1CCC(CN)CC1</smiles>

B6<smiles>[R]C(=O)CCCCCN</smiles>

B3<smiles>[R]C(=O)c1cccc(CN)c1</smiles>

B4<smiles>[R7]C(=O)CC1CCNCC1</smiles>

Mol. Wt.: 376,41 


\section{Ergebnisse}

Die Ergebnisse aus Analytik und Messung des Hemmwerts sind in Tabelle 9 angegeben:

Tabelle 9: Analyse- und Messergebnisse aus der MS275 Bibliothek

\begin{tabular}{|c|c|c|c|c|c|c|}
\hline $\begin{array}{l}\text { Produkt- } \\
\mathrm{Nr}\end{array}$ & Kopfgruppe & Mittelgruppe & $\begin{array}{c}\mathrm{m} / \mathrm{z} \\
\text { berechnet }\end{array}$ & $\begin{array}{c}\mathrm{m} / \mathrm{z} \\
\text { gefunden }\end{array}$ & $\begin{array}{c}\text { Reinheit } \\
\%\end{array}$ & $\begin{array}{c}\text { Hemmwert } \\
\% \text { von MS275 }\end{array}$ \\
\hline 1 & $\mathrm{C} 1$ & B1 & 363,2 & 363,3 & 35 & 19 \\
\hline 2 & $\mathrm{C} 2$ & B1 & 363,2 & 363,3 & 37 & 9 \\
\hline 3 & C3 & B1 & 363,2 & 363,3 & 28 & 9 \\
\hline 4 & $\mathrm{C} 4$ & B1 & 377,2 & 377,4 & 33 & 15 \\
\hline 5 & C1 & B2 & 383,2 & 383,3 & 86 & 85 \\
\hline 6 & $\mathrm{C} 2$ & B2 & 383,2 & 383,2 & 88 & 86 \\
\hline 7 & C3 & B2 & 383,2 & 383,3 & 93 & 79 \\
\hline 8 & $\mathrm{C} 4$ & B2 & 397,4 & 397,4 & $>95$ & 74 \\
\hline 9 & $\mathrm{C} 1$ & B3 & 377,3 & 377,3 & $>95$ & 64 \\
\hline 10 & $\mathrm{C} 2$ & B3 & 377,3 & 377,4 & 85 & 69 \\
\hline 11 & C3 & B3 & 377,3 & 377,3 & 82 & 61 \\
\hline 12 & $\mathrm{C} 4$ & B3 & 391,3 & 391,4 & 84 & 65 \\
\hline 13 & $\mathrm{C} 1$ & B4 & 369,3 & 369,3 & 75 & 26 \\
\hline 14 & $\mathrm{C} 2$ & B4 & 369,3 & 369,4 & 82 & 25 \\
\hline 15 & C3 & B4 & 369,3 & 369,3 & 88 & 21 \\
\hline 16 & $\mathrm{C} 4$ & B4 & 383,3 & 383,3 & 84 & 22 \\
\hline 17 & C1 & B5 & 377,3 & 377,4 & $>95$ & 96 \\
\hline $\begin{array}{c}18= \\
M S 275\end{array}$ & $\mathrm{C} 2$ & B5 & 377,3 & 377,4 & 89 & 100 \\
\hline 19 & C3 & B5 & 377,3 & 377,4 & 87 & 96 \\
\hline 20 & C4 & B5 & 391,3 & 391,4 & 75 & 100 \\
\hline 21 & C1 & B6 & 357,3 & 357,3 & 88 & 82 \\
\hline 22 & $\mathrm{C} 2$ & B6 & 357,3 & 357,4 & 74 & 82 \\
\hline 23 & C3 & B6 & 357,3 & 357,3 & 78 & 83 \\
\hline 24 & $\mathrm{C} 4$ & B6 & 371,3 & 371,3 & 81 & 69 \\
\hline
\end{tabular}

Der Einfluß der Kopfgruppen C1-C4 an der Bindung zur HDAC aus der Rattenleber scheint gering zu sein, die Produkte um die Muttersubstanz MS275 (18) mit dem gemeinsamen Mittelteil B5 (17-20) wirken alle vergleichbar gut, auch bei den anderen Gruppen mit gleichem Mittelteil ist keine Tendenz auf eine bevorzugte Position des Stickstoffs in der Kopfgruppe erkennbar. Damit ist es auch wie vermutet unwahrscheinlich, daß dieser Molekülteil in die Bindung zum aktiven Zentrum involviert ist.

Anders beim mittleren Molekülteil: Das Original B5 zeigt die besten Ergebnisse, doch auch B2 und B6 liegen durchschnittlich nur etwa 20\% schlechter. Bei B2 ist der Phenylrest durch einen Cyclohexylrest ersetzt, bei B6 durch eine reine aliphatische Kette, 
wobei vier Methyleneinheiten der Platz des Phenylrests im Vergleich zum Original einnehmen (Abb.42).

Danach folgt B3 mit dem Aminomethylrest in 3- statt 4-Position des Phenylrests und mit deutlichem Abstand B4 mit einem sekundären Amin in einer Piperidinstruktur.

Zählt man die C-Atome der B-Substituenten von der Carboxylfunktion bis zum Amin, erhält man für B5, B2 und B6 je 6 C-Atome, für B3 und B4 je 5-C-Atome. Es scheint sich also um einen hauptsächlich durch den Längenabstand und weniger durch die Struktur ergebenden Effekt zu handeln, was das bisherige Inhibitormodell (Abb. 39) stützt.

Insbesondere der Austausch eines Phenylrests durch eine rein aliphatische Kette weißt auf einen geringen Beitrag zum Gesamteffekt hin.

\subsubsection{Inhibition durch Kojisäure-Derivate}

Kojisäure oder [5-hydroxy-2-(hydroxymethyl)-4H-pyran-4-on] ist ein bekannter Inhibitor der Tyrosinase (Kahn et al., 1995), eines kupferhaltigen Proteins. In der Struktur dieses Naturstoffes (Abb. 44) kann man auch ein mögliches Bindungsmotiv für zinkhaltige HDAC vermuten. Zur Klärung dieser Frage wurden einige chemische Synthesen für die Herstellung von Kojisäure-Derivaten durchgeführt.

Durch die Existenz zweier Hydroxylfunktionen im Ausgangsmaterial Kojisäure mußte bei Verknüpfungsreaktionen, die auf diese Funktionen zielten damit gerechnet werden, zwei Produkte (2- und 7- Derivate) zu erhalten (Kaatz et al., 1999). Auf das Einführen einer Schutzgruppe konnte dennoch verzichtet werden, da bei der Aktivierung mit Carbonyldiimidazol CDI nur das gewünschte 7- Derivat entsteht (Kim et al., 2004).

Mit diesem Zwischenprodukt wurde eine Bibliothek mit 96 verschiedenen Derivaten durch Festphasensynthese hergestellt, deren allgemeiner Aufbau aus Kojisäure KS und drei weiteren Komponenten bestand (Abb.44):

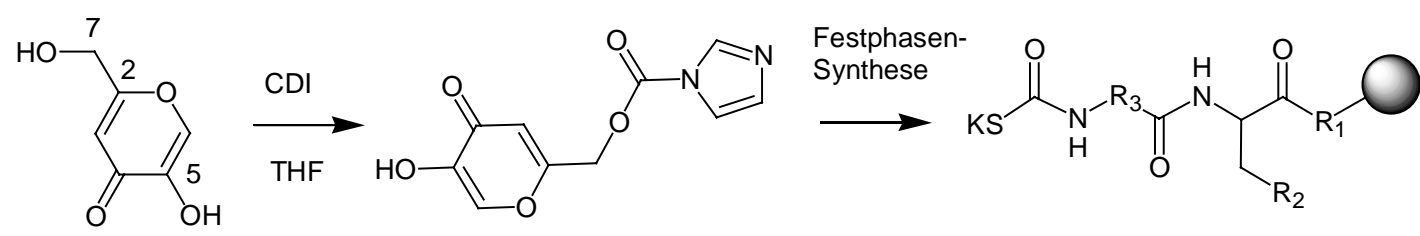

Kojisäure

CDI-aktivierte, aminreaktive Kojisäure

Festphasengebundene Bibliothek

Abbildung 44: Herstellung aminreaktiver Kojisäure und Auf bau einer Bibliothek aus 96 Substanzen 


\title{
Synthese
}

Die Reste bestanden dabei aus verschiedenen Spacer-Aminosäuren (R3), aus einem strukturell diversen Mittelteil (R2 ), für den vor allem aromatische Aminosäuren verwendet wurden und aus einem Linkermolekül zur Festphase, das entweder aus einer Aminosäure oder einem Aminomethyl-Aromaten bestand (R1).

Die Synthese wurde wie unter 2.2.5.4 beschrieben durchgeführt.

\begin{abstract}
Analytik
Nach Abspaltung vom Harz wurde die TFA durch abrotieren entfernt und die Produkte in einer Konzentration von $40 \mathrm{mM}$ in DMSO aufgenommenen. Aliquote davon wurden wie beschrieben der LC-MS-Analytik unterworfen. Bei den meisten Produkten konnten Reinheiten von > 85\% festgestellt werden, bestimmt über das DiodenarrayChromatogramm, Wellenlänge 210-500 nm. Die Identität der Proben wurde durch Nachweis der entsprechenden Molekülionen $[\mathrm{M}+\mathrm{H}]^{+}$im Hauptsignal des Chromatogramms erbracht. Bei 7 der 96 Substanzen war die Verknüpfung mit der aktivierten Kojisäure unvollständig.
\end{abstract}

\section{Screening}

Die mit Assay-Puffer aus der $40 \mathrm{mM}$ Stammlösung in DMSO manuell auf $3 \mathrm{mM}$ vorverdünnten Substanzen wurden bei einer Endkonzentration von $250 \mu \mathrm{M}$ und mit 125 $\mu \mathrm{M}$ Tos-GPK(Ac)-AMC im HDAC-Assay mit Hilfe der CyBio-Screen-Machine zunächst gegen HDAC aus Rattenleber auf ihre inhibitorische Wirkung hin untersucht. Für die Bestimmung der inhibitorischen Wirkung gegen humane rekombinante HDAC8 wurde diese mit $300 \mu \mathrm{M}$ Boc-Lys(Ac)-AMC-Substrat in HDAC8-Puffer und $1 \mathrm{mg} / \mathrm{mL}$ Trypsin in TI-Puffer gemessen. Die Messungen wurden in Dreifachbestimmung durchgeführt. Die Hemmwerte bei der eingesetzten Konzentration von $250 \mu \mathrm{M}$ sind auf die Messung ohne Enzym (Hemmwert 100\%) und ohne Inhibitor (Hemmwert 0\%) bezogen. Der Mittelwert wurde berechnet und ist angegeben. Als Kontrollsubstanz wurde SAHA mitvermessen.

Von der am besten hemmenden Substanz wurde der $\mathrm{IC}_{50}$-Wert für HDAC8 und FB188 HDAH durch Messung bei verschiedenen Konzentrationen bestimmt.

\section{Ergebnis}

Unter den 96 Produkten zeigten mit den Substanzen der laufenden Nummern 47-50 und 73, insgesamt fünf eine signifikante Hemmung der HDAC8, wovon drei auch gegen Rattenleber HDAC wirkten. Die Strukturen dieser Substanzen (Abb. 45) sind sich sehr ähnlich: 


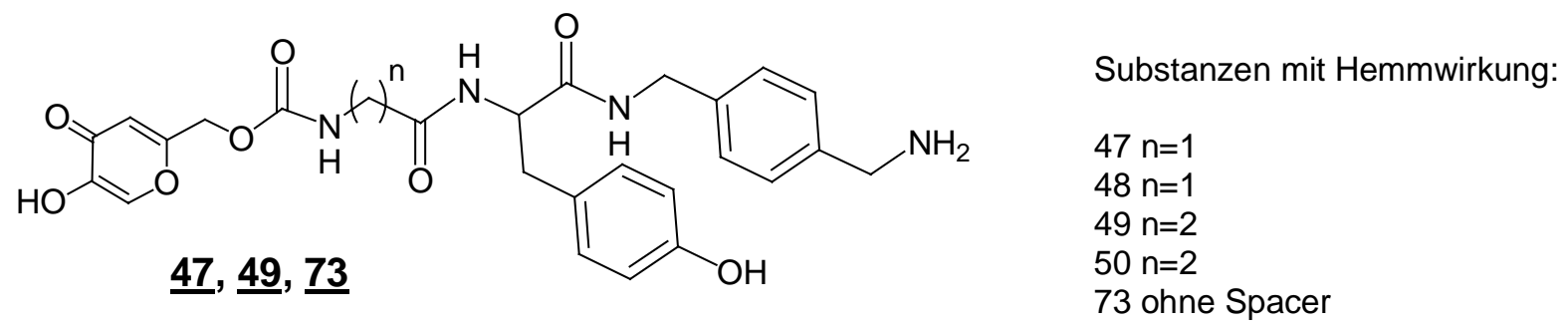<smiles>NCc1ccc(CNC(=O)C(Cc2c[nH]c3ccccc23)NC(=O)NC(=O)OCC2=CC(=O)C(O)=C2)cc1</smiles>

\section{Abbildung 45: Strukturen der inhibitorisch wirksamen Syntheseprodukte mit Kojisäure}

Die strukturellen Unterschiede der gefundenen Substanzen sind gering, sie beschränken sich auf die Länge des Spacers R3 und die Art der aromatischen Aminosäure R2.

R2: Bei vergleichbarer Konzentration wirken die Produkte mit Indolrest (쬬 und $\underline{\mathbf{5 0}}$ ) etwa 50\% besser als diejenigen mit Phenolrest (근 und $\underline{\mathbf{4 9}}$ ). Keines der Produkte mit den 24 anderen Aminosäuren, die in Position R2 verwendet wurden, zeigte Wirkung.

R3: Das Produkt $\underline{\mathbf{5 0}}$ mit $\beta$-Alanin hemmt 10 bis $15 \%$ besser als das Analoge mit Glyzin $\underline{\mathbf{4 8}}$, jedoch verhält es sich bei $\underline{\mathbf{4 7}}$ und $\underline{49}$ genau anders herum und das Produkt ohne Spacer, mit direkter Kopplung der aktivierten Kojisäure an den Tyrosyl-Rest $\underline{\mathbf{7 3}}$ ist in dieser Reihe am wenigsten aktiv.

Insgesamt war die Hemmung recht moderat. Für die beste Substanz $\underline{\mathbf{5 0}}$ wurde der $\mathrm{IC}_{50}$ gegen HDAC8 mit $450 \mu \mathrm{M}$ bestimmt.

Eine auffällig bessere Hemmung zeigte diese Verbindung gegen FB188 HDAH, wobei ein IC50 von $69 \mu \mathrm{M}$ bestimmt werden konnte.

Die Hinweise, daß der Kojisäureanteil der wirksamen Substanz den hemmenden Effekt verursacht und nicht etwa andere Molekülteile, konnte mit der Synthese eines Derivats von $\underline{\mathbf{5 0}}$ erbracht werden. Dabei wurde die 5-Hydroxylgruppe durch Derivatisierung mit einer Methylgruppe blockiert. Dieses Molekül blieb unwirksam.

Zusammenfassend konnte gezeigt werden, daß mit der Pyranonstruktur der Kojisäure in Verbindung mit weiteren aromatischen Molekülanteilen ein gegen HDAC / HDAH wirksames, neues Bindungmotiv für die Entwicklung von Inhibitoren zur Verfügung steht. 


\section{Diskussion}

\subsection{Allgemeine Methodenkritik}

\subsubsection{Auswahl der Targets}

Die ausgewählten Targets Thrombin und Histondeacetylasen beziehen ihre Relevanz aus der hohen Letalitätsrate der sie betreffenden Erkrankungen des thromboembolischen und neoplastischen Formenkreises.

Thromboembolien stellen eine der Haupttodesursachen in der westlichen Welt. Zu diesen Erkrankungen zählen neben Schlaganfall und Myocardinfarkt auch tiefe Beinvenenthrombosen, wie sie nach schweren chirurgischen Eingriffen gefürchtet sind, aber auch nach langen Flugreisen beschrieben wurden (das sogenannte „economy class syndrom" ist eine Vorstufe).

Zur medikamentösen Prophylaxe werden Acetylsalicylsäure und Coumarine oral appliziert, in der Klinik Heparine per subcutaner Injektion verabreicht. Trotz großer Anstrengungen ist es bis heute noch nicht gelungen, den ,idealen“ Thrombininhibitor zu finden, der in sich Eigenschaften wie gute antithrombische Aktivität, hohe Thrombinspezifität, geringe Toxizität, ein vorteilhaftes ADME-Profil mit insbesondere langsamer Elimination und möglichst orale Verfügbarkeit vereint.

Krebs ist eine der häufigsten Todesursachen in Europa, den USA und anderen Industrieländern. Erst in den letzten Jahren wurde die entscheidende Rolle der Histondeacetylasen (HDAC) in der Pathogenese bestimmter Tumoren erkannt und diese folgerichtig als wichtiges molekulares Zielenzym eingestuft (Jung, 2000; Jung, 2001). Die Entwicklung von selektiven und hochpotenten Inhibitoren dieser Enzyme wurde damit zum erklärten Ziel der Pharmaforschung (Krämer et al., 2001).

\subsubsection{Methodenwahl der Wirkstoffsuche}

Die Tatsache, daß nur für ein Drittel aller Krankheiten eine adäquate Behandlung zur Verfügung steht und noch vor Jahren etwa 60 neue Wirkstoffe pro Jahr zugelassen wurden, während es gegenwärtig nur noch 20 bis 30 bei fallender Tendenz sind, belegt eindringlich den Bedarf nach effizienteren Methoden des Wirkstoffdesigns. Es geht dabei nicht nur um eine größere Zahl an Medikamentenzulassungen, sondern das einzelne Medikament soll auch in Bezug auf Wirksamkeit, Verträglichkeit und einfachere Einnahme optimiert werden. 
Strategien zur Lösung dieser Probleme bestanden bisher einerseits darin, eine sehr große Anzahl von Wirkstoffkandidaten aus kombinatorischer Chemie oder aufgereinigten Naturstoffen im HTS zu untersuchen. Andererseits werden Methoden des „Molecular Modelling“ angewandt, wodurch passgenaue Ligandenmoleküle für ein kristallographisch charakterisiertes Target am Computer in-silico konstruiert werden können. Doch weder die blinde Suche nach der molekularen „Stecknadel“ , d.h. durch HTS, noch der Ansatz eines ,,rationalen“, d.h. strukturbasierten Designs haben sich bisher als universell einsetzbares Werkzeug erwiesen, das effizient genug wäre, sich den Anforderungen der modernen Wirkstoffforschung zu stellen.

Die enormen Kosten und langen Entwicklungszeiten sind ein weiterer wichtiger Aspekt. Nicht selten zeigt es sich erst in der klinischen Prüfungsphase, ob das neu entwickelte Präparat zugelassen werden kann. Um unerwünschte Wirkungen schon in der frühen Entwicklungsphase zu erkennen, werden daher in der Pharmaforschung vermehrt weitere wichtige Eigenschaften der Wirkstoffkandidaten frühzeitig bestimmt (,early ADME/Tox"). Die Pharmako- und Toxikogenomik, ein relativ junger Zweig der Pharmaforschung, geht dieses Problem durch Untersuchung von Expressionsprofilen an.

Der hier vorgestellte Ansatz versuchte sehr erfolgreich, einen etwas anderen Weg zu beschreiten. Durch Kombination von Methoden des Hochdurchsatzscreenings, der kombinatorischen Synthese und last not least durch Verfahren aus dem Bereich der künstlichen Intelligenz wurde ein effizientes Verfahren in der Wirkstoffoptimierung gleich mehrerer Parameter gefunden. Von Vorteil ist, daß strukturelle Details über das Targetmolekül nicht benötigt werden und innerhalb einer Optimierung nur eine relativ begrenzte Zahl von Substanzen getestet werden muß. Dabei werden etliche, bei der Entwicklung eines Wirkstoffes wichtige Parameter wie Primärwirkung, Spezifität, pharmakologische Eigenschaften und Toxizität mit Hilfe computer-unterstützter Verfahren gleichzeitig und parallel optimiert. Bei der Kombination verschiedener Methoden müssen Kompromisse eingegangen werden, so ist der hier verwendete Ansatz auch gewissen Einschränkungen ausgesetzt.

Erstens soll angemerkt werden, daß die experimentell bestimmten Parameter nicht nur eine möglichst genaue Abbildung der in-vivo Situation darstellen müssen, sondern die zugehörigen Assays bedingt auch HTS-tauglich sein sollten.

Zweitens waren mit der Wahl von Peptiden als chemischer Stoffklasse von vorne herein Bedenken bezüglich deren Verwendbarkeit als Wirkstoffe, bedingt durch im Allgemeinen schlechter (oraler) Bioverfügbarkeit und hoher Elimination, angebracht. Andererseits war es nicht das primäre Ziel, einen oral verfügbaren Wirkstoff zu entwickeln, sondern zu zeigen, daß die Methode zu selektiv wirksamen, ungiftigen und metabolisch stabilen Verbindungen führt und dieses Ziel mit relativ begrenztem materiellem und zeitlichem Aufwand erreicht. Mit dem Instrument der Peptidchemie konnte diese Aufgabe unter Anbetracht der zur Verfügung stehenden Ressourcen am besten gelöst werden und wie die ersten Ergebnisse der ersten Untersuchungen am Tiermodell (3.3.5.) zeigen, ist das gefundene Molekül im Eliminationsverhalten einem pharmazeutischen Wirkstoff 
mindestens ebenbürtig.

Ein möglicher Weg aus der Schwierigkeit, die orale Bioverfügbarkeit der Kandidaten von vorne herein in die Multi-Parameter-Optimierung zu integrieren, wäre das Screening der Zellpermeabilität in den entsprechenden zellbasierten Assays, wie beispielsweise mit Caco-2-Zellschichten (Artursson et al., 1991), deren HTS-Tauglichkeit aus Gründen des zeitlichen und finanziellen Aufwands allerdings fragwürdig scheint und im Rahmen der hier vorgestellten Arbeit nicht möglich war. Eine interessante Alternative böte sich in der Anwendung von auf Chromatographiesäulen immobilisierten, künstlichen Membranen (IAMC / Pidgeon et al., 1995) und massenspektroskopischer Detektion. Denkbar wären auch Techniken aus der Kapillarelektrophorese (Holland \& Leigh, 2003). Ob die erwähnten Techniken allerdings die in vivo-Situation ausreichend genau abbilden, mag dahingestellt bleiben. Da mit dem hier beschriebenen Optimierverfahren nur eine sehr überschaubare Zahl von Substanzen überhaupt getestet werden müssen, um zum Ziel zu kommen, kann man sogar daran denken, in Zukunft auch teurere Assaysysteme (z.B. mit Schweinedarmgewebe) einzusetzen, die eine viel besseren prädiktiven Charakter haben.

Schon jetzt kann aber festgehalten werden, daß mit dem hier erstmalig eingesetzten Computer-unterstützten Verfahren zur Wirkstoffsuche eines der effizientesten solchen Verfahren, wenn nicht sogar das effizienteste Verfahren überhaupt, identifiziert werden konnte. Von der Anlage des Gesamtprozesses her, ist das Verfahren prinzipiell nicht auf die hier bearbeitete Problemstellung (inkl. Screeningassays) oder die verwendete Peptidchemie beschränkt, so daß in Zukunft auch die Suche nach niedermolekularen Wirkstoffen anderer Stoffklassen und im Kontext anderer Fragestellungen denkbar ist.

\subsection{Diskussion der Resultate im Thrombinprojekt}

Die speziell zur Bearbeitung der gestellten Aufgaben ausgewählten Methoden beinhalten zunächst die Synthesen der verschiedenen Produkte, Substrate und Inhibitoren. Auch deren Analytik über LC-MS und die Untersuchung in den verschiedenen Assays soll einem kurzen Rückblick unterworfen werden.

\subsubsection{Peptidsynthese und Analytik}

Die Synthese von Peptiden ist ein wichtiges Instrument der biochemischen und pharmazeutischen Forschung. Sie ist eine Bindeglied zwischen Chemie, Medizin und Biologie und über die Zeit sind mehr und mehr direkt in der Synthese verwendbare Bausteine auf den Markt gekommen, die in Verbindung mit der effizienten Chemie die Herstellung hochdiverser, aber auch stark fokussierter Produkte erlauben. 
Das eingesetzte Peptidsynthese-System (2.1.1., Abb.7) zeichnet sich durch seine Flexibilität und Robustheit aus. Die meisten Schwierigkeiten, was die Synthese betrifft, resultierten aus unzureichend löslichen Bausteinen, was gelegentlich zu Fehlern beim Verteilen des Bausteins oder zum Verstopfen der kapillarartigen Auslässe der Syntheseplatten führte, wenn bei längerem Stehen Edukt ausfiel. Aus der Vielzahl der im Verlauf der Projekte erhobenen analytischen Daten konnte abgeleitet werden, daß die jeweils angenommenen Ausbeuten aus den Synthesen, die sich immer auf die Beladungshöhe der Harze bezogen, im Wesentlichen auch erreicht wurden. Mit der Kombination von automatisierten und manuellen Syntheseschritten konnte der Synthesizer auch für andere Reaktionen der organischen Chemie verwendet werden, wenn beispielsweise erhitzt werden mußte oder Lösemittel verwendet wurden, die aufgrund ihrer geringen Viskosität nicht von den Kapillarkräften am Auslass zurückgehalten wurden. In der praktischen Handhabung kommt einem das 96er MTP Format durch dessen weite Verbreitung und seine Anschlußmöglichekeiten an gängige Screeningformate sehr entgegen.

In diesem Kontext erlaubt auch das eingesetzte LC-MS System (2.1.2., Abb.8) die Verwendung von vier handelsüblichen MTP im Probenkarrusel. Dieses System hat sich als ein sehr wichtiges Instrument in vielerlei Hinsicht gezeigt. Einerseits wurden einige Assays aus dem Bereich ADME/Tox mit LC-MS ausgewertet, wenn es um Konzentrations-bestimmungen ging, andererseits wurde es zur Kontrolle von Reaktionsverläufen ebenso eingesetzt wie zur Analytik von Produkten und Feststellung von deren korrekten Massen. Schließlich konnten auch HPLC-Aufreinigungen im semipräparativen Bereich (einige $\mathrm{mg}$ ) effektiv und über das Massensignal der Zielsubstanz gesteuert mit dem gleichen System ohne Umbauarbeiten durchgeführt werden.

Im Verlauf der vorliegenden Arbeit wurden mit diesem Gerät > 20.000 Analysen durchgeführt. Die Wartung ist relativ einfach und wurde nach einem festen Schema ausgeführt. Die Kalibrierung erfolgt standardmässig mit Salzlösungen, mit deren Hilfe man den gesamten Messbereich von 20-2000 m/z erfasste.

Bei bestimmten Anwendungen, namentlich der Bestimmung der Fragmente nach Proteaseverdau (3.1.1.) hätte eine auf bestimmte Massenbereiche fokussierte Kalibrierung die Abweichungen zwischen berechneter und gefundener Masse (Tab.3) noch reduzieren können.

\subsubsection{Auswahl der Assays}

Die richtige Auswahl zu treffen für einen Satz von Assays, der möglichst nahe an den tatsächlichen Verhältnissen in der späteren Applikation orientiert sein soll, gleichzeitig aber schnell und kostengünstig durchgeführt werden können muß, stellt schon für sich eine schwierige Aufgabe dar. Der erste Gedanke „Viel ist besser“ mag zutreffen, übersteigt aber schnell den Rahmen des materiell und zeitlich vertretbaren. Mit der getroffenen Auswahl für Assays auf 
○ (Primär-)Wirkung bezüglich eines Targets

○ Selektivität

○ Verteilungskoeffizient

○ Wasserlöslichkeit

○ Serumproteinbindung

○ Metabolische Stabilität

$\circ$ Toxizität

○ Hämolyse

wurde ein vernünftiger Kompromiß eingegangen. Im Verlauf der Optimierung zeigte sich, daß unter den ADME/T-Parametern die Bestimmung der Wasserlöslichkeit und z.T. des Verteilungskoeffizienten und der Serumproteinbindung weniger neue Information hervorbrachte, als die Bestimmung der metabolischen Stabilität.

Die ersten drei genannten Parameter beschreiben eher das physikochemische Verhalten der Testsubstanzen und korrelieren mit der sich im Verlauf der Optimierung herausbildenden strukturellen Verwandschaft der untersuchten Substanzen. Im Gegensatz dazu lieferten die Toxizitäts- und Hämolyseassays und der Test auf metabolische Stabilität wichtige Informationen und dabei auch manche Überraschungen. Wie bereits erwähnt, wäre ein zusätzlicher Assay auf Zellpermeabilität in zukünftigen Anwendungen dieses Ansatzes zu erwägen.

\subsubsection{Computer-unterstützte Multiparameteroptimierung}

Der Ansatz der computer-unterstützten Wirkstoffentwicklung mit Hilfe genetischer Algorithmen wurde bisher vor allem im Zusammenhang mit quantitativen StrukturAktivitäts-Beziehungen und dem Design kombinatorischer Substanz"bibliotheken" verwendet (Terfloth \& Gasteiger, 2001). Speziell generierte, für die Anwendung auf die Optimierung von Wirkstoffen ausgerichtete Algorithmen (Kamphausen et al., 2002) wurden im hier beschriebenen Ansatz mit experimentell erhobenen Daten „trainiert“ um eine optimale Wirkstruktur zu entwickeln.

Die Ergebnisse aus der 1-Parameteroptimierung (3.2.) von peptidischen Thrombininhibitoren erbrachten mit dem Peptid NSCI 521, das einen $\mathrm{K}_{\mathrm{i}}$-Wert von 297 nM aufwies, eine gut wirksame Substanz, die allerdings unselektiv auch Trypsin hemmte und zudem eine zytotoxische Wirkung zeigte. Auch das relativ hohe Molekulargewicht $(>1500 \mathrm{~g} / \mathrm{mol})$ und das Vorhandensein von 6 basischen Aminosäureresten machen diese Verbindung unattraktiv im Sinne einer Verwendung als Medikament. Da diese Eigenschaften nicht Teil des Optimierverfahrens waren, sondern alleine auf Thrombininhibitorische Wirkung optimiert worden war, konnte mit diesem Ergebnis immerhin aber gezeigt werden, daß das Verfahren an sich funktionierte.

Daraufhin wurde der Versuch unternommen, ein weiterentwickeltes Verfahren des Computer-unterstützten Wirkstoffdesigns auf die Multiparameter-Optimierung 
auszudehnen, um unerwünschte Nebenwirkungen von vorn herein auszuschließen. Die Ergebnisse wurden hier vorgestellt (3.3.) und sie sind überzeugend.

Es wurden Peptide einer Länge von maximal 5 Aminosäuren unter Verwendung von insgesamt 66 Bausteinen erzeugt, womit sich bei freier Kombination aller Bausteine auf allen Positionen eine Gesamtmenge von $66^{5}$ oder etwa $1,25 \times 10^{9}$ möglichen Produkten ergibt, wovon zirka 1000 tatsächlich hergestellt und getestet wurden.

In der praktischen Anwendung erwies sich der Prozeß als robust gegen experimentelle Fehler, wie sie bei experimentellen Ansätzen auch bei großer Sorgfalt unvermeidbar sind. Wichtig zu erwähnen, daß mit steigender Wirksamkeit der Testsubstanzen ein Verfahren zur Normierung der Daten eingeführt werden muß, um miteinander vergleichbare Wirkungs- / Konzentrationswerte zu erhalten. Dieses Verfahren bestand einfach in der Bestimmung der Wirkung bei verschiedenen Konzentrationen, in einem Bereich möglichst geringer Abweichungen zu halten, d.h. beim halblogarithmischen Auftrag von Effekt gegen Konzentration im Bereich des linearen Anstiegs (Abb. 46).

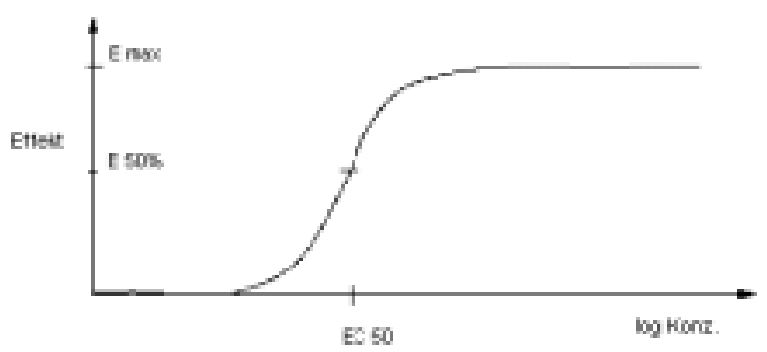

\section{Abbildung 46: Halblogarithmischer Auftrag von Effekt gegen Konzentration einer Testsubstanz}

Mit der Computer-unterstützten Wirkstofffindung konnte auf der Basis experimenteller Daten in einem zyklischen Prozess mit der Substanz 8-5 tatsächlich ein Molekül entwickelt werden, daß in vielen seiner Eigenschaften Wirkstoffkandidaten der pharmazeutischen Industrie ebenbürtig ist (Abb. 20).

Mit der Auflösung der Kristallstruktur wurde zudem ein Bindungs- und Inhibitionsmodus nachgewiesen, der einzigartig unter den bekannten Thrombininhibitoren ist, indem ein nicht-basischer Molekülteil in S1 bindet und dabei sogar eine Wasserstoffbrücke zum Asp189 ausbildet. Darüberhinaus bindet ein Cyclohexylalanin-Rest besonders paßgenau in die sogenannte Aromatentasche (Publikation in Vorbereitung). 
Die herausragenden Eigenschaften dieser Verbindung sind neben der ausgezeichneten Wirksamkeit $\left(\mathrm{K}_{\mathrm{i}}=3 \mathrm{nM}\right)$ ihre Selektivität mit einem Faktor von mehr als 100.000 gegenüber Trypsin, aber auch gegen eine ganze Reihe weiterer Proteasen, wie zum Beispiel die Faktoren Xa und XIIa, Urokinase und Plasmin. Sogar zwischen Thrombin vom Menschen und vom Rind findet eine Diskriminierung um mehr als den Faktor 2 statt.

Hier liegt der besondere Vorteil des neuen Inhibitors: Im Vergleich erreicht keine der bekannten Substanzen Argatroban, NAPAP oder Melagatran diese Selektivitätswerte (Tab. 5).

Bei den ersten Untersuchungen am Tiermodell (3.1.3.5.) schnitt 8-5 auch im Eliminations-verhalten sehr gut ab, zeigte hier im Rattenmodell eine gegenüber Melagatran sogar leicht verbesserte, d.h. langsamere Elimination praktisch vollständig über die Niere, während Melagatran auch über den Leber-Galle-Weg aus dem Körper entfernt wird. Dies ist insofern ein interessanter Punkt, da gerade die toxische Wirkung, die Melagatran auf diesem Eliminationsweg über die Leber entwickelt, diesem Wirkstoff kürzlich zum Verhängnis wurde. Ximelagatran, der schon erwähnten Prodrug-Form von Melagatran, wurde im September 2004 von einem Komitee der amerikanischen Zulassungsbehörde FDA eine Zulassung in den USA und Canada wegen des erhöhten Risikos von Nebenwirkungen, namentlich eines Leberversagens (,liver failure“), verweigert. Ein derartiges Risiko birgt unser neuer Inhibitor schon aufgrund seines Eliminationsverhaltens nicht in sich.

Auch in den anderen, getesteten Eigenschaften (keine Cytotoxizität oder hämolytische Wirkung, hohe metabolische Stabilität, moderate Serumproteinbindung) schneidet der neue Inhibitor ausgezeichnet ab, d.h. er besitzt schon eine ganze Reihe von Eigenschaften eines typischen Wirkstoffs.

Naheliegend wäre jetzt auch noch eine Testung auf Membranpermeabilität, bzw. „orale Verfügbarkeit“, auch wenn diese Eigenschaften im zyklischen Suchprozess nicht explizit mit optimiert wurden. Sollten sich die neuen Inhibitoren an dieser Stelle suboptimal verhalten, so stehen für die Weiterentwicklung eine ganze Reihe von Wegen offen. Dabei dürften die zwei vorhandenen Guanidin-Funktionen vermutlich das größte Hindernis darstellen.

Pro-Drug-Formen wie bei Ximelagatran, bei dem das Amidin hydoxyliert (und die Säurefunktion verestert) kann man sich auch für 8-5 vorstellen: Die für die kinetischen Studien (3.1.3.3) hergestellten Derivate 8-5N und 8-5O, bei denen das Guanidin des homoArginins durch ein Amin bzw. ein acetyliertes Amin ersetzt sind zeigen $\mathrm{K}_{\mathrm{i}}$-Werte von 10 bzw. $17 \mathrm{nM}$ (Tab.6). Auch beim zweiten Guanidin liegen sie beim Ersatz der Tranexamsäure mit einem acetylierten Alaninrest oder D-Methionin in beiden Fällen immer noch im zweistelligen nanomolaren Bereich. Die Ladungen sind also nicht essentiell für die Wirksamkeit gegen Thrombin. Möglichkeiten zur Ladungsentfernung sind also gegeben, zudem stimmt für die weitere Entwicklung optimistisch, daß die 
fehlende biliäre Exkretion als ein Indiz für eine geringe präsystemische Elimination gewertet werden kann.

Zukünftig herzustellende Derivate von 8-5 werden zeigen, welche Wege hier zum Ziel führen.

Schon jetzt werden aufgrund der genannten positiven Eigenschaften erste Versuche am Rattenmodell in Richtung der Anwendung von 8-5 bei arteriellen Thrombosen angegangen, da bei dieser Erkrankung üblicherweise höhere Dosen des Wirkstoffs (mit einem erhöhten Risiko an Nebenwirkungen) zu applizieren sind und damit der Vorteil des ausgezeichneten Selektivitäts-Spektrums von 8-5 genutzt werden kann.

\subsection{Diskussion der Resultate im HDAC-Projekt}

Die HDAC8-Expression ist in einer Reihe von Krebszellinien stark erhöht (Van den Wyngaert et al., 2000) und somit das Enzym ein medizinisch relevantes Zielenzym. Bei der Entwicklung eines Wirkstoffes ist neben dessen Potenz auch die Selektivität ein wichtiges Kriterium. Die unterschiedlichen und teilweise gegenläufigen biologischen Aufgaben verschiedener Isoformen der HDAC machen die Wichtigkeit der Entwicklung möglichst selektiver HDAC-Inhibitoren deutlich (Glaser et al., 2003a; Hu et al., 2003; Kook et al., 2003; Verdin et al., 2003; Zhang et al., 2003b), um möglicherweise fatale Wirkungen auf nicht-transformierte Zellen bzw. normale Zellabläufe zu minimieren.

Daher sollte neben der HDAC8 des Menschen auch die Wirkung der Inhibitoren auf die HDAC aus Rattenleber (eine Mischung von HDAC 1, 2 und 3) und die HDAC6- ähnliche FB188-HDAH untersucht werden, welche als Modellenzyme für HDAC der Klasse I bzw. II dienten. Die anfangs verwendete, kommerziell erhältliche HDAC8-Präparation (Biomol) litt deutlich unter wiederholtem Auftauen und Einfrieren und wäre im Screening viel zu teuer. Die Eigenproduktion ermöglichte die Verwendung möglichst frischer HDAC8. Daher wurde eine heterologe Expression von HDAC8 unternommen

\subsubsection{Heterologe Expression und Reinigung von HDAC 8}

Escherichia coli hat sich als effektives Expressions-System für eukaryotische Enzyme in vielen Fällen bewährt, und die HDAC-ähnliche FB188-HDAH wurde bereits erfolgreich heterolog in E. coli BL21 produziert (Hildmann et al., 2003). . Es zeigte sich, daß die Expression für humane HDAC8 als aktives Enzym mit einem C-terminalen His-tag möglich war (3.2.1.1.). Allerdings haben die vergeblichen Aufreinigungsversuche der in aktiver Form exprimierten HDAC8 über IMAC mit Chelating-Sepharose-Matrix gezeigt, daß eine Inaktivierung auf der Säule erfolgt sein könnte. 
Mehrere Aufreinigungsversuche mittels IMAC scheiterten, obwohl von einer erfolgreichen Aufreinigung der HDAC8 über IMAC berichtet worden war ( $\mathrm{Hu}$ et al., 2000). Dabei waren nach Dialyse der Eluat-Fraktionen über Western Blot durchaus noch ausreichende Mengen HDAC8 nachzuweisen, allerdings keine HDAC-Aktivität mehr (3.2.1.2.). Ein Verlust des Cofaktors des Enzyms bei der Aufreinigung käme als Grund in Frage. Der Zusatz von hohen Zink-Konzentrationen wirkte sich positiv auf die Aktivität von FB188-HDAH aus (Hildmann et al., 2003). Im Gegensatz dazu konnte bei HDAC8 ein Zusatz von $\mathrm{ZnCl}_{2}$ zum dialysierten HDAC8-Eluat die Enzymaktivität nicht restaurieren. Ein mögliches „Ausbluten“ des Nickels von der Säule könnte die HDAC8 inhibiert haben, indem das Zink-Ion im Enzym durch Nickel verdrängt worden ist.

Die Aufreinigung der HDAC8 über einen Anionenaustauscher war eine effektive Methode, um Medienkomponenten und die meisten Wirtsproteine der Expressionskultur abzutrennen (3.2.1.2.). Zudem beschleunigte die Verwendung hoher Flußraten (10 $\mathrm{mL} / \mathrm{min}$ ) bei der Chromatographie das Verfahren sehr, wodurch das Enzym zudem schnell von Proteasen abgetrennt werden konnte. Die erhaltene, partiell aufgereinigte HDAC8-Präparation war völlig ausreichend für den Einsatz in den HDAC-Assays. Aus einem Liter Expressionskultur konnten dabei etwa 1,4 mg HDAC8-Präparation in ca. 12 $\mathrm{mL}$ Eluat präpariert werden, was ausreichend für über 200 HDAC-Assays mit BocLys(Ac)-AMC wäre. Auch sonst werden HDAC für in vitro-Enzymtests verwandt, die nur partiell über einen Anionenaustauscher aufgereinigt wurden (Hoffmann et al., 1999; Hoffmann et al., 2000; Remiszewski et al., 2002). In Zukunft soll aber durchaus noch einmal versucht werden, die Affintitäts-Tag-Technologie einzusetzen, etwa durch die Wahl alternativer Tags (z.B. Strep-Tag).

\subsubsection{Assay-Optimierung}

Die Verwendung von Tos-GPK(Ac)-AMC als Substrat für HDAC aus der Rattenleber führte zu einer Steigerung der Assay-Qualität. Das für Trypsin optimale Substrat TosGPK-AMC, welches im Assay entsteht, hatte mit $7 \mu \mathrm{M}$ einen im Vergleich zu den anderen Tripeptid-Substraten $\left(\mathrm{K}_{\mathrm{M}}>500 \mu \mathrm{M}\right)$ wesentlich kleineren $\mathrm{K}_{\mathrm{M}}$-Wert und ermöglichte die Verwendung einer 1000fach geringeren Trypsinkonzentration. Der ermittelte $\mathrm{K}_{\mathrm{M}}$-Wert für Trypsin aus Schwein ist etwas niedriger als der Literaturwert für Rinder-Trypsin von $37 \mu \mathrm{M}$ (Grahn et al., 1998), welcher mit dem Trypsin-Assay in dieser Arbeit mit 36,7 $\mu \mathrm{M}$ bestimmt wurde (Daten nicht gezeigt). Im Vergleich zu BocLys-AMC wurden die Tripeptide mindestens 100fach besser von der Endoprotease Trypsin umgesetzt, was auch Grahn und Kollegen bereits feststellten (Grahn et al., 1998). Das Reporterenzym Trypsin war aber immer noch ausreichend im Überschuß gegenüber HDAC vorhanden, um das im ersten Schritt des gekoppelten Assays entstandene, deacetylierte Produkt quantitativ zu spalten und dafür $\mathrm{zu}$ sorgen, daß unspezifisch hemmende Substanzen (mit $\mathrm{IC}_{50}$ für Trypsin im unteren mikromolaren Bereich) sich nicht auswirken können. In HDAC-Assays hemmend wirkende Substanzen sollten dennoch immer zusätzlich auf eine mögliche Trypsinhemmung überprüft werden, um falsch-positive Hits zu vermeiden. 
Humane HDAC8 setzte Tos-GPK(Ac)-AMC schlecht um, ebenso wie ein aus H4 abgeleitetes Oktapeptid (Van den Wyngaert et al., 2000). HDAC8 wurde bislang nicht als Komponente eines HDAC-Komplexes gefunden und besitzt einen ihr eigenen Sequenzabschnitt mit vielen sauren Aminosäureresten. Dies könnte in Analogie zu der zusätzlichen Domäne in Sirtuinen ein Hinweis auf eine stärker ausgeprägte Substratspezifität der HDAC8 sein.

Für einige HDACs bzw. auch für HDAC-ähnliche, bakterielle Enzyme häufen sich in letzter Zeit experimentelle Evidenzen, daß Nicht-Histon-Proteine die eigentlichen Substrate darstellen. Zumindest für HDAC6 scheint mit dem Substrat Tubulin als NichtHiston-Protein ein solcher Fall vorzuliegen (Hubbert et al., 2002). Auch für HDAC8 konnten in jüngster Zeit erste Evidenzen für ein solches Nicht-Histon-Substrat gefunden werden. Ein aus dem in vivo acetylierten Bereich von p53 abgeleitetes diacetyliertes Tetrapeptid wurde von HDAC8 besser umgesetzt als z. B. aus H4 abgeleitete Peptide (Biomol, 2003; Gu and Roeder, 1997; Sakaguchi et al., 1998). Allerdings ist nicht klar, ob p53 ein natürliches Substrat von HDAC8 darstellt oder ob die doppelte Acetylierung von entscheidender Bedeutung ist.

\subsubsection{Substratspezifität und Katalysemechanismus}

Bislang sind keine Untersuchungen der Substratspezifität von HDAC im Hinblick auf Modifikationen der Acylgruppe bekannt. Nur im Hinblick auf Substratspezifität für fluorogene Substrate wurde von der leichten Präferenz für Z-MAL gegenüber BocLys(Ac)-AMC von HDAC aus der Rattenleber berichtet (Heltweg et al., 2003). Z-MAL trägt eine aromatische Benzyloxycarbonyl-Schutzgruppe (Z) anstelle der tertButyloxycarbonylgruppe (Boc) an der $\alpha$-Aminogruppe.

Aus dem Vergleich des Umsatzes von Minimalsubstraten des Typs Boc-Lys(X)-AMC (Abb. 37), die sich in der Größe (dem molekularen Volumen) ihrer Acylreste (X) an der Lysinseitenkette unterscheiden, kann auf die sterischen Verhältnisse im aktiven Zentrum der HDAC geschlossen werden. Somit können Hinweise zum Entwurf selektiver HDACInhibitoren abgeleitet werden. Diese könnten zusätzlich zu bereits untersuchten Modifikationen der Kappenregion als unterscheidendes Strukturmerkmal zur Entwicklung selektiver Inhibitoren beitragen. HDAC mit wenig geräumiger Substrattasche würden wohl nicht von sperrigeren HDAC-Inhibitoren gehemmt.

Zusätzlich sollte untersucht werden, ob Substrate mit anderen Acylgruppen (besseren Abgangsgruppen) eventuell auch besser, aber vor allem selektiver von den HDAC umgesetzt würden. Solche Substrate könnten als biochemische Werkzeuge z. B. zur Differenzierung des Beitrages unterschiedlicher HDAC zur Aktivität eines HDACKomplexes dienen. Die hier haupsächlich verfolgte Strategie zur Entwicklung von besseren Substraten, vor allem für HDAC8 sieht die Substituierung der $\varepsilon$-Aminogruppe 
am Lysin mit anderen Acylgruppen vor, welche nach Abspaltung bessere Abgangsgruppen als Acetat darstellen. Dabei sollten die Substrate umso besser umgesetzt werden, desto niedriger der $\mathrm{pK}_{\mathrm{a}}$ der entstehenden Säure ist. Auch hier könnten die erhaltenen Ergebnisse mit Substraten, die ein nucleophileres Kohlenstoffatom enthalten, Hinweise über die Ladungsverteilung im aktiven Zentrum des Enzyms geben.

Alle drei untersuchten HDAC hatten ein recht enges Substratspektrum und setzten die Substrate mit voluminösen oder verzweigten Acylgruppen (Propionyl-, Butyryl-, Isobutyryl-, Pivalyl- ) so gut wie nicht um. Daher ist anzunehmen, daß alle drei Enzyme eine recht beengte Substrattasche aufweisen müssen, wie sie für HDLP aus der Kristallstruktur abzulesen ist (Finnin et al., 1999).

Für HDAC aus der Rattenleber war Boc-Lys(Ac)-AMC zwar das bevorzugte Substrat $\left(\mathrm{K}_{\mathrm{M}}: 3,7 \pm 1,7 \mu \mathrm{M}, \mathrm{V}_{\max }: 4,41 \pm 0,1 \mathrm{pmol}\right.$ sec-1 mg-1). Als einzige Ausnahme konnte hier ein (etwa um 50\% schlechterer) Umsatz von Boc-Lys(Prop)-AMC ( $\mathrm{K}_{\mathrm{M}}: 105 \pm 14$ $\mu \mathrm{M}, \mathrm{V}_{\max }: 4,38 \pm 0,41 \mathrm{pmol}$ sec-1 mg-1) beobachtet werden, was für eine etwas geräumigere Tasche im aktiven Zentrum des Enzyms spricht. Diese Unterschiede in der Substratspezifität könnten ihre Ursache in veränderten Aminosäuresequenzen um das aktive Zentrum einiger HDAC (Grozinger and Schreiber, 2002) haben und mit den dadurch voneinander abweichenden Geometrien erklärt werden. Das Auftreten einer Produkthemmung durch die Natrium-Salze der Abgangsgruppen der umgesetzten Substrate.

Mit Boc-Lys(Prop)-AMC konnte tatsächlich ein für HDAC aus der Rattenleber spezifisches Substrat entwickelt werden.

Für HDAC8 hingegen war Boc-Lys(TFA)-AMC das mit Abstand beste Substrat $\left(\mathrm{K}_{\mathrm{M}}\right.$ : $247 \pm 89 \mu \mathrm{M}, \mathrm{V}_{\max }: 530 \pm 30 \mathrm{pmol}$ sec-1 mg-1). Hier scheint die saurere Abgangsgruppe $\left(\mathrm{pK}_{\mathrm{a}}\right.$ von 0,23$)$ tatsächlich einen besseren Umsatz als mit acetyliertem Substrat $\left(\mathrm{pK}_{\mathrm{a}}\right.$ von 4,76) $\mathrm{zu}$ bewirken. Zusätzlich wurde auch ein niedrigerer $\mathrm{K}_{\mathrm{M}}$-Wert als für bisherige fluorogene Substrate gefunden $(>500 \mu \mathrm{M})$. Dieses neue Substrat für HDAC8 dürfte biochemische Untersuchungen und besonders ein Screening nach Inhibitoren für HDAC8 sehr erleichtern. Ein spezifisches Substrat scheint es aber nicht zu sein, da auch FB188HDAH Boc-Lys(TFA)-AMC etwa gleich gut wie Boc-Lys(Ac)-AMC mit sehr ähnlichen kinetischen Parametern umsetzte. Zumindest eine Unterscheidung von einigen HDAC sollte jedoch möglich sein, da ja HDAC aus der Rattenleber dieses Substrat nicht umsetzt, obwohl es wahrscheinlich nur aus Klasse I-Enzymen HDAC 1, 2 und 3 besteht.

Seltsamerweise wurde aber in Kompetitionsversuchen wie auch schon im Falle von Rattenleber-HDAC keine Hemmung durch NaTFA gefunden, wohl aber durch NaAc und NaProp. Falls nicht elektrostatische oder sterische Hindernisse bei der HDAC aus der Ratte verhinderten, daß sich der positive Effekt der besseren Abgangsgruppe auswirken konnte, ist dieses Ergebnis nicht gut mit dem postulierten, proteaseähnlichen Katalysemechanismus (Abb. 47) in Einklang zu bringen: 


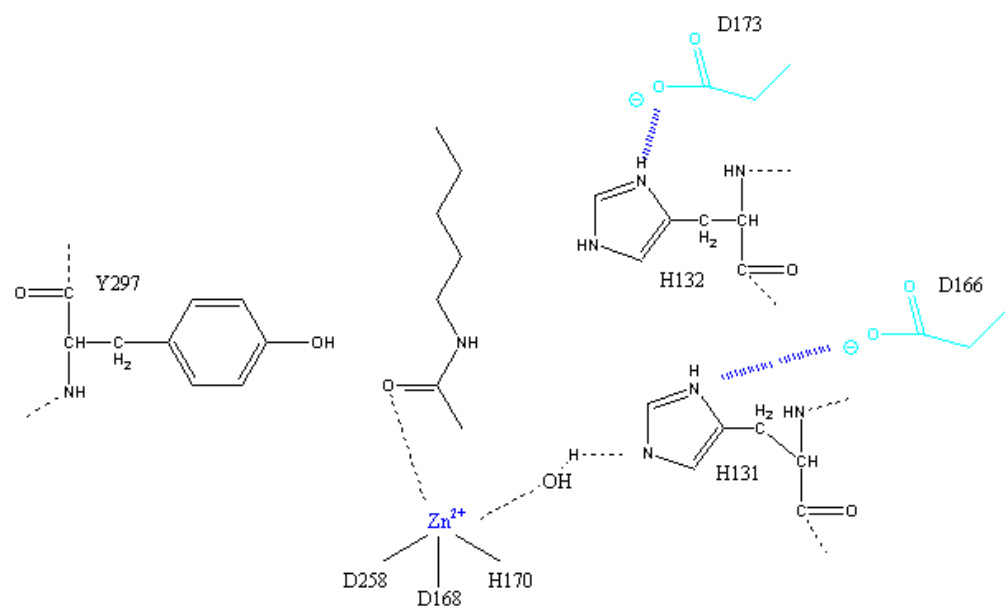

A Bindungzustand nach Eintritt des acetylierten Lysylrestes

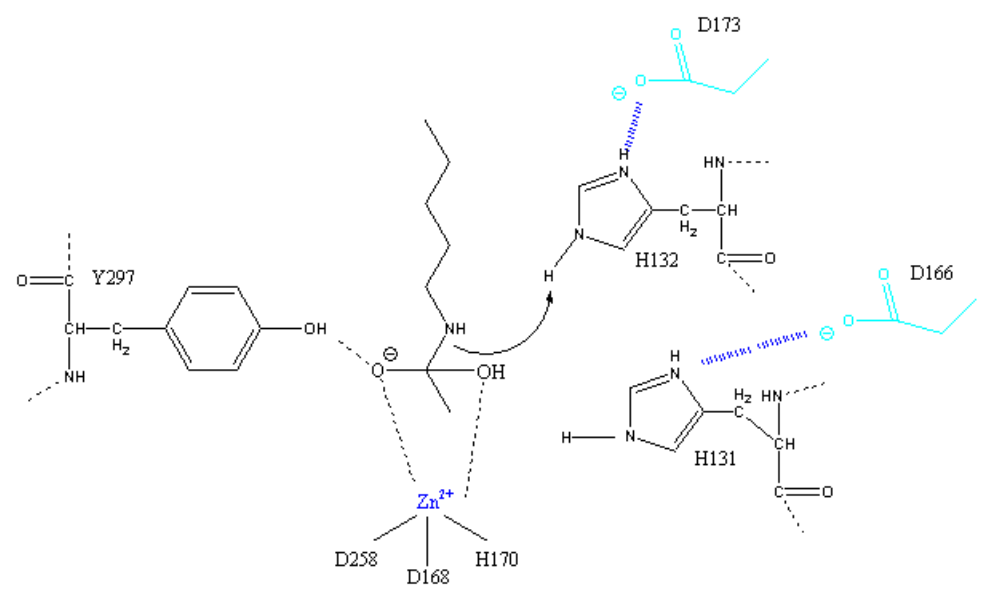

B Tetrahedrischer Übergangszustand

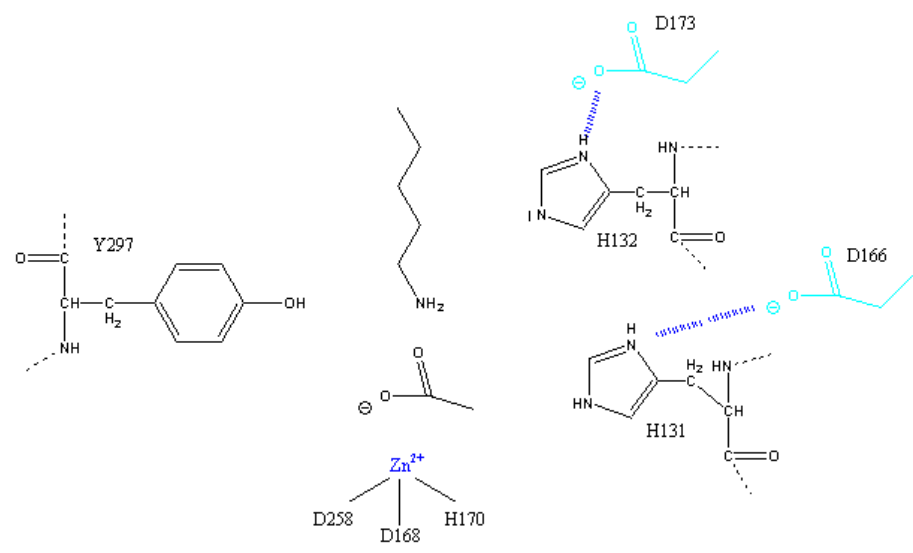

C Spaltung der C-N Bindung, Freisetzung des Acetats

Abbildung 47: Reaktionsmechanismus der Deacetylierung (Finnin et al., 1999) 
Der von Finnin und Mitarbeitern (Finnin et al., 1999) vorgeschlagene Reaktionsmechanismus geht davon aus, daß im Verlauf der Deacetylierunsreaktion ein durch $\mathrm{Zn}^{2+}$ und dem Ladungsübertragungssystem His131 / Asp166 polarisiertes Wassermolekül (Abb. 47, A) den nukleophilen Angriff auf den Carbonyl-Kohlenstoff ausführt, der tetrahedrische Übergangszustand von Tyr297 und dem $\mathrm{Zn}^{2+}$ stabilisiert wird (Abb. 47, B) und schließlich mit Hilfe eines zweiten Ladungsübertragungssystems His132 / Asp173 die Bindung gespalten wird (Abb. 47, C).

Im Lichte der erhaltenen Ergebnisse dieser Arbeit und der zeitgleichen Doktorarbeit von Christian Hildmann steht zumindest infrage, ob die postulierten Reaktionsabläufe im aktiven Zentrums so haltbar sind: Der schlechte Umsatz der besonders des TFA- und auch des Mesyl- gegenüber dem Acetylsubstrat lassen sich nur unzureichend alleine mit den sterischen Verhältnissen erklären, man könnte eher vermuten, daß die Freisetzung des „Acylrestes“ nicht geschwindigkeitsbestimmend ist. Dann müßte aber ein anderer als der beschriebene Übergangszustand, vielleicht mit dem Eingehen einer reversiblen Enzym-Substrat-bindung eintreten. Diese Annahnme unterstützen auch jüngste Untersuchungen der Vorgänge im aktiven Zentrum von HDLP (Vanommeslaeghe et al., 2003), speziell die Rolle des ionisierten Wassers, das sich als aktiviertes Nukleophil nahe des Tyrosylrestes (Tyr297) aufhält (vergl. Abb. 47) und möglicherweise diese Phenolstruktur zum eigentlichen nukleophilen Angreifer macht. Auch die Tatsache einer fehlenden Inhibition durch gezielt hergestellte Übergangszustands-Analoge (Kapustin et al., 2003) unterstützt die Annahme eines möglichen, anderen Mechanismus.

\subsubsection{Inhibitor-Entwicklung}

Bisher wurden nur wenige Versuche, selektiv hemmende Substanzen für HDAC zu entwickeln, unternommen (Hu et al., 2003; Wittich et al., 2002; Yoshida et al., 2001). Dazu wurden teilweise besonders diversifizierte chemische Bibliotheken generiert (Sternson et al., 2001; Wong et al., 2003). Eine Strategie (chemical genetic modifier screen) nutzt beim Screening bislang bekannte unterschiedliche biologischen Funktionen einiger HDAC aus, indem aus entsprechenden phänotypischen Effekten auf die selektive Inhibition einer Isoform geschlossen wurde (Haggarty et al., 2003a; Koeller et al., 2003). Allerdings ist dieses Vorgehen durch das dürftige Wissen über die Aufgabenverteilung der HDAC in der Zelle bislang stark limitiert. Mit diesem Ansatz konnte zwar die Identifizierung eines HDAC6-spezifischen Inhibitors erreicht werden (Haggarty et al., 2003b). Die Aufgabe war allerdings insofern etwas erleichtert, daß HDAC6 ein NichtHiston-Substrat erkennt und in der den Inhibitor Tubacin bindenden Domäne besonders von der HDAC-Consensussequenz abweicht (Grozinger und Schreiber, 2002; Haggarty et al., 2003b). Es sind darüberhinaus noch keine wirklich selektiven HDAC-Inhibitoren bekannt geworden (Kelly et al., 2002; Mai et al., 2003).

Viele Arbeitsgruppen haben die These der Existenz einer generellen HDAC-InhibitorStruktur (Abb. 39) der Form „Kappe-Linker-Hydroxamatgruppe“ aufgestellt (Jung et al., 
1997; Jung 2001; Remiszewski et al., 2003), wobei die Kappe sowohl für die HemmPotenz verantwortlich zeichnete (Curtin et al., 2002) als auch die Selektivität des Inhibitors modulieren können soll (Grozinger and Schreiber, 2002). Die Kappenstruktur hatte in anderen Fällen allerdings nur einen moderaten Einfluß auf die erreichten $\mathrm{IC}_{50^{-}}$ Werte für HDAC aus der Rattenleber (Wittich et al., 2002) oder HDAC1 (Woo et al., 2002). Unterstützende Hinweise für die Idee der Kappenstruktur als Selektivitätsdeterminante wurde durch das Beispiel des HDAC6-spezifischen Inhibitors Tubacin erbracht (Haggarty et al., 2003b; Wong et al., 2003). Tubacin weicht nur in der Kappenstruktur von dem unspezifischen Inhibitor SAHA ab. Es ist bislang aber nur indirekt entweder über phänotypische und Genexpressionsanalysen oder über den Nachweis der Induktion einer Histon-Hyperacetylierung gezeigt worden, daß Tubacin andere HDAC etwa 75 mal schlechter hemmt (Haggarty et al., 2003b; Wong et al., 2003). Ebenfalls ist nicht explizit ausgeschlossen worden, daß die Hemmung der Tubulindeacetylase-Aktivität durch Tubacin auf einer selektiven Interaktion mit dem Substrat Tubulin anstatt auf der selektiven Interaktion der Substanz mit der HDAC6 beruht. Es könnte sich also um einen Inhibitor der Protein-Protein-Interaktion handeln, der dann ebenfalls die Interaktion vieler anderer HDAC mit Tubulin verhindern würde.

Die Länge des aliphatischen Linkers, der die Kappe mit der funktionellen Gruppe verbindet, wurde mit 5-6 C-Atomen als optimal für die Hemmwirkung beschrieben (Jung et al., 1999; Wada et al., 2003; Woo et al., 2002). Dabei sind potente HDAC-Inhibitoren sowohl mit gesättigtem (z.B. SAHA) als auch mit ungesättigtem (z. B. TSA oder Oxamflatin) und daher weniger flexiblem Linker beschrieben. Eine Einführung von Doppelbindungen in den Linker führte in einigen Fällen sogar zu einem dramatischen Verlust der Hemmaktivität (ca.100fach bei MD85 (Van Ommeslaeghe et al., 2003), was auf eine damit einhergehende Verringerung in der Flexibilität des Linkers und in der Drehbarkeit der Kappenstruktur zurückgeführt wurde (Wada et al., 2003). Diese Befunde konnten im Wesentlichen durch die Ergebnisse des Screenings mit den MS275-Derivaten bestätigt werden (3.2.4.2.).

Während einige der HDAC-Inhibitoren mit einem kurzen 4-C-Linker, wie nach der These vom 6-C-Linker-Optimum zu erwarten, nur mikromolare $\mathrm{IC}_{50}$-Werte aufwiesen, existieren auch Ausnahmen. Einige der ,kurzen“ Inhibitoren, die hier im Arbeitskreis entwickelt wurden, liegen mit ihren $\mathrm{IC}_{50}$-Werten überraschenderweise jedoch deutlich im nanomolaren Bereich (Daten nicht gezeigt).

Bisher publizierte selektive Inhibitoren erreichen einen Unterschied in der Wirkung auf zwei HDAC-Isoformen mit einem Faktor von ca. 2-100. So hemmt Tubacin HDAC6 etwa 80 mal besser als andere HDAC, was allerdings nur indirekt gemessen wurde (Wong et al., 2003). Mit HDAC aus Mais als Modellenzyme für HDAC der Klasse I (HD-1B) bzw. der Klasse II (HD1-A) wurden kürzlich Inhibitoren entwickelt, welche in ihrer Hemmung zwischen beiden Klassen mit dem Faktor 7-78 diskriminieren (Mai et al., 2003). Kürzlich wurde von selektiven Inhibitoren gegen humane HDAC1 (SB-429201, IC50 von ca. 1,5 $\mu \mathrm{M}$ ) und HDAC8 (SB-379872, IC50 von ca. 0,5 $\mu \mathrm{M}$ ) berichtet, die mittels HTS bei identifiziert worden sind (Hu et al., 2003). Zusätzlich fand diese Arbeitsgruppe auch eine selektive Wirkung von MS275 auf humane HDAC1 $\left(\mathrm{IC}_{50}\right.$ von 
ca. $300 \mathrm{nM}$ ), wobei die humane HDAC3 wesentlich schlechter inhibiert wurde $\left(\mathrm{IC}_{50}\right.$ von ca. $8 \mu \mathrm{M}$ ) und auf HDAC8 keine Wirkung erzielt wurde. Selbst bei HDAC aus so unterschiedlichen Organismen wie Mais und Ratte konnten aber meist nur moderate Selektivitäten der Inhibitoren von etwa einem Faktor 10-20 beobachtet werden (Wittich et al., 2002).

Unter den bisher hier im Arbeitskreis synthetisierten Hydroxamat-Inhibitoren konnte bisher maximal ein 56facher Unterschied in der Wirkung auf zwei HDAC-Präparationen (Rattenleber-HDAC und FB188 HDAH versus HDAC8) festgestellt werden (D. Wegener, Dissertation 2003).

Unter den nicht-Hydroxamat-haltigen HDAC-Inhibitoren zeichnete sich bei den in dieser Arbeit vorgestellten Kojisäurederivaten (3.2.4.3.) ein Selektivitätsunterschied in der Inhibitionsrate von HDAC8 gegenüber FB $188 \mathrm{HDAH}\left(\mathrm{IC}_{50} 450 \mu \mathrm{M} / 69 \mu \mathrm{M}\right)$ um den Faktor 6 ab.

Weitere Anstrengungen werden aber unternommen werden müssen, um die Wirksamkeit und Selektivität dieser Inhibitoren zu verbessern.

\section{Zusammenfassung und Ausblick}

\subsection{Zusammenfassung der Resultate im Thrombinprojekt}

\section{Analyse der proteaseresistenten Hirudin-Varianten}

Im Forschungsprojekt der evolutiven Optimierung von Hirudin mit dem Ziel einer Protease-resistenten Variante des Moleküls, die aus einem kombinierten Ansatzes aus Phage-Display- und Hochdurchsatz-Screening-Methoden gewonnen worden waren, konnte mit Hilfe der Analytik durch LC-MS das Verhalten im proteolytischen Verdau untersucht und einige interessante Varianten charakterisiert werden (Wirsching et al., 2003). 


\section{Der „Proof-of-Concept“ für einen neuen Computer-unterstützten Wirkstoffsuchprozess wurde erbracht}

In der nachfolgenden Entwicklung niedermolekularer, direkter Thrombin-Inhibitoren wurden statt etablierter Verfahren wie etwa Struktur-basierter Wirkstoffsuche oder des Hochdurchsatz-Screenings ein im Arbeitskreis zusammen mit der Firma Novel Science Int. GmbH (Dr. M. Thürk) entwickeltes Verfahren des Computer-unterstützten Wirkstoffdesigns (CADDIS ${ }^{\mathrm{TM}}$-Verfahren, Computer-assisted Drug Discovery) eingesetzt. Am Beispiel des Design von peptidischen Thrombininhibitoren konnte ein „Proof-of-concept“ für das Verfahren erbracht werden. Beginnend mit zufällig ausgewürfelten Moleküle konnten in nur vier Optimierzyklen nM-Inhibitoren entwickelt werden.

\section{Multiparameter-Optimierung führt zu einer neuen Thrombininhibitor-Klasse mit pharmakologisch interessantem Eigenschaftsprofil und neuem Bindungsmodus}

Nach dem positiven Verlauf der 1-Parameter-Optimierung wurde dann ein weiterentwickeltes Verfahren dieses Computer-unterstützten Wirkstoffdesigns auf die Multiparameter-Optimierung ausgedehnt, um unerwünschte Nebenwirkungen von vorn herein auszuschließen und damit die Entwicklung eines Wirkstoffkandidaten wesentlich zu beschleunigen. Dieses sogenannte CADDIS ${ }^{\top M}$-Verfahren (Computer-assisted Drug Discovery) bietet den Vorteil, schnell und im experimentellen Stadium effizient und kostengünstig zu neuen Wirkstrukturen zu kommen. Im ganzen wurden nicht mehr als ca. 1000 Substanzen getestet, während beim traditionellen HTS- Drug Discovery (HighTroughput Screening) Bibliotheken von >>100.000 Substanzen die Regel sind (Spencer, 1998).

Auf der chemischen Seite fiel die Wahl auf die Substanzklasse der Peptide, das bedeutete zwar hohe Diversität, relativ einfache und schnelle Synthesen, beinhaltet auf der anderen Seite jedoch das Risiko mangelnder oraler Bioverfügbarkeit und schneller Elimination der Produkte. Bei der Auswahl der Bausteine nicht-proteinogene Aminosäuren zugefügt.

Auf der biologischen Seite wurden eine ganze Reihe von Testsysteme etabliert. Essentiell für den Erfolg dieses Projektes war es, bereits bei der Planung und Auswahl der Assays möglichst ein Abbild der in-vivo Situation zu schaffen, entsprechend wurde viel Sorgfalt auf die Auswahl der Assays verwandt. Neben der Primärwirkung wurde jede Substanz auf Selektivität und die sog. ADME-Parameter (Wasserlöslichkeit, Verteilungskoeffizient, Serumproteinbindung, metabolische Stabilität) und Toxizität sowie Hämolyse untersucht. Das Assayformat konnte dabei auf einen mittleren Durchsatz ausgerichtet werden. 
Die implementierte LC-MS-Anlage leistete bei der Durchführung wertvolle analytische Dienste.

In der praktischen Anwendung erwies sich der gesamte Prozeß als robust und konnte schnell und kostengünstig durchgeführt werden.

Mit der Computer-unterstützten Wirkstofffindung konnte auf der Basis experimenteller Daten in einem zyklischen Prozess mit der Substanz 8-5 tatsächlich ein Molekül entwickelt werden, daß in allen getesteten Eigenschaften entsprechenden Wirkstoffkandidaten der pharmazeutischen Industrie mindestens ebenbürtig ist. Die herausragenden Eigenschaften dieser Verbindung sind neben der ausgezeichneten Wirksamkeit $\left(\mathrm{K}_{\mathrm{i}}=3 \mathrm{nM}\right)$ ihre Selektivität mit mehr als dem 100.000 fachen gegen Trypsin, aber auch gegen eine ganze Reihe weiterer Proteasen, wie zum Beispiel die Faktoren Xa und XIIa, Urokinase und Plasmin. Darüberhinaus zeigte sich eine überraschend gute Aktivität in in-vitro-Koagulationsassays.

Bei diesen ersten Untersuchungen am Rattenmodell zeigte 8-5 auch im Eliminationsverhalten eine gegenüber Melagatran sogar leicht verbesserte, d.h. langsamere Elimination die zudem praktisch vollständig über die Niere verlief, während Melagatran auch über den Leber-Galle-Weg aus dem Körper entfernt wird.

Im Rahmen einer umfangreichen kinetische Studien mit Varianten von 8-5 sowie mit der Auflösung der Kristallstruktur des Inhibitor-Thrombin-Komplexes (Kooperation mit Dr. R. Friedrich und W. Bode, MPI f. Biochemie, Martinsried-München) wurde schließlich ein Bindungs- und Inhibitionsmodus nachgewiesen, der einzigartig und neu unter den bekannten Thrombininhibitoren ist (Publikation in Vorbereitung).

\section{Ausblick}

Erste Versuche am Rattenmodell in Richtung der Anwendung von 8-5 bei arteriellen Thrombosen werden zur Zeit angegangen.

Für die Weiterentwicklung von 8-5 in Richtung oraler Bioverfügbarkeit stellen soll (i) eine Ersatz der zwei vorhandenen Guanidin-Funktionen durch weniger basische Reste versucht werden, und (ii) Pro-Drug-Formen, z.B. angelehnt an die entsprechenden Formen bei Melagatran entwickelt werden. 


\subsection{Zusammenfassung der Resultate im HDAC-Projekt}

\section{Erfolgreiche heterologe Expression von HDAC8}

Im Rahmen dieser Arbeit ist es gelungen, die für humane HDAC8 kodierende cDNA zu klonieren und in einem E. coli-System wurde die heterologe Expression erreicht. Das Enzym konnte in hinreichender Reinheit und Menge über Anionenaustauschchromatographie in seiner aktiven Form aufgereinigt werden.

\section{Mitentwicklung und Optimierung des ersten, homogenen, nichtradioaktiven HDAC-Assays}

Zusammen v.a. mit D. Wegener wurde ein fluorogenes HDAC-Assay mit einfach herzustellenden Substraten entwickelt. Der Assay ist aufgrund seiner hohen Empfindlichkeit auch in miniaturisierten Assayformaten (MTP) durchführbar (Wegener et al., 2003c). Dieser Assay konnte durch neue Substratentwicklungen hinsichtlich Umsatz und Menge an benötigtem Substrat optimiert werden, sodaß ein HTS-taugliches Instrument für die Suche nach Inhibitoren zur Verfügung steht (Wegener et al., 2003a).

\section{Identifikation neuer HDAC-Substrate als biochemische Werkzeuge zur Untersuchung der Enzymfunktion}

Bei den Synthesen der verschiedenen Substrate galt es, die Anforderungen der Proteine in Bezug auf strukturelle und stereochemische Beschaffenheiten des Substrats auszuloten, insbesondere hinsichtlich möglicher struktureller Motive für Inhibitoren und um mehr über die Substratspezifität der HDAC's und die Vorgänge im Aktiven Zentrum zu erfahren. Mit Boc-Lys(Prop)-AMC konnte ein für HDAC aus der Rattenleber spezifisches Substrat entwickelt werden, für HDAC8 hingegen war Boc-Lys(TFA)-AMC das mit Abstand beste Substrat. Dieses neue Substrat für HDAC8 dürfte das Screening nach Inhibitoren für HDAC8 sehr erleichtern (Riester et al., 2004).

Der Einsatz der neuen Substrate ergab: (i) Alle drei untersuchten HDAC und HDAH (Hildmann et al., 2004) tolerieren keine voluminösen oder verzweigten $\varepsilon$-ständigen Acylgruppen, (ii) die Enzyme setzen Substrate mit besseren Abgangsgruppen nicht besser um, was nicht zwanglos in Einklang mit dem publizierten, einstufigen Reaktionsmechanismus (Finnin et al., 1999) zu bringen ist. Momentan zu favorisieren ist die These, wonach der Abgang von Acetat nicht geschwindigkeitsbestimmend ist, mit der möglichen Konsequenz eines zweistufigen Reaktionsmechanismus. Möglicherweise 
ergeben sich neue Erkenntnisse mit den Ergebnissen aus parallel zu dieser Arbeit betriebenen Mutagenese-Studien (C. Hildmann, Dissertation).

\section{Inhibitorentwicklung und Ausblick}

Alle vorangegangenen Aufgaben können als Vorarbeiten einer Entwicklung selektiver, spezifischer Inhibitoren gelten. Dieses Vorhaben wurde an wenigen Kleinserien von Molekülen aus der Stoffklasse der Peptide, Phenylendiamin- und Pyranonderivaten begonnen, die als Basis für die weitere Entwicklung von Nicht-Hydroxamat-Inhibitoren gelten sollen.

Bei den Peptid-basierten Inhibitoren wurden Vertreter mit Hemmwirkung im niedrigen $\mu$ molaren Bereich identifiziert.

Die an Festphase hergestellten Derivate von MS275 bestätigen eine Vielzahl möglicher Substitutionen im Kopf- und Spacerbereich des Moleküls.

Mit der Pyranonstruktur der Kojisäurederivate in Verbindung mit weiteren aromatischen Molekülanteilen konnte ein wirksames, neues Bindungmotiv gegen HDAC / HDAH beschrieben werden, das möglicherweise die Entwicklung von Inhibitoren mit höherer Selektivität erlauben wird. Hier sollen noch weitere mögliche Bindemotive untersucht werden. Solche chemische Strukturen, die außer Hydroxamaten und 2-AminophenylBenzamiden als Bindungsgruppen für Zink (ZBG) in Frage kommen könnten, wurden bereits in einem Modellsystem für Matrixmetalloproteasen als Zinkkomplexe kristallographisch untersucht und mit Acetohydroxamat $\mathrm{CH}_{3} \mathrm{CONHOH}$ verglichen (Puerta et al., 2003).

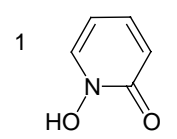

1-hydroxy-2(1H)-
pyridinone

BL $1.97 / 2.09$

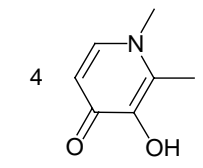

3-hydroxy-1,2-dimethyl-4(1H)pyridinone

BL $1.96 / 2.05$

2

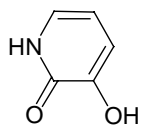

$\begin{array}{ll}\text { 3-hydroxy-2(1H)- } & \text { 3-hydroxy-1-methyl-2(1H)- } \\ \text { pyridinone } & \text { pyridinone }\end{array}$

BL 1.92 / 2.23

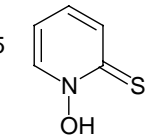

1-hydroxy-2(1H)- 3-hydroxy-2-methyl-4pyridinthione pyrone

$\mathrm{BL} 2.08 / 2.32 \quad \mathrm{BL} 1.94 / 2.18$

Abbildung 48: Chemische Struktur möglicher ZinkBindungsGruppen

Kristallographisch bestimmte Bindungslängen BL in Angström. 
Bei Hydroxamat-Inhibitoren ist an einen weiteren kombinatorischer Ansatz unter Verwendung der Horner-Wadsworth-Emmons Reaktion zur Erzeugung von Doppelbindungen gedacht, einige sehr vielversprechende Verbindungen diese Typs wurden in unserem Arbeitkreis bereits von Dr. M. Gebinoga hergestellt (Abb. 49):
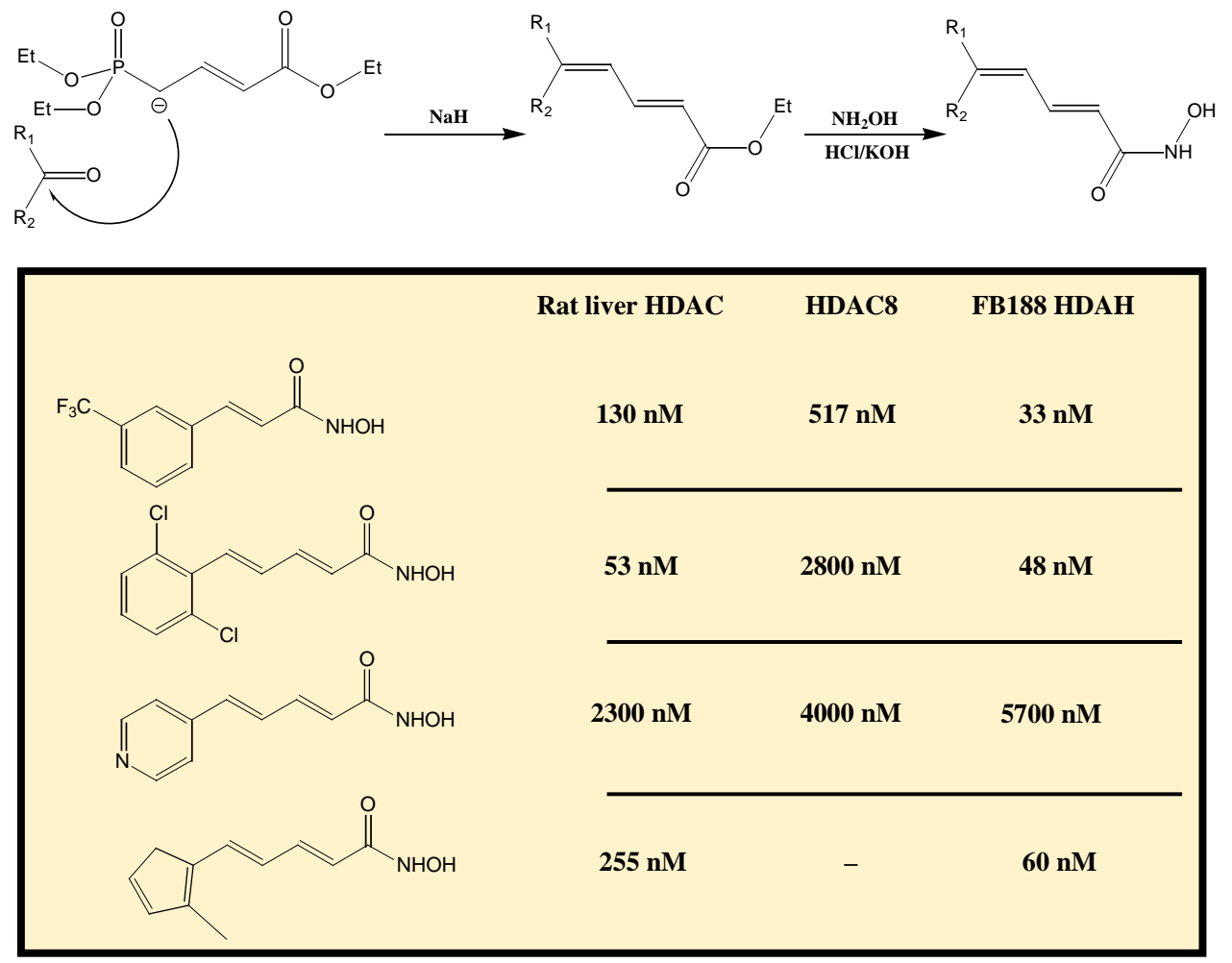

Abbildung 49: Horner-Wadsworth-Emmons Reaktions (Wadsworth \& Emmons, 1961)

Dargestellt sind das Reaktionsschema und einige bereits hergestellte und untersuchte Produkte

Schließlich wird mit der Synthese von Benzimidazol-Derivaten an die Erschließung einer weiteren, auch unter pharmakologischen Gesichtspunkten interessanten, Stoffklasse als möglichen Inhibitoren gedacht.

Die nötigen Instrumente für eine zügige und kostengünstige Entwicklung in dieser Richtung, d.h. effiziente Festphasensynthesen, durch rekombinante Expression verfügbar gemachte Targets, HTS-taugliche Assaysysteme und nicht zuletzt „intelligente“ Multiparameter-Optimierverfahren sind in dieser Arbeit beschrieben worden. 


\section{Literatur}

Artursson,P., Karlsson,J., (1991) Correlation Between Oral Drug Adsorption in Humans and Apparent Drug Permeability Coefficients in Human Intestinal Epithelial (Caco-2)Cells. Biochem Biophys Res Commun, (175), $880-885$.

Allfrey, V.G., Faulkner, R. and Mirsky, A.E. (1964). Acetylation and Methylation of Histones and Their Possible Role in the Regulation of Rna Synthesis. Proc Natl Acad Sci U S A, (51), 786-94.

Balbas, P. (2001). Understanding the art of producing protein and nonprotein molecules in Escherichia coli. Mol Biotechnol, (19), 251-67.

Bernatowicz, M.S.; Wu, Y. und Matsueda, G. R. (1993). Urethane protected derivatives of 1guanylpyrazole for the mild and efficient preparation of guanidines. Tetrahedron Lett 34, 3389-3392

Bichler, J., Fichtl, B., Siebeck, M., and Fritz, H. (1988). Pharmacokinetics and pharmacodynamics of hirudin in man after single subcutaneous and intravenous bolus administration. Arzeinm. Forsch./Drug Res. 38, 704-710.

Bichler, J., Baynes, J. W., and Thorpe, S. R. (1993). Catabolism of hirudin and thrombin-hirudin complexes in the rat. Biochemical J. (296), 771-776.

Biomol. (2003) Product News.

Blondelle, S.E., Takahashi, E., Weber, P.A., und Houghten, R.A. (1994). Identification of antimicrobial peptides by using combinatorial libraries made up of unnatural amino acids. Antimicrob. Agents Chemother. 38, 2280-2286.

Bode, W., Mayr, I., Baumann, U., Huber, R., Stone, S.R. \& Hofsteenge, J. (1989). The refined $1.9 \AA$ crystal structure of human alpha-thrombin: Interaction with D-Phe-Pro- Arg chloromethylketone and the significance of the Tyr-Pro-Pro-Trp insertion. EMBO J. (8), 3467-3475.

Bode, W., Turk, D. \& Stürzebecher, J. (1990). Geometry of binding of the benzamidine- and argininebased inhibitors NAPAP and MQPA to human $\alpha$-thrombin. X-ray crystallographic determination of the NAPAP-trypsin complex and modeling of NAPAP-thrombin and MQPA-thrombin. European Journal of Biochemistry (193), 175-182.

Bode, W., and Huber, R. (1991). Ligand binding: proteinase-protein inhibitor interactions. Curr. Opin. Struct. Biol. (1), 45-52.

Bode, W., Turk, D. \& Karshikov, A. (1992). The refined 1.9 Å X-ray crystal structure of D-Phe-Pro-Arg chloromethylketone inhibited human a-thrombin. Structure analysis, overall structure, electrostatic properties, detailed active site geometry, structurefunction relationships. Protein Sci. (1), 426-471.

Bode, W. \& Stubbs, M.T. (1995). Die Raumstruktur des Thrombins: ein Wegweiser zu seinen vielfältigen Functionen. Hämostaseologie (15), 1-13.

Boffa LC, Vidali G, Mann RS, Allfrey VG. (1978). Suppression of histone deacetylation in vivo and in vitro by sodium butyrate. J Biol Chem (10), 3364-6. 
Bouchain, G., Leit, S., Frechette, S., Khalil, E.A., Lavoie, R., Moradei, O., Woo, S.H., Fournel, M., Yan, P.T., Kalita, A., Trachy-Bourget, M.C., Beaulieu, C., Li, Z., Robert, M.F., MacLeod, A.R., Besterman, J.M. and Delorme, D. (2003). Development of potential antitumor agents. Synthesis and biological evaluation of a new set of sulfonamide derivatives as histone deacetylase inhibitors. $J$ Med Chem, (46), 820-30.

Braun, P. J., Dennis, S., Hofsteenge, J., and Stone, S. R. (1988). Use of site-directed mutagenesis to investigate the basis for the specificity of hirudin. Biochemistry (27), 6517-6522

Broach, J. R., and Thorner, J. (1996). High-throughput screening for drug discovery. Nature (384), 1416.

Butler, L.M., Agus, D.B., Scher, H.I., Higgins, B., Rose, A., Cordon-Cardo, C., Thaler, H.T., Rifkind, R.A., Marks, P.A. and Richon, V.M. (2000). Suberoylanilide hydroxamic acid, an inhibitor of histone deacetylase, suppresses the growth of prostate cancer cells in vitro and in vivo. Cancer Res, (60), 5165-70.

Butler, L.M., Zhou, X., Xu, W.S., Scher, H.I., Rifkind, R.A., Marks, P.A. and Richon, V.M. (2002). The histone deacetylase inhibitor SAHA arrests cancer cell growth, up-regulates thioredoxin-binding protein-2, and down-regulates thioredoxin. Proc Natl Acad Sci U S A, (99), 11700-5.

Byrd JC, Shinn C, Ravi R, Willis CR, Waselenko JK, Flinn IW, Dawson NA, Grever MR. (1999). Depsipeptide (FR901228): a novel therapeutic agent with selective, in vitro activity against human B-cell chronic lymphocytic leukemia cells. Blood. (4), 1401-8. Erratum in: Blood 2000 (2), 409.

Carmen, A.A., Griffin, P.R., Calaycay, J.R., Rundlett, S.E., Suka, Y. and Grunstein, M. (1999). Yeast HOS3 forms a novel trichostatin A-insensitive homodimer with intrinsic histone deacetylase activity. Proc Natl Acad Sci U S A, (96), 12356-61.

Carmichael J, DeGraff WG, Gazdar AF, Minna JD, Mitchell JB. (1987). Evaluation of a tetrazoliumbased semiautomated colorimetric assay: assessment of radiosensitivity. Cancer Res, (4), 943-6.

Chan, W.C. und White, P.D. „Fmoc Solid Phase Peptid Synthesis: A Practical Approach”, Oxford University Press, Oxford, 2000

Chang, J.-Y. (1990). Production, properties, and thrombin inhibitory mechanism of hirudin amino-terminal core fragments. J Biol . Chem , (265), 22159-22166.

Cheng, Y., Prusoff, W.H., (1973) Relationship between the inhibitory constant $\left(\mathrm{K}_{\mathrm{i}}\right)$ and the concentration of inhibitor which causes 50 percent inhibition $\left(\mathrm{I}_{50}\right)$ of an enzyme reaction Biochem Pharmacol (22): 30993108 .

Chung, D. (2002). Histone modification: the 'next wave' in cancer therapeutics. Trends Mol Med, (8), S101.

Crowther, M. A., and Weitz, J. I. (2004). Ximelagatran: the first oral direct thrombin inhibitor. Expert Opinion on Investigational Drugs 13, 403-413.

Curtin, M.L., Garland, R.B., Heyman, H.R., Frey, R.R., Michaelides, M.R., Li, J., Pease, L.J., Glaser, K.B., Marcotte, P.A. and Davidsen, S.K. (2002). Succinimide hydroxamic acids as potent inhibitors of histone deacetylase (HDAC). Bioorg Med Chem Lett, (12), 2919-23.

Darkin-Rattray SJ, Gurnett AM, Myers RW, Dulski PM, Crumley TM, Allocco JJ, Cannova C, Meinke PT, Colletti SL, Bednarek MA, Singh SB, Goetz MA, Dombrowski AW, Polishook JD, Schmatz DM. (1996). Apicidin: a novel antiprotozoal agent that inhibits parasite histone deacetylase. Proc Natl Acad Sci U S A, (23), 13143-7. 
Degryse, E., Acker, M., Defreyn, G., Bernat, A., Maffrand, J. P., Roitsch, C., and Courtney, M. (1989). Point mutations modifying the thrombin inhibition kinetics and antithrombotic activity in vivo of recombinant hirudin. Prot. Eng. (2), 459-465.

de Ruijter, A.J., van Gennip, A.H., Caron, H.N., Kemp, S. and van Kuilenburg, A.B. (2003). Histone deacetylases (HDACs): characterization of the classical HDAC family. Biochem J, (370), 737-49.

Dodt, J., Köhler, S., and Baici, A. (1988). Interaction of site specific hirudin variants with $\alpha$-thrombin. FEBS Lett. (229), 87-90.

Dower, W.J., Miller, J.F. and Ragsdale, C.W. (1988). High efficiency transformation of E. coli by high voltage electroporation. Nucleic Acids Res, (16), 6127-45.

Dullweber, F., Stubbs, M. T., Musil, G., Stürzebecher, J. \& Klebe, G. (2001). Factorising ligand affinity: a combined thermodynamic and crystallographic study of trypsin and thrombin inhibition. $J$ Mol Biol 313, 593-614.

Duran N, Menck CF. (2001). Chromobacterium violaceum: a review of pharmacological and industiral perspectives. Crit Rev Microbiol, (3), 201-22.

Edwards, C.P. and Aruffo, A. (1993). Current applications of COS cell based transient expression systems. Curr Opin Biotechnol, (4), 558-63.

Finnin, M.S., Donigian, J.R., Cohen, A., Richon, V.M., Rifkind, R.A., Marks, P.A., Breslow, R. and Pavletich, N.P. (1999). Structures of a histone deacetylase homologue bound to the TSA and SAHA inhibitors. Nature, (401), 188-93.

Fischetti, V.A., Medaglini, D., Oggioni, M. and Pozzi, G. (1993). Expression of foreign proteins on gram-positive commensal bacteria for mucosal vaccine delivery. Curr Opin Biotechnol, (4), 603-10.

Fishman, W. H., and Doellgast, G. J. (1975) in The plasma proteins, structure, function and genetic control (Putnam, F. W., Ed.), Vol. 2, pp. 213-261, Academic Press, London.

Floyd, C.D., Lewis, C.N., Patel, S.R., \& Whittaker, M. (1996) A method for the synthesis of hydroxamic acids on solid phase. Tetrahedron Lett., (37), 8045-8048.

Furumai, R., Komatsu, Y., Nishino, N., Khochbin, S., Yoshida, M. and Horinouchi, S. (2001). Potent histone deacetylase inhibitors built from trichostatin A and cyclic tetrapeptide antibiotics including trapoxin. Proc Natl Acad Sci U S A, (98), 87-92.

Gao, L., Cueto, M.A., Asselbergs, F. and Atadja, P. (2002). Cloning and functional characterization of HDAC11, a novel member of the human histone deacetylase family. J Biol Chem, (277), 25748-55.

Geisse, S., Gram, H., Kleuser, B. and Kocher, H.P. (1996). Eukaryotic expression systems: a comparison. Protein Expr Purif, (8), 271-82.

Glaser, K.B., Li, J., Staver, M.J., Wei, R.Q., Albert, D.H. and Davidsen, S.K. (2003a). Role of class I and class II histone deacetylases in carcinoma cells using siRNA. Biochem Biophys Res Commun, (310), $529-36$.

Grahn, S., Ullmann, D. and Jakubke, H. (1998). Design and synthesis of fluorogenic trypsin peptide substrates based on resonance energy transfer. Anal Biochem, (265), 225-31.

Grozinger, C.M. and Schreiber, S.L. (2002). Deacetylase enzymes. Biological functions and the use of small-molecule inhibitors. Chem Biol, (9), 3-16. 
Grunstein, M. (1997). Histone acetylation in chromatin structure and transcription. Nature, (389), 349-52.

Gu, W. and Roeder, R.G. (1997). Activation of p53 sequence-specific DNA binding by acetylation of the p53 C-terminal domain. Cell, (90), 595-606.

Gustafsson, D., Nyström, J. E., and Carlsson, S. (2001). The direct thrombin inhibitor melagatran and its oral prodrug H 376/95: intestinal absorption properties, biochemical and pharmacodynamic effects.

Thromb. Res. (101), 171-181.

Haggarty, S.J., Koeller, K.M., Wong, J.C., Butcher, R.A. and Schreiber, S.L. (2003a).

Multidimensional chemical genetic analysis of diversity-oriented synthesis-derived deacetylase inhibitors using cell-based assays. Chem Biol, (10), 383-96.

Haggarty, S.J., Koeller, K.M., Wong, J.C., Grozinger, C.M. and Schreiber, S.L. (2003b). Domainselective small-molecule inhibitor of histone deacetylase 6 (HDAC6)-mediated tubulin deacetylation. Proc Natl Acad Sci U S A, (100), 4389-94.

Hamamori, Y. and Schneider, M.D. (2003). HATs off to Hop: recruitment of a class I histone deacetylase incriminates a novel transcriptional pathway that opposes cardiac hypertrophy. J Clin Invest, (112), 824-6.

Hauptmann, J., Steinmetzer, T., Vieweg, H., Wikstrom, P., and Stürzebecher, J. (2002). Influence of structural variations in peptidomimetic 4-amidinophenylalanine-derived thrombin inhibitors on plasma clearance and biliary excretion in rats. Pharm. Res. (19), 1027-1033.

He, L.Z., Tolentino, T., Grayson, P., Zhong, S., Warrell, R.P., Jr., Rifkind, R.A., Marks, P.A., Richon, V.M. and Pandolfi, P.P. (2001). Histone deacetylase inhibitors induce remission in transgenic models of therapy-resistant acute promyelocytic leukemia. J Clin Invest, (108), 1321-30.

Heltweg, B., Dequiedt, F., Verdin, E. and Jung, M. (2003). Nonisotopic substrate for assaying both human zinc and NAD(+)-dependent histone deacetylases. Anal Biochem, (319), 42-8.

Hildmann, C., Ninkovic, M., Dietrich, R., Wegener, D., Riester, D., Zimmermann, T., Birch, O.M., Bernegger, C., Loidl, P. and Schwienhorst, A. (2003). A new amidohydrolase from Bordetella/Alcaligenes strain FB188 with similarities to histone deacetylases. J Bacteriol, (186), 2328-39.

Hoffmann, K., Brosch, G., Loidl, P. and Jung, M. (1999). A non-isotopic assay for histone deacetylase activity. Nucleic Acids Res, (27), 2057-8.

Hoffmann, K., Brosch, G., Loidl, P. and Jung, M. (2000). First non-radioactive assay for in vitro screening of histone deacetylase inhibitors. Pharmazie, (55), 601-6.

Holland, L. A. und Leigh, A. M. (2003) Bilayered phospholipid micelles and capillary electrophoresis: A new additive for electrokinetic chromatography. Electrophoresis, 24,2935-2939

Hollenberg, C.P. and Gellissen, G. (1997). Production of recombinant proteins by methylotrophic yeasts. Curr Opin Biotechnol, (8), 554-60.

Hu, E., Chen, Z., Fredrickson, T., Zhu, Y., Kirkpatrick, R., Zhang, G.F., Johanson, K., Sung, C.M., Liu, R. and Winkler, J. (2000). Cloning and characterization of a novel human class I histone deacetylase that functions as a transcription repressor. J Biol Chem, (275), 15254-64.

Hu, E., Dul, E., Sung, C.M., Chen, Z., Kirkpatrick, R., Zhang, G.F., Johanson, K., Liu, R., Lago, A., Hofmann, G., Macarron, R., De Los Frailes, M., Perez, P., Krawiec, J., Winkler, J. and Jaye, M. (2003). Identification of Novel Isoform-Selective Inhibitors within Class I Histone Deacetylases. $J$

Pharmacol Exp Ther, (307), 720-8. 
Hubbert, C., Guardiola, A., Shao, R., Kawaguchi, Y., Ito, A., Nixon, A., Yoshida, M., Wang, X.F. and Yao, T.P. (2002). HDAC6 is a microtubule-associated deacetylase. Nature, (417), 455-8.

Ikonomou, L., Schneider, Y.J. and Agathos, S.N. (2003). Insect cell culture for industrial production of recombinant proteins. Appl Microbiol Biotechnol, (62), 1-20.

Jackman, J.E., Fierke, C.A., Tumey, L.N., Pirrung, M., Uchiyama, T., Tahir, S.H., Hindsgaul, O. and Raetz, C.R. (2000). Antibacterial agents that target lipid A biosynthesis in gram-negative bacteria. Inhibition of diverse UDP-3-O-(r-3-hydroxymyristoyl)-n-acetylglucosamine deacetylases by substrate analogs containing zinc binding motifs. J Biol Chem, (275), 11002-9.

Johnstone, R.W. (2002). Histone-deacetylase inhibitors: novel drugs for the treatment of cancer. Nat Rev Drug Discov, (1), 287-99.

Judkins, B.D., Allen, D.G., Cook, T.A., Evans, B., Sardharwala, T.E. (1996). A versatile synthesis of amidines from nitriles via amidoximes. Synth Comm , (26), 4351-4367.

Jung, M., Hoffmann, K., Brosch, G. und Loidl, P. (1997) Analogues of Trichostatin A and Trapoxin B as histone deacetylase inhibitors. Bioorg Med Chem Lett , (7), 1655-1658.

Jung, M. (2000). Inhibitors of histone deacetylase as new agents for prevention and treatment of cancer. Pharm Unserer Zeit, (29), 385-8.

Jung, M. (2001). Inhibitors of histone deacetylase as new anticancer agents. Curr Med Chem, (8), 1505-11.

Jung, M., Brosch, G., Kolle, D., Scherf, H., Gerhauser, C. and Loidl, P. (1999). Amide analogues of trichostatin A as inhibitors of histone deacetylase and inducers of terminal cell differentiation. J Med Chem, (42), 4669-79.

Kaatz, H., Streffer, S., Wollenberger, U. und Peter, M. (1999) Inhibition of Mushroom Tyrosinase by Kojic Acid Octanoates. Z Naturforsch, (54c), 70-74

Kahn, V., Lindner, P. und Zakin, V., (1995) Effect of kojic acid on the oxidation of o-dihydroxyphenols by mushroom tyrosinase. J.Food Biochem. , (18), 253-271.

Kaiser E, Colescott R, Cook P: (1970) Color test for diction of free terminal amino groups in the solid phase synthesis of peptides. Anal Biochem, (34), 595-598.

Kamphausen, S., Höltge, N., Wirsching, F., Morys-Wortmann, C., Riester, D., Goetz, R., Thürk, M., and Schwienhorst, A. (2002). Genetic algorithm for the design of molecules with desired properties. $J$. Comp.-Aid. Mol. Design 16, 551-567.

Kapustin, G. V., Fejer, G., Gronlund, J. L., McCafferty, D. G., Seto, E., Etzkorn, F. A. (2003).

Phosphorus-based SAHA analogues as histone deacetylase inhibitors. Org Lett, (5), 3053-3056

Kasper, C. B. (1975) in Protein sequence determination (Needleman, S. B., Ed.), pp. 114-161, Springer Verlag, New York.

Kawai M, Rich DH, Walton JD. (1983). The structure and conformation of HC-toxin. Biochem Biophys Res Commun, (2), 398-403.

Kelly, W.K., O'Connor, O.A. and Marks, P.A. (2002). Histone deacetylase inhibitors: from target to clinical trials. Expert Opin Investig Drugs, (11), 1695-713. 
Kervabon, A., Mery, J. and Parello, J. (1979). Enzymatic deacetylation of a synthetic peptide fragment of histone H4. FEBS Lett, (106), 93-6.

Kettner, C., and Shaw, E. (1979). D-Phe-Pro-ArgCH2Cl - a selective affinity label for thrombin. Thrombosis Research (14), 969-973.

Kijima, M., Yoshida, M., Sugita, K., Horinouchi, S. and Beppu, T. (1993). Trapoxin, an antitumor cyclic tetrapeptide, is an irreversible inhibitor of mammalian histone deacetylase. J Biol Chem, (268), 22429-35.

Kim, D.H., Kim, M. and Kwon, H.J. (2003). Histone deacetylase in carcinogenesis and its inhibitors as anti-cancer agents. J Biochem Mol Biol, (36), 110-9.

Kim, H., Choi, J., Cho, J.K., Kim, S.Y. und Lee, Y-S. (2004) Solid-phase synthesis of kojic-acid tripeptides and their tyrosinase inhibitory activity, storage stability, and toxicity. Bioorg Med Chem Lett, (14), 2843-2846

Kim, M.S., Kwon, H.J., Lee, Y.M., Baek, J.H., Jang, J.E., Lee, S.W., Moon, E.J., Kim, H.S., Lee, S.K., Chung, H.Y., Kim, C.W. and Kim, K.W. (2001). Histone deacetylases induce angiogenesis by negative regulation of tumor suppressor genes. Nat Med, (7), 437-43.

Kim, Y.B., Lee, K.H., Sugita, K., Yoshida, M. and Horinouchi, S. (1999). Oxamflatin is a novel antitumor compound that inhibits mammalian histone deacetylase. Oncogene, (18), 2461-70.

Kline, T., Andersen, N.H., Harwood, E.A., Bowman, J., Malanda, A., Endsley, S., Erwin, A.L., Doyle, M., Fong, S., Harris, A.L., Mendelsohn, B., Mdluli, K., Raetz, C.R., Stover, C.K., Witte, P.R., Yabannavar, A. and Zhu, S. (2002). Potent, novel in vitro inhibitors of the Pseudomonas aeruginosa deacetylase LpxC. J Med Chem, (45), 3112-29.

Koeller, K.M., Haggarty, S.J., Perkins, B.D., Leykin, I., Wong, J.C., Kao, M.C. and Schreiber, S.L. (2003). Chemical genetic modifier screens. Small molecule trichostatin suppressors as probes of intracellular histone and tubulin acetylation. Chem Biol, (10), 397-410.

Kohn, J., Wilchek, M. (1982). Mechanism of activation of Sepharose and Sephadex by cyanogen bromide. Enzyme Microb Technol (4), 161-163.

Kolle, D., Brosch, G., Lechner, T., Pipal, A., Helliger, W., Taplick, J. and Loidl, P. (1999). Different types of maize histone deacetylases are distinguished by a highly complex substrate and site specificity. Biochemistry, (38), 6769-73.

Kook, H., Lepore, J.J., Gitler, A.D., Lu, M.M., Wing-Man Yung, W., Mackay, J., Zhou, R., Ferrari, V., Gruber, P. and Epstein, J.A. (2003). Cardiac hypertrophy and histone deacetylase-dependent transcriptional repression mediated by the atypical homeodomain protein Hop. J Clin Invest, (112), 863-71.

Kost, T.A. and Condreay, J.P. (1999). Recombinant baculoviruses as expression vectors for insect and mammalian cells. Curr Opin Biotechnol, (10), 428-33.

Krämer, O.H., Gottlicher, M. and Heinzel, T. (2001). Histone deacetylase as a therapeutic target. Trends Endocrinol Metab, (12), 294-300.

Kubinyi, H. (1998). Molekulare Ähnlichkeit. 2: Strukturbasierter Entwurf von Wirkstoffen. Pharm Unserer Zeit, (27), 158-72.

Kuhnz W. and Gieschen H. (1998) Predicting the oral bioavailability of 19-nortestosterone progestins in vivo from their metabolic stability in human liver microsomal preparations in vitro. Drug metab Dispos, (26), 1120-1127. 
Kwon, H.J., Kim, M. and Kim, D.H. (2003). Histone Deacetylase in Carcinogenesis and Its Inhibitors as Anti-cancer Agents. J Biochem Mol Biol, (36), 110-9.

Kwon, H.J., Kim, M.S., Kim, M.J., Nakajima, H. and Kim, K.W. (2002). Histone deacetylase inhibitor FK228 inhibits tumor angiogenesis. Int J Cancer, (97), 290-6.

Laemmli, U.K. (1970). Cleavage of structural proteins during the assembly of the head of bacteriophage T4. Nature, (227), 680-5.

Lagger, G., O'Carroll, D., Rembold, M., Khier, H., Tischler, J., Weitzer, G., Schuettengruber, B., Hauser, C., Brunmeir, R., Jenuwein, T. and Seiser, C. (2002). Essential function of histone deacetylase 1 in proliferation control and CDK inhibitor repression. Embo J, (21), 2672-81.

Lechner, T., Lusser, A., Brosch, G., Eberharter, A., Goralik-Schramel, M. and Loidl, P. (1996). A comparative study of histone deacetylases of plant, fungal and vertebrate cells. Biochim Biophys Acta, (1296), 181-8.

Lee, D.Y., Hayes, J.J., Pruss, D. and Wolffe, A.P. (1993). A positive role for histone acetylation in transcription factor access to nucleosomal DNA. Cell, (72), 73-84.

Li, X., Uchiyama, T., Raetz, C.R. and Hindsgaul, O. (2003). Synthesis of a Carbohydrate-Derived Hydroxamic Acid Inhibitor of the Bacterial Enzyme (LpxC) Involved in Lipid A Biosynthesis. Org Lett, (5), 539-41.

Lipinski C., Lombardo F, Dominy BW, Feeney PJ. (1997). Experimental and computational approaches to estimate solubility and permeability in drug discovery and development setting. Adv Drug Del Rev, (23), 3-25.

Luger, K., Mader, A.W., Richmond, R.K., Sargent, D.F. and Richmond, T.J. (1997). Crystal structure of the nucleosome core particle at 2.8 A resolution. Nature, (389), 251-60.

Lumma, W. C., Witherup, K. M., Tucker, T. J., Brady, S. F., Sisko, J. T., Naylor-Olsen, A. M., Lewis, S. D., Lucas, B. J., and Vacca, J. P. (1998). Design of novel, potent, noncovalent inhibitors of thrombin with nonbasic P-1 substructures: rapid structure-activity studies by solid-phase synthesis. J. Med. Chem. 41, 1011-1013.

Magnaghi-Jaulin, L., Groisman, R., Naguibneva, I., Robin, P., Lorain, S., Le Villain, J.P., Troalen, F., Trouche, D. and Harel-Bellan, A. (1998). Retinoblastoma protein represses transcription by recruiting a histone deacetylase. Nature, (391), 601-5.

Mai, A., Massa, S., Pezzi, R., Rotili, D., Loidl, P. and Brosch, G. (2003). Discovery of (Aryloxopropenyl)pyrrolyl Hydroxamides as Selective Inhibitors of Class IIa Histone Deacetylase Homologue HD1-A. J Med Chem, (46), 4826-9.

Maraganore, J. M., Bourdon, P., Jablonski, K. L., Ramachandran, K. L., and Fenton II, J. W. (1990). Design and characterization of hirulogs: a novel class of bivalent peptide inhibitors of thrombin.

Biochemistry (29), 7095-7101.

Marks, P.A., Richon, V.M. and Rifkind, R.A. (2000). Histone deacetylase inhibitors: inducers of differentiation or apoptosis of transformed cells. J Natl Cancer Inst, (92), 1210-6.

Markwardt, F. (1957). Die Isolierung und chemische Charakterisierung des Hirudins. Hoppe-Seyler's Z. Physiol. Chem. (308), 147-156. 
Meinke, P.T., Colletti, S.L., Doss, G., Myers, R.W., Gurnett, A.M., Dulski, P.M., Darkin-Rattray, S.J., Allocco, J.J., Galuska, S., Schmatz, D.M., Wyvratt, M.J. and Fisher, M.H. (2000). Synthesis of apicidin-derived quinolone derivatives: parasite-selective histone deacetylase inhibitors and antiproliferative agents. J Med Chem, (43), 4919-22.

Meinke, P. and Liberator, P. (2001). Histone deacetylase: a target for antiproliferative and antiprotozoal agents. Curr Med Chem, (8), 211-35.

Mellor, S.L., McGuire, C., \& Chan, W.C. (1997) N-Fmoc-Aminooxy-2-chlorotrityl polystyrene resin: A facile solid-phase methodology for the synthesis of hydroxamic acids. Tetrahedron Lett., (38), 3311-3314

Merrifield, R.B., (1963) Solid phase peptide synthesis. I. The synthesis of a tetrapeptide. J Am Chem Soc, (85), 2149-2153

Mullis, K.B. and Faloona, F.A. (1987). Specific synthesis of DNA in vitro via a polymerase-catalyzed chain reaction. Methods Enzymol, (155), 335-50.

Nakajima, H., Kim, Y.B., Terano, H., Yoshida, M. and Horinouchi, S. (1998). FR901228, a potent antitumor antibiotic, is a novel histone deacetylase inhibitor. Exp Cell Res, (241), 126-33.

Ninkovic, M., Riester, D., Wirsching, F., Dietrich, R. and Schwienhorst, A. (2001). Fluorogenic assay for penicillin G acylase activity. Anal Biochem, (292), 228-33.

Norton, V.G., Marvin, K.W., Yau, P. and Bradbury, E.M. (1990). Nucleosome linking number change controlled by acetylation of histones H3 and H4. J Biol Chem, (265), 19848-52.

Nygren, P.A., Stahl, S. and Uhlen, M. (1994). Engineering proteins to facilitate bioprocessing. Trends Biotechnol, (12), 184-8.

Oh, Y. S., Yun, M., and Hwang, S. Y. (1998). Discovery of LB30057, a benzamidrazone-based selective oral thrombin inhibitor. Bioorg. Med. Chem. Lett. (8), 631-634.

Oka, M.S. and Rupp, R.G. (1990). Large-scale animal cell culture: a biological perspective. Bioprocess Technol, (10), 71-92.

Okamoto, S., Hijikata, A., Kikumoto, R., Tonomura, S., Hara, H., Ninomiya, K., Maruyama, A., Sugano, M., and Tamao, Y. (1981). Potent inhibition of thrombin by the newly synthesized arginine derivative No. 805. The importance of stereo-structure of its hydrophobic carboxamide portion.

Biochemical and Biophysical Research Communications (101), 440-446.

Park, C. und Burgess, K. (2001). Facile macrocyclizations to beta-turn mimics with diverse structural, physical, and conformational properties. J Comb Chem (3), 257-266.

Patra, S.K., Patra, A. and Dahiya, R. (2001). Histone deacetylase and DNA methyltransferase in human prostate cancer. Biochem Biophys Res Commun, (287), 705-13.

Peterson, C.L. (2002). HDAC's at Work. Everyone Doing Their Part. Mol Cell, (9), 921-2.

Pidgeon,C., Ong, S., Liu, H., Qui, X., Pidgeon, M., Dantzig, A.H., Munroe, J., Hornback, W.J., Kasher, J.S., Glunz, L.., (1995) IAM Chromatography: An in vitro Screen for Predicting Drug Membrane Permeability. J Med Chem, (38), 590-594.

Porath, J., Carlsson, J., Olsson, I. and Belfrage, G. (1975). Metal chelate affinity chromatography, a new approach to protein fractionation. Nature, (258), 598-599. 
Poschel, K.A., Bucha, E., Esslinger, H.U., Nortersheuser, P., Jansa, U., Schindler, S., Nowak, G., Stein, G. (2000) Pharmacodynamics and pharmacokinetics of polyethylene glycol-hirudin in patients with chronic renal failure, Kidney Int, (58), 2478-2484.

Puerta, D.T. and Cohen, Seth M., (2003) Examination of Novel Zinc-Binding groups for use in Matrix Metalloproteinase Inhibitors, Inorganic Chemistry, (42), 3423-3430

Puig, O.M., Belles, E., Lopez-Rodas, G., Sendra, R. and Tordera, V. (1998). Interaction between Nterminal domain of $\mathrm{H} 4$ and DNA is regulated by the acetylation degree. Biochim Biophys Acta, (1397), 7990 .

Reeve, J.N. (2003). Archaeal chromatin and transcription. Mol Microbiol, (48), 587-98.

Remiszewski, S.W., Sambucetti, L.C., Atadja, P., Bair, K.W., Cornell, W.D., Green, M.A., Howell, K.L., Jung, M., Kwon, P., Trogani, N. and Walker, H. (2002). Inhibitors of human histone deacetylase: synthesis and enzyme and cellular activity of straight chain hydroxamates. J Med Chem, (45), 753-7.

Remiszewski, S.W., Sambucetti, L.C., Bair, K.W., Bontempo, J., Cesarz, D., Chandramouli, N., Chen, R., Cheung, M., Cornell-Kennon, S., Dean, K., Diamantidis, G., France, D., Green, M.A., Howell, K.L., Kashi, R., Kwon, P., Lassota, P., Martin, M.S., Mou, Y., Perez, L.B., Sharma, S., Smith, T., Sorensen, E., Taplin, F., Trogani, N., Versace, R., Walker, H., Weltchek-Engler, S., Wood, A., Wu, A. and Atadja, P. (2003). N-hydroxy-3-phenyl-2-propenamides as novel inhibitors of human histone deacetylase with in vivo antitumor activity: discovery of (2E)-N-hydroxy-3-[4-[[(2-

hydroxyethyl)[2-(1H-indol-3-yl)ethyl]amino]methyl ]phenyl]-2-propenamide (NVP-LAQ824). J Med Chem, (46), 4609-24.

Richmond, T.J. and Davey, C.A. (2003). The structure of DNA in the nucleosome core. Nature, (423), 145-50.

Richon, V.M., Sandhoff, T.W., Rifkind, R.A. and Marks, P.A. (2000). Histone deacetylase inhibitor selectively induces p21WAF1 expression and gene-associated histone acetylation. Proc Natl Acad Sci US A, (97), 10014-9.

Richon, V.M., Webb, Y., Merger, R., Sheppard, T., Jursic, B., Ngo, L., Civoli, F., Breslow, R., Rifkind, R.A. and Marks, P.A. (1996). Second generation hybrid polar compounds are potent inducers of transformed cell differentiation. Proc Natl Acad Sci U S A, (93), 5705-8.

Riester, D., Wegener, D., Hildmann, C., and Schwienhorst, A. (2004). Members of the histone deacetylase superfamily differ in substrate specificity towards small synthetic substrates. Biochem Biophys Res Commun (324), 1116-1123.

Riester, D., Wirsching, F., Salinas, G., Keller, M., Gebinoga, M., Kamphausen, S., Merkwart, C., Goetz, R., Wiesenfeldt, M., Stürzebecher, J., Thürk, M. and Schwienhorst, A. (2004). Novel thrombin inhibitors identified by computer-assisted multiparameter design. eingereicht.

Rose, T., Di Cera, E. (2002). Three-dimensional modeling of thrombin-fibrinogen interaction, J Biol Chem (277), 18875-18880.

Rosato, R.R., Almenara, J.A. and Grant, S. (2003). The histone deacetylase inhibitor MS-275 promotes differentiation or apoptosis in human leukemia cells through a process regulated by generation of reactive oxygen species and induction of p21CIP1/WAF1 1. Cancer Res, (63), 3637-45.

Saiki, R.K., Gelfand, D.H., Stoffel, S., Scharf, S.J., Higuchi, R., Horn, G.T., Mullis, K.B. and Erlich, H.A. (1988). Primer-directed enzymatic amplification of DNA with a thermostable DNA polymerase. Science, (239), 487-91. 
Saito, A., Yamashita, T., Mariko, Y., Nosaka, Y., Tsuchiya, K., Ando, T., Suzuki, T., Tsuruo, T. and Nakanishi, O. (1999). A synthetic inhibitor of histone deacetylase, MS-27-275, with marked in vivo antitumor activity against human tumors. Proc Natl Acad Sci U S A, (96), 4592-7.

Sakaguchi, K., Herrera, J.E., Saito, S., Miki, T., Bustin, M., Vassilev, A., Anderson, C.W. and Appella, E. (1998). DNA damage activates p53 through a phosphorylation-acetylation cascade. Genes Dev, (12), 2831-41.

Sanderson, P. E. J., and Naylor-Olsen, A. M. (1998). Thrombin inhibitor design. Curr. Med. Chem. (5), 289-304.

Sanger, F., Nicklen, S. and Coulson, A.R. (1977). DNA sequencing with chain-terminating inhibitors. Proc Natl Acad Sci U S A, (74), 5463-7.

Sangster, J.: Octanol-Water Partition coefficients: Fundamentals and Physico Chemistry. Wiley Series in solutions chemistry 1997, Volume 2

Saunders, N., Dicker, A., Popa, C., Jones, S. and Dahler, A. (1999). Histone deacetylase inhibitors as potential anti-skin cancer agents. Cancer Res, (59), 399-404.

Schechter, I. \& Berger, O. (1967). On the size of the active site in proteases. I. Papain. Biochem Biophys Res Commun, (27), 157.

Schillberg, S., Fischer, R. and Emans, N. (2003). Molecular farming of recombinant antibodies in plants. Cell Mol Life Sci, (60), 433-45.

Schuster, P., and Stadler, P. F. (1994). Landscapes: complex optimization problems and biopolymer structures. Computers Chem. 18, 295-324.

Scudiero DA., Shoemaker RH., Paull KD., Monks A., Tierney S., Nofziger TH., Currens MJ., Seniff D., Boyd MR. (1988) Evaluation of a soluble tetrazolium/formazan assay for cell growth and drug sensitivity in culture using human and other tumor cell lines. Cancer Research. 48 (17):4827-33.

Shuman, S. (1994). Novel approach to molecular cloning and polynucleotide synthesis using vaccinia DNA topoisomerase. J Biol Chem (269), 32678-84

Sitaram, N. , Nagaraj, R. (1990) A synthetic 13-residue peptide corresponding to the hydrophobic region of bovine seminalplasmin has antibacterial activity and also causes lysis of red blood cells. Journal of Biological chemistry 265 (18), 10438-10442.

Spencer, R.W. (1998). High-Throughput Screening of Historic Collections: Observations on File Size, Biological Targets, and File Diversity. Biotechnol Bioeng, (61), 61-67.

Spotswood, H.T. and Turner, B.M. (2002). An increasingly complex code. J Clin Invest, (110), 577-82.

Steinmetzer, T., Hauptmann, J., and Stürzebecher, J. (2001). Advances in the development of thrombin inhibitors. Exp. Opin. Invest. Drugs (10), 845-864.

Steinmetzer, T., Schweinitz, A., Kunzel, S., Wikstrom, P., Hauptmann, J., and Stürzebecher, J. (2002). Structure-activity relationships of new NAPAP-analogs. J. Enzyme Inhib. Med. Chem. (17), 241249

Sternson, S.M., Wong, J.C., Grozinger, C.M. and Schreiber, S.L. (2001). Synthesis of 7200 small molecules based on a substructural analysis of the histone deacetylase inhibitors trichostatin and trapoxin. Org Lett, (3), 4239-42. 
Stone SR, Hofsteenge J. (1986). Kinetics of the inhibition of thrombin by hirudin.

Biochemistry, (16), 4622-8.

Stürzebecher, J., Markwardt, E., Voigt, B., Wagner, G., and Walsmann, P. (1983). Cyclic amides of $\mathrm{N}$-alpha-arylsulfonylaminoacylated 4-amidinophenylalanine-tight binding inhibitors of thrombin.

Thrombosis Research (29), 635-642.

Sudbery, P.E. (1996). The expression of recombinant proteins in yeasts. Curr Opin Biotechnol, (7), 51724.

Suzuki, T., Ando, T., Tsuchiya, K., Fukazawa, N., Saito, A., Mariko, Y., Yamashita, T., Nakanishi, O. (1999). Synthesis and histone deacetylase inhibitory activity of new benzamide derivatives, J Med Chem (42), 3001-3

Szewczuk, Z., Gibbs, B.F., Yue, S.Y. Purisima, E.O., Konoshi, Y., (1992). Conformationally restricted thrombin inhibitors resistant to proteolytic digestion. Biochemistry (31), 9132-9140.

Tame, J. R. H. (1999). Scoring functions: A view from the bench. J Compu.-Aided Mol Design, (13), 99108.

Taube, C., Beitrag in Pharmakologie und Toxikologie, Herausgeber Oberdisse, Hackenthal und Kuschinsky, Springer Verlag Berlin, ISBN 3-540-61953-4, Kapitel 26, 423-441.

Taunton, J., Hassig, C.A. and Schreiber, S.L. (1996). A mammalian histone deacetylase related to the yeast transcriptional regulator Rpd3p. Science, (272), 408-11.

Teger-Nilsson, A. C., Bylund, R., Gustafsson, D., Gyzander, E., and Eriksson, U. (1997). In vitro effects of inogatran, a selective low molecular weight thrombin inhibitor. Thrombosis Research (85), 133 145.

Terfloth, L. und Gasteiger, J. (2001). Neural Networks and Genetic Algorithms in Drug Design. Drug Discovery Today, (6), 102-108

Tsuda, Y., Cygler, M., Gibbs, B. F., Pedyczak, A., Féthière, J., Yue, S. Y., and Konishi, Y. (1994).

Design of potent bivalent thrombin inhibitors based on hirudin sequence: incorporation of nonsubstratetype active site inhibitors. Biochemistry (33), 14443-14451.

Tsuji N, Kobayashi M, Nagashima K, Wakisaka Y, Koizumi K. (1976). A new antifungal antibiotic, trichostatin. J Antibiot (Tokyo), (1), 1-6.

Tucker, T. J., Brady, S. F., Lumma, W. C., Lewis, S. D., Gardell, S. J., Naylor-Olsen, A. M., Yan, Y., Sisko, J. T., Stauffer, K. J., Lucas, B. J., Lynch, J. J., Cook, J. J., Stranieri, M. T., Holahan, M. A., Lyle, E. A., Baskin, E. P., Chen, I. W., Dancheck, K. B., Krueger, J. A., Cooper, C. M., and Vacca, J. P. (1998). Design and synthesis of a series of potent and orally bioavailable noncovalent thrombin inhibitors that utilize nonbasic groups in the P1 position. J. Med. Chem. (41), 3210-3219.

Ueda H, Nakajima H, Hori Y, Goto T, Okuhara M. (1994). Action of FR901228, a novel antitumor bicyclic depsipeptide produced by Chromobacterium violaceum no. 968, on Ha-ras transformed NIH3T3 cells.

Biosci Biotechnol Biochem, (9), 1579-83.

Van den Wyngaert, I., de Vries, W., Kremer, A., Neefs, J., Verhasselt, P., Luyten, W.H. and Kass, S.U. (2000). Cloning and characterization of human histone deacetylase 8. FEBS Lett, (478), 77-83. 
Van Lint, C., Emiliani, S. and Verdin, E. (1996). The expression of a small fraction of cellular genes is changed in response to histone hyperacetylation. Gene Expr, (5), 245-53.

Van Ommeslaeghe, K., Elaut, G., Brecx, V., Papeleu, P., Iterbeke, K., Geerlings, P., Tourwe, D. and Rogiers, V. (2003). Amide analogues of TSA: synthesis, binding mode analysis and HDAC inhibition. Bioorg Med Chem Lett, (13), 1861-4.

Vanommeslaeghe, K., Van Alsenoy, C., De Proft, F., Martins, J.C., Tourwe, D. and Geerlings, P. (2003). Ab initio study of the binding of Trichostatin A (TSA) in the active site of histone deacetylase like protein (HDLP). Org Biomol Chem, (1), 2951-7.

Vassiliou S, Mucha A, Cuniasse P, Georgiadis D, Lucet-Levannier K, Beau F, Kannan R, Murphy G, Knauper V, Rio MC, (1999) Phosphinic pseudotripeptides as potent inhibitors of matrix metalloproteinases: a structure-activity study. J Med Chem (42), 2610-2620.

Velazquez OC, Rombeau JL. (1997). Butyrate. Potential role in colon cancer prevention and treatment. Adv Exp Med Biol, (427), 169-81.

Verdin, E., Dequiedt, F. and Kasler, H.G. (2003). Class II histone deacetylases: versatile regulators. Trends Genet, (19), 286-93.

Vindigni, A., De Filippis, V., Zanotti, G., Visco, C., Orsini, G., and Fontana, A. (1994). Probing the structure of hirudin from Hirudinaria manillensis by limited proteolysis. Isolation, characterization and thrombin-inhibitory properties of N-terminal fragments. Eur. J. Biochem. (226), 323-333.

Vogelauer, M., Wu, J., Suka, N. and Grunstein, M. (2000). Global histone acetylation and deacetylation in yeast. Nature, (408), 495-8.

Wada, C.K., Frey, R.R., Ji, Z., Curtin, M.L., Garland, R.B., Holms, J.H., Li, J., Pease, L.J., Guo, J., Glaser, K.B., Marcotte, P.A., Richardson, P.L., Murphy, S.S., Bouska, J.J., Tapang, P., Magoc, T.J., Albert, D.H., Davidsen, S.K. and Michaelides, M.R. (2003). Alpha-keto amides as inhibitors of histone deacetylase. Bioorg Med Chem Lett, (13), 3331-5.

Wade, P.A. (2001). Transcriptional control at regulatory checkpoints by histone deacetylases: molecular connections between cancer and chromatin. Hum Mol Genet, (10), 693-8.

Wade, P.A., Jones, P.L., Vermaak, D. and Wolffe, A.P. (1999). Purification of a histone deacetylase complex from Xenopus laevis: preparation of substrates and assay procedures. Methods Enzymol, (304), $715-25$.

Wadsworth, W.S. und Emmons, W.D. (1961). The Utility of Phosphonate Carbanions in Olefin Synthesis. J Am Chem Soc, (83), 1733-42

Wallace, A., Dennis, S., Hofsteenge, J., and Stone, S. R. (1989). Contribution of the N-terminal region of hirudin to its interaction with thrombin. Biochemistry (28), 10079-10084.

Wang, X., Moore, S. C., Laszckzak, M. Ausio, J. (2000). Acetylation increases the alpha-helical content of the histone tails of the nucleosome. J Biol Chem (275), 35013-20

Wang, W. and Malcolm, B.A. (2002). Two-stage polymerase chain reaction protocol allowing introduction of multiple mutations, deletions, and insertions, using QuikChange site-directed mutagenesis. Methods Mol Biol, (182), 37-43.

Wegener, D., Hildmann, C., Riester, D. and Schwienhorst, A. (2003a). Improved fluorogenic histone deacetylase assay for high-throughput-screening applications. Anal Biochem, (321), 202-8. 
Wegener, D., Hildmann, C. and Schwienhorst, A. (2003b). Recent progress in the development of assays suited for histone deacetylase inhibitor screening. Mol Genet Metab, (80), 138-47.

Wegener, D., Wirsching, F., Riester, D. and Schwienhorst, A. (2003c). A fluorogenic histone deacetylase assay well suited for high-throughput activity screening. Chem Biol, (10), 61-8.

Werner, R.G., Noe, W., Kopp, K. and Schluter, M. (1998). Appropriate mammalian expression systems for biopharmaceuticals. Arzneimittelforschung, (48), 870-80.

Whittaker M, Floyd CD, Brown P, Gearing AJH. (1999). Design and therapeutic application of matrix metalloproteinase inhibitors. Chem Rev, (99), 2735-2776.

Wirsching, F., Opitz, T., Dietrich, R., Schwienhorst, A. 1997. Display of functional thrombin inhibitor hirudin on the surface of phage M13. Gene 204, 177-184.

Wirsching, F., Luge, C., and Schwienhorst, A. (2002). Modular design of a novel chimeric protein with combined thrombin inhibitory activity and plasminogen activating potential. Mol. Genet. Metab. (75), 250259.

Wirsching, F., Keller, M., Hildmann, C., Riester, D. und Schwienhorst, A. (2003).

Directed evolution towards protease-resistant hirudin variants. Mol Genet Metab 80, 451-462.

Wittich, S., Scherf, H., Xie, C., Brosch, G., Loidl, P., Gerhauser, C. and Jung, M. (2002). Structureactivity relationships on phenylalanine-containing inhibitors of histone deacetylase: in vitro enzyme inhibition, induction of differentiation, and inhibition of proliferation in Friend leukemic cells. $J$ Med Chem, (45), 3296-309.

Wolffe, A.P. and Hayes, J.J. (1999). Chromatin disruption and modification. Nucleic Acids Res, (27), 711-20.

Wong, J.C., Hong, R. and Schreiber, S.L. (2003). Structural biasing elements for in-cell histone deacetylase paralog selectivity. J Am Chem Soc, (125), 5586-7.

Woo, S.H., Frechette, S., Abou Khalil, E., Bouchain, G., Vaisburg, A., Bernstein, N., Moradei, O., Leit, S., Allan, M., Fournel, M., Trachy-Bourget, M.C., Li, Z., Besterman, J.M. and Delorme, D. (2002). Structurally simple trichostatin A-like straight chain hydroxamates as potent histone deacetylase inhibitors. J Med Chem, (45), 2877-85.

Wright, J.D., Boudinot FD, Ujhelyi MR. (1996) Measurement and analysis of unbound drug concentrations. Clin Pharmacokinet, (30), 445-462.

Yoshida, M., Furumai, R., Nishiyama, M., Komatsu, Y., Nishino, N. and Horinouchi, S. (2001). Histone deacetylase as a new target for cancer chemotherapy. Cancer Chemother Pharmacol, (48 Suppl 1), S20-6.

Yoshida, M., Horinouchi, S. and Beppu, T. (1995). Trichostatin A and trapoxin: novel chemical probes for the role of histone acetylation in chromatin structure and function. Bioessays, (17), 423-30.

Yoshida, M., Kijima, M., Akita, M. and Beppu, T. (1990). Potent and specific inhibition of mammalian histone deacetylase both in vivo and in vitro by trichostatin A. J Biol Chem, (265), 17174-9.

Yoshida, M., Matsuyama, A., Komatsu, Y. and Nishino, N. (2003). From discovery to the coming generation of histone deacetylase inhibitors. Curr Med Chem, (10), 2351-8. 
Zhang, Y., LeRoy, G., Seelig, H.P., Lane, W.S. and Reinberg, D. (1998). The dermatomyositis-specific autoantigen Mi2 is a component of a complex containing histone deacetylase and nucleosome remodeling activities. Cell, (95), 279-89.

Zhang, Y., Li, N., Caron, C., Matthias, G., Hess, D., Khochbin, S. and Matthias, P. (2003b). HDAC-6 interacts with and deacetylates tubulin and microtubules in vivo. Embo J, (22), 1168-79.

Zimmerman, M., Ashe, B., Yurewicz, E.C. and Patel, G. (1977). Sensitive assays for trypsin, elastase, and chymotrypsin using new fluorogenic substrates. Anal Biochem, (78), 47-51.

Zinchenko, A. A., Rumsh, L. D., and Antonov, V. K. (1976). Bioorg. Chem. (USSR) 2, 803.

\section{Anhang: Material}

\subsection{Chemikalien und verwendete Kürzel in der Standard-Peptidsynthese}

\begin{tabular}{|c|c|c|c|}
\hline Kurzform & Name & Firma & $\begin{array}{l}\text { Bestell- } \\
\text { nummer }\end{array}$ \\
\hline $\begin{array}{l}\text { Fmoc-AS } \\
\text { oder AS }\end{array}$ & Fmoc geschützte Aminosäure-Bausteine & wie gelistet & \\
\hline $\begin{array}{l}\text { ACN od. } \\
\text { MeCN }\end{array}$ & Acetonitril & Roth & A3330 \\
\hline $\mathrm{Ac}_{2} \mathrm{O}$ & $\begin{array}{l}\text { Essigsäureanhydrid } \\
\mathrm{C}_{4} \mathrm{H}_{6} \mathrm{O}_{3}\end{array}$ & Fluka & 45830 \\
\hline CDI & $\begin{array}{l}\text { Carbonyldiimidazol } \\
\mathrm{C}_{7} \mathrm{H}_{6} \mathrm{~N}_{4} \mathrm{O}\end{array}$ & Lancaster & 0223 \\
\hline DCM & $\begin{array}{l}\text { Dichlormethan } \\
\mathrm{CH}_{2} \mathrm{Cl}_{2}\end{array}$ & Fluka & 66749 \\
\hline DIPEA & $\begin{array}{l}\text { N-Ethyldiisopropylamine } \\
\mathrm{C}_{8} \mathrm{H}_{19} \mathrm{~N}\end{array}$ & Fluka & 03440 \\
\hline $\begin{array}{l}\text { DMF* } \\
\text { Wasserfrei } \\
\text { DMF }\end{array}$ & $\begin{array}{l}\text { N,N-Dimethylformamide } \\
\mathrm{C}_{3} \mathrm{H}_{7} \mathrm{NO}\end{array}$ & \begin{tabular}{|l} 
Fluka \\
Scharlau
\end{tabular} & 40248 \\
\hline DMSO & Dimethylsulfoxid & Fluka & 41648 \\
\hline EDC & $\begin{array}{l}\text { Ethyl-dimethylaminopropyl-carbodiimid } \\
\mathrm{C}_{8} \mathrm{H} 18 \mathrm{~N}_{3} \mathrm{Cl}\end{array}$ & Lancaster & 0232 \\
\hline $\mathrm{EtOH}$ & $\begin{array}{l}\text { Ethanol } \\
\mathrm{C}_{2} \mathrm{H}_{5} \mathrm{OH}\end{array}$ & & \\
\hline tBME & $\begin{array}{l}\text { Tert-Butylmethylether } \\
\mathrm{C}_{5} \mathrm{H}_{12} \mathrm{O}\end{array}$ & Fluka & 20252 \\
\hline
\end{tabular}




\begin{tabular}{|c|c|c|c|}
\hline Harz & Rink Amid MBHA resin & $\begin{array}{l}\text { Nova } \\
\text { Biochem }\end{array}$ & 01-64-0037 \\
\hline $\mathrm{H}_{2} \mathrm{O}$ & Aquadest & & \\
\hline NMM & $\begin{array}{l}\text { 4-Methylmorpholine } \\
\mathrm{C}_{5} \mathrm{H}_{11} \mathrm{NO}\end{array}$ & Fluka & 67869 \\
\hline NMP & 1-Methyl-2-pyrrolidone & Fluka & 69117 \\
\hline Piperidin & $\begin{array}{l}\text { Piperidin } \\
\mathrm{C}_{5} \mathrm{H}_{11} \mathrm{~N} \\
\end{array}$ & Fluka & 80640 \\
\hline TBTU & $\begin{array}{l}\text { 2-(1-H-Benzotriazol-1-yl)-1,1,3,3- } \\
\text { tetramethyluronium-tetrafluoroborate }\end{array}$ & $\begin{array}{l}\text { Nova } \\
\text { Biochem }\end{array}$ & $01-62-0015$ \\
\hline TFA & $\begin{array}{l}\text { Trifluoressigsäure } \\
\mathrm{C}_{2} \mathrm{HF}_{3} \mathrm{O}\end{array}$ & Fluka & 91700 \\
\hline TIPS & $\begin{array}{l}\text { Triisopropylsilane } \\
{ }_{\mathrm{C}_{9} \mathrm{H}_{22} \mathrm{Si}}\end{array}$ & Fluka & 92095 \\
\hline
\end{tabular}

\subsection{Material, Chemikalien für Molekularbiologische Arbeiten}

\subsubsection{Bakterienstämme von Escherichia coli}

XL1-Blue (Stratagene, USA) (Bullock et al., 1987)

recA1, endA1, gyrA96, thi-1, hsdR17, supE44, relA1, lac [F' proAB lacI $\left.{ }^{\mathrm{q}} \mathrm{Z} \Delta \mathrm{M} 15 \operatorname{Tn} 10\left(\mathrm{Tet}^{\mathrm{r}}\right)\right]$

\subsubsection{Plasmide}

\section{pCR $^{\mathrm{TM}}$ 2.1-TOPOTM (Invitrogen, Leek, NL)}

Größe: 3908 bp

Elemente: Gen für $\beta$-Laktamase (bla), Aminoglycosid-3'-Phosphotransferase-Gen (kan), ColE1-

Replikationsursprung (ColE1), Lac Promotor/Operator-Region $\left(P_{l a c}\right)$, Multiklonierungsstelle (MCS) mit flankierenden EcoRI-Schnittstellen, LacZ $\alpha$-Fragment (lacZ $\alpha$ )

\section{pCR $^{\mathrm{TM} 4-\mathrm{TOPO}^{\mathrm{TM}}}$ (Invitrogen, Leek, NL)}

Größe: 3957 bp

Elemente: Gen für $\beta$-Laktamase (bla), Aminoglycosid-3'-Phosphotransferase-Gen (kan), ColE1-

Replikationsursprung (ColE1), Lac Promotor/Operator-Region $\left(P_{l a c}\right)$, Multiklonierungsstelle $(M C S)$ mit flankierenden EcoRI-Schnittstellen, LacZ $\alpha$-ccdB-Fusionsgen (lacZ $\alpha$-ccdB) 
pQE70 (Qiagen, Hilden)

Größe: 3427 bp

Elemente: Gen für $\beta$-Laktamase (bla), ColE1-Replikationsursprung (ColE1), T5-Promotor/Lac-Operator-

Region $\left(P_{T 5}\right)$, Multiklonierungsstelle mit Codons für His-tag (HIS-tag), Transkriptionsterminator (TT)

\subsubsection{DNA-Längenstandards und Protein Molekulargewichtsmarker}

\section{DNA-Längenstandards}

DNA-Längenstandard-Lösungen wurden mit TE-Puffer und Sucrosefarbmarker auf eine Konzentration von $100 \mathrm{ng} / \mu \mathrm{l}$ eingestellt und bei $4{ }^{\circ} \mathrm{C}$ gelagert.

\section{$\lambda$-DNA/Eco47I (AvaII)-Marker (MBI Fermentas, Vilnius, Litauen)}

Fragmentgrößen [bp]: 8126, 6555, 6442, 3676, 2606, 2555, 2134, 2005, 1951, 1611, 1420, 1284, 985, 974, 894, 597, 590, 513, 511, 433, 398, 345, 310, 308, 272, 242, 215, $151,88,73,67,45,42,32,29,23$

\section{Protein-Molekulargewichtsmarker}

\section{Prestained Protein Ladder 10-160 kDa (MBI Fermentas, Vilnius, Litauen)}

apparentes relatives Molekulargewicht der mit einem blauen Chromophor gekoppelten Proteine: 160000, 110000, 90000, 70000, 55000, 45000, 35000, 25000, 15000, 10000.

Das Protein mit einem $\mathrm{M}_{\mathrm{r}}$ von ca. 70000 wurde mit einem rotem Chromophor gekoppelt.

\subsubsection{Oligodesoxyribonukleotide}

Alle synthetischen Oligodesoxyribonukleotide wurden lyophylisiert von der Fa. Metabion GmbH (Martinsried) bezogen, mit demineralisiertem Wasser zu $100 \mathrm{pmol} / \mu 1$ gelöst und bei $-20{ }^{\circ} \mathrm{C}$ gelagert. Wichtige, in den Primern enthaltene Restriktionsschnittstellen sind unterstrichen, Nukleotide, die einen

Basenaustausch bewirken, sind fett dargestellt.

Primer zur Klonierung von HDAC8

HDAC8pQEcoRIfor: 5'-GAGAATTCATTAAAGAGGAGAAATTAAGCATGGAGGA GCCGGAG-3'

HDAC8XaHISrev: 5'-TTATAAATTAAGCTTATCAATGGTGATGGTGATGGTGGC TGCCGCGGCCTTCAATGACCACATGCTTCAGATTCCCTTTG-3'

QCM-HD8for: 5'-CATGACTCCAGTGGGAATTGGC-3'

QCM-HD8rev: 5'-GCCAATTCCCACTGGAGTCATG-3'

\subsubsection{Enzyme und Proteine}

Biomol, Hamburg oder Biomol Research Laboratories, Plymouth Meeting,USA rekombinante, humane HDAC8 
Calbiochem, Schwalbach am Taunus

HDAC aus Rattenleber (rat liver HDAC)

Hildmann, Christian, Abteilung für Molekulare Genetik und Präparative

Molekularbiologie, Institut für Mikrobiologie und Genetik, Universität Göttingen FB188-HDAH

MBI Fermentas, Vilnius, Litauen

Restriktionsendonukleasen und zugehörige Puffer, Rinderserumalbumin (BSA), T4 DNA-Ligase, SAP (shrimp alkaline phosphatase)

Perkin Elmer, Branchburg, USA

Amplitaq DNA-Polymerase mit PCR-Puffer

Sigma, Deisenhofen

Trypsin (vom Schwein), Anti-Maus-IgG-AP-Konjugat, Anti-Kaninchen-IgG-APKonjugat,

Stratagene, La Jolla,USA

$P f u$-DNA-Polymerase

\subsection{Chemikalien}

Alle nicht gesondert aufgeführten Chemikalien wurden von Merck (Darmstadt) bezogen.

Bachem Feinchemikalien, Bubendorf, $\mathbf{C H}$

Boc-Lys(Ac)-AMC, Boc-Lys-AMC, Tos-Gly-Pro-Lys-AMC, Tos-Gly-Pro-Arg$\mathrm{AMC}$

Biomol, Hamburg

SAHA

BioRad, CA, USA

Tween ${ }^{\circledR}-20$

Biozym, Hess. Oldendorf

Biozym DNA Agarose

Calbiochem-Novabiochem Corporation, La Jolla, USA

MS275

Difco, Dreieich

Bacto-Agar, Bacto-Peptone

Fluka, Neu-Ulm

DMSO, NMP, MeCN, Bromphenolblau, Glyzerin, $\beta$-Mercaptoethanol,

Saccharose, Coomassie Brillant Blue R250, Natriumchlorid, D(+)-Glukose

Monohydrat,

Gerbu, Gaiberg

Isopropyl- $\beta$-D-thiogalactopyranosid (IPTG) 
ICN Biochemicals, Aurora, USA

Ethylendiamintetraessigsäure Dinatriumsalz (EDTA), Tris(hydroxy-methyl)aminomethan (Tris)

Life Technologies Inc., Gaithersburg, USA

UltraPure Agarose (Electrophoresis Grade)

Metabion, Martinsried

Oligodesoxyribonukleotide

National Diagnostics, Simerville, USA

Oxoid, Wesel Protogel ${ }^{\circledR} 30$

Agar Bacteriological, Trypton, Pepton, Yeast Extract

Pharmacia Biotech AB, Uppsala, Schweden

Chelating Sepharose Fast Flow, NHS-aktivierte Sepharose, CNBr-aktivierte Sepharose

Riedel-De Haen, Seelze

Ammoniumacetat, Chloroform, Ethanol, Methanol, Natriumchlorid, Salzsäure, Ammoniumsulfat

Roth, Karlsruhe

Einmalküvetten für das Photometer, Aqua Roti-Phenol, TEMED, Rotiphorese 30 bzw. 40

Scharlau Chemie S.A., Spanien

HPLC-grade Wasser, $\mathrm{MeOH}$ und $\mathrm{MeCN}$

Serva, Heidelberg

EDTA (Dinatriumsalz), D(+)-Glukose Monohydrat, SDS, TEMED

Sigma, Deisenhofen

Ethidiumbromid, Polyethylenglycol 8000, Bromphenolblau, Triethanolamin,

Tris(hydroxymethyl)-aminomethan (Tris), Triton X-100, Tween-20 (Polyethylen-

Sorbitan-Monolaureat), Trichostatin A, Tos-Gly-Pro-Arg-AMC

\title{
7.4. Kits
}

Invitrogen, Groningen, NL

TOPO TA Cloning Kit

Pierce, Rockfort,USA

Coomassie Protein Assay Reagent Kit

\subsection{Sonstige Materialien und Geräte}

\author{
American National Can., Chicago, USA \\ Parafilm $^{\circledR}$ "M" Laboratory Film \\ Ansell, München \\ Nitrilierte Einmalhandschuhe \\ Bender \& Hobein, Zürich, Schweiz \\ Vortex $^{\circledR}$ Genie 2
}




\section{Biometra, Göttingen \\ TRIO-Thermocycler, Elektrophoresekammern}

BioRad, München

E. coli Pulser ${ }^{\circledR}$ Elektroporator, Gene Pulser ${ }^{\circledR}$ Elektroporator, Elektroporationsküvetten, Power Pac 200, Trans-Blot semi-dry Elektroblotapparat, Sequi-Blot PVDF-Membran $(0,2 \mu \mathrm{m})$

Biozym, Hessisch Oldendorf Gestopfte, sterile Pipettenspitzen (Safeseal Tips, 10, 20, 100, $200 \mu \mathrm{l}$ )

BMG LabTechnologies, Offenburg BMG Fluoreszenz-Reader POLARstar Galaxy

Branson Ultrasonics, Danbury, CT., USA Sonifier Ultraschallstab und Steuereinheit

\section{Brother, Japan}

Mikrowellenherd Powerwave

CyBio AG, Jena CyBi-Screen-Machine mit $10 \mu 1$ und $250 \mu 1$ 96-Spitzen-Pipettierigel mit integriertem MTP-Fluoreszenzreader (BMG), Stacker, Übergabe-Dreharm, Inkubator/MTP-Paternoster und zwei Waschstationen

Eppendorf-Netheler-Hinz, Hamburg

Reaktionsgefäße 2,0 ml Safe-Lock, Reaktionsgefäße 1,5 ml, SpeedVac Concentrator 5301, Thermomixer 5436, Kühlzentrifuge 5804R

Gilson, Medical Electronics, Frankreich Mikroliter-Pipetten, $1000 \mu \mathrm{l}, 200 \mu \mathrm{l}, 100 \mu \mathrm{l}, 20 \mu \mathrm{l}, 10 \mu \mathrm{l}$ und $2 \mu \mathrm{l}$

Greiner Bio-One, Frickenhausen

Petrischalen, Röhrchen 12 ml, schwarze 96-Well Mikrotiterplatten Fluotrac 200, schwarze 384-Well Mikrotiterplatten, Deep Well-Platten (Masterblock 96 well, 2 $\mathrm{ml})$

Helma, Müllheim/Baden

Quarzküvetten (1 und $2 \mathrm{ml}, 1 \mathrm{~cm}$ Schichtdicke)

Heraeus, Osterode

Tischzentrifuge Biofuge pico, Brutschränke B6060 und 6420

Herolab, Wiesloch

UVT2035 $302 \mathrm{~nm}$ UV-Leuchttisch

Hettich Zentrifugen, Tuttlingen

Kühlzentrifuge Mikro Rapid/K, Kühlzentrifuge Roto Silenta/RP, Kühlzentrifuge Rotixa/RP, Kühlzentrifuge Rotanta/RPC, Mikroliter-Tischzentrifuge

Hitachi, Tokio, Japan Fluorimeter F-4500

Hoefer Scientific, San Francisco, USA Platten für SDS-Gele

IKA-Labortechnik, Staufen beheizbarer Magnetrührer IKAMAG RCT basic

Infors AG, Bottmingen, Schweiz Kultur-Shüttler mit Inkubatorhaube

IUL Instruments GmbH, Königswinter Constant Systems Hochdruck-Zellaufschlußsystem (Zelldisruptor)

Kimberley-Clark, USA Kimwipes ${ }^{\circledR}$ fusselfreie Papiertücher, puderfreie Einmal-Handschuhe 


\section{Knick, Berlin}

pH-Meter 761 Calimatic

Kontron, Eching

Zweistrahl-Spektrophotometer Uvicon ${ }^{\circledR} 930$

Köttermann Labortechnik, Uetze/Hänigsen

Wasserbad

\section{Labsystems}

Finnpipetten 8-Kanal Multipetten 0,5 - $10 \mu 1,50-300 \mu 1$

Matrix, Wilmslow Chesire, UK

Magazine mit je 96 mal $250 \mu 1$ Spitzen (D.A.R.T.s extended length),

Digitale Pipette Impact2 und digitale 8-Kanal-Pipette Impact8 mit zugehörigen gestopften Spitzen

Merck, Darmstadt

$\mathrm{pH}$-Indikatorstreifen

Millipore, Eschborn

Filtereinheiten Millex FG13, Ultrafree-20 Nanopore-Wasser-Anlage,

Nitrocellulose Rundfilter 0,25 $\mu \mathrm{m}, \varnothing 13 \mathrm{~mm}$, Microcon-Konzentratoren YM-10,

Nalgene, Hereford, England

Cryoware Cryovial (2 ml-Röhrchen für Gefrierkulturen)

neoLab, Heidelberg

8 ml-Braunglasröhrchen mit Schraubdeckel (Wheaton-Röhrchen)

Nunc GmbH \& Co. KG, Wiesbaden

96 well Polypropylen-MTP mit V-Boden

Perseptive Biosystems Incorporated, Framingham, USA

Vision Workstation für Perfusions-Chromatographie, Poros 20 HQ-Säule

Pharmacia/LKB, Freiburg

Elektrophorese Stromversorger ECPS 3000/150

Sarsted, Nümbrecht; Newton, USA

Reaktionsgefäße 1,5 ml, Röhrchen $5 \mathrm{ml}$, Röhrchen $50 \mathrm{ml}$ (Falcon tubes), Multiple

Well Plate 96-Well, Round bzw. Flat Bottom with Lid (Mikrotiterplatten, steril mit Deckel), PCR-cups $0,5 \mathrm{ml}$

Sartorius, Göttingen

Minisart NML Sterilfilter, Sartorius Universal U 4800P Feinwaage

Schleicher und Schuell, Dassel

Sterilfilter für Spritzen 0,2 und 0,45 $\mu \mathrm{m}, 3 \mathrm{MM}$-Filterpapier (Whatman), Falten-

Filter, Ø $240 \mathrm{~mm}$,

Schott, Mainz

Glaswaren

Schütt Labortechnik, Göttingen

pH-Meter 526, Schüttler Titramax und Inkubator 1000

Serva, Heidelberg

Visking Dialyseschläuche verschiedener Stärken und einem molecular cut off von $\mathrm{M}_{\mathrm{r}} \sim 12000-14000$

Sorvall, Bad Nauheim

Zentrifuge RC-5C, Rotortyp SS34

Terumo, Leuven, Belgien 
Spritzen, $5 \mathrm{ml}, 10 \mathrm{ml}, 30 \mathrm{ml}$

Wissenschaftlich-Technische Werkstätten, Weilheim

$\mathrm{pH}-\mathrm{Meter}-522$

Ziegra, Stockport, England

Eismaschine

\subsection{Nährmedien}

Zur Sterilisation wurden die Nährmedien 20 min bei $121^{\circ} \mathrm{C}$ autoklaviert, wobei Glukose immer separat autoklaviert wurde. Festmedien (Platten) enthalten zusätzlich 1,5\% (w/v) Agar. Hitzelabile Ingredienzen (z. B. Antibiotika) wurden nach Abkühlen des Mediums auf etwa $55{ }^{\circ} \mathrm{C}$ zugesetzt. Platten wurden bei $4{ }^{\circ} \mathrm{C}$ gelagert und vor Benutzung auf RT gebracht.

\section{Nährmedien für Escherichia coli}

dYT

$1 \%(w / v)$ Hefe-Extrakt, $1,6 \%$ (w/v) Trypton, $0,5 \%$ (w/v) NaCl

LB

0,5\% (w/v) Hefe-Extrakt, $1 \%(w / v)$ Tryptone, $1 \%(w / v) ~ N a C l$

SOC

0,5\% (w/v) Hefe-Extrakt, $2 \%$ (w/v) Trypton, 2,5 mM KCl, 0,05\% (w/v) NaCl, nach dem Autoklavieren wurden $2 \%$ (w/v) Glukose und $10 \mathrm{mM}$ (Endkonzentration) $\mathrm{MgCl}_{2}$ und $\mathrm{MgSO}_{4}$ zugesetzt.

Antibiotika wurden aus 1000fach konzentrierten Stammlösungen bis zu einer Endkonzentration von $100 \mu \mathrm{g} / \mathrm{ml}$ für Ampicillin, $75 \mu \mathrm{g} / \mathrm{ml}$ für Kanamycin bzw. $50 \mu \mathrm{g} / \mathrm{ml}$ für Tetracyclin zugegeben.

\subsection{Lösungen und Puffer}

\begin{tabular}{|c|c|}
\hline $\begin{array}{l}\text { Ac-Arg-Gly-Lys(Ac)-AMC } \\
\text { Arbeitslösung }\end{array}$ & $\begin{array}{l}\text { Boc-Lys(Ac)-AMC in DMSO angelöst und auf } 1 \mathrm{mM} \text { mit } \\
\text { HD-Puffer verdünnt, lichtgeschützt bei }-20^{\circ} \mathrm{C} \text { gelagert } \\
\text { (DMSO-Gehalt } 1,7 \% \text { ) }\end{array}$ \\
\hline $\begin{array}{l}\text { Ac-Arg-Gly-Lys-AMC } \\
\text { Arbeitslösung }\end{array}$ & $\begin{array}{l}\text { Boc-Lys(Ac)-AMC in DMSO angelöst und auf } 1 \mathrm{mM} \text { mit } \\
\text { HD-Puffer verdünnt, lichtgeschützt bei }-20^{\circ} \mathrm{C} \text { gelagert } \\
\text { (DMSO-Gehalt } 1,7 \% \text { ) }\end{array}$ \\
\hline $\begin{array}{l}\text { Ac-Gly-Ala-Lys(Ac)-AMC } \\
\text { Arbeitslösung }\end{array}$ & $\begin{array}{l}\text { Boc-Lys(Ac)-AMC in DMSO angelöst und auf } 1 \mathrm{mM} \text { mit } \\
\text { HD-Puffer verdünnt, lichtgeschützt bei }-20^{\circ} \mathrm{C} \text { gelagert } \\
\text { (DMSO-Gehalt } 1,7 \% \text { ) }\end{array}$ \\
\hline $\begin{array}{l}\text { Ac-Gly-Ala-Lys-AMC } \\
\text { Arbeitslösung }\end{array}$ & $\begin{array}{l}\text { Boc-Lys(Ac)-AMC in DMSO angelöst und auf } 1 \mathrm{mM} \text { mit } \\
\text { HD-Puffer verdünnt, lichtgeschützt bei }-20^{\circ} \mathrm{C} \text { gelagert } \\
\text { (DMSO-Gehalt } 1,7 \% \text { ) }\end{array}$ \\
\hline $\begin{array}{l}\text { Ac-Gly-Gly-Lys(Ac)-AMC } \\
\text { Arbeitslösung }\end{array}$ & $\begin{array}{l}\text { Boc-Lys(Ac)-AMC in DMSO angelöst und auf } 1 \mathrm{mM} \text { mit } \\
\text { HD-Puffer verdünnt, lichtgeschützt bei }-20^{\circ} \mathrm{C} \text { gelagert } \\
\text { (DMSO-Gehalt } 1,7 \% \text { ) }\end{array}$ \\
\hline
\end{tabular}




\begin{tabular}{|c|c|}
\hline $\begin{array}{l}\text { Ac-Gly-Gly-Lys-AMC } \\
\text { Arbeitslösung }\end{array}$ & $\begin{array}{l}\text { Boc-Lys(Ac)-AMC in DMSO angelöst und auf } 1 \mathrm{mM} \text { mit } \\
\text { HD-Puffer verdünnt, lichtgeschützt bei }-20^{\circ} \mathrm{C} \text { gelagert } \\
\text { (DMSO-Gehalt } 1,7 \% \text { ) }\end{array}$ \\
\hline $\begin{array}{l}\text { Ac-Leu-Gly-Lys(Ac)-AMC } \\
\text { Arbeitslösung }\end{array}$ & $\begin{array}{l}\text { Boc-Lys(Ac)-AMC in DMSO angelöst und auf } 1 \mathrm{mM} \text { mit } \\
\text { HD-Puffer verdünnt, lichtgeschützt bei }-20^{\circ} \mathrm{C} \text { gelagert } \\
\text { (DMSO-Gehalt } 1,7 \% \text { ) }\end{array}$ \\
\hline $\begin{array}{l}\text { Ac-Leu-Gly-Lys-AMC } \\
\text { Arbeitslösung }\end{array}$ & $\begin{array}{l}\text { Boc-Lys(Ac)-AMC in DMSO angelöst und auf } 1 \mathrm{mM} \text { mit } \\
\text { HD-Puffer verdünnt, lichtgeschützt bei }-20^{\circ} \mathrm{C} \text { gelagert } \\
\text { (DMSO-Gehalt } 1,7 \% \text { ) }\end{array}$ \\
\hline AMC-Stammlösung & $10 \mathrm{mM}$ in DMSO, lichtgeschützt und bei $-20^{\circ} \mathrm{C}$ gelagert \\
\hline Ammoniumacetat-Puffer & 7,5 $\mathrm{M} \mathrm{NH}_{4} \mathrm{Ac}$ in Wasser, $\mathrm{pH} 7,5$ \\
\hline Ampicillin-Stammlösung & $100 \mathrm{mg} / \mathrm{ml}$ Ampicillin (Na-Salz) in Wasser, sterilfiltriert \\
\hline Anoden-Puffer I & $300 \mathrm{mM}$ Tris/HCl, $\mathrm{pH}$ 10,4 in Wasser \\
\hline Anoden-Puffer II & $25 \mathrm{mM}$ Tris/ $\mathrm{HCl}, \mathrm{pH} 10,4$ in Wasser \\
\hline AP-Entwicklungspuffer & $100 \mathrm{mM}$ Tris/HCl, $100 \mathrm{mM} \mathrm{NaCl}, 50 \mathrm{mM} \mathrm{MgCl}_{2}, \mathrm{pH} 9$ \\
\hline APS & $10 \%$ APS in Wasser \\
\hline $\mathrm{BBT} / \mathrm{PBS}$ & $\begin{array}{l}\text { Blocking Buffer Tween zu gleichen Teilen mit PBST } \\
\text { vermischt }\end{array}$ \\
\hline BCIP & $50 \mathrm{mg} / \mathrm{ml}$ in Wasser, bei $-20^{\circ} \mathrm{C}$ gelagert \\
\hline Blocking Buffer & 5 g Magermilchpulver in PBS, frisch angesetzt \\
\hline Blocking Buffer Tween & Blocking Buffer mit $0,05 \%$ Tween 20 \\
\hline $\begin{array}{l}\text { Boc-Lys(Ac)-AMC } \\
\text { Stammlösung }\end{array}$ & $\begin{array}{l}30 \mathrm{mM} \text { Boc-Lys(Ac)-AMC in DMSO gelöst, } \\
\text { lichtgeschützt bei }-20^{\circ} \mathrm{C} \text { gelagert }\end{array}$ \\
\hline Boc-Lys-AMC Stammlösung & $\begin{array}{l}\text { Boc-Lys-AMC in DMSO angelöst und auf } 1 \mathrm{mM} \text { mit HD- } \\
\text { Puffer verdünnt, lichtgeschützt bei }-20^{\circ} \mathrm{C} \text { gelagert } \\
\text { (DMSO-Gehalt } 1,7 \% \text { ) }\end{array}$ \\
\hline Chloroform/Isoamylalkohol & 24 Vol. Chloroform, 1 Vol. Isoamylalkohol \\
\hline Coomassie-Färbelösung & $\begin{array}{l}0,2 \% \text { Coomassie Brilliant Blue R250 in } 50 \% \text { EtOH und } \\
10 \% \text { Eisessig, lichtgeschützt bei RT gelagert. }\end{array}$ \\
\hline dNTPs-Arbeitslösung (10 mM) & je 2,5 mM dATP, dCTP, dGTP, dTTP in Wasser \\
\hline DTT-Stammlösung & 1 M DTT in Wasser, sterilfiltriert \\
\hline EDTA & $0,5 \mathrm{M} \mathrm{Na}_{2} \mathrm{~K}-\mathrm{EDTA}, \mathrm{pH} 8,0$ \\
\hline $\begin{array}{l}\text { Ethidiumbromid-Stammlösung } \\
(1000 \mathrm{x})\end{array}$ & $10 \mathrm{mg} / \mathrm{ml}$ Ethidiumbromid in Wasser \\
\hline HDAC8-Puffer (I bzw. A) & $\begin{array}{l}15 \mathrm{mM} \text { Tris/HCl, } 3 \mathrm{mM} \mathrm{MgCl}_{2}, 10 \mathrm{mM} \mathrm{KCl} \text {, } \\
10 \% \text { Glyzerin, } \mathrm{pH} 8,0\end{array}$ \\
\hline HDAC8-Puffer B & $\begin{array}{l}15 \mathrm{mM} \text { Tris/HCl, } 3 \mathrm{mM} \mathrm{MgCl} 2,10 \mathrm{mM} \mathrm{KCl}, 3 \mathrm{M} \mathrm{NaCl} \text {, } \\
10 \% \text { Glyzerin, } \mathrm{pH} 8,0\end{array}$ \\
\hline HDAC8-Puffer II & $\begin{array}{l}15 \mathrm{mM} \text { Tris/ } \mathrm{HCl}, 3 \mathrm{mM} \mathrm{MgCl} \\
2,10 \mathrm{mM} \mathrm{KCl}, 1 \mathrm{M} \\
\text { Imidazol, } 10 \% \text { Glyzerin, } \mathrm{pH} \mathrm{8,0}\end{array}$ \\
\hline $2 \times$ HDP-Puffer & $\begin{array}{l}1,5 \mathrm{ml} 1 \mathrm{M} \text { Tris/HCl, } \mathrm{pH} 8.1 \\
50 \mu \mathrm{l} 0,5 \mathrm{M} \text { EDTA, pH } 8 \\
6.25 \mathrm{ml} 4 \mathrm{M} \mathrm{NaCl} \\
200 \mu \mathrm{l} 50 \% \text { iges PEG } 8000 \\
a d \text { auf } 50 \mathrm{ml} \text { mit HPLC- } \mathrm{H}_{2} \mathrm{O}\end{array}$ \\
\hline $2 \times$ HD-Puffer & $\begin{array}{l}15 \mathrm{mM} \text { Tris/HCl, } 250 \mathrm{mM} \mathrm{NaCl}, 250 \mu \mathrm{M} \text { EDTA, } \\
10 \% \text { Glyzerin, } \mathrm{pH} 8,5\end{array}$ \\
\hline IMAC-Puffer I & $100 \mathrm{mM} \mathrm{NaP}, 100 \mathrm{mM} \mathrm{NaCl}, \mathrm{pH} 8$ \\
\hline IMAC-Puffer II & IMAC-Puffer I mit 1 M Imidazol \\
\hline IPTG-Stammlösung & $1 \mathrm{M}$ IPTG in Wasser, sterilfiltriert, bei $-20^{\circ} \mathrm{C}$ gelagert \\
\hline
\end{tabular}




\begin{tabular}{|c|c|}
\hline Kanamycin-Stammlösung & $75 \mathrm{mg} / \mathrm{ml}$ Kanamycin (Monosulfat) in Wasser, sterilfiltriert \\
\hline Kaliumphosphat-Puffer & $1 \mathrm{M} \mathrm{KH}_{2} \mathrm{PO}_{4}, \mathrm{pH} 6,0$ mit $1 \mathrm{M} \mathrm{K}_{2} \mathrm{HPO}_{4}$ einstellen \\
\hline Kathoden-Puffer & $\begin{array}{l}25 \mathrm{mM} \text { Tris/HCl, pH 9,4 , } 40 \mathrm{mM} \text { D/L-Norleucin in } \\
\text { Wasser }\end{array}$ \\
\hline Laemmli-Laufpuffer & $\begin{array}{l}33 \mathrm{mM} \text { Tris- } \mathrm{HCl}, 190 \mathrm{mM} \text { Glycin, } \\
0,1 \% \text { (w/v) SDS, } \mathrm{pH} 8,3\end{array}$ \\
\hline DNA Loading Dye & $\begin{array}{l}10 \% \text { (v/v) Glyzerin, } 10 \mathrm{mM} \text { EDTA, } 0,03 \% \\
\text { Xylencyanol/Bromphenolblau, } 10 \mathrm{mM} \text { Tris- } \mathrm{HCl}, \mathrm{pH} \text { 7,6 }\end{array}$ \\
\hline MS275-Stammlösung & $1 \mathrm{mg} / \mathrm{ml}$ in DMSO, bei $-20^{\circ} \mathrm{C}$ gelagert \\
\hline $\mathrm{NaAc}$ & $\begin{array}{l}2,5 \mathrm{M} \mathrm{NaAc} \text { in Wasser, mit Essigsäure auf pH } 5.2 \\
\text { eingestellt }\end{array}$ \\
\hline $\mathrm{NaCl}$ & $4 \mathrm{M} \mathrm{NaCl}$ in Wasser, autoklaviert \\
\hline Natriumphosphat-Puffer & $1 \mathrm{M} \mathrm{Na}_{2} \mathrm{HPO}_{4}$ mit $1 \mathrm{M} \mathrm{NaH}_{2} \mathrm{PO}_{4}$ auf $\mathrm{pH} 8$ einstellen \\
\hline NBT & $75 \mathrm{mg} / \mathrm{ml} \mathrm{NBT}$ in $70 \%$ igem DMF \\
\hline PBS & $\begin{array}{l}140 \mathrm{mM} \mathrm{NaCl} 10 \mathrm{mM} \mathrm{KCl}, 6,4 \mathrm{mM} \mathrm{Na}_{2} \mathrm{HPO}_{4}, 2 \mathrm{mM} \\
\mathrm{NaH}_{2} \mathrm{PO}_{4}\end{array}$ \\
\hline PBST & PBS mit $0,05 \%$ Tween 20 \\
\hline P1-Puffer & $\begin{array}{l}50 \mathrm{mM} \text { Tris-HCl, } \mathrm{pH} 8,0,10 \mathrm{mM} \text { EDTA, } \\
0,1 \mathrm{~g} / \mathrm{l} \text { RNase A }\end{array}$ \\
\hline P2-Puffer & $200 \mathrm{mM} \mathrm{NaOH}, 1 \% \mathrm{SDS}$ \\
\hline P3-Puffer & 2,55 mM KAc, $\mathrm{pH} 4,8$ \\
\hline PEG-Lösung & 13 bzw. $50 \%$ (w/v) PEG 8000 in Wasser, sterilfiltriert \\
\hline 10 x Pfu-PCR-Puffer & $\begin{array}{l}200 \mathrm{mM} \text { Tris/HCl, } 100 \mathrm{mM}\left(\mathrm{NH}_{4}\right)_{2} \mathrm{SO}_{4}, 100 \mathrm{mM} \mathrm{KCl} \text {, } \\
20 \mathrm{mM} \mathrm{MgSO}_{4}, 1 \% \text { Triton-100, } 1 \mathrm{mg} / \mathrm{ml} \mathrm{BSA}, \mathrm{pH} \mathrm{8,8}\end{array}$ \\
\hline Phenol/TE & Phenol p.A. mit TE-Puffer gesättigt \\
\hline Proteinfärbelösung & $\begin{array}{l}45 \%(\mathrm{v} / \mathrm{v}) \text { Methanol, } 0,2 \%(\mathrm{v} / \mathrm{v}) \text { Coomassie Brilliant Blue } \\
\mathrm{R} 250,10 \%(\mathrm{v} / \mathrm{v}) \text { Eisessig }\end{array}$ \\
\hline Proteinprobenpuffer & $\begin{array}{l}2,5 \mathrm{ml} 4 \text { x Sammelgelpuffer, } 3 \mathrm{ml} 10 \% \text { (w/v) SDS, } 300 \mu \mathrm{l} \\
\beta \text {-Mercaptoethanol, } 2,5 \mathrm{ml} 80 \% \text { Glycerol, } 100 \mu \mathrm{l} 2 \% \\
\text { Bromphenolblau }\end{array}$ \\
\hline Protogel $^{\mathrm{TM}} 30$ & $30 \%(\mathrm{v} / \mathrm{v})$ Acrylamid, 0,8 \% (v/v) Bisacrylamid \\
\hline Protogel $^{\mathrm{TM}} 40$ & $40 \%(\mathrm{v} / \mathrm{v})$ Acrylamid, $2 \%(\mathrm{v} / \mathrm{v})$ Bisacrylamid \\
\hline SAHA-Stammlösung & $10 \mathrm{mg} / \mathrm{ml}$ in DMSO \\
\hline Sammelgelpuffer $(4 \mathrm{x})$ & $0,5 \mathrm{M}$ Tris-HCl, $0,4 \%$ (w/v) SDS, $\mathrm{pH} 6,8$ \\
\hline Sammelgel, $5 \%$ ig für 2 Gele & $\begin{array}{l}3 \mathrm{ml} 4 \mathrm{x} \text { Sammelgelpuffer, } 2 \mathrm{ml} 30 \% \text { Protogel }^{\mathrm{TM}}, 7 \mathrm{ml} \\
\mathrm{H}_{2} \mathrm{O}, 50 \mu 1 \text { APS, } 25 \mu \mathrm{TEMED}\end{array}$ \\
\hline SDS & $10 \%(\mathrm{w} / \mathrm{v}) \mathrm{SDS}$ in Wasser \\
\hline T4 DNA-Ligase Puffer $(10 \mathrm{x})$ & $\begin{array}{l}400 \mathrm{mM} \text { Tris- } \mathrm{HCl}, \mathrm{pH} \text { 7,8, } 100 \mathrm{mM} \mathrm{MgCl} \\
100 \mathrm{mM} \text { DTT, } 5 \mathrm{mM} \text { ATP }\end{array}$ \\
\hline TAE-Puffer & $10 \mathrm{mM}$ Tris-Acetat, $1 \mathrm{mM}$ EDTA, $\mathrm{pH} 8,0$ \\
\hline TBE-Puffer & $\begin{array}{l}89 \text { mM Tris-Base, } 89 \text { mM Borsäure, 2,5 mM EDTA, } \\
\text { pH 8,0 }\end{array}$ \\
\hline TE-Puffer & $10 \mathrm{mM}$ Tris-HCl, $1 \mathrm{mM}$ EDTA, $\mathrm{pH} 7,5$ \\
\hline Thrombin-Puffer & $\begin{array}{l}50 \mathrm{ml} 1 \mathrm{M} \text { Tris/HCl } \\
20 \mathrm{ml} 5 \mathrm{M} \mathrm{NaCl} \\
10 \mathrm{ml} \mathrm{BSA}(10 \mathrm{mg} / \mathrm{ml}) \\
2 \mathrm{ml} \text { PEG8000 }(50 \%) \\
\text { ad } 1000 \mathrm{ml} \mathrm{A.} \mathrm{dest.,} \mathrm{sterilfiltriert}(0,25 \mu \mathrm{m}) \text { bei } 4{ }^{\circ} \mathrm{C} \\
\text { gelagert. }\end{array}$ \\
\hline
\end{tabular}




\begin{tabular}{|c|c|}
\hline TI-Puffer & $\begin{array}{l}15 \mathrm{ml} \text { Isopropanol } \\
2.5 \mathrm{ml} 1 \mathrm{M} \text { Tris/ } \mathrm{HCl}, \mathrm{pH} 8.0 \\
1.25 \mathrm{ml} 4 \mathrm{M} \mathrm{NaCl} \text { ad auf } 50 \mathrm{ml} \text { mit HPLC- } \mathrm{H}_{2} \mathrm{O}\end{array}$ \\
\hline $\begin{array}{l}\text { Tos-GPK(Ac)-AMC } \\
\text { Stammlösung }\end{array}$ & $\begin{array}{l}30 \mathrm{mM} \text { Tos-GPK(Ac)-AMC in DMSO, lichtgeschützt bei - } \\
20^{\circ} \mathrm{C} \text { gelagert }\end{array}$ \\
\hline Tos-GPK-AMC Stammlösung & $\begin{array}{l}\text { Tos-GPK-AMC in DMSO angelöst und auf } 1 \mathrm{mM} \text { mit HD- } \\
\text { Puffer verdünnt, lichtgeschützt bei }-20^{\circ} \mathrm{C} \text { gelagert } \\
\text { (DMSO-Gehalt } 1,7 \% \text { ) }\end{array}$ \\
\hline Tos-GPR-AMC Stammlösung & $\begin{array}{l}\text { Tos-GPK-AMC in DMSO angelöst, mit Thrombin-Puffer } \\
\text { bzw. HD-Puffer auf } 300 \mu \mathrm{M} \text { verdünnt, lichtgeschützt bei - } \\
20^{\circ} \mathrm{C} \text { gelagert }\end{array}$ \\
\hline Trenngelpuffer $(4 \mathrm{x})$ & 1,5 M Tris-HCl, 0,4 \% (w/v) SDS, $\mathrm{pH} 8,8$ \\
\hline Trenngel, $10 \%$ ig für 2 Gele & $\begin{array}{l}4,5 \mathrm{ml} 4 \mathrm{x} \text { Trenngelpuffer, } 6 \mathrm{ml} 30 \% \text { Protogel }^{\mathrm{TM}}, 7,5 \mathrm{ml} \\
\mathrm{H}_{2} \mathrm{O}, 80 \mu \mathrm{l} \text { APS, } 40 \mu \mathrm{TEMED}\end{array}$ \\
\hline Trichostatin A-Stammlösung & $1 \mathrm{mg} / \mathrm{ml}$ in DMSO, bei $-20^{\circ} \mathrm{C}$ gelagert \\
\hline Tris/HCl-Puffer & $\begin{array}{l}1 \mathrm{M} \text { in Wasser, der } \mathrm{pH}-\text { Wert wurde mit } \mathrm{HCl} \text { eingestellt } \\
\text { (mit Hilfe von } \mathrm{pH}-\mathrm{Me} ß \text { streifen) }\end{array}$ \\
\hline Trituration-Buffer & $\begin{array}{l}100 \mathrm{mM} \mathrm{CaCl}_{2}, 70 \mathrm{mM} \mathrm{MgCl} \\
\text { sterilfiltriert }\end{array}$ \\
\hline Trypsin-Puffer & $\begin{array}{l}5 \mathrm{ml} 1 \mathrm{M} \text { Tris/HCl } \\
2 \mathrm{ml} 5 \mathrm{M} \mathrm{NaCl} \text { ad } 100 \mathrm{ml} \text { A. dest. }\end{array}$ \\
\hline Trypsin-Stammlösung & $10 \mathrm{mg} / \mathrm{ml}$ Trypsin in Trypsin-Puffer \\
\hline Trypsin/TSA-Stoplösung & $\begin{array}{l}50 \mu 1 \text { Trypsin-Stammlösung mit } 50 \mathrm{ml} \text { TI-Puffer verdünnt } \\
(1: 1000), 100 \mu \mathrm{l} \text { TSA-Stammlösung }(2 \mu \mathrm{M} \text { TSA- } \\
\text { Endkonzentration })\end{array}$ \\
\hline
\end{tabular}

\subsection{Software}

GraphPad Software Incorporated, San Diego, USA

Graph Pad Prism 3.03

BMG LabTechnologies, Offenburg

FLUOStar Galaxy 4.01-0

CyBio AG, Jena

CyBio-Control 1.70

Netscape Communications Corporation

Netscape Communicator 4.7 und 7.01

Microsoft Corporation

Word 97, 2000; Excel 97, 2000

CambridgeSoft Corporation, Cambridge, USA

CS Chem Draw Std 


\subsection{Abkürzungsverzeichnis}

Für Aminosäuren wurden die Ein- und Dreibuchstabenkürzel nach dem „,white book“ der IUPAC-IUBMB Joint Commission on Biochemical Nomenclature and Nomenclature Commission of IUBMB (Liebecq, 1992) benutzt. Dies gilt ebenfalls für physikalische Größen, Einheiten und eventuelle Präfixe.

$\begin{array}{ll}\text { A } & \text { Adenin } \\ \text { Abb. } & \text { Abbildung } \\ \text { abs. } & \text { absolut } \\ \text { Ac } & \text { Acetat } \\ \text { AMC } & \text { 7-Amino-4-methylcoumarin } \\ \text { amp } & \text { Ampicillin (-resistenzgen) } \\ \text { APS } & \text { Ammoniumperoxodisulfat } \\ \text { AS } & \text { Aminosäure(n) } \\ \text { ATP } & \text { Adenosintriphosphat } \\ \text { bp } & \text { Basenpaare } \\ \text { BSA } & \text { bovine serum albumine, Rinderserumalbumin } \\ \text { bzw. } & \text { beziehungsweise } \\ \text { C } & \text { Cytosin } \\ { }^{\circ} \text { C } & \text { Grad Celsius } \\ \text { C-Terminus } & \text { Carboxyterminus } \\ \text { ca. } & \text { circa } \\ \text { cDNA } & \text { copy DNA, komplementäre DNA } \\ \text { cfu } & \text { colony forming unit, Koloniebildende Einheit } \\ \text { CRX } & \text { crude extract, lösliche Fraktion des Zellysates } \\ \text { ddNTP } & \text { Didesoxynukleosidtriphosphat } \\ \text { dem. } & \text { demineralisiert } \\ \text { d.h. } & \text { das heißt } \\ \text { DMSO } & \text { Dimethylsulfoxid } \\ \text { DNA } & \text { desoxyribonucleic acid, Desoxyribonukleinsäure } \\ \text { dNTP } & \text { Desoxynukleosidtriphosphat } \\ \text { dsDNA } & \text { double stranded DNA, doppelsträngige DNA } \\ \text { dYT } & \text { double Yeast Tryptone } \\ \text { E. coli } & \text { Escherichia coli } \\ \text { EDTA } & \text { Ethylendiamintetraacetat } \\ \varepsilon & \text { molarer Extinktionskoeffizient } \\ \text { et al. } & \text { et alii, und andere } \\ \text { EtOH } & \text { Ethanol } \\ \text { F } & \text { Farad } \\ \text { G } & \text { Guanin } \\ \text { g } & \text { Gramm } \\ \text { h } & \text { Stunde(n) } \\ \text { His-tag } & \text { lineares Epitop aus sechs Histidinen } \\ & \end{array}$




\begin{tabular}{|c|c|}
\hline IPTG & Isopropyl- $\beta$-D-thiogalactopyranosid \\
\hline kan & Kanamycin (-resistenzgen) \\
\hline $\mathrm{kb}$ & Kilobasenpaare \\
\hline $\mathrm{Ki}$ & Inhibitorkonstante \\
\hline $\mathrm{K}_{\mathrm{M}}$ & Michaelis-Menten-Konstante \\
\hline KP & Kaliumphosphat \\
\hline LB & Luria Bertani (-Medium) \\
\hline M & $\mathrm{mol} / \mathrm{l}$ \\
\hline MCS & multiple cloning site, Mehrfachklonierungsstelle \\
\hline MD & Minimal-Medium mit Glukose \\
\hline $\mathrm{MeOH}$ & Methanol \\
\hline $\min$ & Minute(n) \\
\hline $\mathrm{ml}$ & Milliliter \\
\hline$\mu$ & mikro- \\
\hline N-Terminus & Aminoterminus \\
\hline $\mathrm{OD}_{260}$ & Optische Dichte bei $260 \mathrm{~nm}$ \\
\hline $\mathrm{OD}_{280}$ & Optische Dichte bei $280 \mathrm{~nm}$ \\
\hline $\mathrm{OD}_{600}$ & Optische Dichte bei $600 \mathrm{~nm}$ \\
\hline ori & origin of replication, Replikationsursprung \\
\hline p.A. & pro analysii \\
\hline PAA & Polyacrylamid \\
\hline PAGE & Polyacrylamid-Gelelektrophorese \\
\hline $\mathrm{P}_{\mathrm{AOX} 1}$ & AOX1-Promotor \\
\hline PCR & polymerase chain reaction, Polymerase-Kettenreaktion \\
\hline $\mathrm{pH}$ & negativer dekadischer Logarithmus der Protonenkonzentration \\
\hline PEG & Polyethylenglycol \\
\hline P. pastoris & Pichia pastoris \\
\hline RNA & ribonucleic acid, Ribonukleinsäure \\
\hline RT & Raumtemperatur \\
\hline RT-PCR & Reverse Transkription mit anschließender PCR \\
\hline $\mathrm{s}$ & Sekunde(n) \\
\hline SDS & sodiumdodecylsulfate, Natriumdodecylsulfat \\
\hline S. cerevisiae & Saccharomyces cerevisiae \\
\hline ssDNA & single stranded DNA, einzelsträngige DNA \\
\hline $\mathrm{T}$ & Thymin \\
\hline Tab. & Tabelle \\
\hline TAE & Tris-Acetat-EDTA-Puffer \\
\hline TE & Tris-EDTA-Puffer \\
\hline TEMED & N,N,N',N'-Tetramethylethylendiamin \\
\hline tet & Tetracyclin (-resistenzgen) \\
\hline Tris & Tris(hydoxymethyl)aminomethan \\
\hline $\mathrm{U}$ & Uracil \\
\hline $\mathrm{U}$ & unit(s), Enzymeinheit(en) \\
\hline u. a. & unter anderem \\
\hline üN & über Nacht \\
\hline Upm & Umdrehungen pro Minute \\
\hline
\end{tabular}




$\begin{array}{ll}\text { UV } & \text { Ultraviolett } \\ \text { V } & \text { Volt } \\ \text { (v/v) } & \text { Volumenprozent } \\ \text { Vol. } & \text { Volumen } \\ \mathrm{wt} & \text { Wildtyp } \\ \text { (w/v) } & \text { Gewichtsprozent } \\ \text { X-Gal } & \text { 5-bromo-4-chloro-3-indolyl-B-D-Galactopyranosid } \\ \text { YNB } & \text { yeast nitrogen base } \\ \text { YPD } & \text { yeast peptone dextrose } \\ \text { Z. B. } & \text { zum Beispiel }\end{array}$




\section{Lebenslauf}

$N A M E$ :

Daniel Riester

GEBURTSDATUM: 3. Dezember 1963

GEBURTSORT: Gottmadingen

STAATSANGEHÖRIGKEIT: Deutsch

FAMILIENSTAND: $\quad$ Verheiratet, 2 Kinder (4 und 2 Jahre)

Juni $1983 \quad$ Otto-Hahn-Gymnasium Tuttlingen

Abschluss Abitur, Allgemeine Hochschulreife

(Schwerpunkte Chemie, Biologie, Englisch)

1984-1985

Zivildienst Intensivstation KKH Tuttlingen

1986-1989

Ausbildung zum Krankenpfleger, Abschluss: staatl. Examen

1989-1991

Krankenpfleger KKH Tuttlingen, dann KKH Reutlingen

1991-7/1995 Studium der Chemie an der FH Reutlingen

Schwerpunkt: Allgemeine Chemie, insbesondere

Instrumentelle Analytik und Biochemie

2/1994-8/1994 Praxissemester an der Universität Tübingen, Chemische Pflanzenphysiologie/Pflanzenbiochemie, Prof. Dr. Ninnemann

Thema: Isolierung von Naturstoffen, Inhibitorstudien an Enzymen

1/1995-7/1995 Diplomarbeit am Naturwissenschaftlichen und Medizinischen Institut (NMI) der Universität Tübingen in der Arbeitgruppe von PD Dr. Wiesmüller und unter Leitung von Prof. Dr. Kuhn Thema: Chirale Trennungen synthetischer Tripeptide mit Kapillarelektrophorese

$7 / 1995$

Abschluss: Diplom-Ingenieur (FH) Chemie

$7 / 1995-12 / 1999$

Research Scientist bei der EVOTEC BioSystems AG, Hamburg ab 1998 Laborleitung Massenspektroskopie

1/2000-2004 Doktorarbeit am Institut für Mikrobiologie und Genetik der GeorgAugust-Universität, in Zusammenarbeit mit der Firma NScI, Göttingen

4/2003-9/2004 Promotionsstudium an der Biologischen Fakultät der GeorgAugust-Universität Göttingen 